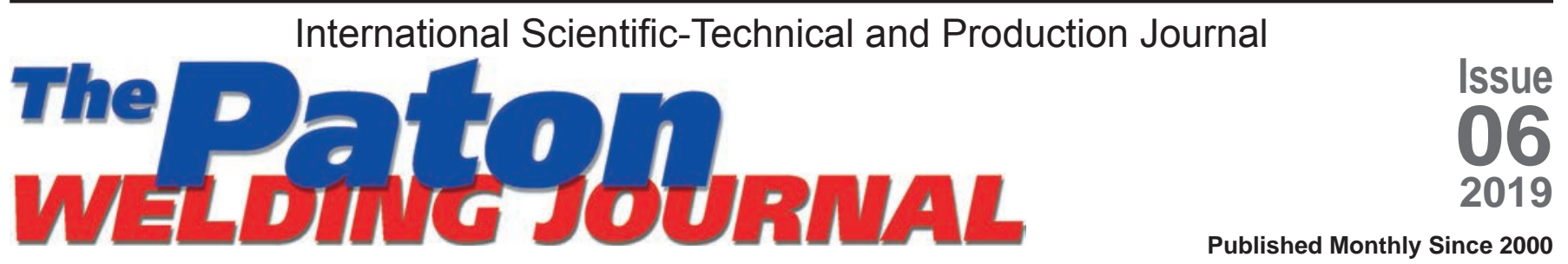

English translation of the monthly «Avtomaticheskaya Svarka» (Automatic Welding) journal published in Russian since 1948

\section{EDITORIAL BOARD \\ Editor-in-Chief B.E. Paton}

Scientists of PWI, Kyiv S.I. Kuchuk-Yatsenko (vice-chief ed.), V.N. Lipodaev (vice-chief ed.)

Yu.S. Borisov, G.M. Grigorenko, A.T. Zelnichenko, V.V. Knysh,

I.V. Krivtsun, Yu.N. Lankin, L.M. Lobanov, V.D. Poznyakov, I.A. Ryabtsev, K.A. Yushchenko

Scientists of Ukrainian Universities V.V. Dmitrik, NTU «KhPI», Kharkov V.V. Kvasnitsky, NTUU «KP|», Kyiv E.P. Chvertko, NTUU «KPI», Kyiv

Foreign Scientists N.P. Alyoshin

N.E. Bauman MSTU, Moscow, Russia Guan Qiao

Beijing Aeronautical Institute, China M. Zinigrad

Ariel University, Israel V.I. Lysak

Volgograd STU, Russia Ya. Pilarczyk

Welding Institute, Gliwice, Poland U. Reisgen

Welding and Joining Institute, Aachen, Germany G.A. Turichin

St. Petersburg SPU, Russia

Founders

E.O. Paton Electric Welding Institute, NASU

International Association «Welding» Publisher

International Association «Welding» Translators

A.A. Fomin, O.S. Kurochko, I.N. Kutianova Editor

N.G. Khomenko

Electron galley

D.I. Sereda, T.Yu. Snegiryova Address

E.O. Paton Electric Welding Institute,

International Association «Welding»

11 Kazimir Malevich Str. (former Bozhenko Str.),

03150, Kyiv, Ukraine

Tel.: (38044) 20060 16, 2008277

Fax: (38044) 20082 77, 2008145

E-mail: journal@paton.kiev.ua

www.patonpublishinghouse.com

State Registration Certificate

KV 4790 of 09.01 .2001

ISSN 0957-798X

DOI: http://dx.doi.org/10.15407/tpwj Subscriptions

$\$ 384,12$ issues per year

air postage and packaging included. Back issues available.

All rights reserved.

This publication and each of the articles contained herein are protected by copyright.

Permission to reproduce material contained in this

journal must be obtained in writing from the Publisher.

\section{CONTENTS}

\section{Plenary Papers for International Conference «Consumables for Welding, Surfacing and Coating Deposition and 3D Technologies", Kyiv, PWI, 4-5 June 2019}

Bonnel J.-M., Maurer M. and Rosert R. Submerged arc surfacing of high-alloy

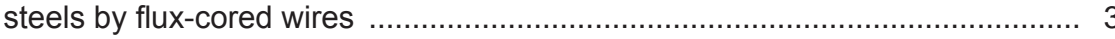

Golovko V.V., Stepanyuk S.N. and Ermolenko D.Yu. Dispersion modification of dendrite structure of weld metal

Yushchenko K.A., Gakh I.S., Zadery B.A., Zvyagintseva A.V. and

Karasevskaya O.P. Repair surfacing of gas turbine engine blades from

high-temperature nickel alloys with surface defects and damage

Goncharov I.O., Sudavtsova V.S., Mishchenko D.D., Duchenko A.M. and

Sokolsky V.E. Influence of refractory dispersed phases on physical-chemical properties of slag metls of $\mathrm{MgO}-\mathrm{Al}_{2} \mathrm{O}_{3}-\mathrm{SiO}_{2}-\mathrm{CaF}_{2}$ system ....

Shlepakov V.N. and Kotelchuk A.S. Improvement of technological and sanitary-hygienic characteristics of gas-shielded arc welding process

Akhonin S.V. and Schwab S.L. Filler flux-cored wire for TIG welding and surfacing of VT22 titanium alloy

Voronchuk A.P., Zhudra A.P., Petrov A.V. and Kochura V.O. Effect of temperature on hardness and wear resistance of high-chromium cast irons deposited with flux-cored strips

Kuskov Yu.M., Kuzmenko O.G. and Lentyugov I.P. Application of chips of steel $5 \mathrm{KhNM}$ in electroslag surfacing of dies in current-conducting mold ......... 43

Babinets A.A. Effect of chemical composition and structure of deposited metal on deformation of thin steel plates .............................................. 46

Golyakevich A.A., Orlov L.N. and Maksimov S.Yu. Peculiarities of welding process using metal cored wire of TMV5-MK grade

Adzhamsky S.V. and Kononenko A.A. Investigation of conditions of deep penetration in manufacture of samples of heat-resistant alloy Inconel 718 by the method of selective laser melting

Lipodaev V.N. Nitrogen alloying of weld metal in arc welding of corrosion-resistant steels (Review)

Fedorchuk V.E., Poklyatsky A.G., Falchenko Yu.V. and Kislaya G.P.

Scandium effect on the properties and structure of alloys of $\mathrm{Al}-\mathrm{Zn}-\mathrm{Mg}-\mathrm{Cu}$ system and their welded joints

\section{INFORMATION}

Electrode Manufacturing at PPWE of the E.O. Paton Electric Welding Institute 


\section{Dear Ladies and Gentlemen, Colleagues!}

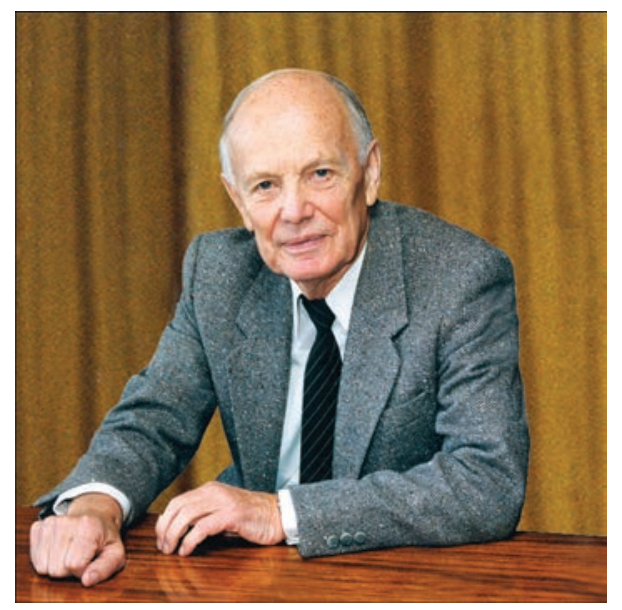

It is a great pleasure for me to welcome all the participants and guests of the International Conference devoted to problems urgent for modern welding production - materials for welding, surfacing, coating and 3D-technologies.

The range of problems and tasks chosen for discussion during the Conference, information on the recent achievements in this field, as well as familiarization with the samples of welding consumables from local manufacturers, presented in the exhibition, will promote strengthening the scientific and business contacts, and further development of research and applied work in the considered areas.

Traditional fruitful cooperation of science and production, constant scientific support by the E.O. Paton Electric Welding Institute and active position of welding consumables manufacturers allow providing high quality, and wide demand for domestic welding consumables, both in the internal and external markets. Evidence of this is the fact that during the years of independence Ukraine managed to prevent expansion of foreign manufacturers in the Ukrainian market. More over, Ukrainian specialists helped establishing a number of welding consumables productions in many countries of post-Soviet space. Unlike Ukrainian economy as a whole domestic manufacturers of welding consumables ensure positive foreign trade balance.

Among the new tasks facing specialists - manufacturers of welding consumables - we should mention organization of manufacturing of consumables for welding titanium and aluminium alloys, materials for application in additive technologies and robotic complexes.

On behalf of the Conference Organizing Committee, I would like to express my sincere gratitude to all the institutions, enterprises, organizations and specialists, whose active support enabled conducting this event.

I am confident that consideration of the questions to be discussed during the Conference, sharing information about the recent achievements in this field, establishing new scientific and business contacts will allow us making our contribution to reviving and enhancing the business activity of our country.

I wish fruitful work, great achievements, welfare and strong health to all the Conference participants.

Academician B.E. Paton

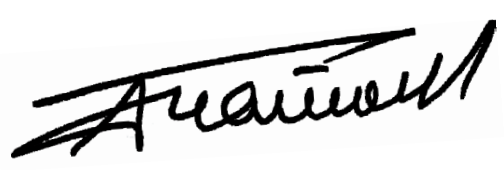




\title{
SUBMERGED ARC SURFACING OF HIGH-ALLOY STEELS BY FLUX-CORED WIRES
}

\author{
J.-M. BONNEL ${ }^{1}$, M. MAURER ${ }^{1}$ and R. ROSERT ${ }^{2}$ \\ ${ }^{1}$ Welding Alloys Group, Holtzwihr, France \\ ${ }^{2}$ Dr. Rosert RCT GmbH, Dresden, Germany
}

\begin{abstract}
Cored wires are used in numerous welding processes with or without external gas or flux shielding. Submerged arc welding (SAW) with cored wires, seamed or seamless, for joining mild and low alloyed steel grades is a technique that has demonstrated clear advantages during the three last decades. Ever since its invention, the SAW process has evolved with one main goal: to combine quality with productivity. With low alloy wires, the benefits have already been clearly demonstrated and widely exploited. However, little has been written on SAW and cladding with cored wires for corrosion or heat resisting applications. Its extension to high alloy compositions brings corresponding benefits and adds some specific and unique features. This paper focuses on consumable specificities and on the quality and productivity features of SAW with CRA (corrosion resistant alloy) cored wires. It describes the potential as well as the limitations of this technique. Cored wires are now used for submerged arc welding of almost all stainless steels ranging from soft martensitic to super-duplex, and for a series of nickel base compositions as well as for cladding cobalt base alloys. Examples of industrial applications with austenitic, duplex, martensitic and heat resisting stainless steels are given to illustrate the potential of the cored wire solution. 13 Ref., 4 Tables, 25 Figures.
\end{abstract}

Keywords : submerged arc welding, surfacing, cored wire, high-alloy steels

Submerged arc welding (Figures $1-4)$. The process allows deposition rates and welding speeds greater than most other welding processes and is very productive. It can produce deeply penetrating high quality welds as well as it can be used for weld surfacing where shallow penetration is required. It exists in many forms and it can be adapted to allow the welding of stainless steel base material from a few millimeters thickness up to more than $150 \mathrm{~mm}$. The flux covering suppresses fume and the operator is not hindered by the light of the arc which dispenses him from a welding shield.

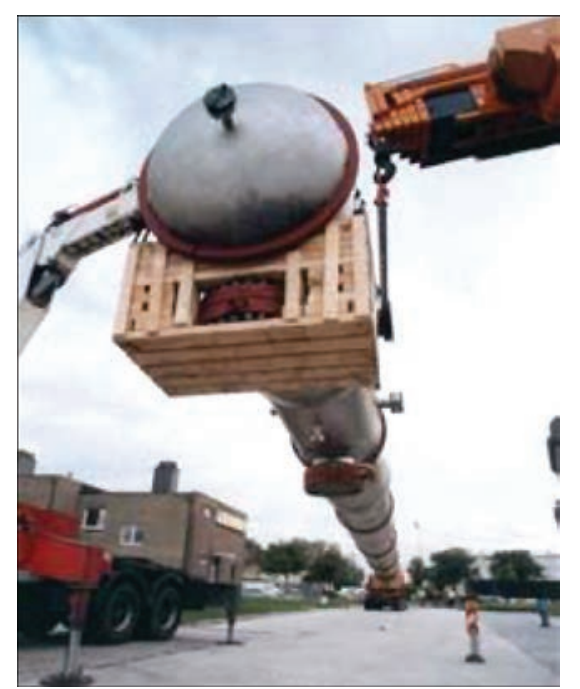

Figure 1. Submerged arc welding with cored wire: Duplex UNS S32205
The disadvantages are not serious: the weld pool cannot be seen, the flux can get into machinery parts and welding must be carried out in the flat or horizontal vertical positions. Circumferential welds are more difficult to be made in small diameters because the flux falls away.

There are two kinds of consumables for submerged arc welding: solid wire (the most commonly used) and cored wire. The characteristics of cored wire give advantages over solid wire. Cored wires comprise a metal sheath and a core. This core consists of a mixture of various metallic ingredients (such as nickel, iron or molybdenum powder) and non-metallic powders (for instance, slag forming components or agents that clean and deoxidize the weld).

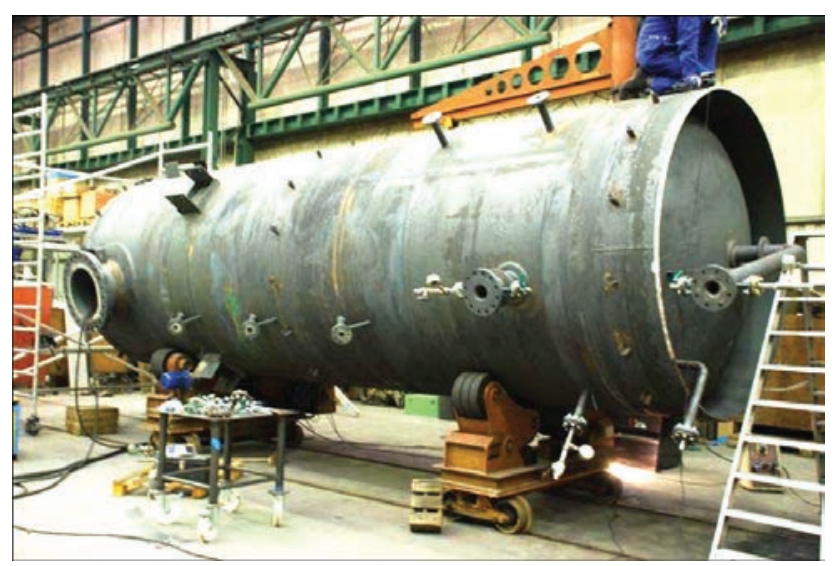

Figure 2. Submerged arc welding with cored wire: Austenitic CrNi steel AISI $310 \mathrm{~S}$ 
Compares submerged arc welding to other most common arc processes for welding stainless steel

\begin{tabular}{|c|c|c|c|c|c|c|}
\hline Parametrs & SAW & SMAW & GMAW & GTAW & PAW & FCAW \\
\hline Welding positions & $1 \mathrm{G}, 2 \mathrm{G}$ & All & All & All & $1 \mathrm{G}, 2 \mathrm{G}$ & All \\
\hline Heat input & High & Moderate & Moderate & High & Moderate & Moderate \\
\hline Slag cover & Yes & Both sides & No & No & No & Both sides \\
\hline Investment & High & Very low & High & Moderate & High & Low \\
\hline Analysis available & Limited & Any & Limited & Limited & Limited & Any \\
\hline $\begin{array}{l}\text { Possibility to modify } \\
\text { composition }\end{array}$ & Limited & Yes & No & No & No & Yes \\
\hline Employability & Limited & $\begin{array}{l}\text { Everywhere and } \\
\text { always }\end{array}$ & Often & Everywhere (gas) & Limited & Often \\
\hline Set time & Long & Short & Longer & Longer & High & Short \\
\hline $\begin{array}{l}\text { Sensitivity to contami- } \\
\text { nation }\end{array}$ & Low & Low & High & High & High & Low \\
\hline Heat / Filler supply & Together & Together & Together & Separate & Together & Together \\
\hline Slag & Yes & Yes & No & No & No & Yes \\
\hline Spatter & No & No/few & No/few & No & No & No / Few \\
\hline Weld bead protection & Good & Good & Good/moderate & Excellent & Excellent & Good \\
\hline Welding speed & High/very high & Moderate & Low/moderate & Low & Very high & Moderate/high \\
\hline Distortion & Moderate/high & Moderate & Low/moderate & High & Low & Low/moderate \\
\hline Automate & Yes & No & Yes & Yes & Yes & Yes \\
\hline Duty cycle & High & Moderate & Moderate & Low & High & Moderate \\
\hline Dilution & $30-70 \%$ & $10-25 \%$ & $5-50 \%$ & $0-100 \%$ & $100 \%$ & $10-25 \%$ \\
\hline Visible arc & No & Yes & Yes & Yes & Yes & Yes \\
\hline Welding fumes & No & Yes & Some & A few & A few & Yes \\
\hline Weld appearance & \begin{tabular}{|l|} 
Excellent \\
\end{tabular} & Very good & Good & \begin{tabular}{|l|} 
Excellent \\
\end{tabular} & \begin{tabular}{|l|} 
Excellent \\
\end{tabular} & Very good \\
\hline Micro-slag inclusions & Yes & Yes & No & No & No & Yes \\
\hline $\begin{array}{l}\text { Sophisticated power } \\
\text { ources }\end{array}$ & No & No & Yes & Yes & Yes & No \\
\hline Backing gas / Ceramic & No/ceramic & No & Gas & Gas & Gas & Ceramic \\
\hline Undercut & No & No & Sensitive & No & No & No \\
\hline Deposit rate in position & N.A. & Moderate & Low & Low & N.A. & High \\
\hline
\end{tabular}

The deposition efficiency (but not systematically the deposition rate) will increase with the amount of metallic core ingredients in a composite tubular wire up to a given degree of compaction above which, metal cored unlike flux cored wire, will almost have the same characteristics as solid wire.

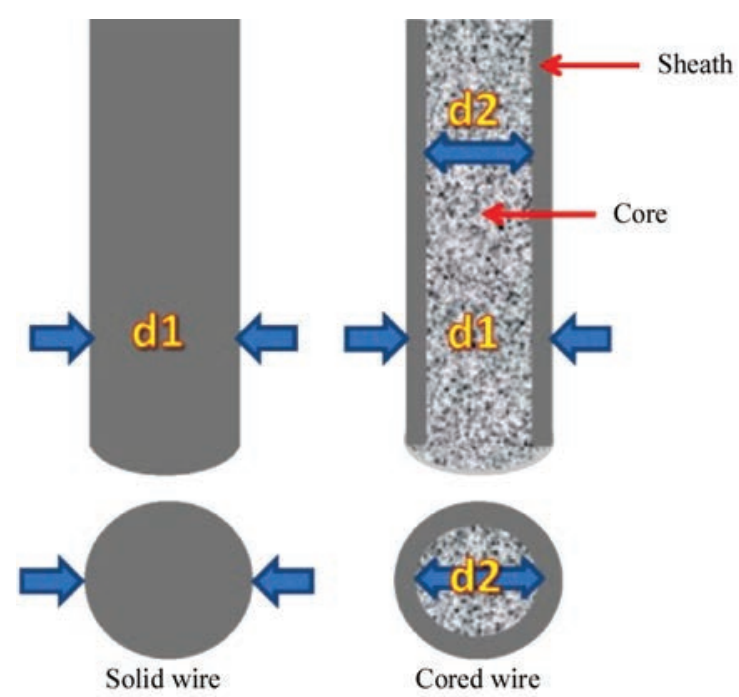

Figure 3. Current densities on solid wire vs cored wire. Solid wire $=3.14 \cdot\left(\mathrm{d} 1^{2}\right) / 4$, cored wire $=3.14 \cdot\left(\mathrm{d} 1^{2}-\mathrm{d} 2^{2}\right) / 4$
When welding with a tubular electrode, most of the welding current is conducted by the metal sheath. In a solid wire the current travels through the entire cross-section of the wire. Thanks to this difference, cored wires for submerged arc welding provide advantages:

At an equivalent amperage setting, a cored wire will experience higher current densities than a solid wire. The resulting increased melt-off rates, in combination with a high percentage of metallic core ingredients, offers higher deposition rates. At high currents,

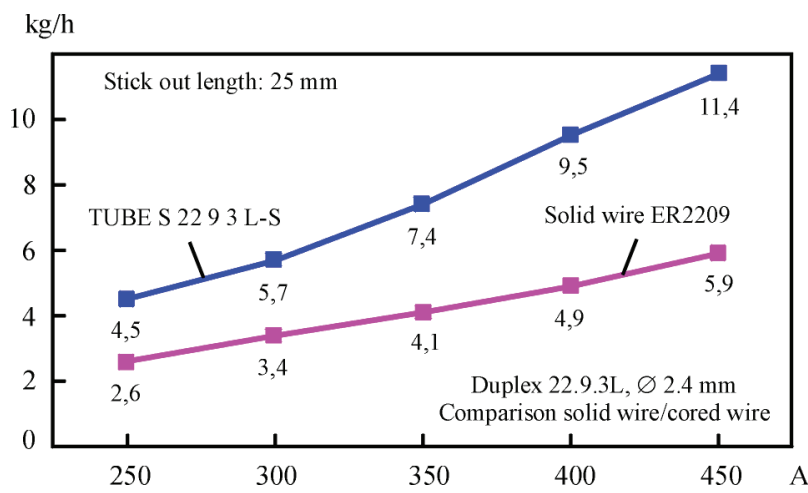

Figure 4. Deposition rates with solid wire and duplex cored wire for submerged arc welding - Duplex UNS S32205. Measured for application Figure 1 
the difference between solid wire and cored wire is amplified.

The benefit of an increased deposit rate, for a given wire diameter, at same amperage and same wire stick out is amplified by the physical characteristics of the strip. The electrical resistivity of stainless steel is higher when compared to mild or low alloy steel hence, for a given weld metal composition, deposition rates achieved with stainless steel cores wires will usually outperform these of solid wires having the same composition. The stainless steel sheath composition, its quality and dimensions, the production route of the cored wire as well as wire cross section design revealing filling ratio are important contributors not only to deposition rate but also to global weld performance.

Cored wires contribute to provide productivity which is important in any business. With stainless steels, corrosion resistance properties as well as metallurgical specificities such as embrittlement or hot cracking tendency are often the limiting factor. In many cases, these can be dealt with easier by exchanging solid to metal cored wires, without sacrificing productivity.

An efficiency of $99 \%$ is used when calculating the deposition rates of stainless steel solid wires when used in the SAW process. In comparison, TUBE S metal cored wires use a $98 \%$ efficiency rate for calculating deposition rates.

In many cases, stainless steel cored wires for SAW are formulated differently than those designed to run with shielding gas. For example, they contain additions to improve slag release or to enhance impact toughness.

Stainless steel cored wire designs (Figures 5, 6). The overriding majority of submerged arc wires for corrosion resistant application are seamed. The seam is overlapped. Cored wires with a seam are all manufactured from strip formed into a U-shape, filled and closed to give a round section. They are then reduced to the desired diameter by drawing or rolling.

In the case of drawing, the wire is reduced by passing it through a series of dies lubricated with soap. Drawing soaps contain hydrogen and must be eliminated at the end of the cycle to avoid porosity and excessive hydrogen content in the weld metal. Lubrication residues remaining on the wire surface must be removed either by dissolution or by baking.

In the case of rolling, the reduction is carried out in a more gradual manner with little or no lubricant, between rolls of appropriate profile. Rolling and drawing may be combined during the manufacture of cored wires.

High alloy seamless wires can be produced today as well. Low alloy seamless wires are manufactured

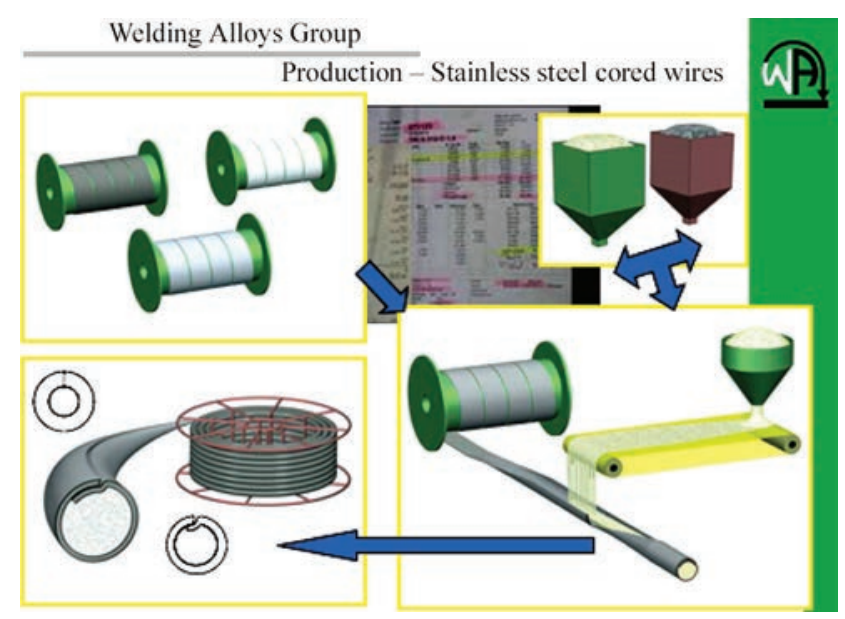

Figure 5. Corrosion resistant alloy cored wire production schematic description

from a metal tube filled by vibration then drawn to the desired diameter with intermediate annealing.

It is difficult to produce high alloy stainless grades his way because of the limitation in filling ratio. However, new production techniques for seamless highfill wires are now possible. One starts from a strip formed into a U-shape, filled with powder and then seam-welded by a proprietary laser system. The wire is then drawn to the required diameter with eventual intermediary annealing(s).

A drawback of stainless steel seamless wires for submerged arc welding is their lower performance in deposition rate.

Quality. Virtually all stainless steel compositions are feasible with cored wires. In order to obtain a weld deposit with the desired composition, structure, mechanical properties and corrosion resistance, the cored wire manufacturer has at his disposal a vast variety of strip analyses, which he combines with metal and/or mineral powders, with or without binders.

What determines the quality of the finished product is the experience and knowledge brought to bear in production. Close attention is essential to ensure

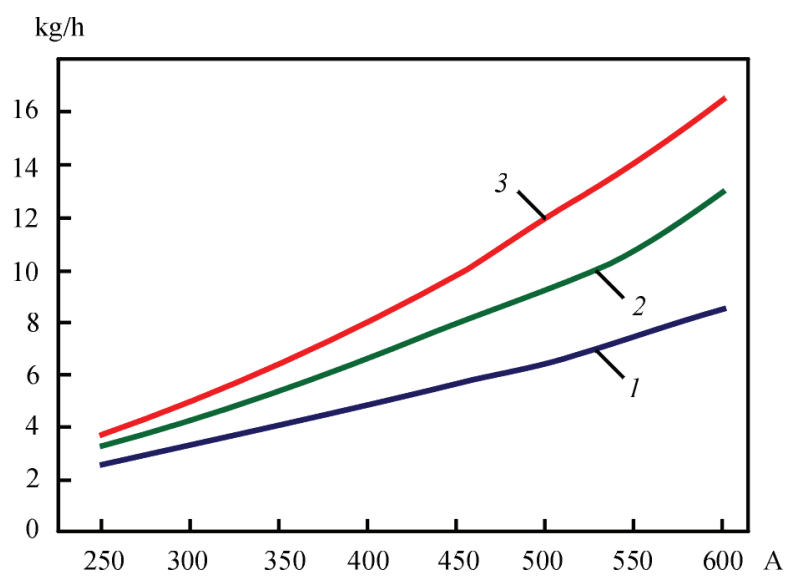

Figure 6. 308L composition. Deposition rates diameter $2.4 \mathrm{~mm}$. Stick out length $25 \mathrm{~mm}$ : 1 - solid wire; 2 - seambless cored; 3 - seamed cored 


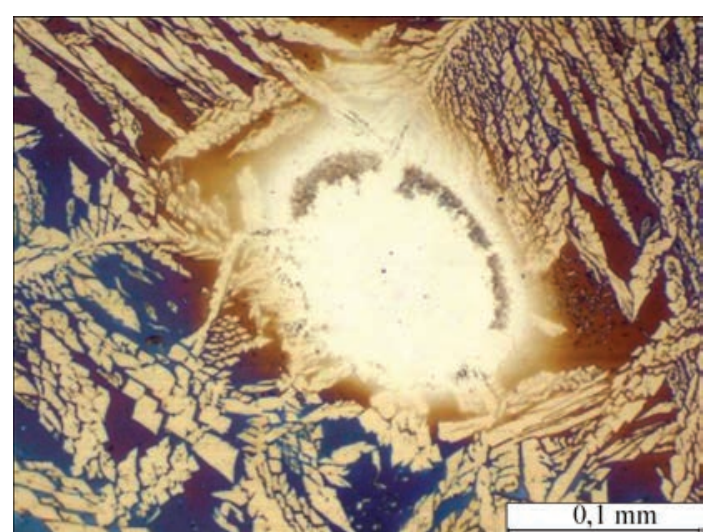

Figure 7. Submerged arc duplex cored wire $2.4 \mathrm{~mm}$. Low parameters: 250 A, $28 \mathrm{~V}, 40 \mathrm{~cm} / \mathrm{min}$. Coarse molybdenum metal. Unmolten molybdenum in structure. Pitting corrosion temperature under $22{ }^{\circ} \mathrm{C}$

the core is continuous and homogeneous. Strict quality control must be exercised from the procurement of raw materials until the finished product is prepared for dispatch.

Stainless steel cored wires are produced mainly by rolling and may undergo one or several heat treatments. One may arrive at a particular weld deposit analysis starting from a more or less highly alloyed strip. The composition is adjusted by adding elements to the flux filling of the tube. For example, it is possible by this means to produce a $316 \mathrm{~L}$ austenitic stainless steel cored wire with using mild steel, 430L, 304L or 316L strip.

The performance of high alloy cored wires for submerged arc welding in terms of productivity and weldability in addition to mechanical properties and resistance to various forms of corrosion - according to the type of stainless steel deposited - depends on a large number of factors:

- the strip: composition, dimensions, surface finish, impurity levels, general condition;

- the manufacturing process: rolling sequence, lubrication system, heat treatments etc;

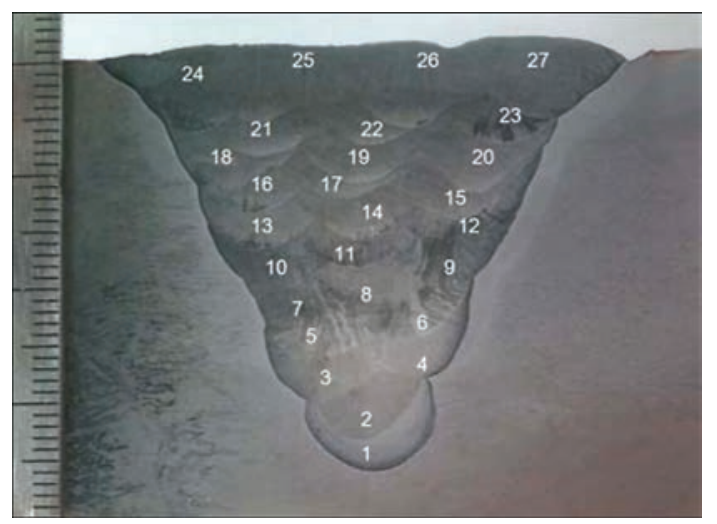

Figure 8. $60^{\circ}$ V-joint, $50 \mathrm{~mm}$ ER309L, $3.2 \mathrm{~mm}, 450 \mathrm{~A}, 31 \mathrm{~V}$, $50 \mathrm{~cm} / \mathrm{min}, 27$ runs
- the core type: flux or metal cored, amount and type of non-metallic additions, wet mix or dry mix.

The details of the slag/core formulation, the consistency of the raw materials used, their grain size and their purity are of overriding importance: it is well known that cored wires of the same classification from different manufacturers are never quite the same. Economic considerations (raw material prices, production output and initial cost price of the wire) should not occult the stringent requirements in terms of formulation otherwise problems will arise sooner or later (Figure 7).

Cored wires for submerged arc welding - advantages. The main benefits of the cored wire route for submerged arc welding stainless steels can be summarized as follows:

- tailored compositions to cope with specific dilution levels or to achieve particular compositional requirements and mechanical/corrosion resistance properties (fabrication welding and weld overlay);

- increased productivity: higher deposition rates and/or improved corrosion resistance;

- higher welding speeds: reduced heat input, reduced warping of welded structures;

- enhanced weldability: excellent wetting, easy slag release even for the first beads in narrow preparations, very good weld appearance;

- versatility: it is possible to weld the first layers, for example the first run on a root pass at low settings (e. g. $<250 \mathrm{~A}$ for $\varnothing 2.4 \mathrm{~mm}$ ) and to fill the joint with the same wire, taking benefit from the improved deposition rates at higher parameters (e. g. $450 \mathrm{~A}$ for Ø $2.4 \mathrm{~mm}$ );

- logistical advantage: one wire diameter can be used for all thicknesses.

The above advantages are illustrated by some examples of applications.

Joining of common chrome nickel austenitic stainless steel. Submerged arc welding is commonly applied to joining applications. As it is restricted to

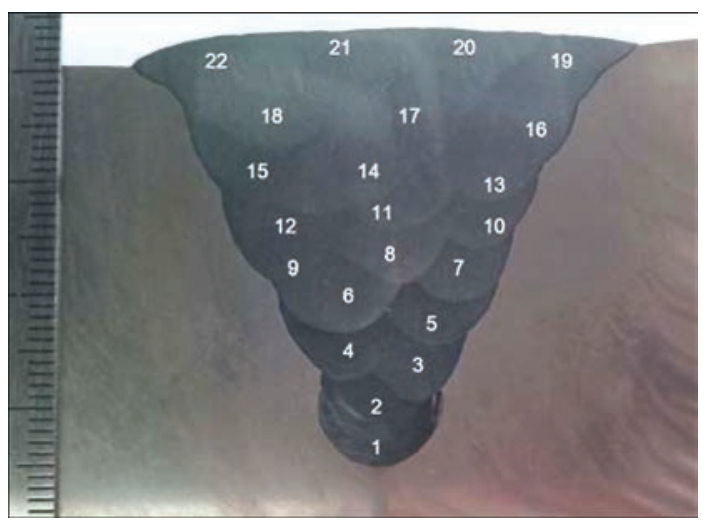

Figure 9. $60^{\circ}$ V-joint, $50 \mathrm{~mm}$, EC309L $3.2 \mathrm{~mm}, 450 \mathrm{~A}, 31 \mathrm{~V}$, $50 \mathrm{~cm} / \mathrm{min}, 22$ runs 


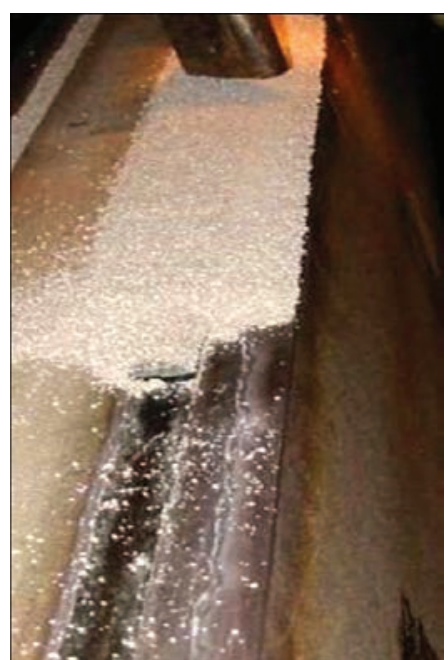

Figure 10. Submerged arc welding with EC316L wire

work in the flat position and the weld pool is not visible, it has been developed essentially as an automatic or robotic process.

Pressure to increase productivity, reliability and quality is unrelenting. Thus, nowadays we find many possible combinations: tandem, twin, tandem-twin, multi-wire and a series of derivatives or digressions from these techniques. Whatever process is used, cored wire can increase quality and productivity. A simple change of consumable can bring clear benefits, as shown on figures 8 and 9. Using cored wire instead of solid wire, a higher deposit rate is achieved with fewer passes.

Thanks to its wide parameter range, cored wire can be used for a large range of submerged arc applications, from two-run processes to multi-pass groove welding (Figure 10).

Weld bead shapes are easier to adjust, less weld preparation is required, as fewer layers are necessary to complete the joint, less flux is consumed and there is less downtime and distortion (Figure 11).

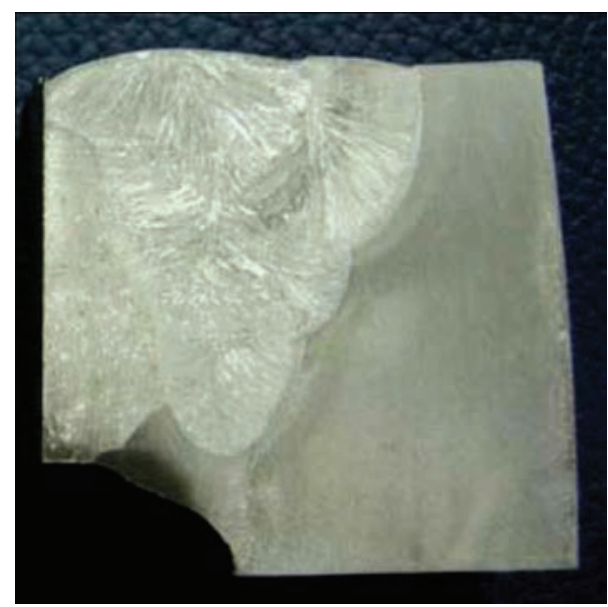

Figure 11. Macrography illlustrating bead shaping possibilities and penetration

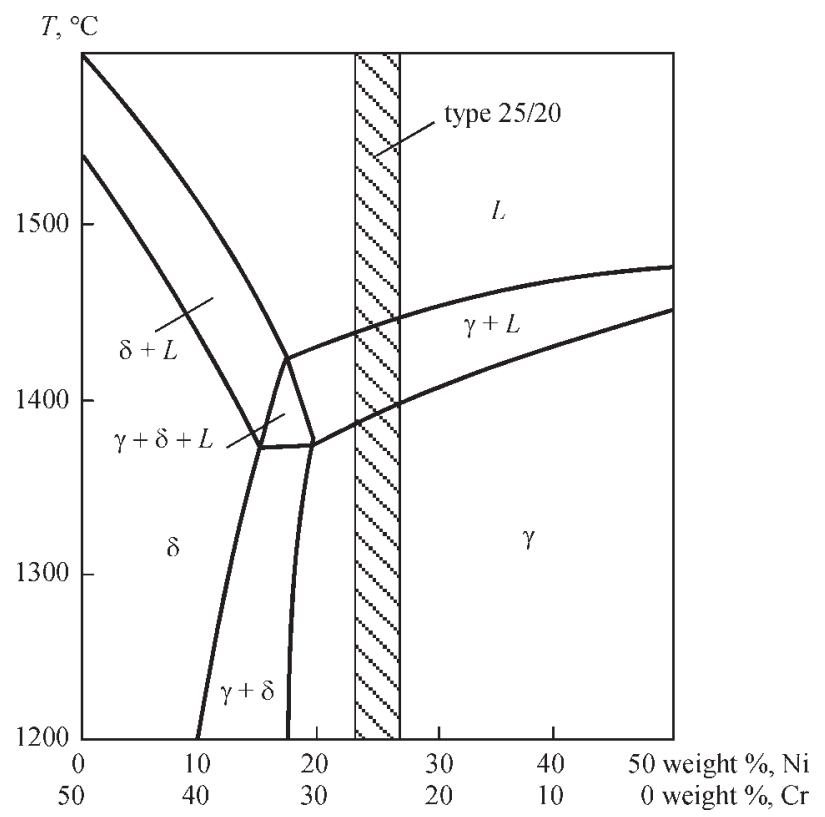

Figure 12. FeCrNi diagram $18 \mathrm{Cr} / 8 \mathrm{Ni}$ composition. FA solidification mode

Joining of standard chrome nickel austenitic stainless steel (Figures 12,13). As a rule of thumb, most austenitic stainless steels with a $\mathrm{Cr}_{\mathrm{eq}} / \mathrm{Ni}_{\mathrm{eq}}>$ $>1.5$ with $\mathrm{Cr}_{\text {eq }}=\% \mathrm{Cr}+\% \mathrm{Mo}+0.7 * 0 \mathrm{Nb}$ and $\mathrm{Ni}_{\text {eq }}=$ $=\% \mathrm{Ni}+35 \% * \mathrm{C}+20 \% \mathrm{~N}+0.25 * 0 \mathrm{Cu}$ are quite easy to weld, provided some elementary precautions are taken. They do not normally require preheat, post-heat or post weld heat treatment. Austenitic weld metal with adequate ferrite content has good resistance to hot cracking.

Austenitic stainless steels undergoing a primary austenitic solidification (A or AF) are more sensitive to hot cracking and require special care during welding (example 310,385 ).

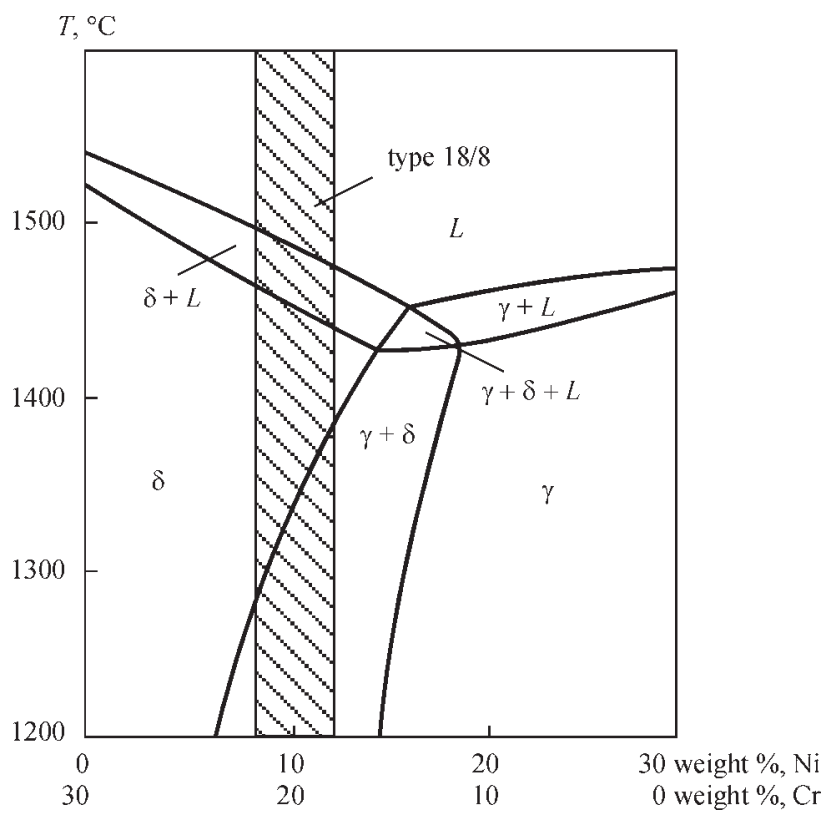

Figure 13. FeCrNi diagram $25 \mathrm{Cr} / 20 \mathrm{Ni}$ composition. Primary austenitic solidification mode 


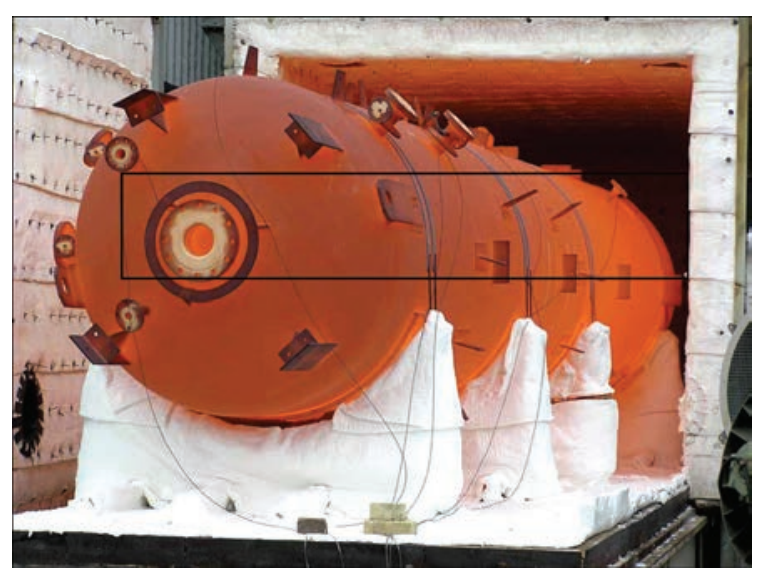

Figure 14. $310 \mathrm{~S}$ reactor under heat treatment. SAW: TUBE S 310-S + WAF 380

Austenitic stainless steels have lower thermal conductivity than carbon and low alloy steels, the welding zone will be at high temperatures for longer. During welding, impurities can become concentrated at the grain boundaries resulting in a risk of cracking. To avoid this, welding conditions and welding consumables must be chosen with care:

- control residual impurity levels (S, P, B etc.) in the weld metal i.e. in wire and flux;

- limit oxygen content in weld metal;

- alloy with manganese when possible and allowed;

- avoid burn off of alloying elements;

- control dilution;

- keep heat input low;

- work with a low inter-pass temperature;

- adapt welding speeds;

- check weld bead geometry (width/depth ratio).

With cored wire, welding can be carried out at a low heat input with a higher deposition rate than with solid wire. Thus, cored wires allow quality to be combined with productivity including for austenitic stainless steels.

He SAW process using cored wire wire is now being implemented with success on AISI 310 stainless steel. Cored wire improves hot cracking resistance when compared to solid wire. The constructions are

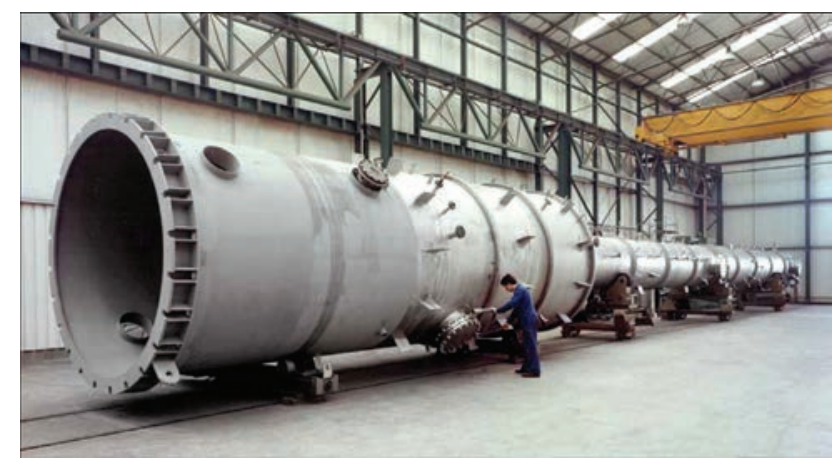

Figure15. Reboiler in duplex stainless steel FCAW - TETRA S B 229 3L-G. SAW - TUBE S 229 3L-S + WAF 385

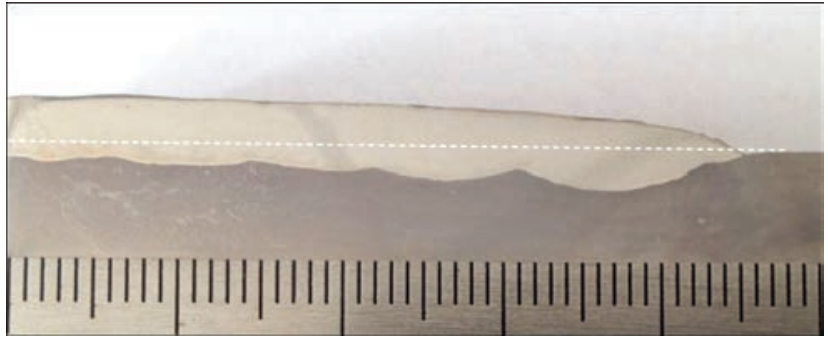

Figure 16. Cladding ER309L 3.2 mm, 330 A, 30 V, 41 cm/min, $30 \%$ dilution

for example $\mathrm{H}_{2} \mathrm{~S}$ reactors and involve thicknesses above $40 \mathrm{~mm}$. PWHT is specified with a holding time at $870{ }^{\circ} \mathrm{C}$. Other PWHT is solution annealing at $1080^{\circ} \mathrm{C}$.

Joining duplex stainless steels. Lean duplex, duplex and super-duplex steels have good weldability as well. Duplex stainless steel cored wires can be tuned in order to achieve required composition, ferrite level and mechanical properties according to specific joint preparations or specific requirements on the cladding. Though submerged arc welding is a process that uses a high heat input it is well adapted to welding duplex stainless steels. Cored wire is often an attractive solution to expand the possibilities of the submerged arc welding process with these materials.

Duplex cored wire TUBE S 229 3L-S allows deposit rates $30 \%$ higher than those of solid wire of the same diameter to be attained (Figures 14, 15).

Cladding applications (Figures 16-18). Stainless steel cladding involves careful monitoring of the dilution. The Schaeffler, Espy and WRC 92 extended constitution diagrams are useful tools to predict the structure of a weld metal in the case of weld overlays. The closer one comes to the boundary of the martensite region of the diagrams, the greater is the risk of cold cracking. Procedure qualification according to EN ISO 15614-7 \& ASME IX prescribes bend tests to reveal any cracking tendency and to guarantee the soundness of the weld deposit.

The electroslag welding process (ESW) is currently very widely used for cladding on account of its advantages: low dilution, high deposition rate, high quality.

This process is however sometimes difficult to use for several reasons:

- size: strip width + the magnetic steering system;

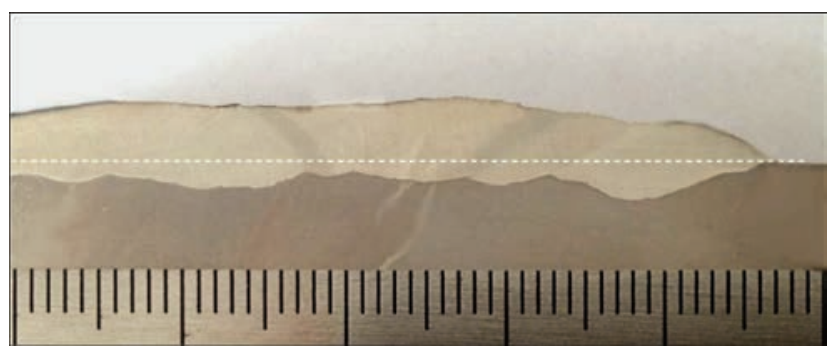

Figure 17. Cladding EC309L 3.2 mm, 330 A, 30 V, 41 cm/min, $23 \%$ dilution 


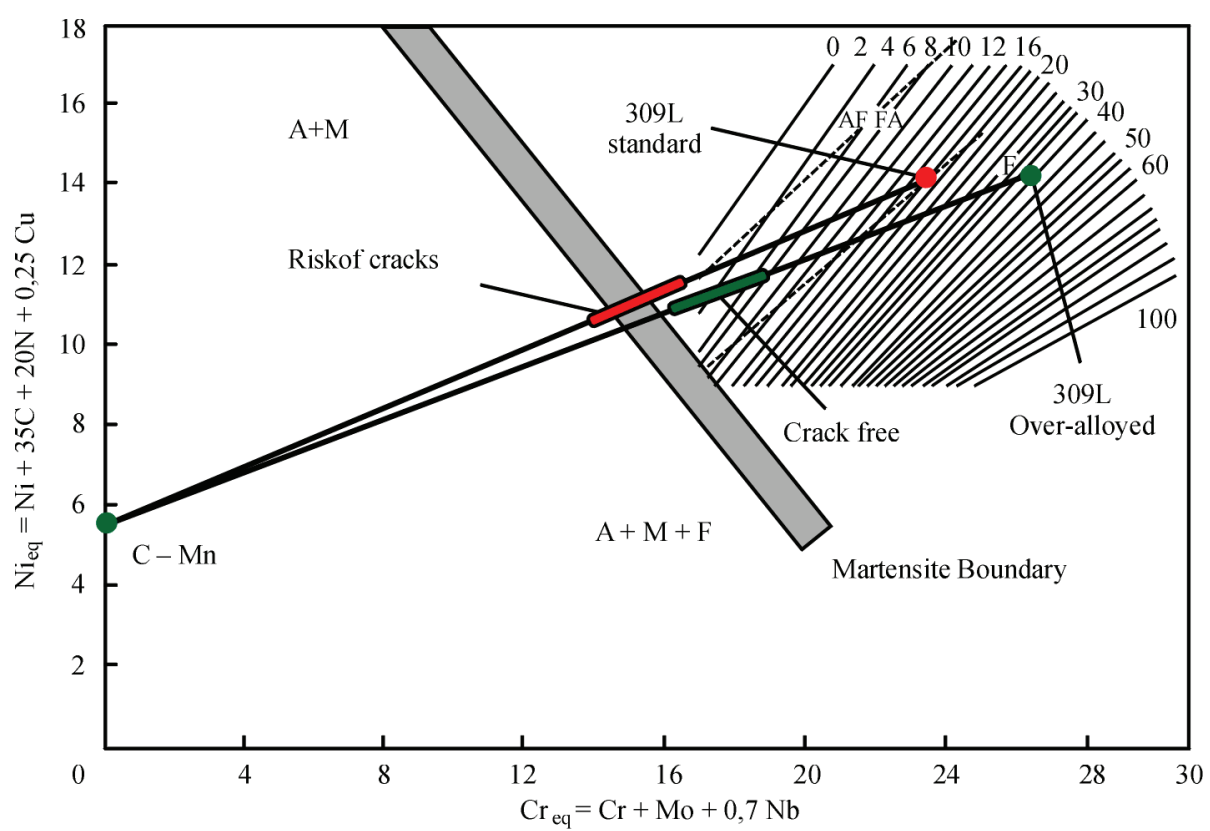

Figure 18. Extended WRC 1992 Diagram. High dilution tolerance with cored wire

- minimum base metal thickness is required: approximately half the width of the strip (e.g. minimum base metal thickness of $30 \mathrm{~mm}$ if a $60 \mathrm{~mm}$ wide strip is used);

- high distortion due to the high heat input;

- need of a high-current power source delivering typically 1200 A for a $60 \mathrm{~mm}$ strip.

Submerged arc deposits with cored wire are characterized by bead profiles that are wider and less penetrated than solid wire. Thus, at the same parameters (330 A, $30 \mathrm{~V}, 41 \mathrm{~cm} / \mathrm{min}$ ), SAW with cored wire will involve less dilution and a lower risk of martensite formation in weld metal (about $10 \%$ less dilution with cored wire at same parameter settings). This martensite is a problem, for example during the bend tests.

Despite the high deposition rates offered by SAW, it is difficult to use it as a substitute for ESW due to its high dilution with solid wires and the lack of suitable compositions to compensate this dilution.
With cored wire this problem is overcome by working with an over-alloyed 309L alloy for use as a buffer layer. By increasing the amount of chromium, one move away from the martensite boundary and provide high dilution tolerance (more than $40 \%$ ). Thanks to this custom-made buffer wire, one can obtain the required chemical analysis in two or three layers with no risk of cracking in the first layer.

This enables SAW cored wires to be used in numerous applications, for example:

- restoration of cladding (e.g. longitudinal and circular seams of pressure vessel equipment);

- overlay welding of components with limited access;

- flexible groove preparation.

Cladding - focus on UNS N 08904 austenitic overlay welding. UNS N 08904 is a multipurpose high corrosion resistance austenitic stainless steel developed 40 years ago. Due to combined additions

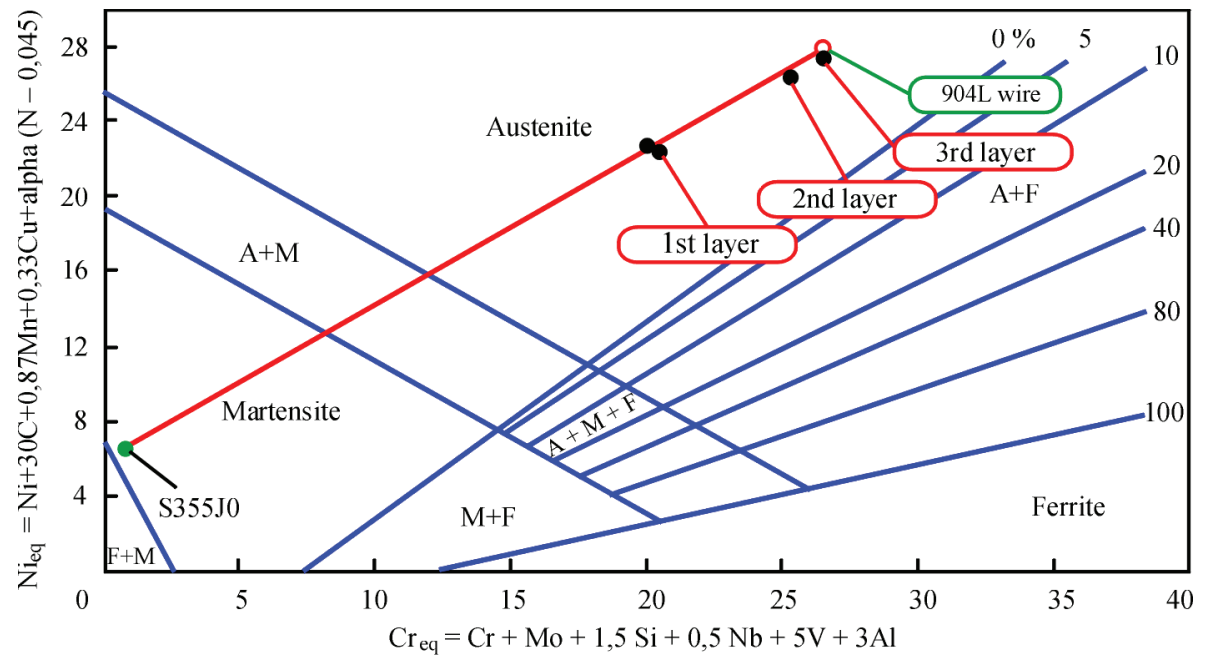

Figure 19. Extended WRC 1992 Diagram: 385 cladding 


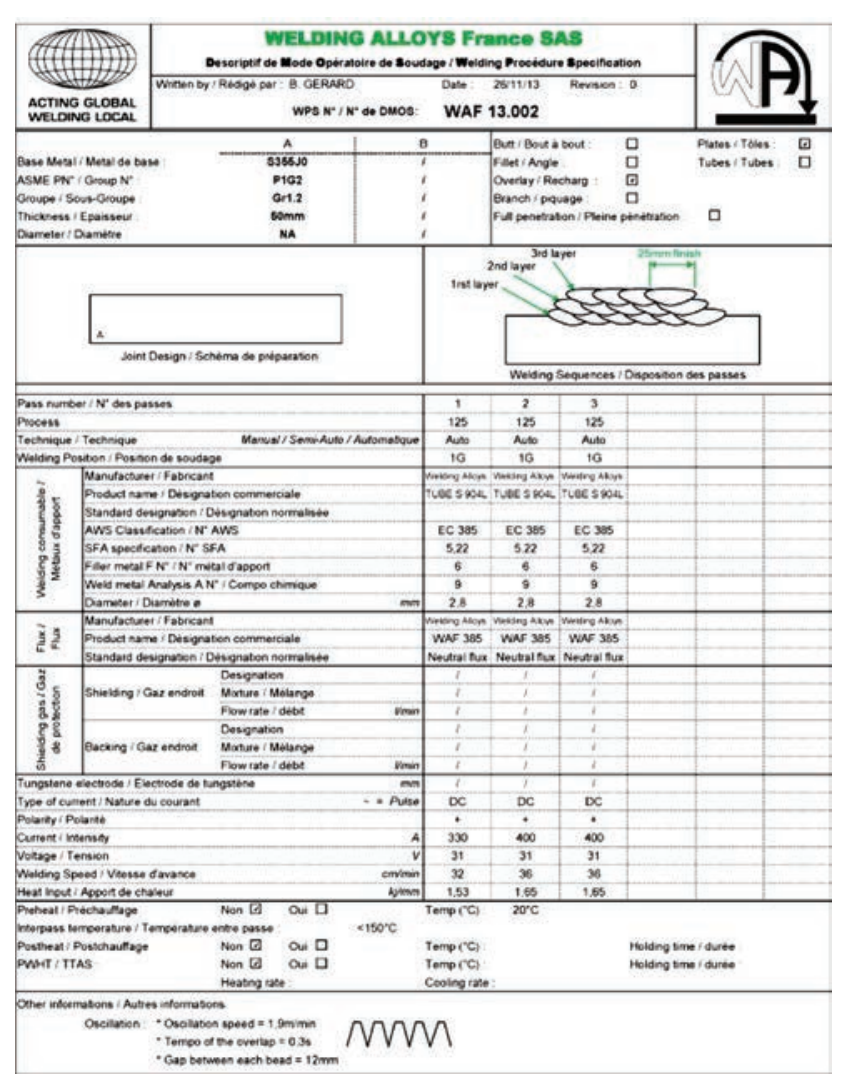

Figure 20. Submerged arc cladding with cored wire EC385. Welding procedure

of chromium (20\%), molybdenum (4.3\%), copper $(1.5 \%)$ combined with its high nickel content, the grade is recommended for most applications dealing with medium to severe corrosive solutions and is particularly used in sulfuric and phosphoric acids applications. It is well adapted to clad plates applications.

When welding with rutile cored wire or shielded metal arc electrode, it is common practice to weld a 309LMo buffer layer before cladding with 385 (20 25 $5 \mathrm{Cu} \mathrm{N} \mathrm{L}$ ) which is the matching filler metal for UNS N 08904. No buffer layer is required when cladding with a metal cored wire for submerged arc welding.

Cladding - focus on martensitic overlay welding. Continuous caster rolls in steel mills operate in particularly harsh service environments. Mold fluxes are added to the top of the continuous casting mold in order to cover the liquid steel. Within the caster, molten steel poured from a tundish flows into an oscillating copper mold where it forms a skin against the water cooled copper plates. The partially solidified

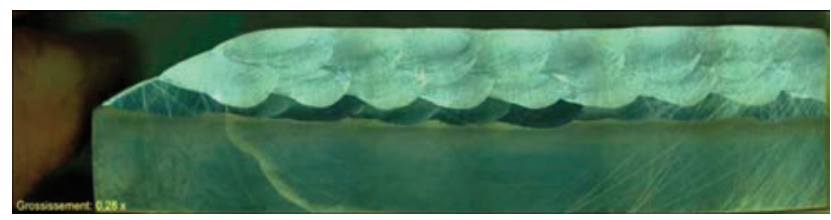

Figure 21. Submerged arc cladding with cored wire EC385. Macrography-stinger bead technique slab is then pulled out of the mold through a series of containment segments containing drive rolls.

The slab is usually bent into the curved section of the caster, and unbent towards the run-out portion. Within the containment of the caster, the slab is subjected to water spraying to promote solidification.

In order to optimize roll reclamation and service life, cladding consumables have to be designed with the aim of preventing the failure mechanisms described above.

The most important requirements for continuous caster roll clad layers are listed below:

- elevated temperature oxidation resistance;

- resistance to localized pitting and crevice corrosion;

- maximum resistance to stress corrosion cracking and corrosion fatigue;

- maximum tempering resistance to prevent softening during service;

- resistance to thermal and thermo-mechanical fatigue;

- high thermal conductivity;

- low coefficient of thermal expansion;

- high hardness and resistance to abrasive and adhesive wear;

- high strength and sufficient toughness;

- good weldability;

- reasonable cost.

In order to obtain the required hardness, strength, wear resistance and corrosion resistance required in this application, stainless steels with martensitic microstructures are preferred. They are cost effective, provide high hardness, strength and wear resistance, as well as a low coefficient of thermal expansion hence improved thermal fatigue resistance.

A minimum of $12 \%$ chromium generally provides the adequate corrosion and elevated temperature oxidation resistance necessary for slab caster operation. The presence of ferrite is believed to reduce the hardness and strength of the deposit, a $\delta$-ferrite content of less than $10 \%$ is often required. The addition of controlled

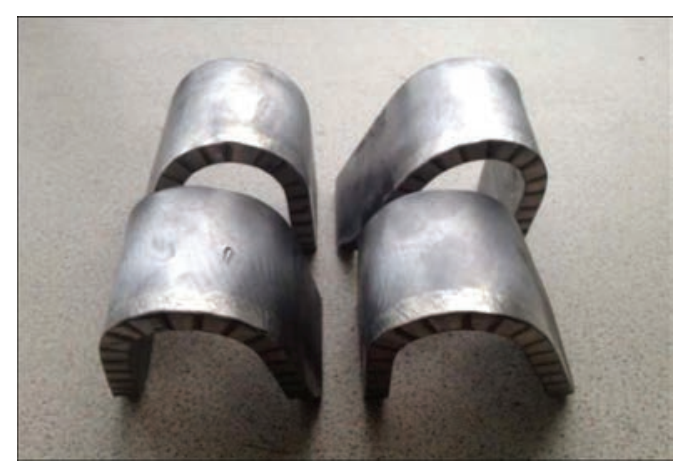

Figure 22. Submerged arc cladding with cored wire EC385. Side bend tests 
CHROMECORE 414N-S - typical all-weld analysis with flux WAF 415

\begin{tabular}{|c|c|c|c|c|c|c|}
\hline $\mathrm{C}$ & $\mathrm{Mn}$ & $\mathrm{Si}$ & $\mathrm{Cr}$ & $\mathrm{Ni}$ & $\mathrm{Mo}$ & $\mathrm{N}$ \\
\hline 0.08 & 1.0 & 0.6 & 13.5 & 4.3 & 0.5 & 0.10 \\
\hline
\end{tabular}

Operating conditions (recovery: $95 \%$ )

\begin{tabular}{|c|c|c|c|c|c|c|}
\hline \multirow{2}{*}{ Wire diameter, $\mathrm{mm}$} & \multicolumn{2}{|c|}{ Current, A } & \multicolumn{2}{c|}{ Voltage, V } & \multicolumn{2}{c|}{ Stick-out, mm } \\
\cline { 2 - 7 } & Range & Optimum & Range & Optimum & Range & Optimum \\
\hline 2.4 & $200-450$ & 350 & $26-30$ & 30 & $25-60$ & 30 \\
\hline 2.8 & $250-550$ & 400 & $28-32$ & 30 & $25-60$ & 30 \\
\hline 3.2 & $300-650$ & 500 & $28-32$ & 30 & $25-60$ & 30 \\
\hline
\end{tabular}

amounts of nickel and molybdenum improves the high temperature properties. Nickel also raises the toughness of the deposit and stabilizes martensite, whereas molybdenum improves resistance to localized corrosion as well as it increases hardness and temper resistance.

Further improvement can be obtained by substituting part of the carbon normally added to martensitic stainless steels with nitrogen, a potent austenite promoting element. Nitrogen-enhanced $12 \%$ chromium martensitic stainless steels exhibit faster re-passivation kinetics, a fine homogeneous distribution of nitride precipitates which inhibit grain growth and an increase in the stability and passivity range of the oxide film. This results in improved oxidation and corrosion resistance, higher strength, improved impact toughness, enhanced temper resistance, and higher resistance to thermal and thermo-mechanical fatigue. These improved properties result in considerably less material loss during service and explain the success of our 400N series pioneered and designed by Welding Alloys.

Incorporating the required amount of nitrogen up to the solubility limit and without porosity by submerged arc welding has proven to be an effective solution (Tables 2, 3).

Cladding - focus on high chromium cast irons overlay welding (Figures 23-25). During its whole service life, mechanical equipment is undergoing the deleterious effects of corrosion and/ or wear. In most

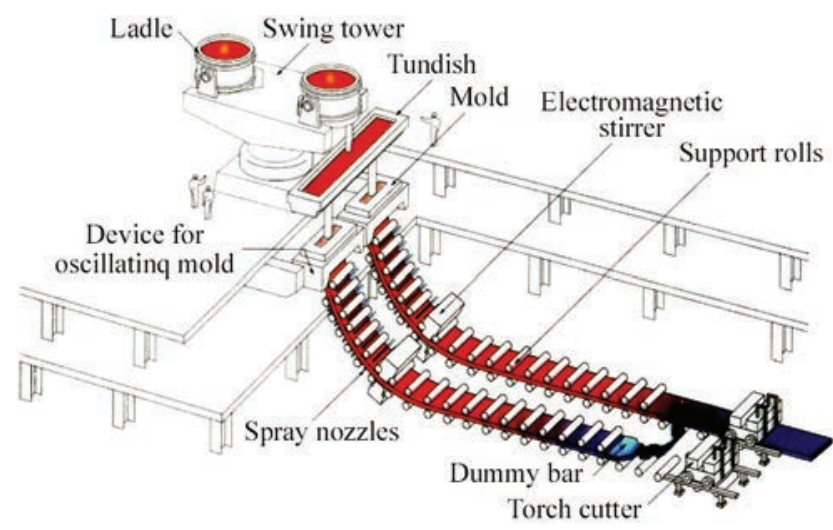

Figure 23. Continuous casting cases, wear or corrosion are synonym of lost metal and parts reduced down to the stage where they can no longer efficiently perform their intended function.

Flux and metal cored wires are implemented for joining, cladding and hardfacing application.

Cladding consists in depositing a corrosion resistant surfacing on a base metal providing mechanical strength whereas hardfacing is a solution to increase wear resistance.

Hardfacing has numerous advantages:

- longer service life of wear parts;

- improved efficiency to plant operation and an increase in production;

- reduced idle time in plant operation;

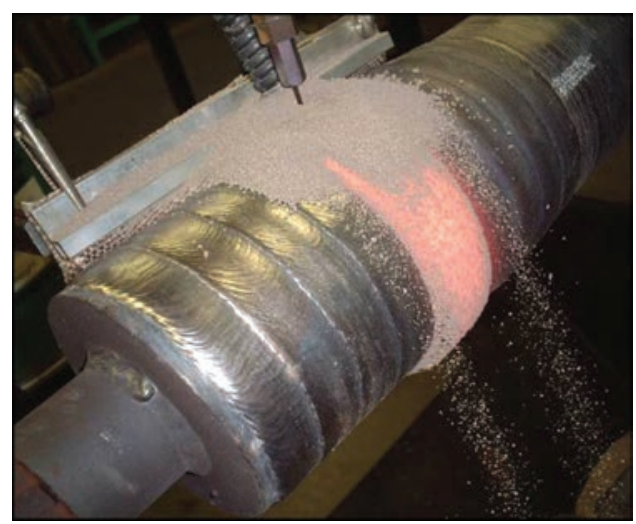

Figure 24. Continuous casting roller cladding with cored wire CHROMECORE $414 \mathrm{~N}-\mathrm{S}$

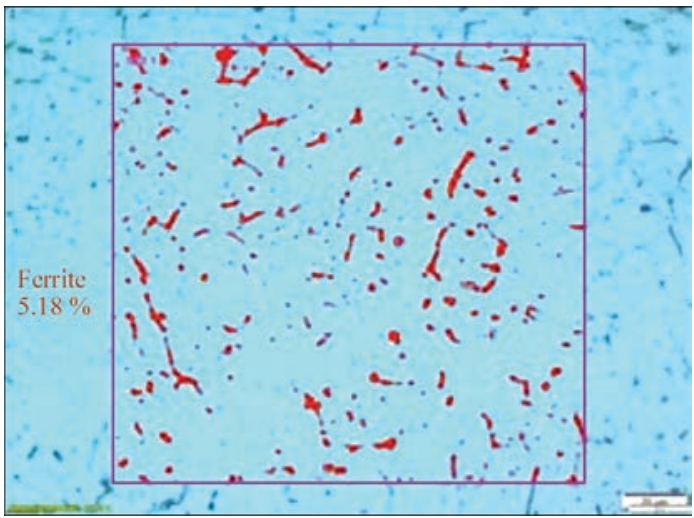

Figure 25. Structure martensite $+5.2 \%$ delta ferrite 
Typical chemical composition high chromium cast irons (weight \%)

\begin{tabular}{|c|c|c|c|c|c|c|c|c|}
\hline WA HARDFACE & Symbole & C & Cr & Nb & Mo & W & V & Hardness \\
\hline HC-O & Fe15/PKE & 5.0 & 27 & - & - & - & - & 60 HRC \\
\hline CN-O & Fe15/KKA & 5.5 & 22 & 7 & - & - & - & 62 HRC \\
\hline CNV-O & Fe16/KKA & 5.5 & 22 & 7 & 7 & 2 & 1 & 64 HRC \\
\hline
\end{tabular}

- use of reconditioned components rather than costly new replacements, and a reduction in labor costs due to fewer replacements;

- basic savings of replacing expensive alloy steel parts with cheaper mild or low-carbon steel parts, hardfaced with a minimum amount of superior wear-resistant alloy located only in the area of wear;

- reduced overall dependence on replacement parts and considerable saving in maintenance costs.

High chromium cast irons are cost effective solutions when abrasion is the main wear factor. The choice of a given composition within this family of products depends on whether or not secondary wear mechanisms such as temperature, impact or corrosion are present.

Hardness is not a guarantee of abrasion resistance: a suitable microstructure is. Microstructure for high chromium cast irons, is governed by two elements: carbon and chromium. The ratio between chromium and carbon is of paramount importance to guarantee the presence of primary carbides and to optimize their amount: both are essential for wear resistance.

The welding procedure actually influences the orientation of these carbides, thus the overall performance of the weld deposit. Wear resistance often is a compromise: extreme resistance to abrasive wear is synonym of a lower resistance to impact. Taking this into account, three families of high chromium cast irons are available to the end user:

Near eutectic compositions that present a good solution for applications where besides abrasion resistance, a combination of resistance to impact and eventually corrosion is required

Primary carbides with eutectic for extreme resistance to abrasion

Primary carbides + alloy carbides in a eutectic austenite/carbide matrix. Such deposits contain harder and finer carbides for improved resistance to a wider range of abrasives and/or combined wear mechanisms, for example abrasion + temperature.
Globally, if we do not consider the «black magic trend» three or four compositions are enough to cope with most of the abrasion related applications.

Conclusion. For years [1-13], the submerged arc welding process has evolved with one main goal: to combine quality with productivity. Cored wires depositing corrosion resistant alloys are dedicated to this process. They offer satisfactory versatility both in joining and in cladding and provide useful and economically attractive process improvements as well as high quality performance required for corrosion and heat resisting application.

1. Fils tubulaires pour le soudage d'aciers inoxydables, JM Bonnel, N Vass, N.C Pease, Soudage Automatique - Applications Industrielles du Soudage avec Fil Fourré - Institut de Soudure - 11/12/2001.

2. Tubular wire welding, D. Widgery, Abington Publishing, ISBN 185573 088X.

3. Cored wires for corrosion resistant alloys: status report 2006, JM Bonnel, N.C. Pease, International Institute of Welding Congress, 8-10/03/2006, Stellenbosch, South Africa.

4. EN ISO 4063: Welding and allied processes — Nomenclature of processes.

5. Gevulde draad MIG/MAG en onderpoederdek lassen van austenitisch en duplex roestvast staal, JM Bonnel, Welding Alloys - Seminarie Belgisch Instituut voor Lastechniek, Stivak en De Nayer Instituut, 2001.

6. Fils fourrés à poudre métallique, JM Bonnel — Journée d'étude «Soudage et mise en œuvre de l'acier inoxydable», Institut Belge de la Soudure - 28 novembre 2002.

7. EN ISO 17633: Welding consumables - Tubular cored electrodes and rods for gas shielded and non-gas shielded metal arc welding of stainless and heat-resisting steels - Classification.

8. Proceskeuze van modern lastechnieken in roestvast staal, F. Neessen, H. Meelker, F. Naber - Lincoln, Roestvaststaalgids 2012.

9. ASME II C SFA-5.22: Specification for stainless steel flux cored and metal cored welding electrodes and rods.

10. Technical report ISO/TR 17671-5: Welding - Recommendations for welding of metallic materials — Part 5: Welding of clad steels.

11. Which process? Peter Houldcroft, Abington Publishing, ISBN I 855730081.

12. Arcelor Product Information: URANUS B6 and B6N. A multipurpose Austenitic stainless steel with PREN $\geq 34$.

13. Submerged arc welding with tubular cored wires: Welding \& cladding of high alloy steels, B.Gerard, N.C. Pease, Welding Alloys. 


\title{
DISPERSION MODIFICATION OF DENDRITE STRUCTURE OF WELD METAL
}

\author{
V.V. GOLOVKO, S.N. STEPANYUK and D.Yu. ERMOLENKO
}

E.O. Paton Electric Welding Institute of the NAS of Ukraine

11 Kazimir Malevich Str., 03150, Kyiv, Ukraine. E-mail: office@paton.kiev.ua

\begin{abstract}
The paper deals with the effect of dispersed particles of refractory compounds $\left(\mathrm{Al}_{2} \mathrm{O}_{3}, \mathrm{MgO}, \mathrm{ZrO}_{2}\right)$ added as cold filler to $1.6 \mathrm{~mm}$ flux-cored wire, on modification of the dendrite structure in low-alloy weld metal of $\mathrm{C}-\mathrm{Mn}-\mathrm{Cr}-\mathrm{Ni}-\mathrm{Mo}-$ $\mathrm{Si}-\mathrm{Cu}$ system of K65 strength class. Obtained results allow expanding a data base on the mechanism of the effect of refractory oxides on dendrite structure modification. 5 Ref., 6 Tables, 14 Figures.
\end{abstract}

Keywords : arc welding, low-alloy steel, weld metal, modification by refractory oxides, dendrite structure, mechanical properties

Formation of weld metal structure starts from the processes of nucleation and growth of dendrite phase in a metallic melt of weld pool. Dendrites nucleation centers are the boundaries of fused grains of the base metal on fusion line and refractory inclusions present in the melt. Reduction of size of inclusions leads to rise of relationship between amount of particles on their surface and in volume, respectively, increase of energy of particle interaction with melt that promote enhancement of their efficiency as modifiers. Application of dispersed inclusions [1] is perspective from this point of view. Works $[2,3]$ showed that addition into a steel melt of 3-30 $\mu \mathrm{m}$ size refractory particles results in formation on their surface of cluster shells of up to 30-60 $\mu \mathrm{m}$ thickness. It is proved by decrease of melt toughness index. Such clusters can be effective centers of new phase nucleation in the melt and promote change of dendrite morphology [4]. Aim of the present work lied in investigation of possibility of effect of dispersed nonmetallic inclusions on modification of dendrite structure of weld metal of low-alloy high-strength steels.

Procedure of work. Investigations were carried out on weld metal obtained in welding with flux-cored wire of $1.6 \mathrm{~mm}$ diameter in shielding gas M21 medium on ISO 14175-2010 of butt joints of low-alloy steel. Welding was carried out using 240-250 A reverse polarity direct current at arc voltage $31-32 \mathrm{~V}$

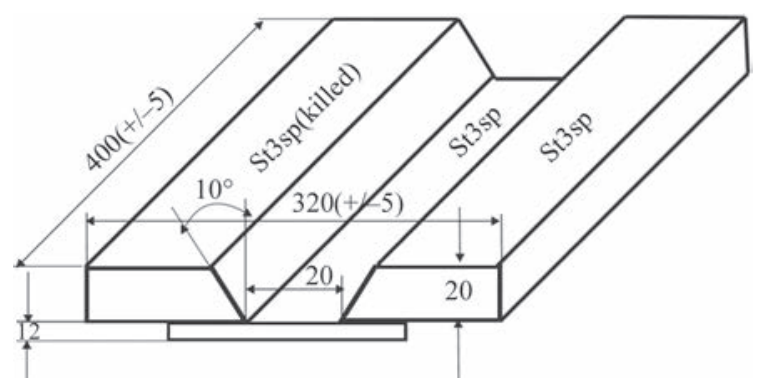

Figure 1. Scheme of preparation of welded joint

(c) V.V. GOLOVKO, S.N. STEPANYUK and D.Yu. ERMOLENKO, 2019 and welding rate $10-12 \mathrm{~m} / \mathrm{h}$. Scheme of welded joint assembled in accordance with the requirements of ISO 14171 is given in Figure 1. Figure 2 shows a scheme of groove filling, according to which passes 1-9 were carried out in welding using a wire of basic alloying system, and in performance of passes 10-18 a flux-cored wire of $1.6 \mathrm{~mm}$ diameter having a core with particles of dispersed refractory compounds was introduced in a weld pool in form of cold filler. The particles of aluminum, magnesium and zirconium ox-

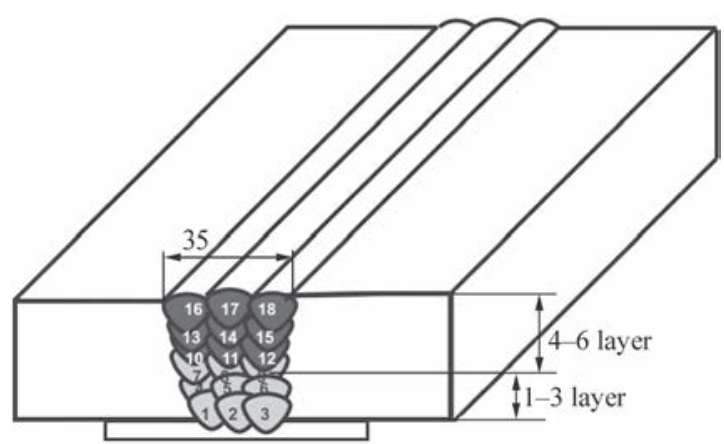

Figure 2. Scheme of arrangement of beads in filling of butt joint groove

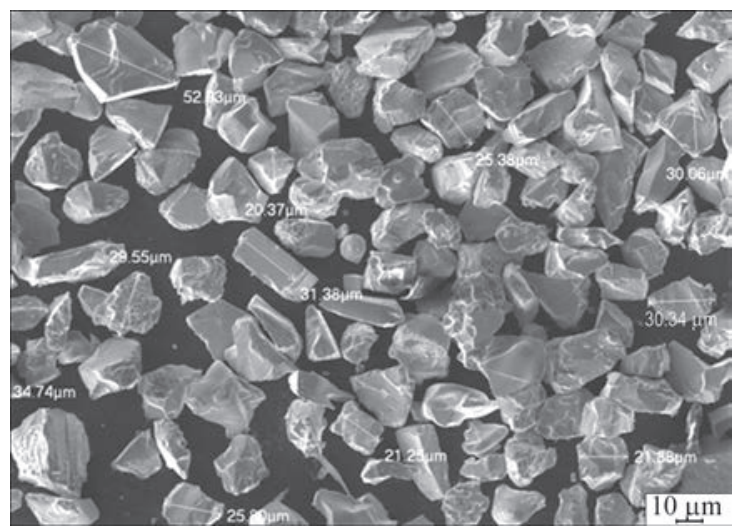

Figure 3. Particles of refractory oxides added in weld pool 


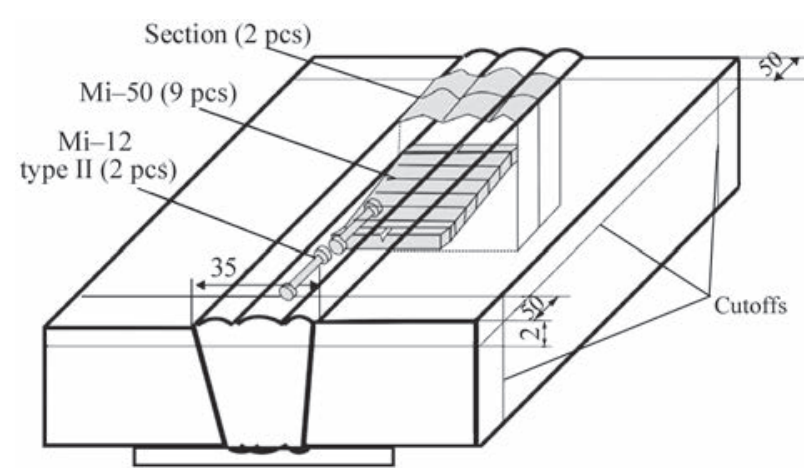

Figure 4. Scheme of samples cut out for determination of composition, mechanical properties and weld metal microstructure

ides of 20-60 $\mu \mathrm{m}$ size (Figure 3) were used as modifying additives (Figure 3 ).

The basic alloying system $\mathrm{C}-\mathrm{Mn}-\mathrm{Cr}-\mathrm{Ni}-\mathrm{Mo}-\mathrm{Si}-\mathrm{Cu}$ provided formation of weld metal with ferrite-bainite structure, which on their mechanical properties correspond to low-alloy steels of K65 strength category.

The transverse samples for investigation of structure and phase composition of weld metal as well as mechanical properties of welded joints on scheme presented in Figure 4 were cut out of the welded joints.

Metallographic examinations were used for determination of weld metal composition, fraction of separate constituents of its microstructure, volume fraction and distribution nonmetallic inclusions on sizes. Microstructure was examined by methods of optical and electron metallography using optical microscope Neophot-32 and scanning electron microscope JSM-840 of JEOL Company equipped with frame grabber MicroCapture with next registration of images on computer screen.

Quantitative determination of microstructural constituents was carried out in accordance with ASTM E112-12 procedure. Microhardness of separate structural constituents was measured on M-400 hardness gage of LECO Company at $100 \mathrm{~g}$ loading and integral hardness was determined on Vickers at $1 \mathrm{~kg}$ loading. A digital image was obtained using Olympus camera.

Table 1. Composition of metal of examined welds, wt.\%

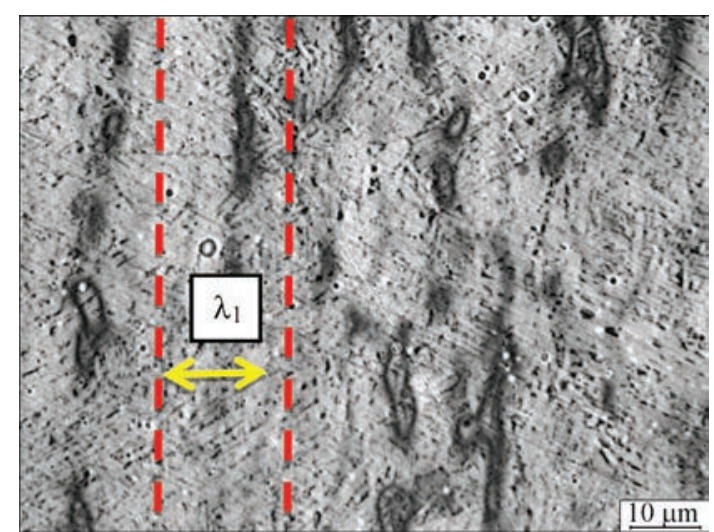

Figure 5. Scheme of determination of distance between the dendrite axes

A weld metal primary structure was examined on polished samples etched in boiling saturated solution of sodium picrate in water. A microstructure of the last pass of metal in multipass weld (i.e. cast structure) was examined. The samples were cut out in a direction normal to weld longitudinal axis in such a way that on the surface of the section it was possible to see the dendrites, which grew in direction of the highest thermal gradient in a weld pool. Sizes of columnar dendrites $\left(\lambda_{1}\right.$ sizes in Figure 5) were determined in examination of the primary structure on images obtained by method of optical microscopy.

Obtained results. Tables 1 and 2 show the results of determination of composition and mechanical properties of metal of examined welds.

The results of metallographic analysis revealed that microstructure of examined welds consists of austenite decay products in process of metal cooling and contains some amount of nonmetallic inclusions. Figure 6 provides the histograms, which were obtained as a result of analysis of distribution of inclusions on sizes in metal of the examined welds. Total fraction of nonmetallic inclusions $\left(V_{\text {n.in }}\right)$ is shown in Figure 3.

Metallographic analysis of microstructure of weld metal using optical and electron metallography meth-

\begin{tabular}{|c|c|c|c|c|c|c|c|c|c|c|c|}
\hline Modifier & C & Si & Mn & S & P & Cr & Ni & Mo & Al & Ti & Zr \\
\hline 0 & 0.042 & 0.340 & 1.19 & 0.021 & 0.020 & 0.11 & 2.13 & 0.28 & 0.028 & 0.029 & - \\
\hline $\mathrm{Al}_{2} \mathrm{O}_{3}$ & 0.034 & 0.424 & 1.40 & 0.017 & 0.023 & 0.12 & 2.15 & 0.29 & 0.032 & 0.015 & - \\
\hline $\mathrm{MgO}$ & 0.031 & 0.227 & 1.11 & 0.025 & 0.024 & 0.14 & 1.85 & 0.29 & 0.023 & 0.030 & - \\
\hline $\mathrm{ZrO}_{2}$ & 0.033 & 0.223 & 1.05 & 0.024 & 0.024 & 0.12 & 2.02 & 0.30 & 0.024 & 0.031 & 0.06 \\
\hline
\end{tabular}

Table 2. Mechanical properties of examined welds

\begin{tabular}{|c|c|c|c|c|c|c|c|c|c|}
\hline \multirow{2}{*}{ Modifier } & $\sigma_{t}$ & $\sigma_{0.2}$ & $\delta$ & $\psi$ & \multicolumn{5}{|c|}{$\mathrm{KCV}, \mathrm{J} / \mathrm{cm}^{2}$ at $T,{ }^{\circ} \mathrm{C}$} \\
\hline & \multicolumn{2}{|c|}{$\mathrm{MPa}$} & \multicolumn{2}{|c|}{$\%$} & +20 & 0 & -20 & -40 & -60 \\
\hline 0 & 693 & 605 & 14 & 49 & 97 & 87 & 75 & 53 & 37 \\
\hline $\mathrm{Al}_{2} \mathrm{O}_{3}$ & 728 & 621 & 17 & 54 & 82 & 58 & 50 & 36 & 22 \\
\hline $\mathrm{MgO}$ & 644 & 586 & 19 & 60 & 103 & 85 & 69 & 60 & 34 \\
\hline $\mathrm{ZrO}_{2}$ & 622 & 533 & 19 & 65 & 120 & 107 & 73 & 65 & 41 \\
\hline
\end{tabular}



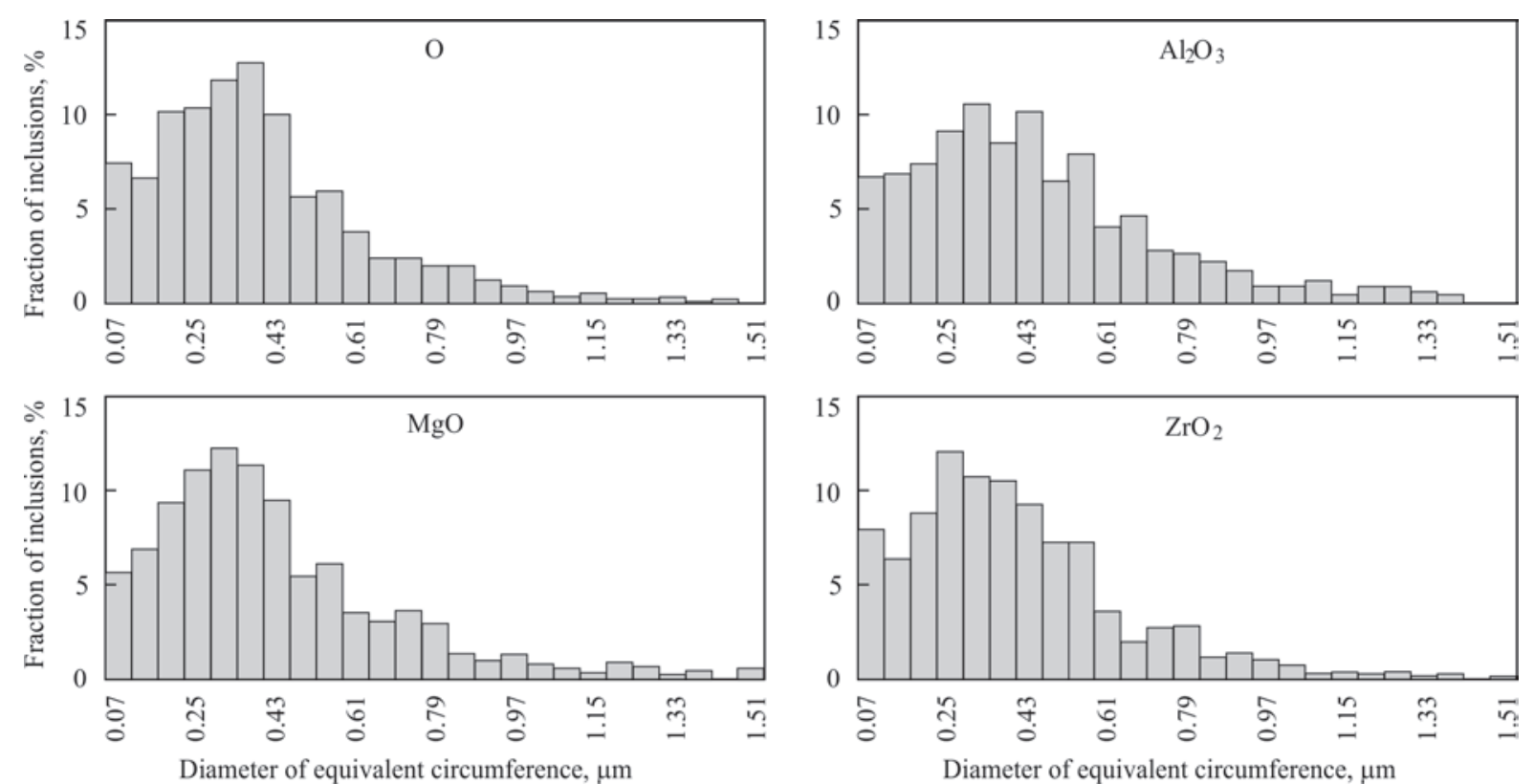

Figure 6. Histograms of distribution on sizes of nonmetallic inclusions in metal of examined welds
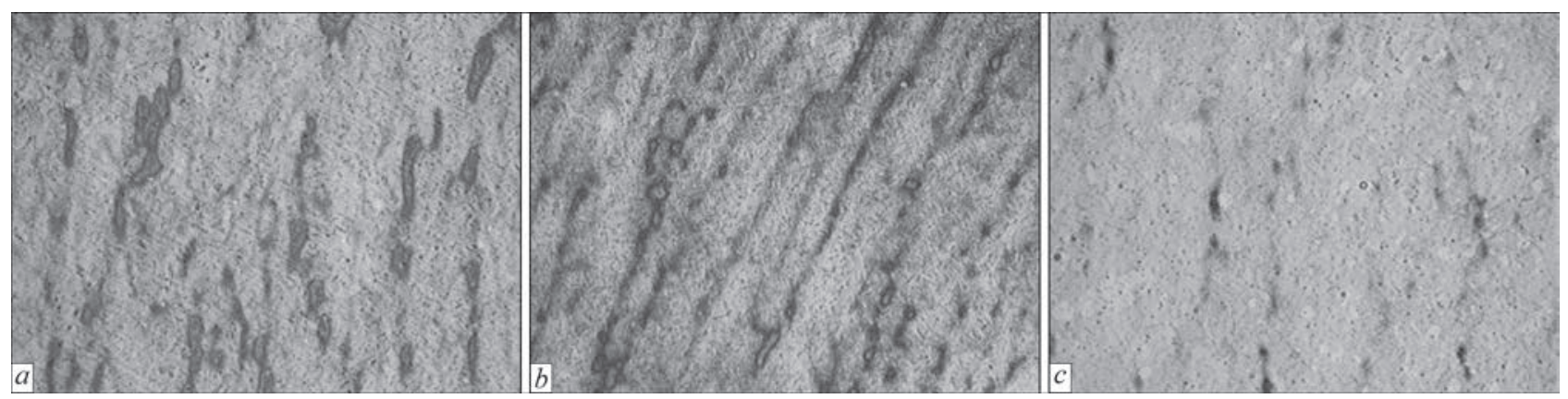

Figure 7. Dendrite structure of weld metal (x630): $a-$ without modifier; $b-\mathrm{Al}_{2} \mathrm{O}_{3}$ modifier; $c-\mathrm{ZrO}_{2}$ modifier

ods showed that each grain of the primary structure contained two or more structural constituents of secondary structure.

The most widespread secondary structures, which were observed in weld metal was grain-boundary allotrimorphic ferrite (GBA), intragranular polygonal ferrite (IPF), globular ferrite (GF), Widmanstatten ferrite (WF), acicular ferrite (AF), upper and lower bainite (UB and LB), phase containing martensite, austenite and carbides (MAC). Content of the main constituents in the weld metal microstructure is given in Table 4.

Table 5 shows the results of measurement of distance between the dendrite axes in the structure of metal of investigated welds. They demonstrate presence of significant differences in their morphology depending on modifying additive (Figure 7).

The structure of weld metal, which did not include modifiers in its content (modifier - 0), is characterized with high content of nonmetallic inclusions of not more than $0.3 \mu \mathrm{m}$ (Figure 8). The grain boundaries are

Table 3. Volume fraction of nonmetallic inclusions in weld metal

\begin{tabular}{|c|c|c|c|c|}
\hline Modifier & 0 & $\mathrm{Al}_{2} \mathrm{O}_{3}$ & $\mathrm{MgO}$ & $\mathrm{ZrO}_{2}$ \\
\hline$V_{\text {n.in }} \%$ & 0.42 & 0.74 & 0.62 & 0.55 \\
\hline
\end{tabular}

well-pronounced and have elongated morphology. Ferrite precipitates along the brain boundaries mostly in the form of Widmanstatten ferrite. Precipitations mainly from intragranular ferrite and lower bainite with mod-

Table 4. Content of main structural constituents in weld metal

\begin{tabular}{|c|c|c|c|c|c|c|c|c|}
\hline $\begin{array}{c}\text { Modi- } \\
\text { fier }\end{array}$ & AF & GBA & IPF & GF & WF & UB & LB & MAC \\
\hline 0 & 8 & 5 & 8 & 2 & 15 & 40 & 17 & 5 \\
\hline $\mathrm{Al}_{2} \mathrm{O}_{3}$ & 2 & 2 & 8 & 4 & 30 & 36 & 11 & 7 \\
\hline $\mathrm{MgO}$ & 32 & 10 & 5 & 10 & 7 & 12 & 19 & 5 \\
\hline $\mathrm{ZrO}_{2}$ & 30 & 15 & 2 & 6 & 7 & 10 & 25 & 5 \\
\hline
\end{tabular}

Table 5. Results of measurement of distance between dendrite axes

\begin{tabular}{|c|c|c|}
\hline Modifier & $\begin{array}{c}\text { Results of measurement of distance between } \\
\text { dendrite axes, } \mu \mathrm{m}\end{array}$ & $\begin{array}{c}\text { Average } \\
\text { value }\end{array}$ \\
\hline 0 & $50 ; 50 ; 60 ; 25 ; 40 ; 50 ; 45 ; 50 ; 40 ; 55$ & 46 \\
\hline $\mathrm{Al}_{2} \mathrm{O}_{3}$ & $50 ; 30 ; 30 ; 40 ; 45 ; 30 ; 50 ; 40 ; 30 ; 30$ & 57 \\
\hline $\mathrm{MgO}$ & $\begin{array}{c}140 ; 150 ; 120 ; 140 ; 90 ; 120 ; 100 ; 130 ; 80 ; \\
150 ; 300\end{array}$ & 152 \\
\hline $\mathrm{ZrO}_{2}$ & $\begin{array}{c}240 ; 200 ; 150 ; 140 ; 120 ; 120 ; 200 ; 80 ; 240 ; \\
90\end{array}$ & 158 \\
\hline
\end{tabular}




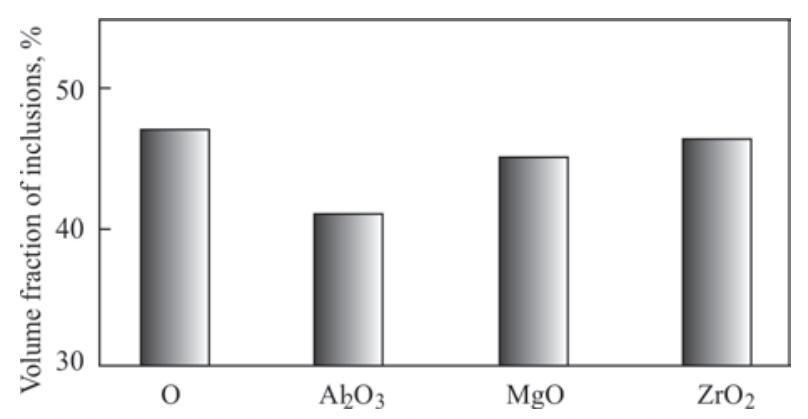

Figure 8. Content in weld metal of nonmetallic inclusions of $<0.3 \mu \mathrm{m}$

erate level of microhardness (Figure 9) are observed in the grain body. Such structural composition provides high indices of weld metal strength (at the level of steels of K70 strength category) and sufficiently high level of ductility and impact toughness (Table 2).

Sufficiently high fraction of nonmetallic inclusions of up to $0.3 \mu \mathrm{m}$ size (Figure 8) is kept in addition of the particles of magnesium oxide into the weld pool. A weld metal microstructure is characterized with high content of intragranular polygonal ferrite with small inclusions of acicular ferrite. Ferrite on the grain boundaries precipitates in form of small fringes of allotriomor- phic ferrite with reduced level of microhardness and Widmanstatten ferrite (Figure 10). Such composition of structural elements results in significant increase of weld metal ductility in comparison with basic alloying system and insignificant drop of impact toughness.

Modification of the weld metal with aluminum oxide leads to decrease of content of nonmetallic inclusions of size less than $0.3 \mu \mathrm{m}$ (Figure 8) in comparison with the weld metal, which did not contain modifiers. The weld metal microstructure is characterized with high content of intragranular polygonal ferrite and lower bainite with frequent inclusions of upper bainite. Also there is an increased content of Widmanstatten ferrite with high level of microhardness on grain boundaries (Figure 11). Such structural composition is characterized with increased level of strength of the weld metal (Table 2).

There is an increase of fraction of nonmetallic inclusions of not more than $0.3 \mu \mathrm{m}$ size (Figure 8 ) in the weld metal during addition of zirconium oxide particles in the weld pool. The weld metal microstructure is characterized with high content of intragranular polygonal ferrite in combination with presence of upper
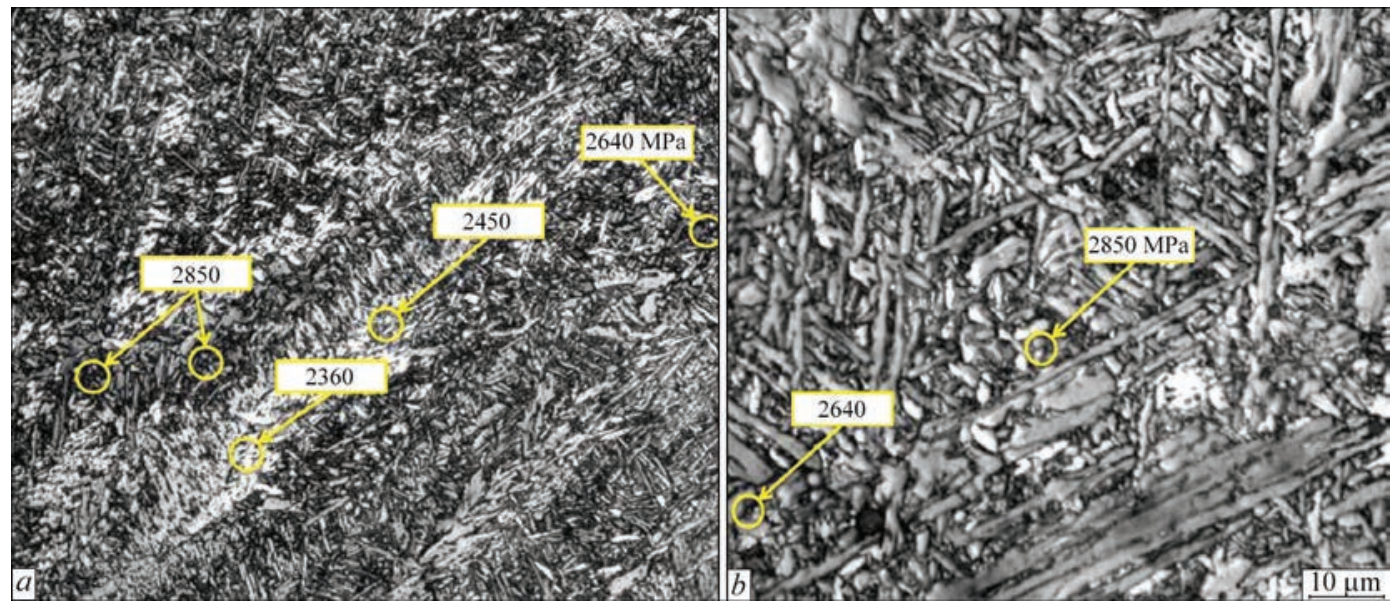

Figure 9. Microstructure and microhardness $(H V 1)$ typical for structural constituents of weld metal, without modifiers: $a-\times 320$; $b-\times 1000$
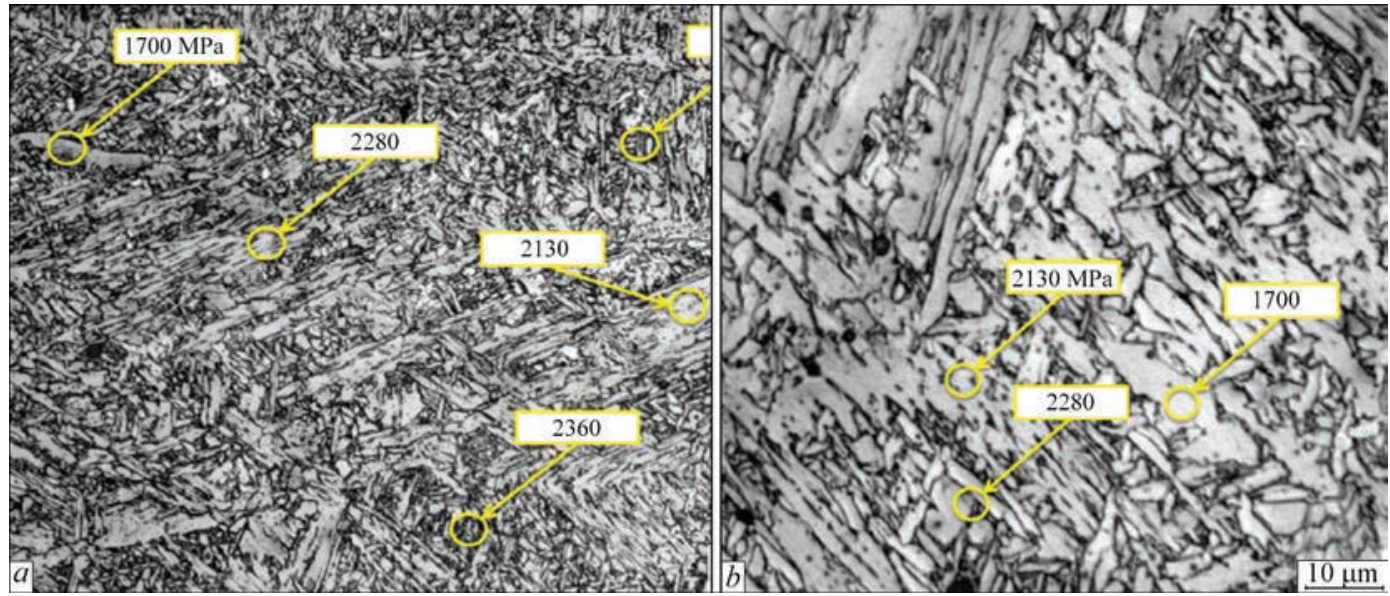

Figure 10. Microstructure and microhardness (HV1) of typical structural constituents of weld metal modified by MgO particles: $a$ $\times 320 ; b-\times 1000$ 


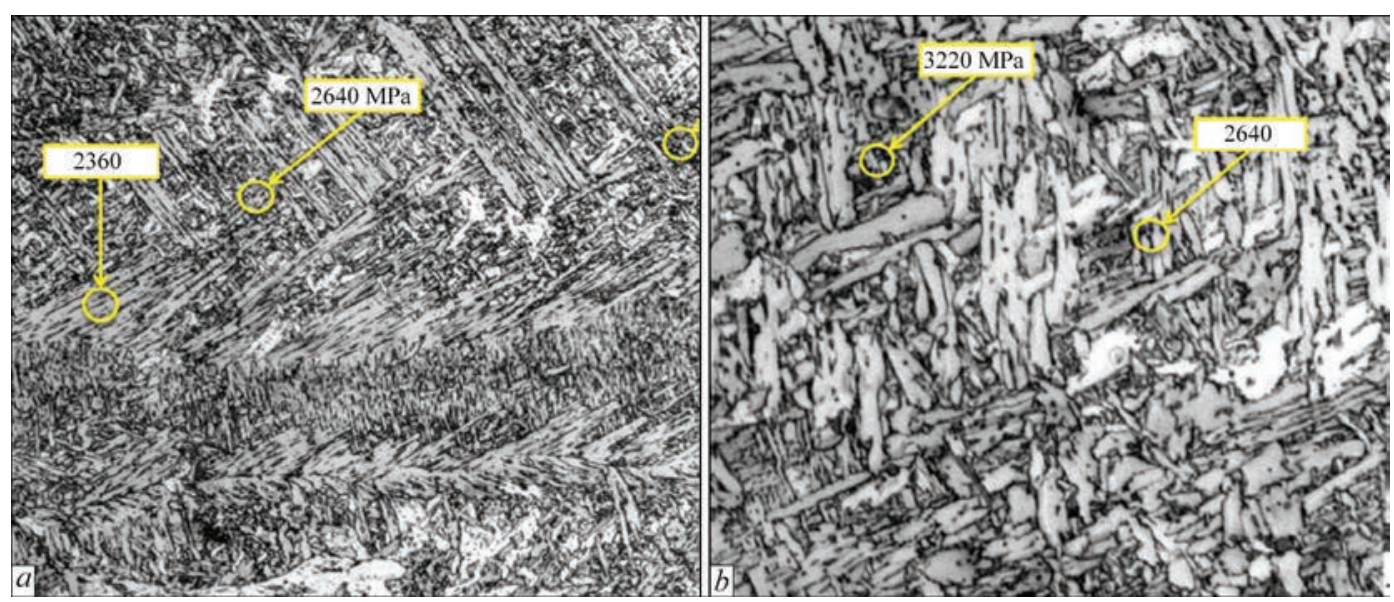

Figure 11. Microstructure and microhardness $(H V 1)$ of typical structural constituents of weld metal modified by $\mathrm{Al}_{2} \mathrm{O}_{3}$ particles: $a-\times 320 ; b-\times 1000$

and lower bainite. Massive precipitations of ferrite with moderate level of microhardness (Figure 12) are observed on the grain boundaries. Such structural composition provides combination in the weld metal of high indices of ductility and impact toughness (Table 2).

Analysis of obtained data. Analysis of the results of examinations was based on general ideas on mechanism of nucleation and growth of dendrites in the metallic melts. Today, there is considerably large amount of models describing these processes that indicates absence of some single approach, which would allow considering all complex of difficult and interrelated phenomena in the process of melts solidification. It is generally accepted that there should be specific solidification centers in the melt in order to start this process. The debates are holding on the issue what should be considered as such centers. Two approaches to solution of this problem are widely presented in scientific literature. In accordance with one of them such centers can be refractory nonmetallic inclusions, from other point of view, cluster formations can initiate solidification. Following from the considerations of thermodynamics the process of crystals nucleation in the metallic melt is possible under two main conditions: firstly, solidification centers should be of size more than critical size of nucleus, secondly, interphase energy on nucleus boundary with melt should be minimum.

Melt of the pool in arc methods of welding of steels contains large amount of refractory inclusions, size of which significantly exceeds a nucleus critical radius in solidification of iron melts (approximately $4 \cdot 10^{-7} \mathrm{~m}$ ). Such inclusions are characterized with sufficiently high interphase energy on the boundary with metallic metal and, as a rule, do not satisfy the principle of structure-size correspondence in relation to iron crystals. Much more effective nucleuses of formation of new phase can be the fused boundaries of base metal grains, however, following the requirements of the minimum interphase surface energy, 2D nucleuses thermodynamically lose 3D ones. Globular nucleuses with minimum interphase energy can be the clusters of metal, presence of which in the melt was shown on practice [4]. Small size of such clusters (approximately $2 \cdot 10^{-9} \mathrm{~m}$ ) causes their high surface activity. Sorption by clusters of structurally free atoms of melt promotes formation of micelles that was proved by
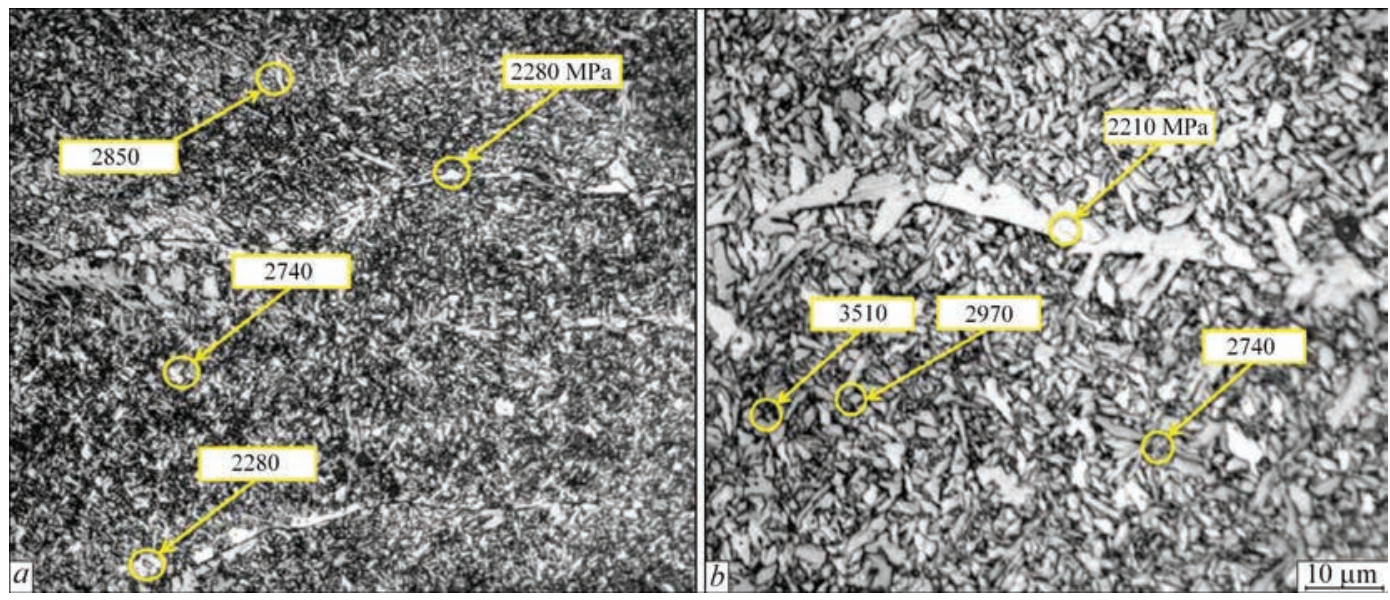

Figure 12. Microstructure and microhardness $(H V 1)$ of typical structural constituents of weld metal modified by $\mathrm{ZrO}_{2}$ particles: $a-\times 320 ; b-\times 1000$ 


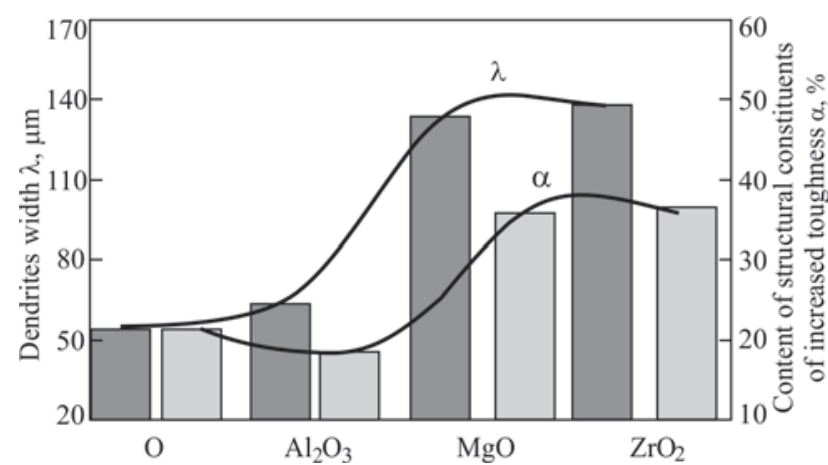

Figure 13. Interaction between sizes of dendrites and content of increased toughness constituents in composition of weld metal secondary structure

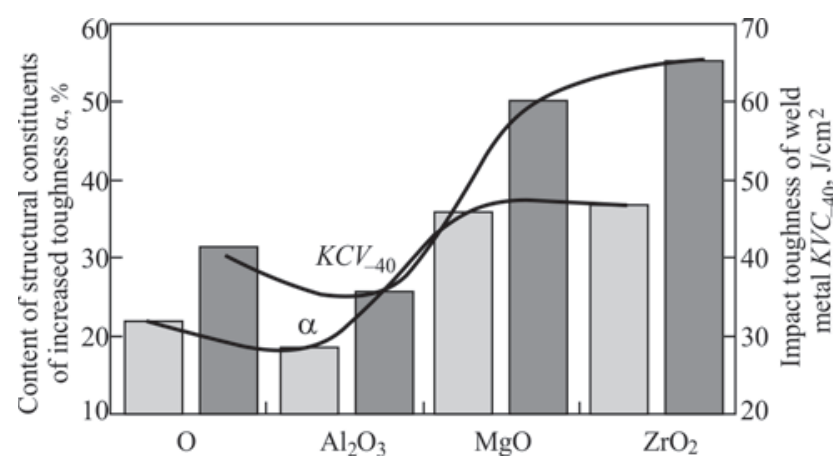

Figure 14. Interaction between content of increased toughness constituents in composition of weld metal secondary structure and weld metal impact toughness

experiments on investigation of effect of refractory oxides on toughness of liquid metals [3].

Table 6 shows the results of determination of dendrite size in comparison with data on thickness of adsorption cluster shells forming on the surface of inclusions at $1600{ }^{\circ} \mathrm{C}$ temperature obtained in work [5].

As can be seen from given data there is a specific dependence between the morphology of dendrites and physicochemical peculiarities of structure of interphase boundary in the system «metallic melt-oxide inclusion». It is noted that a modifying effect on the dendrite structure is observed in the weld metal, to content of which the inclusions with lower interphase tension and wetting angle were added. Increase of dendrite width promotes corresponding changes under conditions of formation of secondary structure that is presented by increase of fraction of low-temperature constituents of bainite transformation in weld metal structure (Figure 13) and change of indices of their strength and toughness (Table 2).

Rise of content of secondary structure constituents with increased resistance to nucleation and propagation of cracks, to which AF, GF, IPF and LB are referred, promotes formation of the weld metal with high indices of toughness. The results of our experiments, presented
Table 6. Comparison of the results of measurement of dendrite width with indices of interaction of inclusions with metallic melt

\begin{tabular}{|c|c|c|c|c|}
\hline Modifier & $\begin{array}{c}\text { Thickness } \\
\text { of cluster } \\
\text { shells, } \mu \mathrm{m}\end{array}$ & $\begin{array}{c}\text { Interphase } \\
\text { tension on } \\
\text { metal-inclu- } \\
\text { sion bound- } \\
\text { ary, } \mathrm{mJ} / \mathrm{m}^{2}\end{array}$ & $\begin{array}{c}\text { Wetting angle } \\
\text { on metal- } \\
\text { inclusion } \\
\text { boundary, } \\
\text { deg }\end{array}$ & $\begin{array}{c}\text { Dendrite } \\
\text { width, } \mu \mathrm{m}\end{array}$ \\
\hline 0 & 29 & - & - & 46 \\
\hline $\mathrm{Al}_{2} \mathrm{O}_{3}$ & 43 & 630 & 130 & 57 \\
\hline $\mathrm{MgO}_{2}$ & 51 & 502 & 108 & 152 \\
\hline $\mathrm{ZrO}_{2}$ & 59 & 470 & 106 & 158 \\
\hline
\end{tabular}

in Figure 13, correspond to this tendency. Following from the comparison of data on dendrite structure size and content in the weld metal of secondary structure constituents of increased toughness, shown in Figure 14 , it can be seen that increase of dendrite width $(\lambda)$ is accompanied by growth of content of secondary structure constituents of increased toughness $(\alpha)$.

It is necessary to outline that the results obtained in this work broaden the ideas on possible mechanisms of effect of refractory oxides on dendrite modification. On the one hand, in accordance with reference data, presence in steel melt of magnesium and zirconium oxides provokes formation of coarser micelles in comparison with aluminum oxide inclusions. On the other hand, absence of the modifying effect at addition into the weld pool of aluminum oxides can be related with decrease in the weld pool of fraction of inclusions of not more than $0.3 \mu \mathrm{m}$, which can be considered as micelle formation centers. In order to answer this question it is necessary to develop the works in this direction, but, nevertheless, obtained results showed the possibility of application of dispersed particles of refractory compounds for modification of dendrite structure of weld metal, regulation of content of constituents of their secondary structure and indices of mechanical properties.

1. Golovko, V.V. (2018) Possibilities of nanomodification of dendrite structure of weld metal. The Paton Welding J., 8, 2-6.

2. Novokhatsky, I.A., Yaroshenko, I.V. (1988) Peculiarities of cluster adsorption on nonmetallic inclusions in liquid steel. Tr. Odesskogo Politekhnicheskogo Univetsiteta, 1(5), 241-244 [in Russian].

3. Yaroshenko, I.V., Novokhatsky, I.A., Kisunko, V.Z. (1999) Influence of cluster adsorption on viscous flow of metallic liquids in near-wall layers. Ibid., 2(8). 241-244 [in Russian].

4. Ershov, G.S., Chernyakov, V.A. (1978) Structure and properties of liquid and solid metals. Moscow, Metallurgiya [in Russian].

5. Yaroshenko, I.V. (2000) Peculiarities of manifestation and taking into account of cluster adsorption in metallic liquids near surface of oxide phases: Syn. of Thesis for Cand. of Chem. Sci. Degree. Odessa [in Russian]. 


\title{
REPAIR SURFACING OF GAS TURBINE ENGINE BLADES FROM HIGH-TEMPERATURE NICKEL ALLOYS WITH SURFACE DEFECTS AND DAMAGE
}

\author{
K.A. YUSHCHENKO ${ }^{1}$, I.S. GAKH ${ }^{1}$, B.A. ZADERY ${ }^{1}$, A.V. ZVYAGINTSEVA ${ }^{1}$ and O.P. KARASEVSKAYA ${ }^{2}$ \\ ${ }^{1}$ E.O. Paton Electric Welding Institute of the NAS of Ukraine \\ 11 Kazimir Malevich Str., 03150, Kyiv, Ukraine. E-mail: office@paton.kiev.ua \\ ${ }^{2}$ G.V. Kurdyumov Institute for Metal Physics of the NAS of Ukraine \\ 36 Akademika Vernadskogo Blvd., Kyiv, Ukraine. E-mail:karas@imp.kiev-ua
}

\begin{abstract}
The main types of defects and damage were determined based on studying full-scale gas turbine blades after manufacture and operation. Most of the defects are located on the surface. The possibility is shown for performance of operations on their elimination by electron beam surfacing with filler of the same composition as that of the blade. Relationship temperature-time of parameters of formation of repair welds, their dimensions and geometry was established. The technological schemes were determined for providing the temperature-time and crystallographic orientation conditions of preservation of single-crystal structure in repair of high-temperature nickel alloy blades. The peculiarities of formation of welds, and their structure, depending on technological parameters of the process of electron beam surfacing were investigated. The methods of practical realization of the obtained results in repair of blade areas of various crystallographic orientation were developed and tested. Examples of repair of blades with structural defects of airfoil surface and damage of edges are given, when restoration of initial geometry, crystallographic orientation and single-crystal structure is provided. 26 Ref., 9 Figures.
\end{abstract}

Keywords : electron beam surfacing, gas turbines, blades, high-temperature nickel alloys, defects and damage restoration, single-crystal structure

Blades of aviation gas turbine are the most loaded elements of the hot section, responsible for operating characteristics, service life and reliability of the power unit as a whole $[1,2]$. This results in high requirements to materials, from which they are made, to their composition and quality of the structure. At present high nickel alloys with single-crystal structure meet these requirements to the most. However, extreme conditions of blade operation cause a considerable extent of erosion damage that significantly lowers the power, cost and other characteristics of the engine, including the safety and reliability of its operation. Highly critical in this respect are also the structural defects, which may arise during growing the single-crystal blades, as a result of disturbance of directed crystallization conditions.

Analysis of statistical data on manufacturing and operational damage of single-crystal blades shows [2-5] that the greater part of them is on the surface. Operational defects include mechanical damage and erosion, surface cracks due to thermal fatigue of airfoil edges, shroud flange seals; manufacturing defects are blisters and grains $150-500 \mu \mathrm{m}$ deep on airfoil surface, freckle-type liquation, and carbide precipitation. A common feature of the defects is their surface location and depth down to $500 \mu \mathrm{m}$.

The urgency of repair becomes obvious, considering the increasing volume of production and application of blades with directional and single-crystal struc- ture from high-temperature nickel alloys (HTNA) in modern gas turbines, high cost, considerable percentage of rejects (up to 30-70 \%) during their manufacture and damage in operation, as well as the need for extension of service life of engines.

The main question, in addition to restoration of surface geometry, is providing the single-crystal structure and initial crystallographic orientation of weld metal in the repaired area. Application of fusion welding in repair of blades with a polycrystalline structure [6-10] allows solving the respective tasks of a number of aircraft-repair plants. At the same time, its application for repair of single-crystal blades is restrained, in view of the structural features and operational requirements.

Analysis of the conditions of formation of single-crystal structure in HTNA welds [11-15], showed that ensuring the high temperature gradient on the growth front and flat macrofront at crystallization are the most essential elements in blade repair. The design and geometrical features of the blade and thickness of metal cross-section in the repaired area impose certain difficulties. This raises the questions not only of selection of the welding process and modes, kind of filler material and method of its feeding into the weld pool, but also providing controllable heat input.

Welding process for repair performance. Such processes of welding with filler, as argon-arc, microplasma, laser, electron beam are used for repair of 
HTNA blades with a polycrystalline structure [6-10]. Each of them has its features, which determine the limitations of their application in repair of blades with single-crystal structure.

Argon-arc and microplasma methods are limited by the complexity of precision control of the thermal cycles, limitation of overheating of the base and deposited metal at formation of a single-crystal structure. In addition, the main alloying elements of HTNA, particularly $\gamma^{\prime}$-forming ones - aluminium and titanium, increase the probability of formation of hot cracks in fusion welding [15-20]. Insufficient protection of the pool melt leads to oxidation and formation of refractory oxides $[20,21]$. The latter not only hinder formation of single-crystal structure of the deposit, but can also be the crystallization centers of randomly oriented grains (ROG) that is an indication for rejection [13, 22, 23]. Particularly inacceptable is oxygen enrichment of the weld pool because of:

- weld pool surface oxidation;

- presence of impurities in filler material;

- presence of residual oxygen in shielding gas atmosphere, in particular, at disturbance of laminarity of shielding gas outflow.

Application of electron beam welding (EBW) in the high vacuum environment of the work chamber $\left(10^{-4}-10^{-5} \mathrm{~mm} \mathrm{Hg}\right)$ eliminates these problems. Selection of the welding process was based on the possibility of preservation of crystallographic orientation [12-15], temperature-time [11] and temperature-space conditions of directed crystallization at surfacing. It was taken into account that in the general case the nonequilibrium and nonuniformity of these conditions both in time and across the welded joint section are in place in welding, which are enhanced by complex, variable geometry, thickness and crystallography of the repaired section. Therefore, the main attention was given to energy and technological characteristics of the welding process, which allowed limiting the negative influence of the above factors.

EBW process allows controlling in a broad range the main structure-determining parameters of weld pool crystallization:

- temperature and time of melt existence;

- geometry of solidification macrofront;

- temperature-time parameters at the crystallization front.

This allowed achieving refinement of the dendrites, as well as $\gamma^{\prime}$-phase, carbides, optimizing their morphology, and reducing dendrite liquation. Such a structure promotes improvement of both the mechanical properties, and operational characteristics at preservation of crystallographic orientation of single crystals.

Surfacing material. In order to provide the mechanical properties and operational characteristics of products at repair operations, matching of chemical composition of the deposited and base metal is required, alongside ensuring the temperature-time and orientational conditions of formation of single-crystal structure of the deposits. In connection with the fact that manufacturing filler wire materials from HTNA with more than $60 \%$ content of strengthening $\gamma^{\prime}$-phase is problematic, because of the high strength and low ductility, the possibility of application of powder and rod materials was considered.

«Selective laser sintering》 scheme can be used as one of the best variants of powder feeding into the surfacing zone [24]. With this technique a layer of powder material of a certain thickness is formed at the first stage, then the powder section is selectively surface melted, followed by formation of a new layer of dispersed material, and this process is repeated until the required height of the deposit has been achieved. Application of such a scheme at EBW can have a number of advantages, one of which is absence of gas transporting the powder that is essential under the high vacuum conditions. However, application of dispersed materials at EBW can be limited as a result of:

- complexity of equipment adaptation and precision metering of powder under the conditions of a vacuum chamber;

- powder spraying under the impact of the electron beam;

- weld metal contamination by oxygen and other impurities, in connection with the developed surface of powder components;

- high probability of ROG formation at crystallization;

- high requirements to uniformity of granulometric and chemical composition, flowability, conditions of powder manufacturing and storage.

In order to limit the above disadvantages of filler materials, it was proposed to use at EBW the standardized rods cut out of HTNA single-crystal billets. Their trials at surfacing $2 \mathrm{~mm}$ samples from ZhS26 alloy showed a positive result - sound formation of deposits of specified dimensions and structural composition is achieved.

Features of formation of the deposits, their structure and crystallographic characteristics. Complex alloying of HTNA single-crystals, high content of the strengthening $\gamma^{\prime}$-phase, absence of high-angle grain boundaries - factors, ensuring the complex of mechanical properties and maximum operational life, impair their weldability at the same time. This is manifested in proneness to formation of cracks, structural defects, ROG appearance, deviation of crystallographic orientation from the initial one, that, eventually, lowers the technological and operational strength $[11-15,23]$. The objective is to produce sound deposits and welded joints of HTNA single-crystals, taking into account formation of the specified structural state and crystallographic characteristics of weld metal. Com- 
plex of performed research showed that [11-15] the optimal parameters of structural perfection of the weld are achieved when ensuring certain temperature-time and orientation conditions of welding, which are defined by the value and direction of temperature gradient $\mathbf{G}$ at weld pool crystallization front, solidification rate $\mathbf{R}$, their ratio $\mathbf{G} / \mathbf{R}$, crystallographic orientation of the edges being joined and welding direction. A relationship between the above crystallization parameters and technological factors was established [11]. The possibility is shown of producing single-crystal welds even at unfavourable crystallographic conditions, at the expense of controlling the temperature-time parameters of weld pool crystallization. This is particularly important in welding or surfacing of blades of a complex spatial shape. It is important to take into account different orientational characteristics of potential repair sections (Figure 1). Some of these areas match [001] orientational that corresponds to symmetrical conditions of crystallization (leading and trailing edge), and some of them do not coincide with [001]. Such combinations of the conditions strongly hinder ensuring directed crystallization and formation of a single-crystal structure of the required perfection.

We assume that the expression «perfection of structure» means orientational uniformity of weld metal, heat-affected zone and base metal at maximum admissible deviation up to $5-8^{\circ}$, absence of grains of other orientation; uniformity of dislocation distribution.

Possibility of ensuring directed crystallization at weld pool solidification front, formation of single-crystal structure of the weld under asymmetrical conditions was the key task, the solution of which allowed establishing the main principles of basic technologies of repair. The dimensional-orientational features of repair sections should be taken into account, and physical conditions of directed crystallization of weld metal should be provided. Therefore, the main part of the work is aimed at investigation of the effect of technological factors on temperature-time and orientation parameters of the surfacing process, and, therefore, on improvement of weld metal structure.

Technique of electron beam surfacing. Surfacing of blade airfoil surface. Part of the studies was performed on flat samples and blades. Samples were cut out by electric-spark method from $80 \times 60 \times 8 \mathrm{~mm}$ billets of ZhS26 alloy. Sample thickness of 1.5 to $2.0 \mathrm{~mm}$ was chosen, proceeding from mid-thickness of the section of blade airfoil flanges. Initial crystallographic orientation of the deposit surface was selected in keeping with the sections of possible blade repair and corresponded both to symmetrical and asymmetrical $(h k l)>20^{\circ}$ of (100)) crystallographic conditions.

We proceeded from the statement of [25] that the rate of weld metal cooling and, consequently, of other temperature-time parameters of welding, is deter-

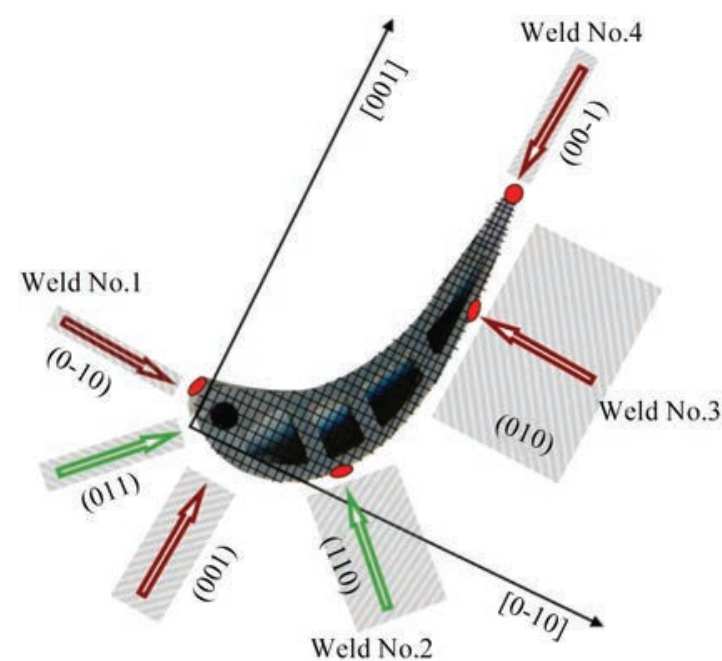

Figure 1. Scheme of location of crystallographic zones and possible repair sections of the blade

mined by the ratio of the mass (volume) of weld pool melt to base metal. Temperature-time conditions of crystallization are established proceeding from the dimensions of the deposit (total height $h$ and width $B$ ). Use of EBW process allows controlling these parameters in a broad range.

Results of metallographic examination showed that at geometrical parameters of the deposit (Figure 2) $h \leq 0.6 \mathrm{~mm}$ and $h / B \leq 0.2$, made in one pass, increase of the stability of directed crystallization zone, formation of finely-dispersed $(\lambda=1.5-2.0 \mu \mathrm{m})$ cellular-dendritic structure are ensured, that limits formation of randomly-oriented grains (Figures 2, 3). Characteristics of dislocation structure correspond to uniform distribution (Figure 4), which is indicated by the shape of closed smooth regular iso-intensive lines $I_{q^{\perp}}$ of X-ray reflections. On the whole, the structure of deposit zones corresponds to typical requirements of HTNA single-crystals.

Increase of deposit height to $0.8 \mathrm{~mm}$ and ratio $h / B=0.25$ leads to formation of isolated ROG. Further change of geometrical parameters of the deposited layer leads to increase of ROG number and cracking (Figures 3, 5).

It should be noted that the results of calculations made by the procedure, described in [11], using the

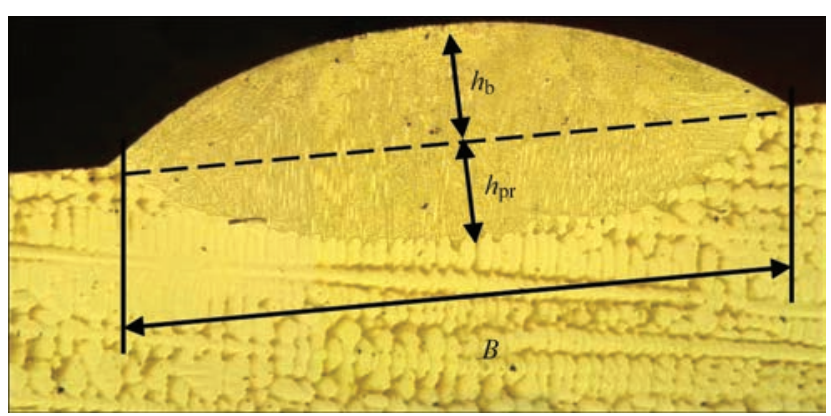

Figure 2. Parameters of geometrical characteristics of the deposit: $B$ - deposit width; $h=h_{\mathrm{b}}+h_{\mathrm{pr}}$ - total deposit height; where $h_{\mathrm{b}}$ is the bead height; $h_{\mathrm{pr}}$ is the base metal penetration depth $(\times 50)$ 


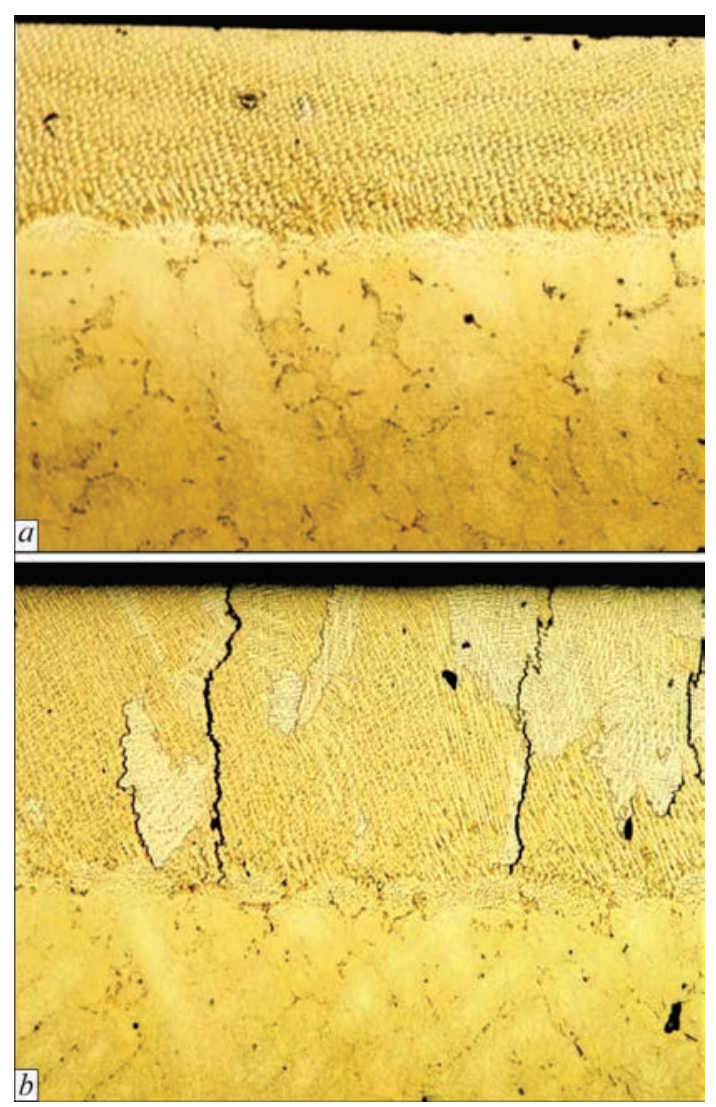

Figure 3. Microstructure $(\times 100)$ of the deposit from single-crystal alloy Zhs26 $2 \mathrm{~mm}$ thick under asymmetrical crystallographic orientation conditions at the ratio of weld geometrical parameters: $a-h / B=0.2$ and deposit height $h=0.6 \mathrm{~mm} ; b-h / B=0.3, h=$ $=0.9 \mathrm{~mm}$ known Brody-Fleming relationship, showed that temperature-time characteristics of deposit crystallization (ratio $\mathbf{G} / \mathbf{R}>10^{4} \mathrm{~s} /{ }^{\circ} \mathrm{C} / \mathrm{mm}^{2}$ ), made in asymmetrical orientation at $h / B \leq 0.2$, correspond to the conditions of formation of single-crystal structure.

Surfacing of blade edge. During GTE operation, the leading attack edge [1] of approximately $3-4 \mathrm{~mm}$ width and thinner trailing edge of about $2-5 \mathrm{~mm}$ are most often damaged. Testing of edge surfacing technique was conducted on the end faces of single-crystal plates from ZhS26 alloy 2-3 mm thick. The effect of temperature-time characteristics of the process on the change of the structure was evaluated using wedge-shaped plates 4-8 $\mathrm{mm}$ thick, which determined the variable width of the substrate, which was surfaced in a constant mode. Crystallographic orientation of the plates corresponded to [001] with deviation of up to $15^{\circ}$. The correspondence of physical conditions $\mathbf{G} / \mathbf{R}$ to formation of single-crystal structure was assessed by deposit dimensions $(h, B)$ and value of their ratio, as in surfacing on the plane.

During investigations a relationship was established between geometrical ratio $h / B$ of the deposit on the edge and its formation quality, preservation of single-crystal structure, formation of ROG and cracks (Figure 6). Differences are observed at geometrical ratio of single-pass deposit $-h / B \geq 0.8$ (Figures 4 , $6,7)$. Disorientation of block-type dendrite structure does not exceed $5-8^{\circ}$. The optimum variant are parameters of geometrical ratio $h / B \leq 0.4$ (Figures 5;
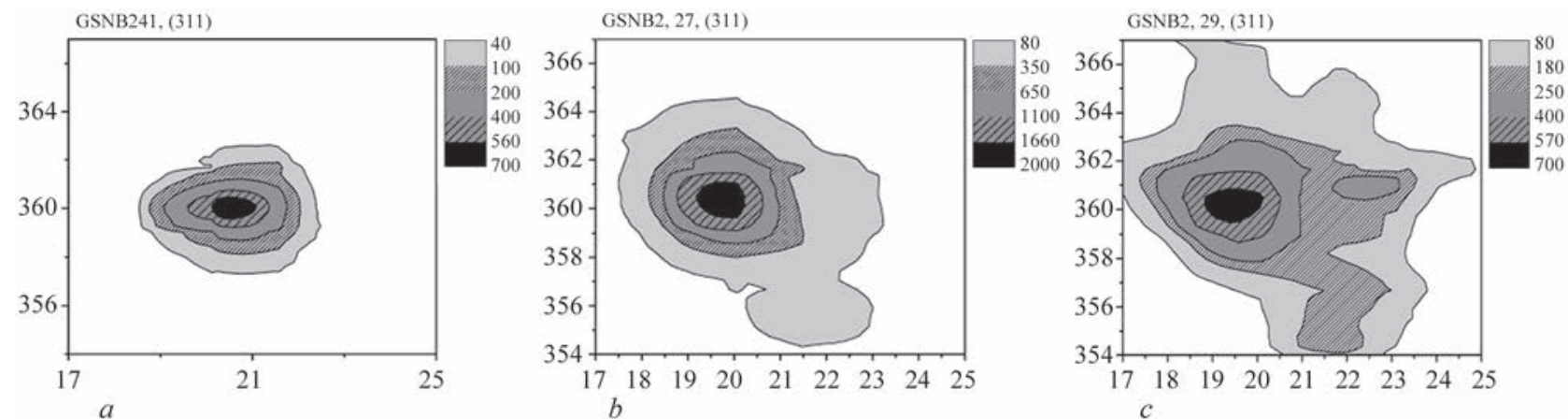

Figure 4. Iso-intensive lines of distribution $I_{a_{\perp}}$ of (311) reflection in base metal (a), HAZ $(b)$ and in the weld (c) for deposits with ratio $h / B=0.8$
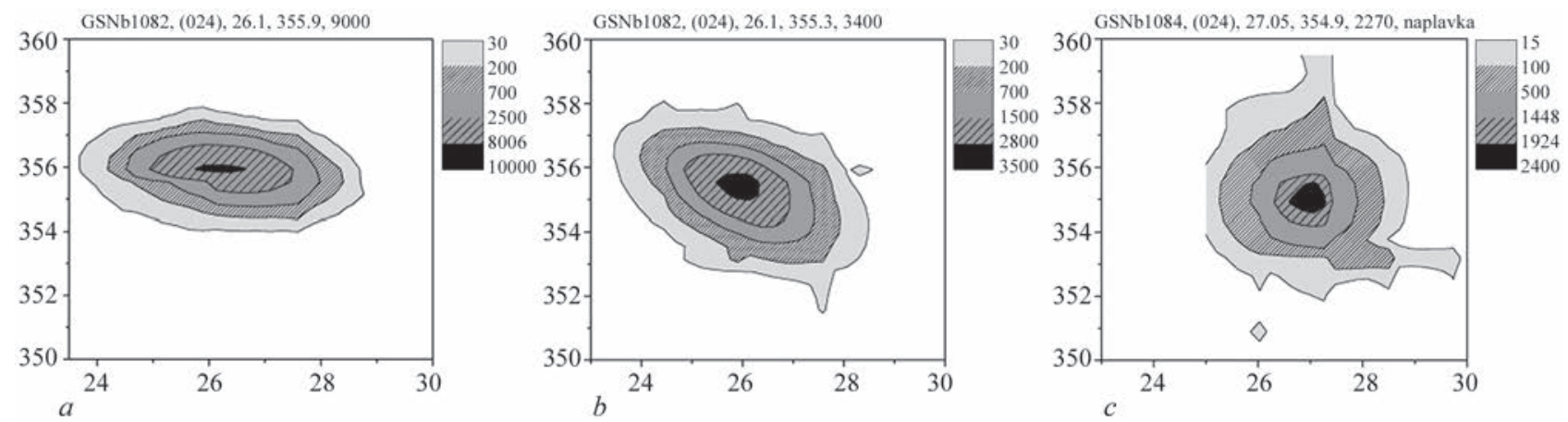

Figure 5. Iso-intensive lines of distribution $I_{\mathbf{q}^{\perp}}$ of (311) reflection in base metal (a), HAZ (b) and in the weld (c) for deposits with ratio $h / B=0.4$ 


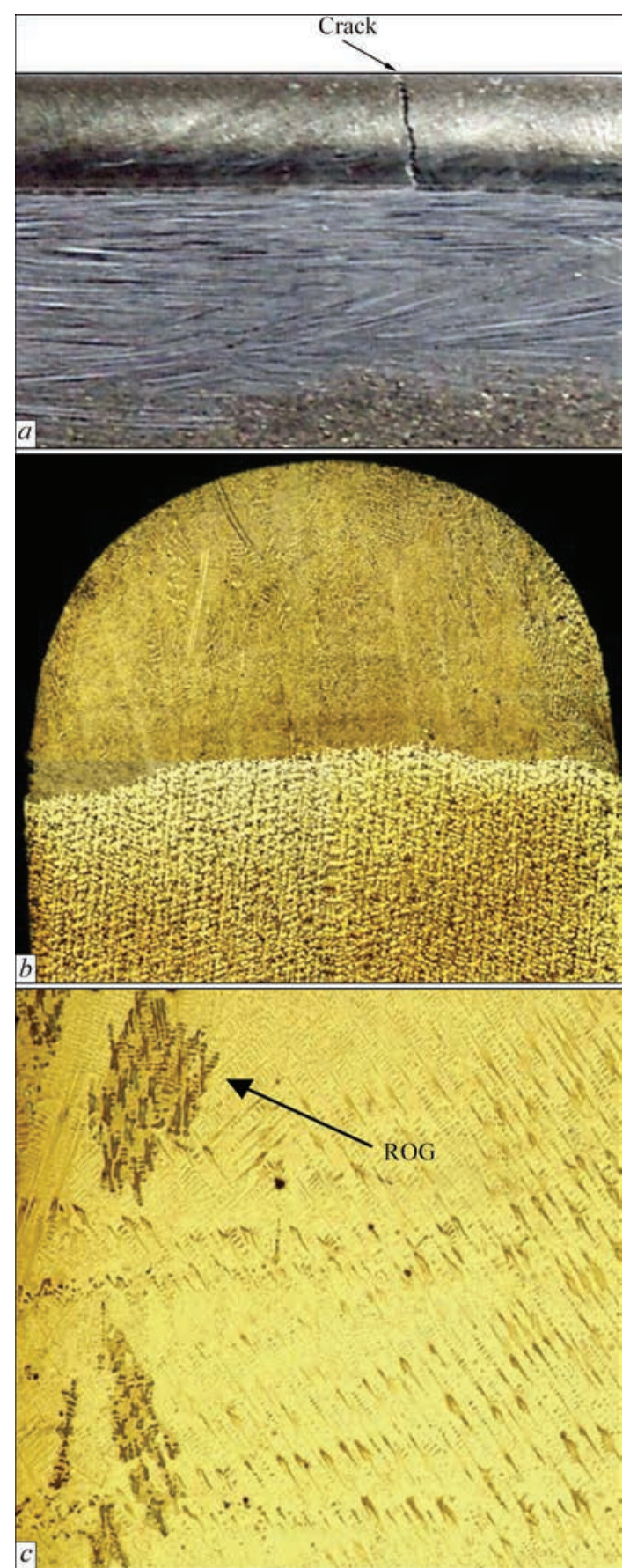

Figure 6. General view of single-pass deposit (a) with formation defects, cracks and ROG $(a-c)$, macro- and microstructure $(b, c)$. Geometrical parameter of the deposit $h / B=0.8(b-\times 25 ; c-\times 100)$

$7, b ; 8)$. Maximum deviation of structural component orientation $\Delta \alpha$ from the crystallographic orientation of initial metal does not exceed $1.5^{\circ}$. Characteristics of dislocation structure correspond to their uniform distribution (Figure 5). On the whole, the deposit zone structure meets typical requirements to the growth structure of single-crystal blades from HTNA.

Increase of the deposit height enhances the probability of ROG and crack formation, in connection with accumulation of structural defects and stresses. Nonetheless, the single-crystal deposit height was brought to $10 \mathrm{~mm}$, by successive deposition of layers

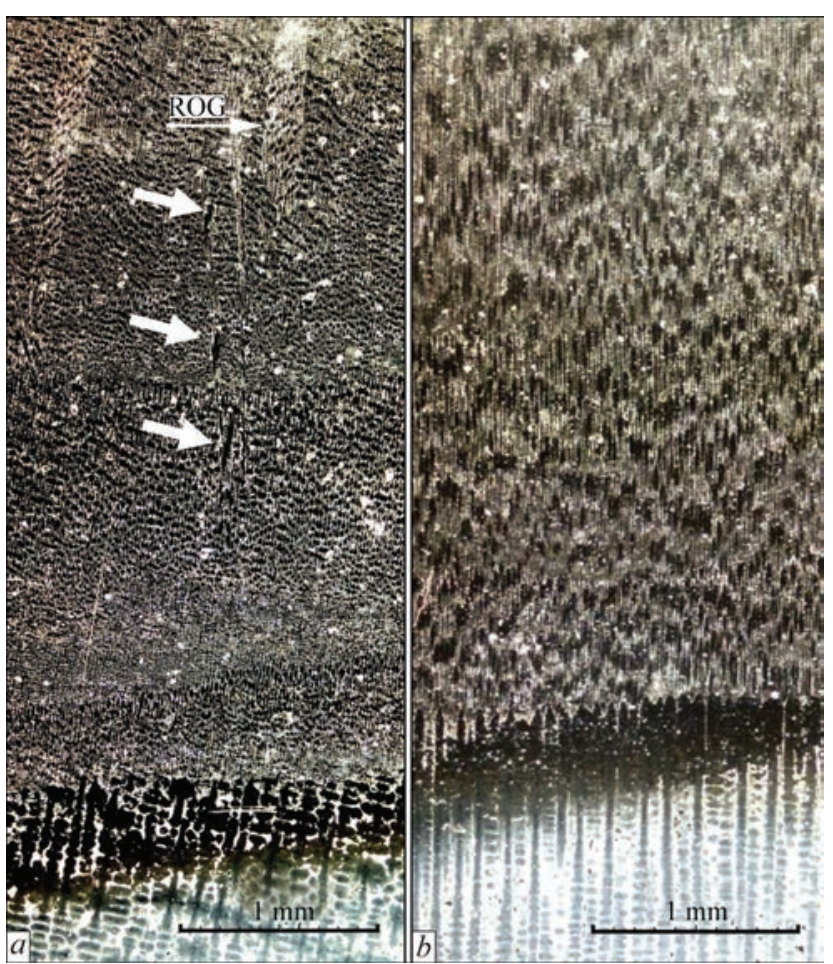

Figure 7. Longitudinal microsections $(\times 50)$ (dark field) of surfaced samples: $a-h / B \geq 0.8$ (arrows show microcracks and ROG); $b-h / B=0.4$

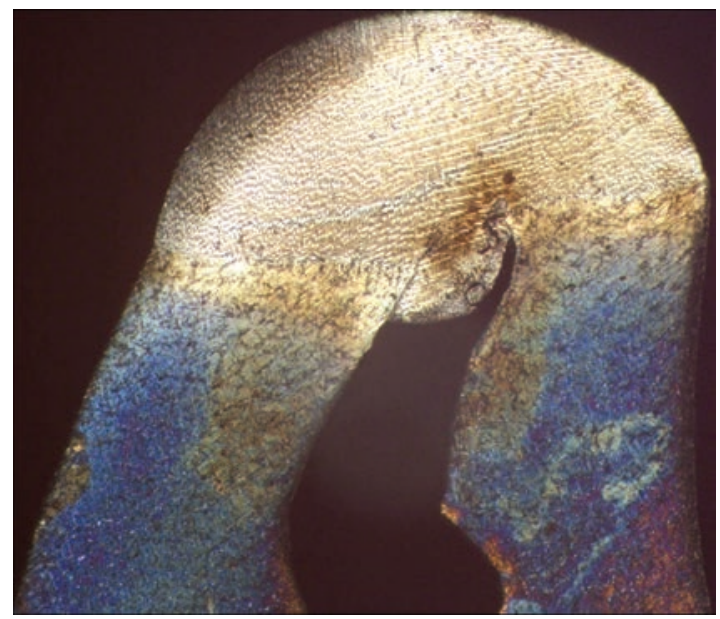

Figure 8. Restored leading edge of a single-crystal blade from ZhS26 alloy of aviation GTE at electron beam surfacing with deposit ratio $h / B=0.4(\times 50)$

made to the respective technological requirements, at initial edge width of 5-7 $\mathrm{mm}$.

Results of the performed studies and test deposits allow recommending repair of sections of different crystallographic orientation of single-crystal blades from HTNA with surface defects (Figure 1) by successive deposition of layers by EBW. The proposed technology was tried out in repair of blades (Figures 8, 9) from ZhS26, ZhS32 alloys [26].

\section{Conclusions}

1. The main objectives of repair of single-crystal blades from HTNA with manufacturing defects and 


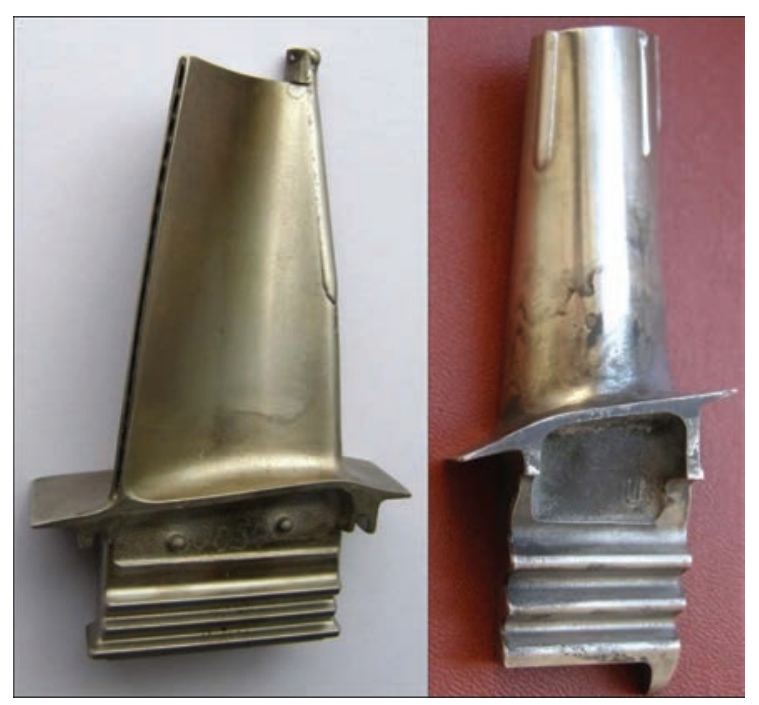

Figure 9. Appearance of single-crystal blades from $\mathrm{ZhS32}$ alloy with repair welds

operational damage is restoration of initial geometry, physical continuity and crystallographic uniformity of near-surface regions of the airfoil and edges.

2. Realization of physical conditions of formation of single-crystal structure of repair welds is achieved by technological means of EBW, by limiting the value of the ratio of deposit geometrical parameters $h / B$, with application of standardized rod filler material in keeping with study results. The technology was tried out both for single-pass and multipass surfacing of single-crystal elements of GTE hot section.

1. Inozemtsev, A.A., Sandratsky, V.L. (2006) Gas turbine engines. Perm, Aviadvigatel [in Russian].

2. Mashoshin, O.F., Chichkov, B.A. (2017) Blades of aircraft gas turbine engines: Design, strength, operation: Manual for professions 25.03.01, 25.04.01. Moscow, BMSTU [in Russian].

3. Smolin, A.A., Sporyagina, N.M. (1976) Evaluation of mechanical damage of compressor rotor in operation. Service life and reliability of gas turbine engines. In: Book 2. Moscow, CIAM, 66-72 [in Russian].

4. Ilchenko, G.A., Andreev, V.I., Guseva, T.P. (1979) Analysis of operating defects and problems of repair of gas turbine engine blades. In: Proc. of 11th Conf. of Young Scientists of NIAT. Moscow, NIAT, 49-52.

5. (2006) Cast high-temperature alloys. S.T. Kishkin effect. Ed. by E.N. Kablov. In: Techn.-Sci. Coll. to 100th Birth Anniversary of S.T.Kishkin. Moscow, Nauka [in Russian].

6. Sorokin, L.I. (2004) Argon-arc surfacing of shroud platforms of high-temperature nickel alloy blades. Svarochn. Proizvodstvo, 7, 36-39 [in Russian].

7. Arzhakin, A.N., Stolyarov, I.I., Turov, A.V. (2003) Development of technology for restoration of 8th stage blades of high-pressure compressor of aircraft engine by automatic surfacing method. Svarshchik, 4, 8-9 [in Russian].

8. Yushchenko, K.A., Savchenko, V.S., Chervyakova, L.V. et al. (2005) Investigation of weldability of nickel superalloys and development of repair technology for gas turbine blades. The Paton Welding J., 6, 3-6.

9. Tarasenko, Yu.P. (2005) Postoperational state of blades of first stage of high-pressure turbine of DZh59 engine and peculiarities of their restoration. Gazoturbinnye Tekhnologii, 11-12, 30-32 [in Russian].

10. Kuznetsov, V.P., Lesnikov, V.P., Belyaev, V.E., Fedotov, E.N. (2005) Restorative repair - second life of aircraft blades. Ibid., 4, 32-34 [in Russian].

11. Yushchenko, K.A., Zadery, B.A., Gakh, I.S., Karasevskaya, O.P. (2016) Formation of weld metal structure in electron beam welding of single crystals of high-temperature nickel alloys. The Paton Welding J., 8, 15-22.

12. Yushchenko, K.A., Gakh, I.S., Zadery, B.A. et al. (2013) Influence of weld pool geometry on structure of metal of welds on high-temperature nickel alloy single crystals. Ibid., 5, 45-50.

13. Yushchenko, K.A., Zadery, B.A., Gakh, I.S. et al. (2013) On nature of grains of random orientation in single crystal welds of high-temperature nickel alloys. Metallofizika i Novejshie Tekhnologii, 35(10), 1347-1357 [in Russian].

14. Yushchenko, K.A., Zadery, B.A., Gakh, I.S. et al. (2009) About possibility of inheriting single crystal structure of complexly-alloyed nickel alloys under nonequilibrium conditions of fusion welding. Ibid., 31(4), 473-485 [in Russian].

15. Yushchenko, K.A., Zadery, B.A., Karasevskaya, O.P., Gakh, I.S. (2008) Sensitivity to cracking and structural changes in EBW of single crystals of heat-resistant nickel alloys. The Paton Welding J., 2, 6-13.

16. Shorshorov, M.Kh., Erokhin, A.A., Chernyshova, T.A. (1972) Hot cracks in welding of heat-resistant alloys. Moscow, Mashinostroenie [in Russian].

17. Sorokin, L.I. (2004) Weldability of high-temperature nickel alloys (Review). Pt 2. Svarochn. Proizvodstvo, 10, 8-16 [in Russian].

18. Sorokin, L.I. (1999) Stresses and cracks in welding and heat treatment of high-temperature nickel alloys. Ibid., 12, 11-17 [in Russian].

19. Shorshorov, M.Kh., Erokhin, A.A., Chernyshova, T.A. (1973) Hot cracks in welding of heat-resistant alloys. Moscow, Mashinostroenie [in Russian].

20. Sorokin, L.I. (2004) Weldability of high-temperature nickel alloys (Review). Pt 1. Svarochn. Proizvodstvo, 9, 3-7 [in Russian].

21. Yushchenko, K.A., Zviagintseva, A.V., Kapitanchuk, L.M., Gakh, I.S. (2018) The role of actively diffusing impurities of sulfur and oxygen in ductility-dip cracking susceptibility of $\mathrm{Ni}-\mathrm{Cr}-\mathrm{Fe}$ welds. J. of Achievements in Materials and Manufacturing Engineering, 89(2), 49-55.

22. Park, J.-W., Baby, S.S., Vitek, J.M. et al. (2003) Stray grain formation in single crystal Ni-base superalloy welds. J. of Applied Physics, 94(6), 4203-4209.

23. Pollock, T.M., Murphy, W.H. (1996) The breakdown of single-crystal solidification in high refractory nickel-base alloys. Metal. Mater. Transact. A, 27A, 1081-1094.

24. Zlenko, M.A., Nagajtsev, M.V., Dovbysh, V.M. (2015) Additive technologies in mechanical engineering. Moscow, NAMI [in Russian].

25. Rykalin, N.N. (1951) Calculations of heat processes in welding. Moscow, Mashgiz [in Russian].

26. Yushchenko, K.A., Zadery, B.A., Gakh, I.S., Zvyagintseva, A.V. (2018) Prospects of development of welded single-crystal structures of high-temperature nickel alloys. The Paton Welding J., 11-12, 83-90. 


\title{
INFLUENCE OF REFRACTORY DISPERSED PHASES ON PHYSICAL-CHEMICAL PROPERTIES OF SLAG METLS OF MgO-Al $\mathrm{O}_{3}-\mathrm{SiO}_{2}-\mathrm{CaF}_{2}$ SYSTEM
}

\author{
I.O. GONCHAROV ${ }^{1}$, V.S. SUDAVTSOVA ${ }^{1}$, D.D. MISHCHENKO ${ }^{1}$, A.M. DUCHENKO ${ }^{1}$ and V.E. SOKOLSKY ${ }^{2}$ \\ ${ }^{1}$ E.O. Paton Electric Welding Institute of the NAS of Ukraine \\ 11 Kazymyr Malevych Str., 03150, Kyiv, Ukraine. E-mail: office@paton.kiev.ua \\ ${ }^{2}$ Taras Shevchenko National University of Kyiv \\ 60 Volodymyrska Str., 01601, Kyiv, Ukraine
}

\begin{abstract}
The article is devoted to the study of basic mechanisms of control of structure and physical-chemical properties of slag oxide-fluoride melts to develop fluxes with predicted chemical, metallurgical and technological parameters for welding high-strength low-alloyed steels. The addition of $\mathrm{MgO}$ into the slag melts of the $\mathrm{MgO}-\mathrm{Al}_{2} \mathrm{O}_{3}-\mathrm{SiO}_{2}-\mathrm{CaF}_{2}$ system provides an abnormal decrease in the thermodynamic activity of silicon oxide in them due to the formation of a refractory dispersed phase $\mathrm{MgO} \cdot \mathrm{Al}_{2} \mathrm{O}_{3}$ in the melt. On the basis of methods of national standard and gravimetric one the procedures for determination of quantitative content of $\mathrm{MgO} \cdot \mathrm{Al}_{2} \mathrm{O}_{3}$ in liquid and solid slags of the $\mathrm{MgO}-\mathrm{Al}_{2} \mathrm{O}_{3}-$ $\mathrm{SiO}_{2}-\mathrm{CaF}_{2}$, system were proposed. Its optimum content in a slag melt was determined, in which the combination of optimal chemical, metallurgical and technological properties of flux during electric arc welding is provided. 12 Ref., 1 Table, 5 Figures.
\end{abstract}

Ke y words: fluxes for electric arc welding, slag melts, refractory dispersed particles, toughness, electric conductivity, thermodynamic activity

The existing conceptions about the behaviour of welding slag melts, which are based on the ion theory of electrolytic dissociation of atoms, are somewhat obsolete. The structure of real welding slags is much more complicated than that of perfect and ideal ionic solutions. In metallurgical and welding slags predominantly a polar bond exists. When describing the structure of such slag melts, the leading role is assigned to the opinions defined by the ability of oxides-complexing agents to polymerize in the melt, forming a framework, as well as by the ability of cations (for example, $\mathrm{Na}^{+}, \mathrm{Ca}^{2+}$ ) to break this framework, releasing, as a result, the atoms of free non-bridging oxygen [1-3]. In the recent years, the ion theory has been criticized in the metallurgical literature due to the lack of adequate approaches in describing the polymerization processes of $\mathrm{SiO}_{2}$ and other oxides. In the metallurgical literature, a number of new theories $[4,5]$ were proposed, which describe the formation of polymer heteromolecular complexes in the melt (nanomicelles, associates, clusters, etc.). K. Mills notes [2] that in the recent years our knowledge about the structure of slag melts has significantly improved with the development of new techniques such as X-ray and neuron diffraction, Raman spectroscopy and nuclear magnetic resonance. In particular, it was established, that metallurgical slag melts are not a homogeneous liquid, as it was considered earlier, but heterogeneous, i.e. those, containing solid and liquid phases $[6,7]$.

The carried out analysis of gradient-temperature conditions of a weld pool existence in submerged electric arc welding [8] and the study of state diagrams of the oxide-fluoride systems $[9,10]$ showed that slag melts are heterogeneous during welding. This was confirmed by the method of high-temperature X-ray diffraction during investigations of the slag system $\mathrm{MgO}-\mathrm{Al}_{2} \mathrm{O}_{3}-\mathrm{SiO}_{2}-\mathrm{CaF}_{2}$ in the solid and molten state [11]. It was established that when the concentration of $\mathrm{MgO}$ is higher than $20 \%$ and $\mathrm{Al}_{2} \mathrm{O}_{3}$ is higher than $25 \%$ at the temperatures above $800{ }^{\circ} \mathrm{C}$, due to the increase in the diffusion of aluminium and magnesium ions, the compound $\mathrm{MgO} \cdot \mathrm{Al}_{2} \mathrm{O}_{3}$ is formed at a melting point of $2135{ }^{\circ} \mathrm{C}$. Such a compound is the only solid crystalline phase in the studied melts at the temperatures up to $1500{ }^{\circ} \mathrm{C}$. By the method of scanning electron microscopy with a local chemical analysis of phases, it was determined that $\mathrm{MgO} \cdot \mathrm{Al}_{2} \mathrm{O}_{3}$ is observed in the form of octahedra with the sizes of $10-35 \mu \mathrm{m}$ after melting of fluxes and in slag crusts in the process of welding.

The aim of this work was to determine the quantitative content of refractory dispersed phases $\mathrm{MgO} \cdot \mathrm{A}_{2} \mathrm{O}_{3}$ in the welding slags of the system $\mathrm{MgO}-$ $\mathrm{A}_{2} \mathrm{O}_{3}-\mathrm{SiO}_{2}-\mathrm{CaF}_{2}$, their influence on physical-chemical properties of slag melts, chemical and metallurgi- 
Composition of model agglomerated fluxes of the system $\mathrm{MgO}-\mathrm{Al}_{2} \mathrm{O}_{3}-\mathrm{SiO}_{2}-\mathrm{CaF}_{2}$, content of $\mathrm{MgOA}_{2} \mathrm{O}_{3}$ in them and results of chemical analysis of the $5^{\text {th }}$ layer of surfacing under these fluxes by the wire Sv-07G1NMA

\begin{tabular}{|c|c|c|c|c|c|c|c|c|c|c|c|}
\hline \multirow[b]{2}{*}{ Object } & \multicolumn{4}{|c|}{ Content of components, $\%$} & \multicolumn{2}{|c|}{$\begin{array}{c}\text { Content of } \\
\mathrm{MgO} \cdot \mathrm{Al}_{2} \mathrm{O}_{3} \cdot \%\end{array}$} & \multicolumn{5}{|c|}{ Content of elements in the weld metal and wire, $\%$} \\
\hline & $\mathrm{MgO}$ & $\mathrm{SiO}_{2}$ & $\mathrm{Al}_{2} \mathrm{O}_{3}$ & $\mathrm{CaF}_{2}$ & $\begin{array}{c}\text { Method of } \\
\text { national } \\
\text { standard }\end{array}$ & $\begin{array}{l}\text { Gravi- } \\
\text { metric } \\
\text { method }\end{array}$ & C & $\mathrm{Si}$ & $\mathrm{Mn}$ & $\mathrm{Ni}$ & Mo \\
\hline Wire Sv-07G1NMA & - & - & - & - & - & - & 0.087 & 0.371 & 1.44 & 0.61 & 0.62 \\
\hline Flux 7 & - & 40 & 25 & 25 & 0 & 0 & 0.040 & 0.561 & 0.69 & 0.46 & 0.48 \\
\hline 9 & 20 & 20 & 35 & 25 & 22 & 21 & 0.046 & 0.525 & 0.81 & 0.48 & 0.49 \\
\hline 4 & 30 & 20 & 25 & 25 & 20 & 19 & 0.049 & 0.484 & 0.81 & 0.46 & 0.48 \\
\hline 15 & 40 & 10 & 25 & 25 & 28 & 27 & 0.05 & 0.315 & 1.03 & 0.47 & 0.51 \\
\hline
\end{tabular}

cal and technological parameters of fluxes in electric arc welding.

Investigation of the structure of liquid and solid slags by the method of high-temperature $\mathrm{X}$-ray diffraction. The methods for determination of the content of compound $\mathrm{MgO} \cdot \mathrm{Al}_{2} \mathrm{O}_{3}$ in solid and molten slags by the methods of gravimetric analysis and national standard, respectively, were developed. The gravimetric method is based on the ability of the spinel not to dissolve in most strong acids. The principle of the national standard method is in the fact that a diffractogram is obtained, in which the studied substance is present and a substance, used as a national standard. In our case, monoclinic tungsten oxide $\mathrm{WO}_{3}$ was chosen. According to the ratio of heights of the peaks of the national standard substance and the studied substance, the content of the latter was determined. The experimental calibration diagrams for $\mathrm{WO}_{3}$ and $\mathrm{MgO} \cdot \mathrm{A}_{2} \mathrm{O}_{3}$ are in a good correlation with the results of simulation conducted with the application of PowderCell program. The results of $\mathrm{MgO} \cdot \mathrm{Al}_{2} \mathrm{O}_{3}$ content in the model agglomerated fluxes of the system $\mathrm{MgO}-$ $\mathrm{A}_{2} \mathrm{O}_{3}-\mathrm{SiO}_{2}-\mathrm{CaF}_{2}$, determined by the gravimetric method, are in a good correlation with the data of the national standard method (Table).

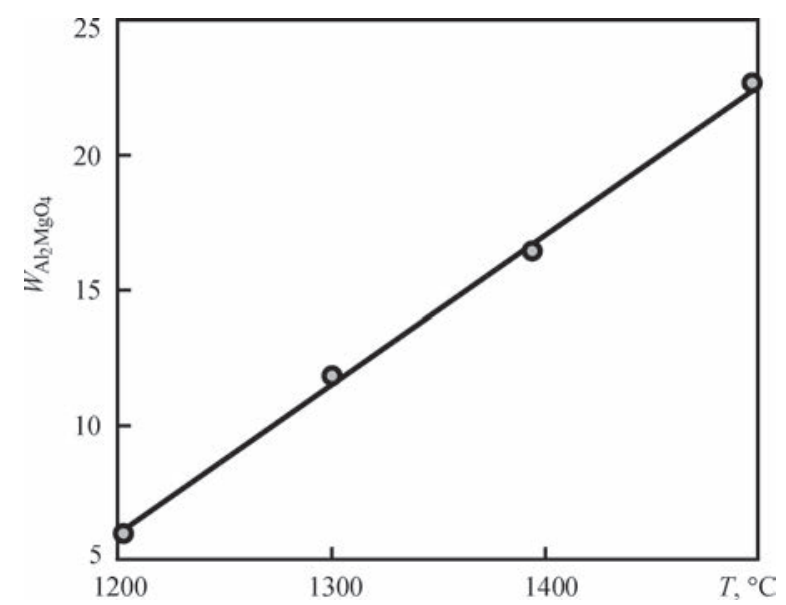

Figure 1. Dependence of mass fraction of $W_{\mathrm{MgAl}_{2} \mathrm{O}_{4}}$ in the flux of the system $\mathrm{MgO}-\mathrm{Al}_{2} \mathrm{O}_{3}-\mathrm{SiO}_{2}-\mathrm{CaF}_{2}$ on the temperature
It was established, that the content of $\mathrm{MgO} \cdot \mathrm{A}_{2} \mathrm{O}_{3}$ in the model of agglomerated fluxes during heating up to $1500{ }^{\circ} \mathrm{C}$ and in the slag crusts during welding is approximately the same. The influence of temperature-concentration factors, which determine the processes of formation of $\mathrm{MgO} \cdot \mathrm{Al}_{2} \mathrm{O}_{3}$ in the melts of the system $\mathrm{MgO}-\mathrm{Al}_{2} \mathrm{O}_{3}-\mathrm{SiO}_{2}-\mathrm{CaF}_{2}$, was investigated. When introducing $\mathrm{CaF}_{2}$ into the slag system $\mathrm{MgO}-$ $\mathrm{A}_{2} \mathrm{O}_{3}-\mathrm{SiO}_{2}$, the temperature of the initial formation of $\mathrm{MgO} \cdot \mathrm{A}_{2} \mathrm{O}_{3}$ decreases from $1300{ }^{\circ} \mathrm{C}$ to 1100 $1150{ }^{\circ} \mathrm{C}$. The temperature dependence of the content $\mathrm{MgO} \cdot \mathrm{A}_{2} \mathrm{O}_{3}$ in the range of $1200-1500{ }^{\circ} \mathrm{C}$ has a linear character (Figure 1). On the basis of the obtained results, the recommendations for the formation of refractory dispersed phases in slag melts in the industrial manufacture of agglomerated and fused fluxes were worked out. Thus, a high-temperature calcination of the charge can be performed not for separate components, as it takes place today, but for mixtures. Perspective is the adding of substances containing fluorine: fluorite or fluorspar into the mixture of magnesite and alumina. In addition, fused fluxes for welding and related processes or fused semi-products with a controlled content of dispersed phases in a melt can be melted in gas-flame or electric arc furnaces due to changes in the conditions of the charge loading into the furnace, temperature melting modes, etc.

Investigations of the activity of $\mathrm{SiO}_{2}$ and $\mathrm{O}^{-2}$ ions by the method of electromotive force. In the work [12] we proposed a method for the in-process determination of the $\mathrm{SiO}_{2}$ activity in oxide and oxide-fluoride slag melts and designed an original electrolytic sensor for measuring the EMF, which is stable in oxide-fluoride slag melts at the temperatures up to $1500{ }^{\circ} \mathrm{C}$.

It was concluded, that a decrease in the activity of $\mathrm{SiO}_{2}$ (Figure 2, a) in the melts of the system MgO$\mathrm{A}_{2} \mathrm{O}_{3}-\mathrm{SiO}_{2}-\mathrm{CaF}_{2}$ from 0.06 to 0.012 wt. $\%$ occurs due to the formation of refractory dispersed phases of $\mathrm{MgO} \cdot \mathrm{Al}_{2} \mathrm{O}_{3}$ in the melt. During the development of modern agglomerated fluxes, it is important to study the influence of metals, being in the composition of 

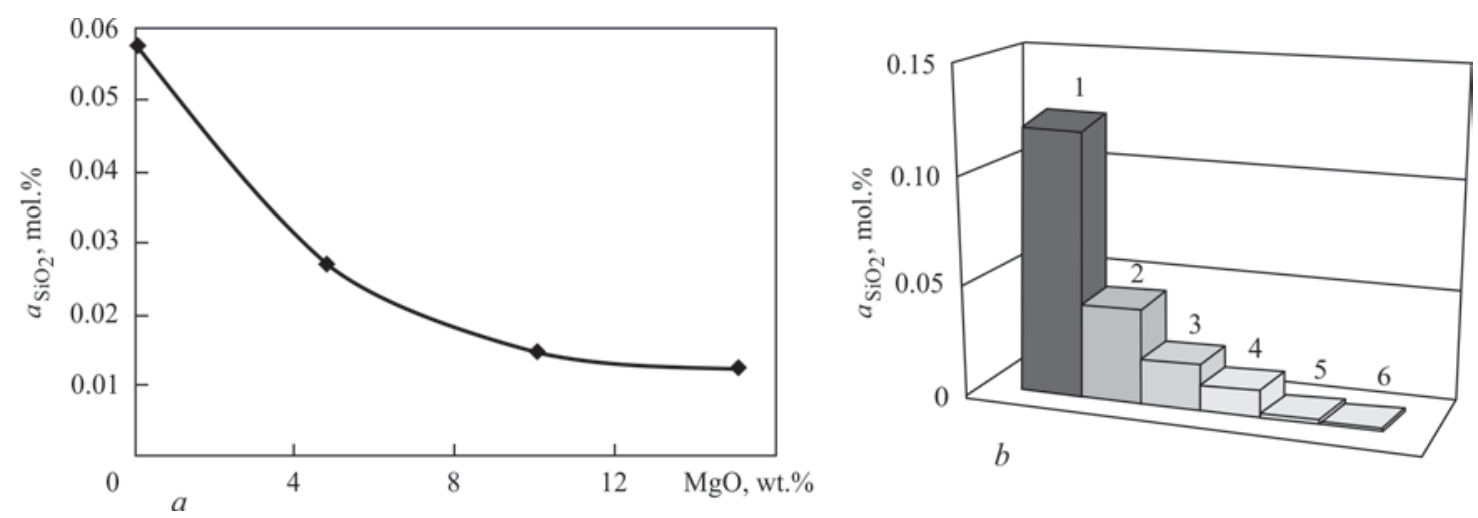

Figure 2. Dependence of thermodynamic activity of $\mathrm{SiO}_{2}$ in a slag melt of the system $\mathrm{MgO}-\mathrm{Al}_{2} \mathrm{O}_{3}-\mathrm{SiO}_{2}-\mathrm{CaF}_{2}$ at $1400{ }^{\circ} \mathrm{C}$ on the content of $\mathrm{MgO}(a)$ and the influence of the following metals on it in the amount of $1 \%(b): 1-$ flux without admixtures; $2-\mathrm{Fe}-\mathrm{Mn}$; $3-\mathrm{Mn} ; 4-\mathrm{Fe}-\mathrm{Si} ; 5-\mathrm{Fe}-\mathrm{Ti} ; 6-\mathrm{Si}-\mathrm{Ca}$

the alloying base of the flux, on the oxidizing effect of molten fluxes on a weld pool metal. A thermodynamic analysis of the probability of running chemical reactions of interaction of silicon oxide with different metals was carried out and their influence in the amount of $1 \%$ on the thermodynamic activity of $\mathrm{SiO}_{2}$ in the melts of the system $\mathrm{MgO}-\mathrm{Al}_{2} \mathrm{O}_{3}-\mathrm{SiO}_{2}-\mathrm{CaF}_{2}$ was experimentally investigated. The most effective (reduction by 2-3 orders) is the adding of silicocalcium and ferrotitanium into the composition of fluxes (Figure 2, b).

The influence of the activity of oxygen ions and the activity of silicon oxide on the transition of oxygen and alloying elements into the deposited metal at applying the model agglomerated fluxes of the system $\mathrm{MgO}-\mathrm{Al}_{2} \mathrm{O}_{3}-\mathrm{SiO}_{2}-\mathrm{CaF}_{2}$ with different contents of $\mathrm{MgO} \cdot \mathrm{A}_{2} \mathrm{O}_{3}$ (Table), formed in the fluxes during their heating, was studied. The dependence between the content of $\mathrm{MgO} \cdot \mathrm{A}_{2} \mathrm{O}_{3}$ in the flux, the thermodynamic activity of oxygen ions in the slag melt (Figures 3 , 4) and the oxygen content in the weld metal was established. The best deoxidizing ability belongs to the flux with the highest content of $\mathrm{MgO} \cdot \mathrm{Al}_{2} \mathrm{O}_{3}$ among investigated fluxes, which is at the level of $28 \%$. In

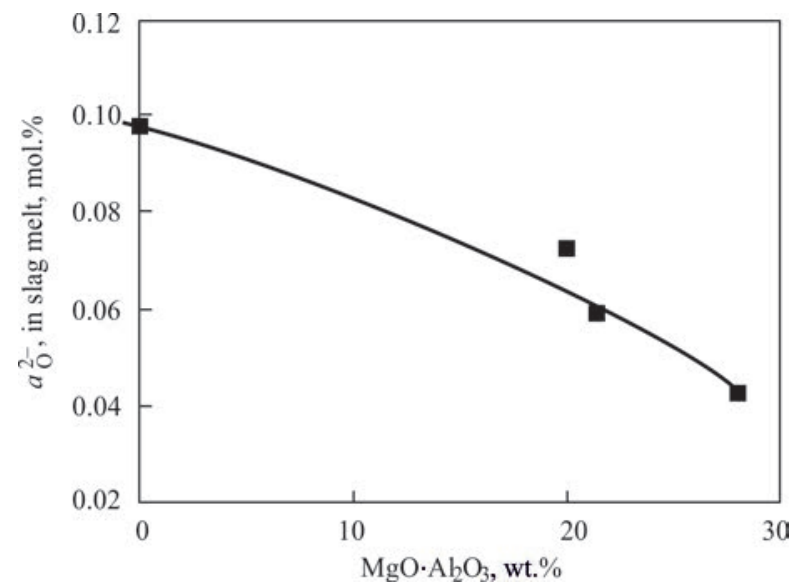

Figure 3. Dependence of the activity of oxygen ions in slag melts of the system $\mathrm{MgO}-\mathrm{Al}_{2} \mathrm{O}_{3}-\mathrm{SiO}_{2}-\mathrm{CaF}_{2}$ on the content of the compound $\mathrm{MgO} \cdot \mathrm{A}_{2} \mathrm{O}_{3}$ in them the field of compositions containing $\mathrm{MgO} \cdot \mathrm{Al}_{2} \mathrm{O}_{3}$ of $19-22 \mathrm{wt} \%$ in the melt, the approximate parameters for the activity of oxygen ions and silicon oxide in the melt were obtained. At the same time, a partial increase in the content of $\mathrm{A}_{2} \mathrm{O}_{3}$ in the flux due to the corresponding reduction in the content of $\mathrm{MgO}$ is not accompanied by an increase in the activity of oxygen ions, by the losses of $\mathrm{Mn}$ and a significant increase in the recovery of Si in the deposited metal (Table) at significantly better properties of the flux formation. With an increase in the activity of oxygen ions in the slag melt to higher than $0.06 \mathrm{~mol} \%$, an increase in the oxygen content in the deposited metal is observed (Figure 4).

Determination of influence of the $\mathrm{MgO} \cdot \mathrm{Al}_{2} \mathrm{O}_{3}$ content in liquid fluxes on their physical and chemical properties and welding-technological characteristics. It was determined that in the range of compositions $\mathrm{MgO}-20-25 \%$; $\mathrm{A}_{2} \mathrm{O}_{3}-25-35 \%$; $\mathrm{SiO}_{2}-15-20 \% ; \mathrm{CaF}_{2}-15-25 \%$, a combination of optimal chemical, metallurgical and technological properties of a flux during electric arc welding is provided due to the formation of refractory dispersed phases $\mathrm{MgO} \cdot \mathrm{A}_{2} \mathrm{O}_{3}$ in a slag melt in the range of 19 $22 \%$. It was established that their formation in the melt expands the temperature range of solidification

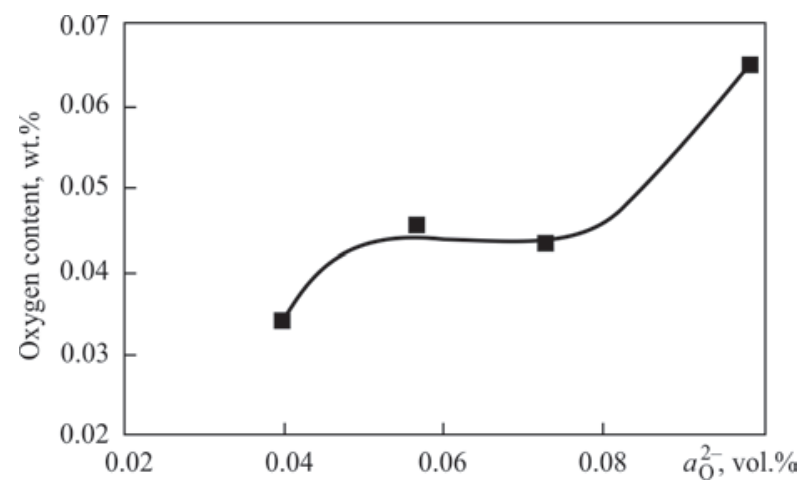

Figure 4. Dependence of the oxygen content in the deposited metal on the activity of oxygen ions in the melt of the system $\mathrm{MgO}-$ $\mathrm{Al}_{2} \mathrm{O}_{3}-\mathrm{SiO}_{2}-\mathrm{CaF}_{2}$ 


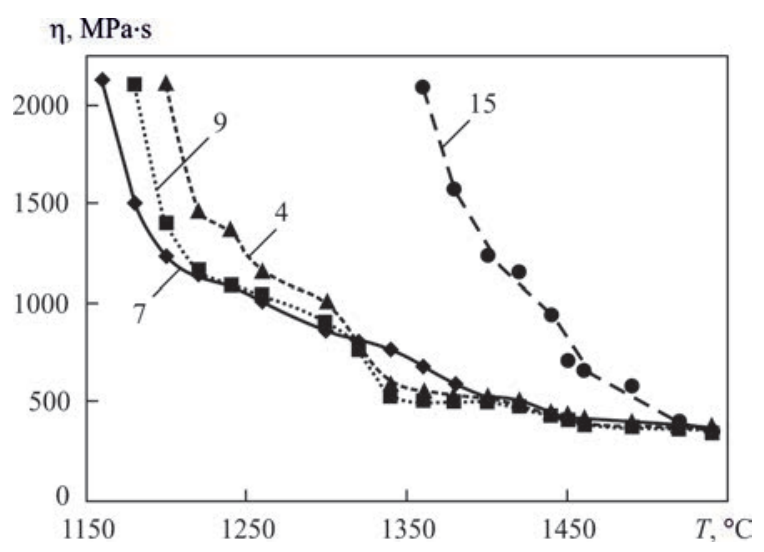

Figure 5. Temperature dependence of toughness of model agglomerated fluxes of the system $\mathrm{MgO}-\mathrm{Al}_{2} \mathrm{O}_{3}-\mathrm{SiO}_{2}-\mathrm{CaF}_{2}$ (compositions of fluxes 4, 7, 9, 15 are given in Table)

of fluxes up to $1180-1510^{\circ} \mathrm{C}$. It is shown that for the temperature dependences of toughness $(\eta)$ (Figure 5) of these fluxes a gradual increase in the toughness in the process of cooling is characteristic, caused by a multistage formation in the melt of solid dispersed phases. At the same time, the conditions for removal of gases from the welding zone are improved. In the above-mentioned range of compositions, the optimal values of electrical conductivity were also achieved at the level of $0.11-0.16(\mathrm{Ohm} \cdot \mathrm{cm})^{-1}$, which is important for preventing the shunting of arcs in multiarc welding. With an increase in the content of $\mathrm{MgO} \cdot \mathrm{Al}_{2} \mathrm{O}_{3}$ to $28 \%$, the melt toughness increases. It results in deterioration of weld shape and the formation of undercuts during welding.

\section{Conclusions}

1. The influence of temperature-concentration factors on the processes of $\mathrm{MgO} \cdot \mathrm{A}_{2} \mathrm{O}_{3}$ formation in the melts of the system $\mathrm{MgO}-\mathrm{Al}_{2} \mathrm{O}_{3}-\mathrm{SiO}_{2}-\mathrm{CaF}_{2}$ was determined. The recommendations for the formation of refractory dispersed phases in slag melts in the technological processes of manufacture of agglomerated and fused fluxes were worked out.

2. On the basis of methods of the national standard and gravimetric method, the procedures for determining the quantitative content of $\mathrm{MgO} \cdot \mathrm{Al}_{2} \mathrm{O}_{3}$ in liquid and solid slags of the system $\mathrm{MgO}-\mathrm{Al}_{2} \mathrm{O}_{3}-\mathrm{SiO}_{2}-\mathrm{CaF}_{2}$ were proposed.

3. Reduction in thermodynamic activity of $\mathrm{SiO}_{2}$ in the melts of the system $\mathrm{MgO}-\mathrm{Al}_{2} \mathrm{O}_{3}-\mathrm{SiO}_{2}-\mathrm{CaF}_{2}$ from
0.06 to $0.012 \mathrm{~mol} \%$ when adding $\mathrm{MgO}$ into the flux in the amount of up to $15 \%$ is caused by the formation of refractory dispersed phases of $\mathrm{MgO} \cdot \mathrm{Al}_{2} \mathrm{O}_{3}$ in the slag melt. The influence of metals adding into the slag melts on the thermodynamic activity of silicon oxide was determined.

4. It was established, that the formation of $\mathrm{MgO} \cdot \mathrm{A}_{2} \mathrm{O}_{3}$ in the melt expands the temperature range of fluxes solidification up to $1180-1510{ }^{\circ} \mathrm{C}$. For polytherms of toughness of these slags, a gradual increase in the toughness in the cooling process is characteristic, caused by the multi-stage formation of solid dispersed phases in the melt.

5. It was determined, that at the composition of a refractory dispersed phase of $\mathrm{MgO} \cdot \mathrm{Al}_{2} \mathrm{O}_{3}$ in a slag melt in the amount of 19-22\%, the combination of optimal chemical, metallurgical and technological properties of a flux during arc welding is provided

1. Mysen, B.O. (1988) Structure and properties of silicate melts. Amsterdam, Elsevier.

2. Mills, K.C. (1993) The influence of structure on the physicochemical properties of slags. ISIJ Int., 1, 148-155.

3. Mills, K.C., Yuan, L, Jones, R.T. (2011) Estimation the physical properties of slags. The J. of Southern African Institute of Mining and Metallurgy, 111, 649-658.

4. Zajtzev, A.I., Shakhpazov, E.Kh. (2009) Development of modern theory of metallurgical slags. Metallurg, 5, 27-31 [in Russian].

5. Zajtzev, A.I., Mogutnov, B.M., Shakhpazov, E.Kh. (2008) Physical chemistry of metallurgical slags. Moscow, Interkontakt Nauka [in Russian].

6. Zhuangzhuang Liu, Lieven Pandelaers, Bart Blanpain, Muxing Guo (2018) Viscosity of heterogeneous silicate melts: A Review. Metallurgical and Materials Transact. B, Oct., 49(5), 2469-2486.

7. Park, J.H. (2007) Solidification structure of $\mathrm{CaO}-\mathrm{SiO}_{2}-\mathrm{MgO}-$ $\mathrm{Al}_{2} \mathrm{O}_{3}\left(-\mathrm{CaF}_{2}\right)$ systems and computational phase equilibria: Crystallization of MgAl2O4 spinel. Computer Coupling of Phase Diagrams and Thermochemistry, 31, 428-437.

8. Christensen, N., Chipman, J. (1953) Slag-metal interaction in arc welding. Weld. Res. Counsil Bul. Ser., 15, 18.

9. (1995) Slag Atlas. 2nd Ed. Verlag Stahleisen GmbH, D-Dusseldorf.

10. (1985) Slag Atlas: Refer. Book. Moscow, Metallurgiya [in Russian].

11. Goncharov, I.A., Sokolsky, V.E., Davidenko, A.O. et al. (2012) Formation of spinel in melt of the $\mathrm{MgO}-\mathrm{Al}_{2} \mathrm{O}_{3}-\mathrm{SiO}_{2}-$ $\mathrm{CaF}_{2}$ system agglomerated welding flux and its effect on viscosity of slag. The Paton Welding J., 12, 18-25.

12. Goncharov, I.A., Galinich, V.I., Mishchenko, D.D. et al. (2013) Methods of control of silicon oxide activity in slag melts. Ibid., 2, 8-12. 


\title{
IMPROVEMENT OF TECHNOLOGICAL AND SANITARY-HYGIENIC CHARACTERISTICS OF GAS-SHIELDED ARC WELDING PROCESS
}

\author{
V.N. SHLEPAKOV and A.S. KOTELCHUK \\ E.O. Paton Electric Welding Institute of the NAS of Ukraine \\ 11 Kazimir Malevich Str., 03150, Kyiv, Ukraine. E-mail: office@paton.kiev.ua
}

\begin{abstract}
The influence of kind and type of electrode wire, characteristics of its melting, as well as composition of shielding gas, on welding-technological properties and technological quality of welds in joints of low-alloyed steels of increased and high strength is considered. The ways and means of achieving a consistently high technological quality of welds, increasing the efficiency of the process and reducing the level of gross evolutions of welding fumes are noted. 14 Ref., 4 Figures.
\end{abstract}

Keywords : mechanized arc welding, low-alloyed steels, electrode wire, welding and technological properties, weld quality, efficiency, welding fumes

Current state of application of automatic and mechanized gas-shielded arc fusion welding is characterized by a significant widening of the fields of its application in development of various-purpose metal structures from increased and high-strength low-alloyed steels. The main factors promoting wider application of these welding processes are high efficiency and optimization of the cost, as well as high quality of welded joints [1-5].

Low-alloyed solid wires, as well as flux-cored wires with metal core became the most widely applied as electrode material for the above processes. Here, the shielding medium is most often created by carbon dioxide gas or argon-based gas mixtures with addition of carbon dioxide gas [6]. With widening of the application of mechanized gas-shielded fusion welding ever more attention has to be given to the main features of the process, which influence the welded joint quality characteristics, efficiency of operations, as well as improvement of sanitary-hygienic conditions of their performance, that is directly related to metal structure fabrication cost [7-10].

Investigations and experimental work performed at PWI in this field were aimed at clarification of the effect of electrode material kind and type, and shielding gas composition on their welding-technological properties and technological quality of welds in joints of low-alloyed steels. In addition, the influence of these factors on efficiency indices and sanitary-hygienic characteristics of the process was assessed. The electrode material used were solid wires, meeting the requirements of DSTU ISO 14341 standard [11], and

(C) V.N. SHLEPAKOV and A.S. KOTELCHUK, 2019 flux-cored wires for arc welding of low-alloyed steels of increased and high strength to standards DSTU ISO 17632 [12] and DSTU ISO 18276 [13]. The shielding gas atmosphere was created in keeping with the recommendations of welding wire manufacturers and standard DSTU 14175 [14]. Used as the base material were plates from low-alloyed steel 09G2S from 6 to $18 \mathrm{~mm}$ thick, treated for making fillet and butt joints with the recommended edge preparation. Welding equipment included two main types of sets: thyristor VDU-506 and inverter TransSynergic 5000 Fronius with the respective feed mechanisms and automatic welding head. Welding mode parameters were established in keeping with the recommendations of wire manufacturer. The electrode materials selected were solid wire of G46 3C (M) type (ESAB), flux-cored wires of T50 (46) C (M) Z type (PWI PPWC, Alloy Rods, Oerlikon, KOBELCO).

Video filming was used to assess the characteristics of arcing and electrode metal transfer. Electrode metal losses were recorded by electrode material consumption and by evaluation of the level of spatter after the joint scraping. Sanitary-hygienic characteristics were assessed by the intensity of evolution of welding fume solid component (WFSC) and its composition [10].

Weld shape and dimensions were studied by measuring the transverse sections, cut out of welded samples after grinding and etching in nitric acid solution. Quantimet microscope was used to determine the cross-sectional area. Penetration depth, weld width, reinforcement shape, total cross-section area were selected as the main characteristics for comparison, and defects in the fusion zone were evaluated. Results of 
the conducted studies and authors' ideas for improvement of the process of mechanized gas-shielded welding are given below in the generalized form.

Influence of the characteristics of wire melting and metal transfer on welding-technological properties. Wire melting and electrode metal transfer into the weld pool are determined in the general case by the section (diameter) of the wire and parameters of the welding mode, as well as the composition of shielding gas atmosphere. The main kinds of transfer are classified as drop, spray and spray-drop transfer. A key role in the change of transfer characteristics is played by the impact of pinch-effect on the end portion of melting wire, caused by lowering of molten metal surface tension. Composition of shielding gas atmosphere, as well as the type and composition of electrode wire, affect the thermal conductivity, ion potential of the arcing zone and, thus, the nature of wire melting. Diameter (for solid wires) or thickness of current-carrying sheath of flux-cored wire determine the value of arc welding parameters, at which the influence of pinch-effect changes the nature of arc burning and melting of the wire tip face. Figure 1 shows the simplified schemes of metal transfer in welding with solid wire and flux-cored wire, characterized both as drop and spray (spray-drop) transfer.

The main difference at application of solid wire and flux-cored wire consists in that at spray transfer of solid melting wire the metal transfer is focused in the

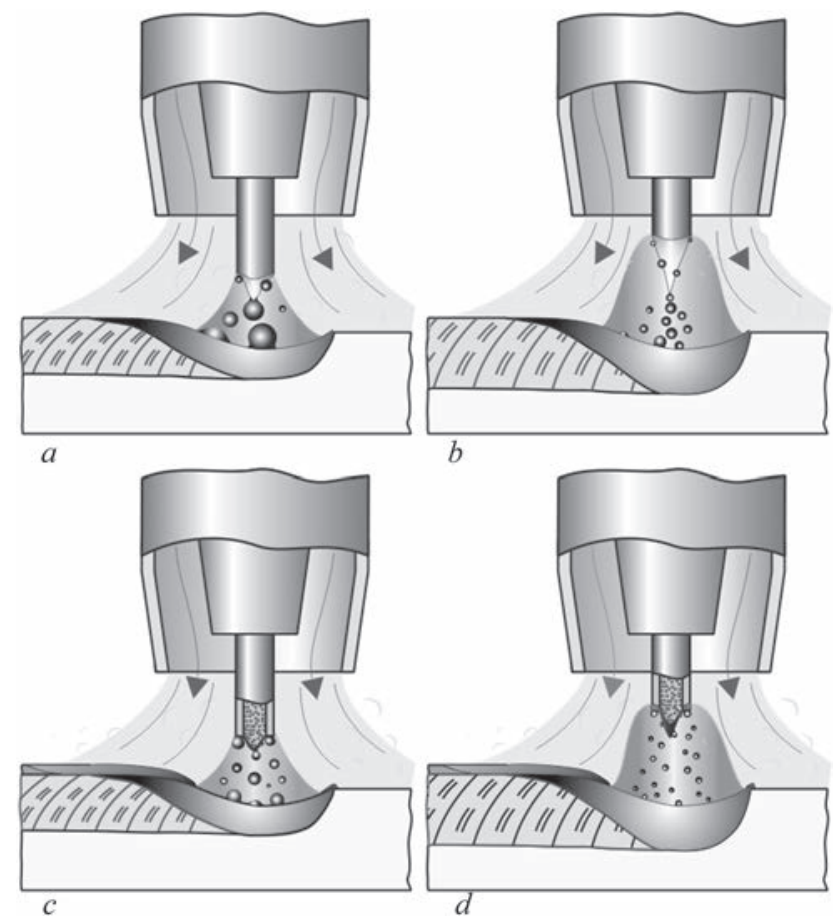

Figure 1. Modes of electrode metal transfer in welding with solid wire $(a, b)$ and flux-cored wire $(c, d)$ in welding in $\mathrm{CO}_{2}(a, c)$ and in $\mathrm{Ar}+\mathrm{CO}_{2}$ mixture $(b, d)$ center of arc burning area, and that of flux-cored wire is focused across the sheath section, the core metal going into the weld pool in the central zone. Presence of slag-forming materials and powders of metals and chemical compounds with a low ionization potential in the composition of flux-cored wire core, which affect the properties of the slag melt, has an impact on surface tension of weld pool molten metal that allows regulation of weld surface shape. In gas-shielded arc welding flux-cored wires mainly with two types of powder core are used: slag-forming, which ensures slag protection and provides metallurgical treatment of the melt of the respective type (rutile or basic), and metallic, the base of which are powders of iron and alloys with a small fraction of active chemical compounds (less than $1.5 \mathrm{wt} . \%$ ). The composition of shielding gas atmosphere has a key role, determining thermal conductivity of the arc gap and degree of development of oxidizing processes at electrode metal transfer and in the weld pool.

Solid wires have deoxidizing elements and alloying additives in their composition, which ensure producing weld metal of the specified composition, determining the level of mechanical properties of the welded joint according to the strength class of welded steels. Type of applied electrode material (wire), similar to shielding gas atmosphere composition, largely determines not only the values of mechanical properties of the metal of weld and welded joint, but also the technological characteristics and quality of welded joints.

Technological quality of welds. Formation of a sound weld in terms of technology is determined by its geometry (penetration depth and shape), correspondence to design dimensions, absence of base metal damage and complete filling of the beginning and end (crater) sections. Meeting these requirements is considerably simplified, if the recommended welding technique requires no further manipulations, in addition to torch movement along the joint trajectory, and even more so, additional adjustment of parameters of the welding mode, established by the process specification.

Shielding gas atmosphere has a significant role, both in the process of electrode metal transfer into the weld pool, and in the technological characteristics, determining the penetration depth and weld shape, as well as the efficiency of the welding process as a whole. Widely used shielding of the melting zone by carbon dioxide gas ensures sufficient depth of penetration and welding process efficiency, owing to high heat conductivity. Nonetheless, application of such gas shielding, having a high oxidizing potential, re- 
quires following the welding technique and mode parameters to ensure the specified dimensions and shape of the weld, because of the susceptibility to formation of base metal undercuts and convexity of the central part of weld surface. Moreover, change of welding mode parameters can lead to both increase of metal losses for spattering, and to greater loss of alloying elements from the wire.

Application of the still widely accepted process of solid and flux-cored wire welding in carbon dioxide gas is accompanied by loss of part of deoxidizing and alloying elements, released into the atmosphere together with welding fumes. A significant effect of welding mode parameters (particularly welding speed) on the weld shape and dimensions is also noted at application of solid wires. Use of wires with slag or metal powder filler allows an essential improvement of the technological properties due to the effect of the formed slag melt and specific characteristics of wire melting, ensuring refinement of the transferred drops of molten metal of the wire sheath and core, as well as technological properties of slag, which ensures protection of weld pool surface from oxidation. Nonetheless, spray-drop transfer of electrode metal is not achieved in either case. Moreover, application of flux-cored wire with slag-forming filler is associated with the need to remove the slag crust after each welding pass. Achievement of the characteristics of spray-drop transfer of electrode metal is possible only at application of small diameter wires at high parameters of the welding mode.

The main effect on the forms of electrode metal transfer is produced by thermal power, which is consumed in melting of electrode wire, fed continuously into the melting zone. Value of this thermal power depends on welding current polarity, welding mode parameters, as well as composition of the used shielding gas. Power required for stable maintenance of welding, is adjusted by the specified rate of wire feed into the melting zone. At small value of power, released in the wire melting zone, electrode metal transfer is performed by molten metal drops with short-circuiting of the arc gap. At the highest power electrode metal transfer takes the spray form (metal transfer by droplets without short-circuiting of the arc gap). Spray transfer is the most stable in terms of melting parameters and allows an abrupt lowering of electrode metal losses for spattering.

Argon is used as shielding gas to achieve spray mode of electrode metal transfer in all the ranges of welding mode. In welding in an argon-based gas mixture (for instance, $\mathrm{Ar}+\mathrm{CO}_{2}$ ) the beginning of transi-

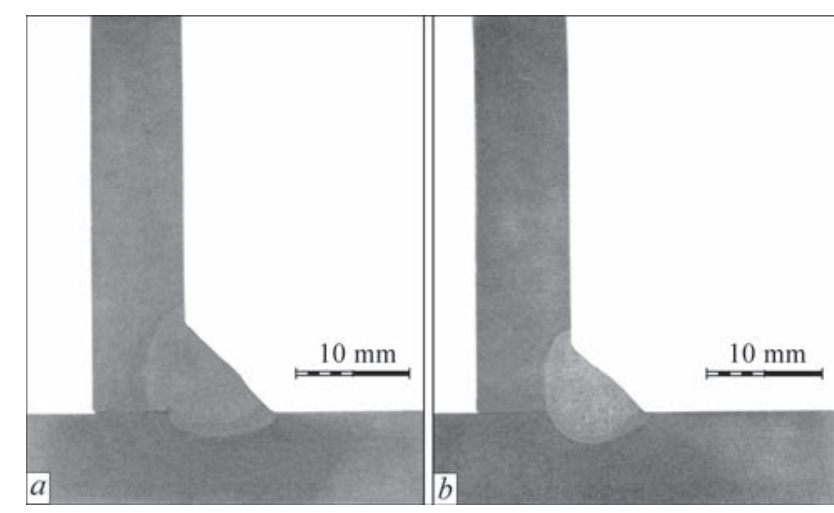

Figure 2. Sections of single-pass fillet welded joints of $8 \mathrm{~mm}$ thick metal, made by solid $(a)$ and flux-cored wire $(b)$ in shielding gas atmosphere M21 $\left(\mathrm{Ar}+18 \mathrm{CO}_{2}\right)$ in the automatic mode

tion from drop to spray type of transfer occurs, when the arc partially transfers from wire end face to side surfaces of wire tip. The wire tip takes the shape close to the conical one. In $\mathrm{CO}_{2}$-welding it is necessary to increase the arc power through increase of arc voltage (as the welding current is related to wire feed rate). The most rational process in modern technology of gas-shielded solid wire welding is believed to be a process, where argon-based gas mixtures are used. The most widely applied are gas mixtures of M21 type to ISO $14175-\mathrm{Ar}+$ from 5 to $25 \mathrm{vol} . \% \mathrm{CO}_{2}$. $\mathrm{CO}_{2}$ addition to argon allows lowering the adverse influence of too high thermal radiation on the operator-welder. Application of such argon-based mixtures allows a significant improvement of penetration shape and surface geometry of the weld, as well as minimizing electrode metal losses for spatter. Figure 2 shows typical sections of fillet welded joints, made with solid wire and flux-cored wire with metal-powder core in carbon dioxide gas and gas mixture of M21 type.

World practice shows a considerable increase of the volume of application of mechanized welding in gas mixtures, in particular, at application of solid wires and flux-cored wires with metal-powder core type, ensuring spray-drop transfer of electrode metal in a broad range of welding mode parameters. Such a technology is less sensitive to the effect of the subjective factor, and readily applicable for high-efficient automatic welding processes.

Effect of electrode wire type and composition of shielding gas atmosphere on sanitary-hygienic characteristics and efficiency of the process. Electric arc fusion welding is always accompanied by welding fumes evolution. Assessment of the total amount of fumes and their composition are initial data for establishing the requirements on protection of welder-operator respiratory organs and organizing the work of the systems of welding fume removal from the working zone and gen- 


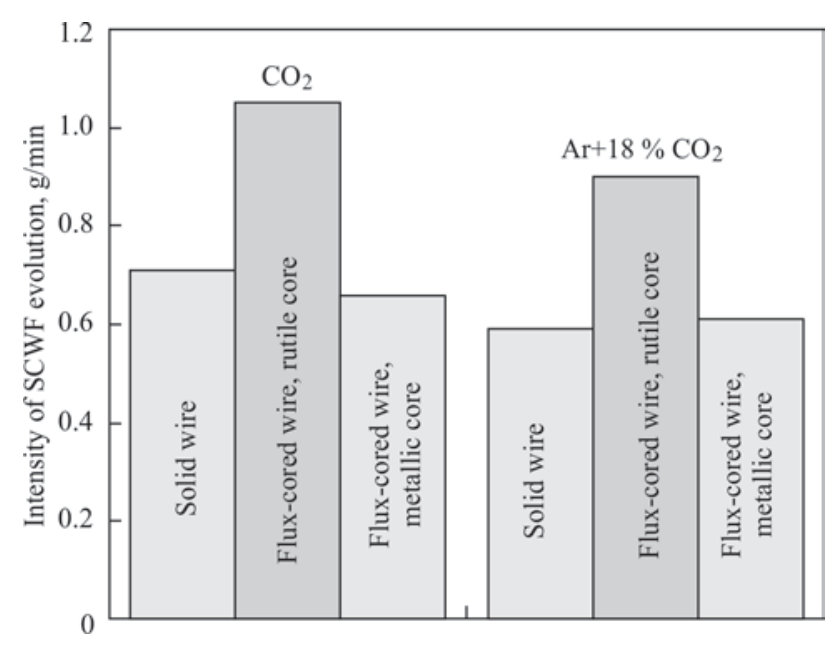

Figure 3. Typical intensity of welding fume evolution in gas-shielded welding with solid and flux-cored wires

eral shop space. Main attention is given to presence and amount of the most toxic components. For the case of welding low-alloyed steels, manganese emissions are considered some of the most toxic. As the material type, composition of shielding gas atmosphere and welding mode parameters have an effect on the volume of welding fume evolution, assessment of the risk is performed in the entire range of welding modes, as the toxic effect of aerosol depends not only on composition and dispersity of particles, but also on the degree of their agglomeration during release, and a number of other factors.

Application of solid wires and flux-cored wires in $\mathrm{CO}_{2}$-welding is associated with development of oxidizing reactions already at the stage of wire heating and melting that makes it necessary to allow for their losses for guaranteed achievement of the required composition of weld metal and obtaining the required quality and performance of the welded joint. Total level of gross evolutions in the case of application of flux-cored wires with slag-forming filler is higher, than at application of solid wires and flux-cored wires with metal-powder filler. However, presence of a slag melt leads to lowering of the level of burning out of deoxidizing and alloying elements that, eventually, allows lowering the level of fume toxicity.

In welding in an argon-based gas mixture, the level of gross evolutions of fumes and their toxic component is essentially lower. Application of flux-cored wires with a metal core type allows lowering the total level of gross evolutions of fumes to the level characteristic for application of solid wires (Figure 3).

The efficiency of the process of electric arc welding, assessed by the quantity of deposited metal (Figure 4), does not completely represent the real efficiency of making welds during metal structure fabrication, as it does not take into account the effect of possible de-

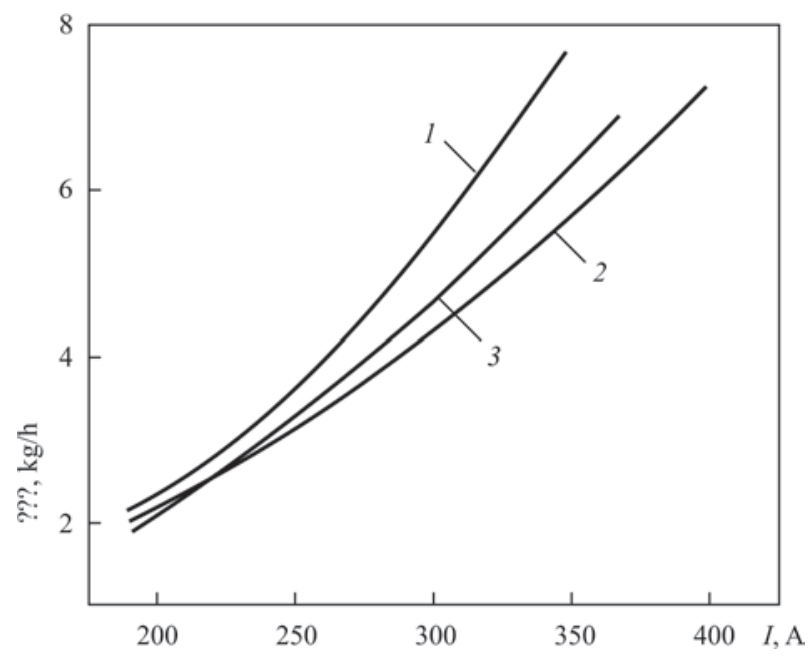

Figure 4. Typical efficiency of deposition with electrode wires of $1.2 \mathrm{~mm}$ diameter of different type in shielding gas atmosphere M21 $\left(\mathrm{Ar}+18 \mathrm{CO}_{2}\right): 1$ - flux-cored wires with metal core; 2 rutile core; 3 - solid wire

viation of weld dimensions from the design values, in particular, shape of the surface (reinforcement), extent of possible losses for electrode metal spatter in the real conditions. Comparative experiments showed that the speed of welding (time of performance) of welds of equivalent design size increases by 5 to $15 \%$ in the case of application of welding in a mixture of gases of M21 type instead of carbon dioxide gas. This is achieved not only through lowering the burn-off and spatter losses, but also due to more precise correspondence of reinforcement size and shape to design values, that is reflected in economic indices of welded metal structure fabrication. Additional economic advantages can also be achieved at application of flux-cored wires instead of solid wires due to reduction of weld metal volume, for instance, when making single-pass fillet joints (Figure 2).

\section{Conclusion}

Analysis of the results of the conducted experimental studies on the influence of the kind and type of electrode wire, and shielding gas, can be the basis for selection of the most rational ways of improvement of the technological quality of welded joints, enhancing the welding operation performance and improvement of sanitary-hygienic characteristics.

Higher cost of welding consumables (flux-cored wires, gas mixtures of argon with carbon dioxide gas) are compensated not only by increase of welding process efficiency, but by lowering of total cost of making the welded joints due to elimination of electrode metal losses, as well as improvement of the shape and greater correspondence of the dimensions and shape of the weld to the design values. All this allows reduc- 
ing the cost of welded metal structure fabrication and improving their quality.

1. Adonyi, Y., Nadzam, J. (2005) Gas metal arc welding. New developments in advanced welding. Ed. by Nasir Ahmed. England, Cambridge: Woodhead Publishing Series in Welding and Other Joining Technologies, 1-20.

2. Shlepakov, V.N., Kotelchuk, A.S., Naumejko, S.M. et al. (2005) Influence of the composition of flux-cored wire core and shielding gas on the stability of arc welding process. The Paton Welding J., 6, 16-20.

3. Potapievsky, A.G. (2007) Consumable electrode shielded-gas welding. Pt 1: Welding in active gases. 2nd ed. Kiev, Ekotekhnologiya [in Russian].

4. Widgery, D. (2005) Tubular cored wire welding. New developments in advanced welding. Ed. by Nasir Ahmed. England, Cambridge: Woodhead Publishing Ltd., 21-39.

5. Millar, D. (2014) Modern seamless gas shielded flux cored arc welding and gas shielded metal cored arc welding wires for high productivity. Welding and Cutting, 12(2), 86-90.

6. Vaidya, V.V. (2002) Shielding gas mixtures for semiautomatic welds shielding gas blends are designed to enhance semiautomatic welding on a variety of ferrous and nonferrous metals. Welding J., 9, 43-48.

7. Shlepakov, V.N. (2011) Current consumables and methods of fusion arc welding (Review). The Paton Welding J., 10, 26-29.
8. Brown, K.J. (2000) Fume composition related to welding processes and consumables. Welding in the World, 44(1), 39-40.

9. Pohmann, G., Holzinger, C., Spiegel-Cionabu, V.E. (2013) Comparative investigations in order to characterise ultrafine particles in fumes in the case of welding and allied processes. Welding and Cutting, 12(2), 97-105.

10. Pokhodnya, I.K., Shlepakov, V.N., Suprun, S.A. et al. (1983) Procedure of primary sanitary and hygienic evaluation of flux-cored wires. Kiev, PWI [in Russian].

11. (2011) DSTU EN ISO 14341:2010: Welding consumables. Wire electrodes and deposits for gas shielded metal arc welding of non alloy and fine grain steels. Classification. German version EN ISO 14341:2011 [in Ukrainian].

12. (2015) DSTU EN ISO 17632:2015 (EN ISO 17632:2008, IDT; ISO 17632:2004, IDT): Welding consumables. Tubular cored electrode for gas shielded and non-gas shielded metal arc welding of non alloy and fine grain steels. Classification. ISO Office, Switzerland [in Ukrainian].

13. (2005) DSTU EN ISO 18276: 2015 (EN ISO 18276:2006, IDT; ISO 18276:2006, IDT): Welding consumables. Tubular cored electrodes for gas shielded and non-gas shielded metal arc welding of high-strength steels. Classification. ISO Office, Switzerland [in Ukrainian].

14. (2010) DSTU EN ISO 14175:2014 (EN ISO 14175:2008, IDT): Welding consumables. Shielding gases for arc welding and cutting. ISO Office, Switzerland [in Ukrainian].

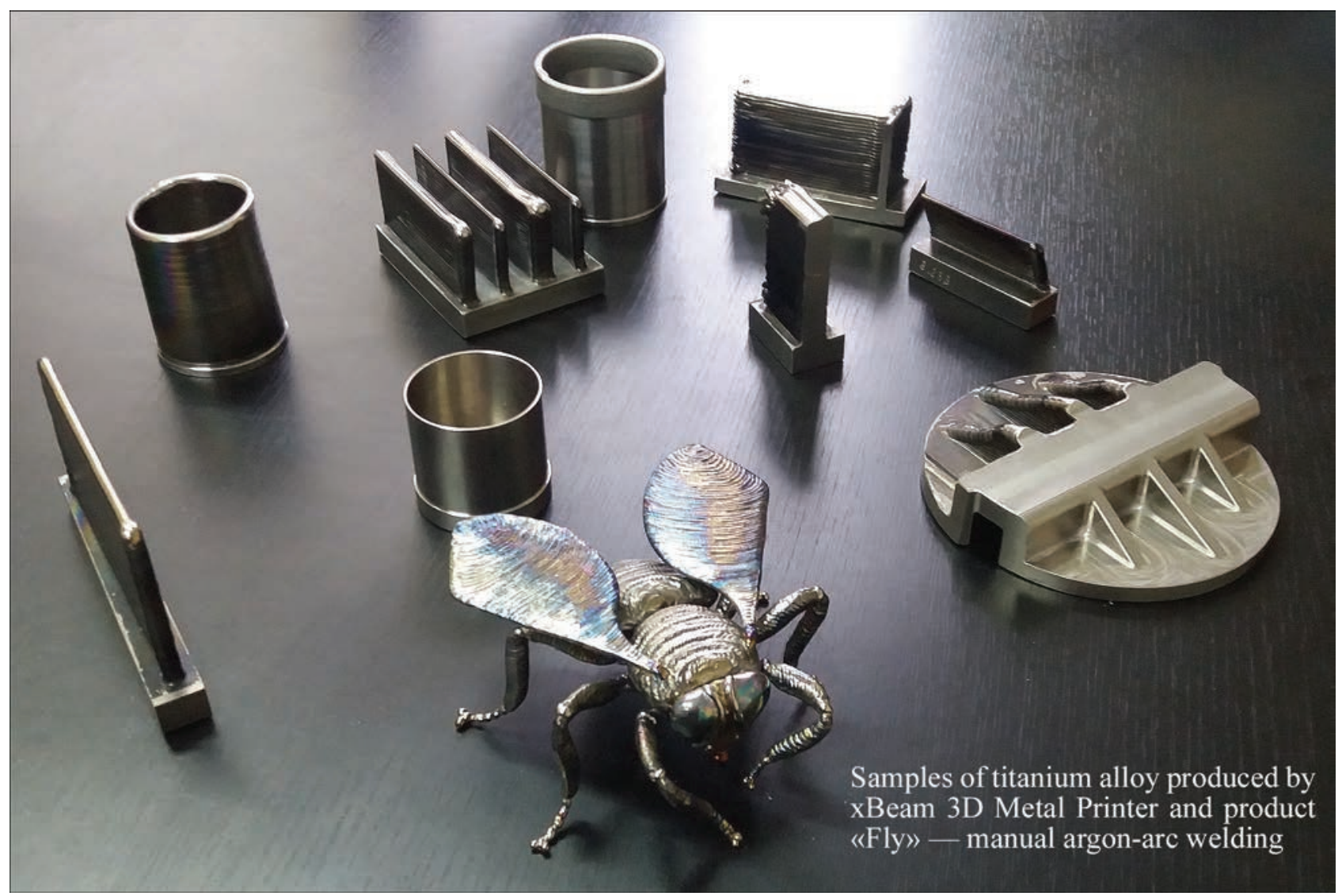




\title{
FILLER FLUX-CORED WIRE FOR TIG WELDING AND SURFACING OF VT22 TITANIUM ALLOY
}

\author{
S.V. AKHONIN and S.L. SCHWAB
}

E.O. Paton Electric Welding Institute of the NAS of Ukraine

11 Kazimir Malevich Str., 03150, Kyiv, Ukraine. E-mail: office@paton.kiev.ua

\begin{abstract}
The paper considers an approach for selection of filler material in TIG welding of VT22 titanium alloy. It is shown that weld metal produced using pilot flux-cored wire PPT-22 is a representative of transient class of titanium alloys, to which VT22 alloy is referred (coefficient of $\beta$-stabilizing of such metal equals to 1 ). This wire can be used for argon-arc welding of high-strength VT22 titanium alloys. Mechanical properties of such welded joints after heat treatment reach the level of base metal indices. Application of PPT-22 wire in restoration argon-arc surfacing of VT22 alloy parts provides their high service characteristics. 15 Ref., 4 Tables, 5 Figures.
\end{abstract}

Keywords : VT22 titanium alloy, flux-cored wire, TIG welding, restoration surfacing

Mechanical characteristics of welded joints of highstrength titanium alloys, in particular of the VT22 alloy, are significantly lower than those of base metal. Therefore, to compensate a low strength and ductility of weld metal, the designed thickening of metal in the weld zone is used. This in turn leads to a significant increase in material consumption and cost of welded products. Therefore, the producing of welded joint of equal strength is an urgent task.

Due to the nature of effect of different alloying elements on titanium, the commercial alloys are divided by the type of structure into the following groups: $\alpha$-alloys, pseudo- $\alpha$-alloys (alloys based on $\alpha$-phase with a small amount of $\beta$-phase $),(\alpha+\beta)$-alloys, pseudo- $\beta$-alloys (alloys based on the $\beta$-phase with a small amount of $\alpha$-phase) and $\beta$-alloys. The authors of works $[1,2]$ also distinguish alloys of a transition class, which according to the structure and transformations occurring in them, occupy an intermediate position between $(\alpha+\beta)$ - and pseudo- $\beta$-alloys, to which the VT22 alloy belongs (Table 1).

For titanium alloys $[1,2]$, a conception about the $\beta$-stabilizing factor $K_{\beta}$ was introduced. This coefficient represents a sum of relations of the concentration of each $\beta$-stabilizer in the alloy to its second critical concentration in a binary titanium alloy with this element [3].

When describing the multicomponent titanium alloys, it is assumed that the effect of all $\beta$-stabilizers can be expressed by the total equivalent content of molybdenum $[\mathrm{Mo}]_{\mathrm{eq}}$. Based on the data of works [46], the authors of the work [3] expressed the following relation for evaluating the equivalent of titanium alloys by molybdenum, wt. $\%$ :

$$
\begin{aligned}
& {[\mathrm{Mo}]_{\mathrm{eq}}=\mathrm{Mo}+\mathrm{Ta} / 4+\mathrm{Nb} / 3.3+\mathrm{W} / 2+} \\
& +\mathrm{V} / 1.4+\mathrm{Cr} / 0.6+\mathrm{Ni} / 0.8+\mathrm{Mn} / 0.6+\mathrm{Fe} / 0 .
\end{aligned}
$$

and the coefficient of $\beta$-stabilization is determined by the formula:

$$
K_{\beta}=[\mathrm{Mo}]_{\mathrm{eq}} / \mathrm{C}_{\mathrm{cr} \mathrm{Mo}}=[\mathrm{Mo}]_{\mathrm{eq}} / 11 .
$$

where $\mathrm{C}_{\mathrm{cr} \mathrm{Mo}}$ is the critical concentration of Mo in the binary titanium alloy with it and is equal to $11 \%$.

According to the type of structure ( $\beta$-stabilization coefficient), titanium alloys are distributed in the succession, presented in Table $2[1,7,8]$.

For today, there is a number of wires based on titanium, which are manufactured by industry. Solid wires on the base of titanium with an ultimate strength of more than $800 \mathrm{MPa}$ (Table 3) do not provide a

Table 1. Chemical composition of VT22 titanium alloy, wt.\% (GOST 19807-91)

\begin{tabular}{|c|c|c|c|c|c|c|c|c|}
\hline $\mathrm{Ti}$ & $\mathrm{Al}$ & $\mathrm{V}$ & $\mathrm{Mo}$ & $\mathrm{Fe}$ & $\mathrm{Cr}$ & {$[\mathrm{O}]$} & {$[\mathrm{H}]$} & {$[\mathrm{N}]$} \\
\hline Base & $4.4-5.7$ & $4.0-5.5$ & $4.0-5.5$ & $0.5-1.5$ & $0.5-2.0$ & Not more than 0.18 & Not more than 0.015 & Not more than 0.05 \\
\hline
\end{tabular}

Table 2. Values of $\beta$-stabilization coefficient for titanium alloys

\begin{tabular}{|c|c|c|c|c|c|c|}
\hline $\begin{array}{c}\text { Classification } \\
\text { parameter }\end{array}$ & \multicolumn{9}{|c|}{ Class of titanium alloy } \\
\hline \multirow{2}{*}{$K_{\beta}$} & $\alpha-$ & Pseudo- $\alpha$ & $(\alpha+\beta)$ & Transition & Pseudo- $\beta$ & $\beta$ \\
\cline { 2 - 8 } & 0 & $<0.25$ & $0.3-0.9$ & $1.0-1.4$ & $1.5-2.4$ & $2.5-3.0$ \\
\hline
\end{tabular}


Table 3. Chemical composition and mechanical properties of titanium-based wires with an ultimate strength of higher than $800 \mathrm{MPa}$ (GOST 27265-87)

\begin{tabular}{|c|c|c|c|c|c|c|c|}
\hline \multirow{2}{*}{ Wire grade } & \multicolumn{9}{|c|}{ Content of alloying elements, wt.\% } & \multicolumn{2}{c|}{ Mechanical properties } \\
\cline { 2 - 8 } & $\mathrm{Al}$ & $\mathrm{Mn}$ & $\mathrm{Mo}$ & $\mathrm{V}$ & $\mathrm{Zr}$ & $\sigma_{\mathrm{t}}, \mathrm{MPa}$ & $\begin{array}{c}\delta, \% \\
\text { (not lower than) }\end{array}$ \\
\hline VT6sv & $3.5-4.5$ & - & - & $2.5-3.5$ & - & $665-865$ & 12 \\
\hline SPT-2 & $3.5-4.5$ & - & - & $2.5-3.5$ & $1-2$ & $645-845$ & 13 \\
\hline VT20-2sv & $3.5-4.5$ & - & $0.5-1.5$ & $0.5-1.5$ & $1-2$ & $635-835$ & 10 \\
\hline SP15 & $3.0-5.5$ & - & $2.0-3.5$ & $2.0-3.5$ & $1-2$ & Not lower than 735 & 10 \\
\hline
\end{tabular}

sufficient complex of mechanical properties during welding of VT22 titanium alloy. The welds produced by TIG welding with the use of wire SPT-2 do not provide the strength of a weld higher than $800 \mathrm{MPa}$ and, therefore, it cannot be used as a filler material for welding alloys with an ultimate strength of higher than $800 \mathrm{MPa}$. The closest to the VT22 alloy as to the chemical composition and mechanical properties is the wire SP15. However, the use of this wire as a filler material does not provide the equal strength of welded joints of VT22 titanium alloy.

Investigations of the quality of solid wire of the VT22 alloy allowed making the conclusions about the inappropriateness of its use in welding and surfacing due to a large number of defects both on its surface and inside the metal itself, which as a result causes contamination of the weld metal [9].

To solve the problem of welding high-strength titanium alloys, at the E.O. Paton Electric Welding Institute of the NAS of Ukraine a filler material based on the titanium alloy of the system $\mathrm{Ti}-\mathrm{Al}-\mathrm{V}-\mathrm{Mo}-\mathrm{Nb}-\mathrm{Zr}$ was proposed [10]. This invention represents a fluxcored wire containing a metallic component and a flux one, which contains fluorides of alkaline earth and rare earth elements in a ratio 2:1 and in the amount of 6-18 wt.\%, and the wire sheath is made of titanium.

The alloy proposed by the authors of the patent [10] (Table 4) is in the range of the chemical composition of the commercially produced alloy SP15 and differs from the VT22 alloy by a degree of alloying. In this regard, during the development of flux-cored wires for TIG welding of VT22 titanium alloy, the VT22 alloy was used as the metallic component of the wire core.

Table 4. Calculated content of alloying elements, wt.\%

\begin{tabular}{|c|c|c|c|}
\hline Element & $C_{\text {wire }} \%$ & $C_{\text {VT22 }},{ }^{*}{ }^{*}$ & $C_{\text {weld }} \%$ \\
\hline $\mathrm{Al}$ & 3.2 & 5.1 & 4.5 \\
\hline $\mathrm{Mo}$ & 2.9 & 4.8 & 4.2 \\
\hline $\mathrm{V}$ & 2.8 & 4.8 & 4.2 \\
\hline $\mathrm{Fe}$ & 0.4 & 1.0 & 0.8 \\
\hline $\mathrm{Cr}$ & 0.6 & 1.3 & 1.1 \\
\hline "Average value according to GOST 19807-91. \\
\hline
\end{tabular}

To determine the degree of alloying of the weld metal by the flux-cored wire, the following calculation formula was proposed:

$$
C_{\text {weld }}=K_{1} C_{\text {wire }}+K_{2} C_{\text {VT22. }}
$$

where $K_{1}, K_{2}$ are the coefficients of the share of alloying elements in the wire and in the VT22 alloy, respectively; $C_{\text {wire }}$ is the concentration of alloying elements in the wire; $C_{\mathrm{VT} 22}$ is the concentration of alloying elements in the VT22 alloy (average value).

During determination of the coefficients $K_{1}$ and $K_{2}$, the macrosection of the welded joint of the VT22 alloy with a thickness of $8 \mathrm{~mm}$ was used, on which the cross-sectional area of the weld metal and the metal in the groove was determined (Figure 1). Based on the ratio of the cross-sectional area of the weld to the area of the metal produced by the wire, the coefficients $K_{1}$ and $K_{2}$ are equal to the values 0.3 and 0.7 , respectively.

For the wire of a diameter of $3.0 \mathrm{~mm}$ with a filling coefficient of $64 \%$ (the share of the flux component with respect to the metal one amounts to $7 \%$ ), the sheath of pure titanium amounts to $36 \%$ with respect to the wire. At the same parameters of the wire, the amount of pure titanium in the metallic component of the VT22 alloy is $48 \%$, the volume of pure titanium in the wire is $83 \%$ and of the alloying elements in the wire is $10 \%$. Based on the ratio of the total amount of alloying elements in the VT22 alloy to the total amount of alloying elements in the wire, the amount of each alloying element in the wire with regard to the sheath of

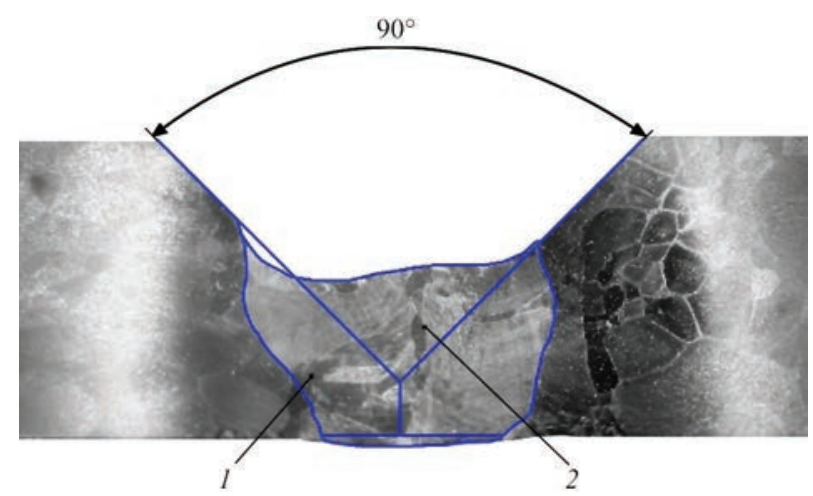

Figure 1. Macrosection of joint of VT22 alloy (after first pass), produced by experimental flux-cored wire: 1 - weld metal; 2 metal in the groove 


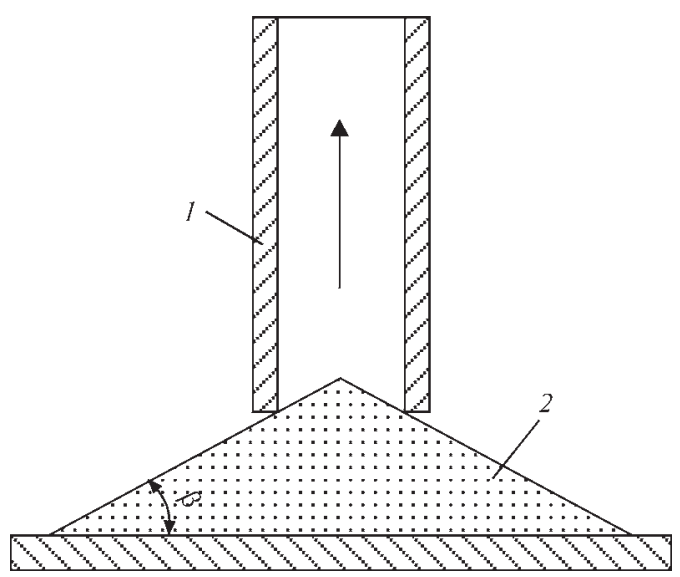

Figure 2. Scheme for determining natural angle of slope: 1 hollow cylinder; 2 - bulk mixture

pure titanium was determined by the calculation method. The obtained data on the amount of each alloying element allowed determining their concentration in the weld (Table 4), and also calculating the molybdenum equivalent $\left([\mathrm{Mo}]_{\mathrm{eq}}=11.1\right)$. The weld metal of a welded joint of VT22 titanium alloy produced using filler fluxcored wire, which includes the metallic component of the VT22 alloy, has a $\beta$-stabilization coefficient equal to 1 , which refers such a metal to the alloys of a transition class, to which VT22 titanium alloy belongs.

A similar calculation was also made for the wire, proposed by the authors of the patent [10], i.e. with a metallic component corresponding to the chemical composition of the alloy SP15, however, in this case $K_{\beta}=0.9$, which refers such a metal to the class of $(\alpha+$ $+\beta)$-titanium alloys.

Welded joints of high-strength titanium alloys should be obligatory subjected to heat treatment to increase their mechanical properties. Since the weld metal and the base metal in combination with the use of flux-cored wire with a charge of SP15 alloy are representatives of a different class, it is necessary to apply different heat treatment conditions for the weld metal and base metal, which is almost impossible to realize in practice. Therefore, as a metallic component in flux-cored wire it is advisable to use granules of the alloy of the same chemical composition as in the alloy subjected to welding, i.e. VT22.

An increased sliding of spherical granules along the length of the wire leads to their spilling and spattering during welding. This in turn has a significant effect on the process of arc burning, on the formation of a weld and its chemical composition. As was shown by the investigations, using the wire with granules of a spherical shape, the amount of alloying elements in the weld metal decreases by $2-3$ times. The spherical surface of granules also has a low adhesion to the flux introduced into the core.

In order to change the shape of granules, a complex of devices was developed. To evaluate the quality of flux-cored wire, the degree of granules deformation was investigated, which was determined by measuring the natural angle of a slope ( $\beta$ ) (Figure 2). For this purpose, the hopper was previously lowered until the contact with the plane and the mixture was poured into it. Then the hopper was lifted at a constant speed $(10 \mathrm{~m} / \mathrm{h})$, and the mixture, which was poured, formed a cone.

At certain modes, such a shape of granules $(\beta=$ $=30^{\circ}$ ) was achieved, at which they did not spill out of the formed tube (using granules of a spherical shape, where $\beta=20^{\circ}$.

In the experimental way the flux component of the wire was determined, which is represented by a three component system $\mathrm{CaF}_{2}-\mathrm{SrF}_{2}-\mathrm{BaF}_{2}$. To obtain the mechanical properties of the weld metal close to the base metal, it is necessary to have the maximum amount of metallic component and the minimum amount of flux component in the charge of a fluxcored wire. It was established experimentally that the use of a flux in the amount of $7 \%$ prevents the formation of pores in the weld, and the slag formed after welding, spalls off well.

As a sheath of the flux-cored wire, a strip of VT100 titanium alloy was used. The formation of flux-cored wire and its drawing to the required diameter was carried out in a special drawing bench [11] intended for manufacturing of titanium flux-cored wires (Figure 3).

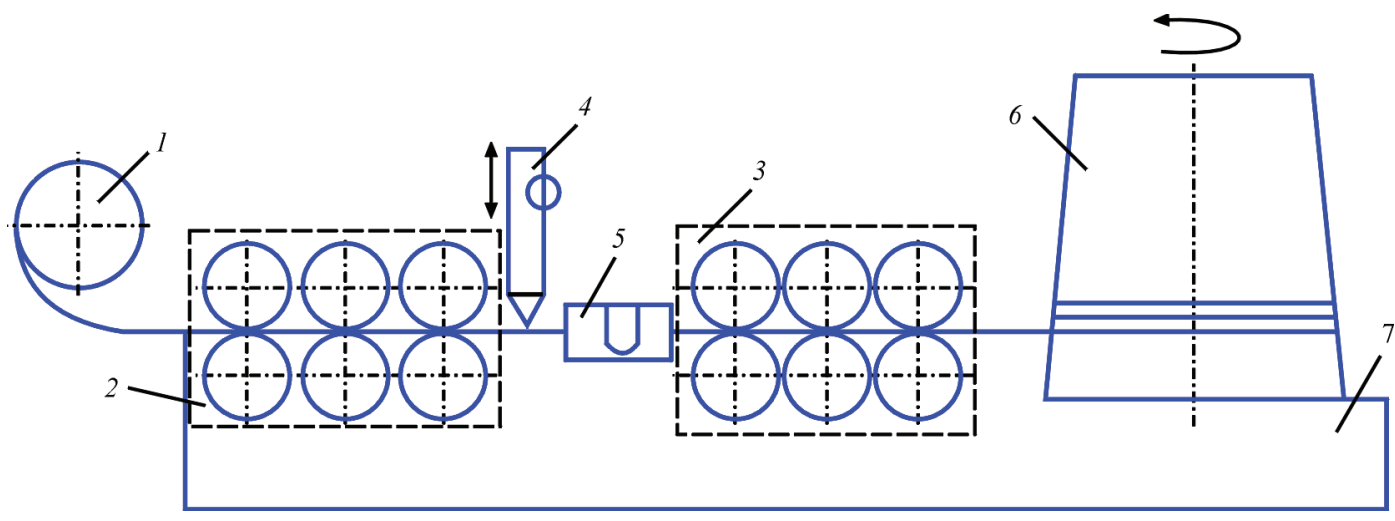

Figure 3. Scheme of drawing bench: 1 - cassette; 2 - roller stands for the formation of U-shaped profile; 3 — roller stands for closing the tubular profile and the primary compaction of the charge; 4 - batcher; 5 - U-shaped strap; 6 - drum; 7 - bed 


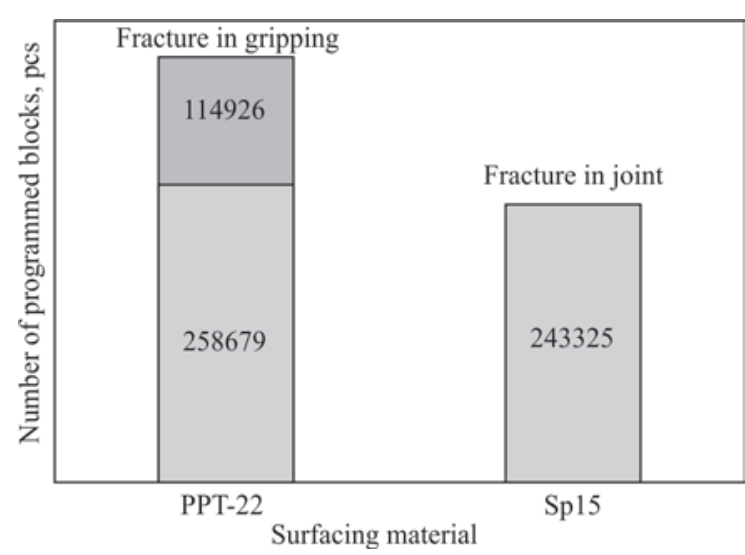

Figure 4. Test results of deposited joints for fatigue strength

According to the results of the experiments, a pilot flux-cored wire PPT-22 with a charge of optimized composition was manufactured. The measurements carried out along the entire length of the manufactured wire showed the constancy of the filling coefficient equal to $0.61 \pm 0.03$ at a wire diameter of $3.0 \mathrm{~mm}$.

The experimental surfacing using the produced wire showed a stable preceding of the welding process (without spilling of nonmelted granules), which indicated a sufficient compaction of the charge and its uniform distribution along the wire length.

The use of the wire PPT-22 as a filler material in MIAB welding of VT22 titanium alloy made it possible to produce welded joints of $8 \mathrm{~mm}$ thickness (after heat treatment) with the values of strength $\left(\sigma_{t}\right)$ and impact toughness $(\mathrm{KCV})$ of welded joint at the level of $1120 \mathrm{MPa}$ and $14.5 \mathrm{~J} / \mathrm{cm}^{2}$, respectively. These mechanical properties are close to those of the base metal $\left(\sigma_{\mathrm{t}}=1067 \mathrm{MPa}, K C V=14.5 \mathrm{~J} / \mathrm{cm}^{2}\right)[12]$.

The wire PPT-22 was also used as a filler material for argon-arc restoration surfacing of parts of the VT22 titanium alloy [13].

After surfacing and local heat treatment, fatigue strength tests were carried out. The test results showed [14] that using the flux-cored wire PPT-22, deposited joints withstood a full cycle of tests according to the preset programs and the fracture after additional cycles occurred at the place of gripping (Figure 4).

The test results of deposited joints for wear resistance under the conditions of fretting corrosion [15] also showed positive results. Thus, a linear wear of deposits, produced applying the wire PPT-22, is almost twice lower than that of the base metal of VT22 (Figure 5).

Thus, at the E.O. Paton Electric Welding Institute of the NAS of Ukraine a titanium filler flux-cored wire PPT-22 was developed, which consists of metallic (VT22 granules) and flux (alkaline earth metal fluoride elements) components, using which the same strength of welded joints of VT22 alloy is achieved during argon-arc welding and a subsequent heat treat-

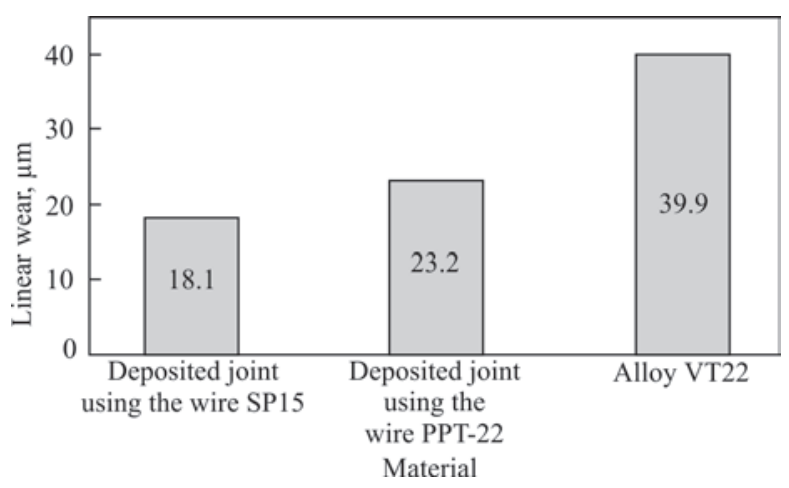

Figure 5. Test results of deposited joints for wear resistance

ment. It is also advisable to use this wire during restoration surfacing of parts made of VT22 alloy.

1. Moiseev, V.N. (2001) Machine-building: Encyclopedia. Vol. II-3: Nonferrous metals and alloys. Ed. by I.N. Fridlyander. Chapter 2: Titanium and titanium alloys [in Russian].

2. Belov, S.P., Brun, M.Ya., Glazunov, S.G. (1992) Metallurgy of titanium and its alloys. Ed. by S.G. Glazunov, B.A. Kolachev. Moscow, Metallurgiya [in Russian].

3. Iliin, A.A., Kolachev, B.A., Polkin, I.S. (2009) Titanium alloys. Composition, structure, properties. Moscow, VILS MATI [in Russian].

4. Chechulin, B.B., Ushkov, S.S., Razuvaeva, I.N., Goldfajn, V.N. (1977) Titanium alloys in machine-building. Leningrad, Mashinostroenie [in Russian].

5. Kolachev, B.A., Polkin, I.S., Talalaev, V.D. (2000) Titanium alloys of different countries. Moscow, VILS [in Russian].

6. Kolachev, B.A., Elagin, V.I., Livanov, V.A. (2005) Metallurgy and heat treatment of nonferrous metals and alloys. Moscow, MISIS [in Russian].

7. Borisova, E.A., Bochvar, G.A., Brun, M.Ya. (1980) Metallography of titanium alloys. Moscow, Metallurgiya [in Russian].

8. Khorev, A.I., Belov, S.P., Glazunov, S.G. (1992) Metallurgy of titanium and its alloys. Moscow, Metallurgiya [in Russian].

9. Prilutsky, V.P., Shvab, S.L., Akhonin, S.V. et al. (2014) Comparative properties of filler materials for surfacing on titanium alloy VT22. In: Proc. of Int. Conf. on Titanium 2014 in CIS (Russia, Nizhny Novgorod, May 2014), 109-114.

10. Prilutsky, V.P., Zamkov, V.M., Radkevich, I.A., Nikiforov, G.A. (1998) Filler material based on titanium alloy. Ukraine, Pat. 25333. Int. Cl. A B23K 35/36 [in Ukrainian].

11. Prilutsky, V.P., Zamkov, V.N., Gurevich, S.M. (1975) Argonarc welding of titanium alloys with application of filler fluxcored wire. Avtomatich. Svarka, 7, 41-44 [in Russian].

12. Prilutsky, V.P., Akhonin, S.V., Schwab, S.L., Petrychenko, I.K. (2018) Effect of heat treatment on the structure and properties of titanium alloy VT22 welded joints produced by TIG-welding with flux-cored wire. Mat. Sci. Forum, 927, 119-125.

13. Prilutsky, V.P., Akhonin, S.V., Schwab, S.L. et al. (2017) Restoration surfacing of parts of titanium alloy VT22. The Paton Welding J., 1, 32-35.

14. Antonyuk, S.L., Abolikhina, E.V., Barannikov, A.M. et al. (2010) Fatigue characteristics of titanium alloy VT22 with argon-arc surfacing and subsequent high-speed heat treatment. In: Proc. of Int. Conf. on Titanium-2010 in CIS (Russia, Ekaterinburg, May 2010), 206-211.

15. Ivasishin, O.M., Markovsky, P.E., Molyar, A.G., Antonyuk S.L (2009) Application of local induction heat treatment for repair of products from VT22 alloy. In: Proc. of Int. Conf. on Titanium-2009 in CIS (Ukraine, Odessa, May 2009), 413-421. 


\title{
EFFECT OF TEMPERATURE ON HARDNESS AND WEAR RESISTANCE OF HIGH-CHROMIUM CAST IRONS DEPOSITED WITH FLUX-CORED STRIPS
}

\author{
A.P. VORONCHUK, A.P. ZHUDRA, A.V. PETROV and V.O. KOCHURA \\ E.O. Paton Electric Welding Institute of the NAS of Ukraine \\ 11 Kazimir Malevich Str., 03150, Kyiv, Ukraine. E-mail: office@paton.kiev.ua
}

\begin{abstract}
The paper presents the procedure and results of investigation of hot hardness of the deposited high-chromium cast irons with different level of alloying of 450Kh30M, 500Kh22B7, 500Kh22B7M7V2F, 300Kh25S3N2G2 type, as well as nickel-chromium-carbide alloy 500Kh40N40S2GRTs. It is determined that hot hardness of deposited metal to a significant extent depends on the presence and types of carbides in metal structure. For relatively low-alloyed high-chromium cast irons, hardness drops at temperature rise and increases at the content of chromium up to $30 \%$ and that of carbon up to $5 \%$. Alloys doped with chromium, niobium, molybdenum, tungsten and vanadium preserve high hardness up to $650{ }^{\circ} \mathrm{C}$ temperature. Niobium is important for indicated alloys. It plays a role of modifier delaying growth of primary chromium carbides, and forming hard cubic niobium carbide. Nickel-chromium-carbide alloy preserves high hardness up to $650{ }^{\circ} \mathrm{C}$ temperature due to the presence of high concentration of higher chromium carbides in a nickel-based matrix. Wear resistance of deposited alloys decreases with the rise of temperature in accordance with lowering of deposited metal hardness. 12 Ref. 3 Tables, 3 Figures.
\end{abstract}

Keywords: hot hardness, flux-cored strips, surfacing, high-chromium cast irons, nickel-carbide-chromium alloy, wear resistance

A considerable number of parts of blast furnace, metallurgical, power and other equipment operate under the conditions of abrasive and gas-abrasive types of wear at elevated temperatures. Improvement of performance of such parts is achieved due to their strengthening by surfacing with different alloys, having high wear resistance in extreme conditions. High-chromium cast irons with the content of carbon up to $5 \%$ and of chromium from 10 up to $30 \%$ take the leading place among such alloys. Based on advertising information, a number of foreign companies tend to modify such alloys by their additional alloying and increasing their carbon content up to $6 \%$. These are alloys of the type of sormite $300 \mathrm{Kh} 25 \mathrm{~S} 3 \mathrm{~N} 2 \mathrm{G} 2$, as well as type $350 \mathrm{Kh} 10 \mathrm{M}, 350 \mathrm{Kh} 10 \mathrm{G} 3,500 \mathrm{Kh} 30 \mathrm{M}$, 500Kh30G2 and many others. Here, we should take into account the fact that increase of the degree of alloying and carbon content above $5 \%$ gives rise to problems of producing thick deposited layers. This is associated with the risk of deposited metal spallation at surfacing in more than two layers [1-3].

One of the important factors of successful performance of such alloys is preservation of high hardness at elevated temperatures. Investigations of the relationship between metal hot hardness and its alloying system are important. Correct selection of alloying components can greatly affect the deposited metal hardness at elevated temperatures and eventually, its wear resistance under real conditions. Given below are the results of studying the hot hardness of deposited alloys with different degree and system of alloying.

The following surfacing alloys of the type of high-chromium cast irons with different degree of alloying were selected for studying the high temperature hardness: 300Kh25S3N2G2, 450Kh30M, 500Kh22B7, 500Kh22B7M7V2F. These alloys are widely used for strengthening parts, operating under the conditions of abrasive and gas-abrasive kinds of wear at normal and elevated temperatures.

Also of interest is investigation of high-temperature hardness of nickel-chromium-carbide alloy 500Kh40N40S2GRTs, which was traditionally accepted for strengthening parts, operating under the conditions of gas-abrasive wear at elevated temperatures.

Investigation of hot hardness of the above alloys was conducted together with G.S. Pisarenko Institute for Problems of Strength of the NAS of Ukraine in UVT-2 unit [4], which is designed for determination of hardness of materials in the temperature range of $300-3300 \mathrm{~K}$ in vacuum or shielding gas atmosphere $[4,5]$.

A combination of inert atmosphere and vacuum allows measuring hardness of materials of different classes: pure metals, alloys and composite materials.

Hardness measurement instrument is the main part of UVT-2 unit. The instrument is a detachable steel vacuum chamber with cooled walls. The following main assemblies are mounted in the instrument chamber: heating system, indenter system, sample loading device, etc. 
The method of static pressing of the indenter in the form of a regular tetragonal pyramid with the angle of $136^{\circ}$ between the opposite faces $[5,6]$ is used for determination of material hardness in a broad temperature range.

By the method of static indentation of pyramidal indenter, the hardness value is determined as average pressure on the imprint area. Allowing for buckling, it acquires the meaning of average contact pressure:

$$
H V=\frac{P}{F}=\frac{2 P \sin \gamma}{b^{2}}=1.8544 \frac{P}{b^{2}}, \mathrm{MPa},
$$

where $P$ is the load on the sample, transmitted through the pyramidal indenter; $F$ is the surface area of pyramidal imprint, $\mathrm{mm}^{2} ; 2 \gamma$ is the angle between the opposite faces of the pyramid; $b$ is the arithmetical mean of the lengths of two imprint diagonals, $\mathrm{mm}$.

At pyramid indentation, geometrically similar imprints are produced. Therefore, at hardness measurement by this method, the condition of mechanical similarity is observed, and test results are independent on load magnitude $P$.

The load on the sample, transmitted through the pyramid, was assumed to be equal to $9.81 \mathrm{~N}$. Testing was conducted in vacuum at not higher pressure than $0.7 \mathrm{MPa}$.

Hardness values of the alloys were obtained in the temperature range of $290-1200 \mathrm{~K}$ with $50-100 \mathrm{~K}$ range for the rate of sample material deformation under the indenter of $10^{-3} \mathrm{~s}^{-1}$, which was determined by the procedure of [4]. The heating rate was equal to $20-40 \mathrm{~K} / \mathrm{min}$.

Before making the imprint, the sample and the indenter were placed at the distance of 1-2 $\mathrm{mm}$ one from the other and were heated up to the same temperature by radiation from strip tungsten heater.

The time of sample soaking at the specified temperature before making the first imprint was not less than:

- $10 \mathrm{~min}$ in the temperature range from 293 to $670 \mathrm{~K}$;

- $6 \mathrm{~min}$ in the temperature range from 670 up to $1070 \mathrm{~K}$.

The duration of soaking under load was $60 \mathrm{~s}$. Limit testing temperature depends on tip material.
Used as the indenter tip for hardness measurement was a single-crystal of synthetic corundum $\mathrm{Al}_{2} \mathrm{O}_{3}$ (leukosapphire), which performs well up to the temperature of $2033 \mathrm{~K}$. Indenters from boron carbide $\mathrm{B}_{4} \mathrm{C}$ and alloys on its base are used for hardness testing of refractory carbides up to $2273 \mathrm{~K}$.

The shape and dimensions of the sample were changed, in connection with the difficulty of machining the studied materials and geometrical features of the object of study. Samples for studying the deposited metal hardness, depending on temperature, were deposited in two layers. Surfacing of plates from St3 steel GOST 380-88 was performed in the modes optimum for each type of electrode material. All the types of surfacing materials were made in the form of fluxcored strips of $6.5 \times 4.0 \mathrm{~mm}$ section. Mechanical mixture of ferroalloys and chemical compounds of various elements was used as the core of flux-cored strips. Sample surfacing was performed with open arc.

After surfacing samples were cut out of the obtained blanks by mechanical method, and were ground to the required size. The surface of the sample, on which hardness measurements were conducted, was further polished.

Hardness measurements were conducted on three samples, then arithmetical mean was determined for each temperature.

Statistical processing of generalized experimental samples for hardness was performed. Here, average sample value $H V_{\text {av }}(x)$, sample standard deviation $S$, variation coefficient $w$ and confidence intervals $\Delta H V(\bar{x})$ for mathematical expectation for significance level $\alpha=$ $=0.05$ were calculated for each temperature [7].

Results, obtained when studying hot hardness of alloys of the type of high-chromium cast irons and nickel-chromium-carbide alloy are shown in Table 1. Hot hardness values are represented by just average values by the results of testing several samples. Figure 1 shows generalized data for all the studied alloys.

As is seen from the given results of investigations, the smallest drop of hardness with temperature rise is observed in $500 \mathrm{Kh} 22 \mathrm{~B} 7,500 \mathrm{Kh} 22 \mathrm{~B} 7 \mathrm{M} 7 \mathrm{~V} 2 \mathrm{~F}$ and

Table 1. Average hardness values $\left(H V_{\text {av }}, \mathrm{MPa}\right)$, depending on temperature

\begin{tabular}{|c|c|c|c|c|c|}
\hline \multirow{2}{*}{$T,{ }^{\circ} \mathrm{C}$} & \multicolumn{5}{|c|}{ Deposited metal type } \\
\cline { 2 - 6 } & $300 K h 25 \mathrm{~S} 3 \mathrm{~N} 2 \mathrm{G} 2$ & $450 \mathrm{Kh} 2230 \mathrm{M}$ & 500 Kh22B7 & 500 Kh22B7M7V2F & 500 Kh40N40S2GRTs \\
\hline 25 & 5793 & 7120 & 7561 & 7986 & 6960 \\
\hline 100 & 4704 & 5546 & 5983 & 6145 & 5953 \\
\hline 200 & 4143 & 4865 & 5473 & 5567 & 5250 \\
\hline 300 & 3067 & 4506 & 5345 & 5545 & 5096 \\
\hline 400 & 2450 & 3327 & 5054 & 5605 & 4956 \\
\hline 500 & 1349 & 2231 & 4436 & 5134 & 3748 \\
\hline 600 & 709 & 1321 & 3056 & 4789 & 3756 \\
\hline 700 & 317 & 978 & 1243 & 2643 & 1878 \\
\hline 800 & 256 & 346 & 521 & 1137 & 975 \\
\hline 900 & 229 & 287 & 387 & 527 & 345 \\
\hline
\end{tabular}




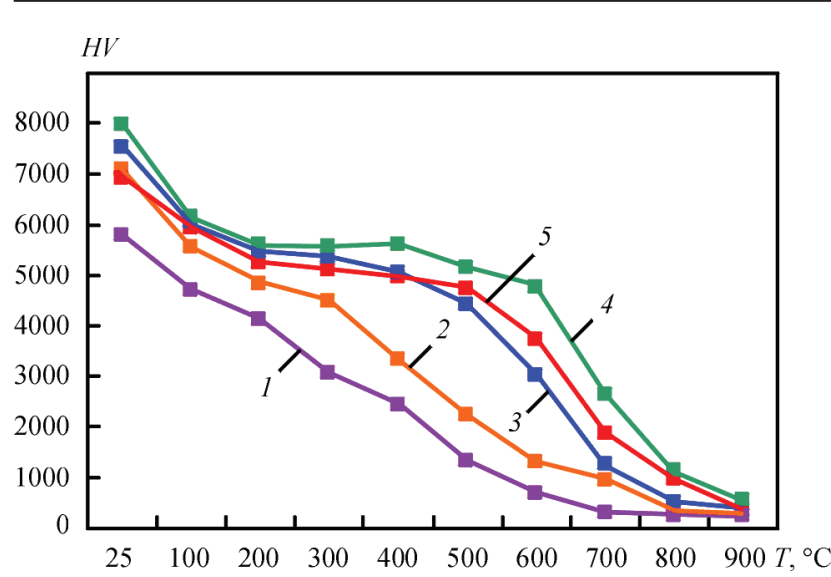

Figure 1. Hardness of alloys of the type of high-chromium cast irons $(1-300 \mathrm{Kh} 25 \mathrm{~S} 3 \mathrm{~N} 2 \mathrm{G} 2 ; 2-450 \mathrm{Kh} 30 \mathrm{M} ; 3-500 \mathrm{Kh} 22 \mathrm{~B} 7$; $4-500 \mathrm{Kh} 22 \mathrm{~B} 7 \mathrm{MV} 2 \mathrm{~F} ; 5-500 \mathrm{Kh} 40 \mathrm{~N} 40 \mathrm{~S} 2 \mathrm{GRTs}$ )

500Kh40N40S2GRTs alloys. The most abrupt hardness drop is observed in 300Kh25S3N2G2 alloy. 450Kh30M alloy takes an intermediate position.

Analysis of the obtained results revealed that hardness of the deposited metal at elevated temperatures largely depends on the type of carbides, formed as a result of weld pool solidification. It was found that in alloys of high-chromium cast irons of 300Kh25S3N2G2 type deposited metal hardness drops abruptly with temperature rise. Microstructure of such an alloy is shown in Figure 2, a. At increase of chromium content to $30 \%$ and of carbon to $5 \%$ stabilization of hardness up to temperatures of $350-400{ }^{\circ} \mathrm{C}$ is observed. This is attributable to presence of higher chromium carbides of $\mathrm{Cr}_{3} \mathrm{C}_{2}$ type in such alloys. Characteristic microstructure of this type of alloys is shown in Figure 2, $b$. As is known $[8,9]$, such carbides have higher melting temperature, are less prone to oxidation, and preserve their mechanical properties at higher temperatures.
An even greater increase of hot hardness is achieved at complex doping of the alloys by chromium, niobium, molybdenum, tungsten and vanadium, the microstructure of which is shown in Figure 2, c. Such alloys preserve their hardness up to temperatures of about $650{ }^{\circ} \mathrm{C}$. Alloys doped by just chromium and niobium, take up an intermediate position (Figure 2, d). Nickel-chromium-carbide alloy also demonstrated a high hot hardness (Figure 2,e).

A combination of high concentration of higher chromium carbides with a nickel-based matrix also allows maintaining stable hardness up to $650{ }^{\circ} \mathrm{C}$.

Effect of niobium is of special interest in alloys of 500Kh22B7 and 500Kh22B7M7V2F type. Structure of such alloys, deposited on low-carbon steel, consists of austenite with chromium and niobium carbide phases (Figure 2, c, d).

In this case niobium plays the role of a sort of modifier, as alloying of high-chromium cast iron by niobium delays the growth of primary chromium carbides $(\mathrm{Cr}, \mathrm{Fe})_{7} \mathrm{C}_{3}$, the coarse needles of which are fragmented at wear, and can readily become exposed and crumble out. The authors of [10] give the results of investigation of wear of alloys of the type of high-chromium cast irons without niobium, with niobium and those additionally alloyed by $\mathrm{Nb}, \mathrm{Mo}, \mathrm{W}$.

$\mathrm{X}$-Ray structural analysis of these materials showed the presence of carbides of $\mathrm{Me}_{7} \mathrm{C}_{3}$ type and solid carbides $(\mathrm{Nb}, \mathrm{Mo}, \mathrm{W}, \mathrm{V}) \mathrm{C}$ and $(\mathrm{Mo}, \mathrm{W})_{2} \mathrm{C}$. Performed heat treatment of these alloys $(T=923 \mathrm{~K}, 1 \mathrm{~h}$, cooling in air) and subsequent testing showed that wear resistance of alloys of the type of high-chromium cast irons, doped by $\mathrm{Nb}, \mathrm{Mo}, \mathrm{W}$ and $\mathrm{V}$, became higher, that is accounted for by secondary strengthening, associated with additional carbide precipitation.

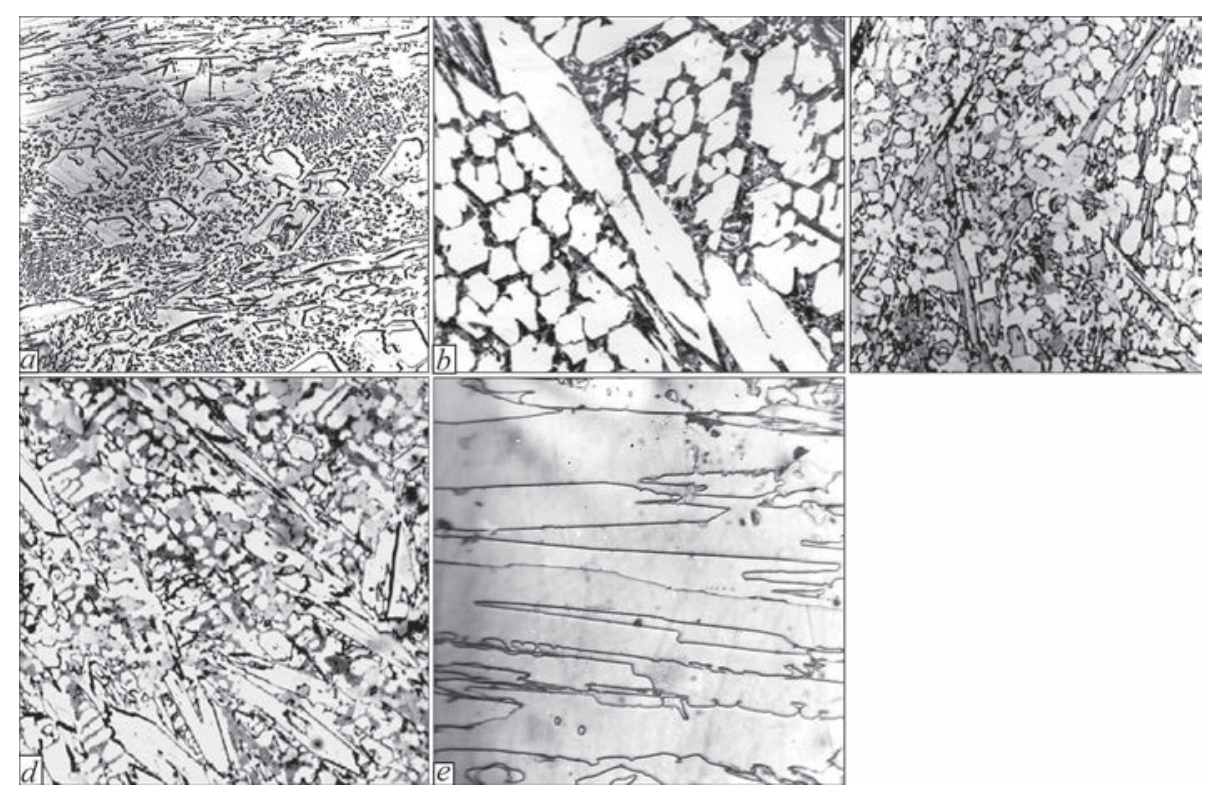

Figure 2. Microstructure $(\times 350)$ of alloys of the following types: $300 \mathrm{Kh} 25 \mathrm{~S} 3 \mathrm{~N} 2 \mathrm{G} 2(a)$; 450Kh30M (b); 500Kh22B7M7B2F (c); $500 \mathrm{Kh} 22 \mathrm{~B} 7(d) ; 500 \mathrm{Kh} 40 \mathrm{~N} 40 \mathrm{~S} 2 \mathrm{GRTs}(e)$ 
Investigations of the microstructure and composition of the carbide phase of $500 \mathrm{Kh} 22 \mathrm{~B} 7 \mathrm{M} 7 \mathrm{~V} 2 \mathrm{~F}$ and $500 \mathrm{Kh} 22 \mathrm{~V} 7$ alloys show that the main amount of carbides are represented by mixed $\mathrm{Me}_{7} \mathrm{C}_{3}$ carbide, rich in chromium. Its volume fraction in the given alloys is practically the same and equal to $40-43 \%$. The fraction of harder cubic niobium carbide of $\mathrm{NbC}$ type is equal to about 8 and $10 \%$ for these alloys, respectively.

Molybdenum and tungsten do not form their own carbides. These elements are almost completely dissolved in the matrix that leads to increase of alloy high-temperature strength, and accounts for their high wear resistance at elevated temperatures. Niobium, having a higher affinity to carbon, than chromium, molybdenum or tungsten, promotes formation of hard, fine, uniformly distributed niobium carbides of a globular shape in alloys of 500Kh22B7MV2F type, that are responsible for higher viscosity and good resistance to impact loads in operation [11].

Thus, niobium is added to surfacing materials to increase the impact toughness of chromium cast irons, and metal wear resistance under the conditions of abrasive wear with shocks and improvement of hot hardness.

Conducted studies of hardness of surfacing high-chromium alloys at elevated temperatures allow optimizing selection of electrode materials for strengthening by surfacing a wide range of parts, operating in extreme conditions of wear at different temperatures.

Investigations of the relationship between hot hardness and wear resistance under the conditions of gas abrasive wear at elevated temperatures are of interest.

Samples of deposited metal of the following types: 300Kh22S3N2G2 (PLAN 101), 450Kh22B7M7V2F (PLAN 179), 450Kh30M (PLAN 180), 500Kh22B7 (PLAN 185), 500Kh40N40S2GRTs (PLAN 111) were made using appropriate flux-cored strips for comparative testing for wear resistance.

Surfacing was performed in A-874N unit, fitted with VDU-1201 power source and AD-167 attachment. The process was conducted in two layers at reverse polarity direct current, at unchanged value of extension equal to $50 \mathrm{~mm}$, and flat external characteristic of the power

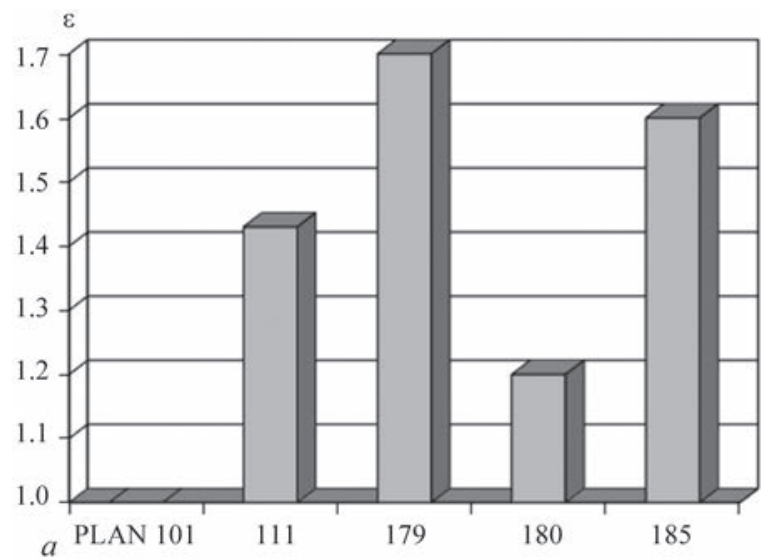

source. Used as the base metal were plates from St3 steel $30 \mathrm{~mm}$ thick of $300 \times 400 \mathrm{~mm}$ size. Anode-mechanical cutting was used to cut out samples of the required size from middle sections of the beads. Modes of surfacing with all the given strips were as follows:

Current, A . . . . . . . . . . . . . . . . . 750-850

Voltage, V . . . . . . . . . . . . . . . . . . . . . 28 28-34

Electrode movement speed, $\mathrm{m} / \mathrm{h} \ldots \ldots \ldots \ldots \ldots \ldots . . \ldots 33.1$

Electrode extension, $\mathrm{mm} \ldots \ldots \ldots \ldots \ldots \ldots$. 50 . . . . . . . . .

Investigations of wear resistance were conducted in an upgraded stand OB-876Ts [12]. The stand provides a scheme of testing by the type of abrasive flow impact, which is as close as possible to the real conditions of strengthened parts operation.

In the stand abrasive particles are accelerated by a centrifugal accelerator in the form of a disc-rotor, in the center of which abrasive is gravity fed into the feed opening (in our case, it is quartz sand).

Sand particles are accelerated through four inner channels. Having reached the rotor outer diameter, the abrasive flow covers the air gap $25 \mathrm{~mm}$ long and produces simultaneous wear of working surfaces of six samples of $170 \times 70 \times 19 \mathrm{~mm}$ size, due to impact of abrasive particles. Cassette with the samples is located in the chamber, the temperature of which is adjustable in the range from 25 up to $450{ }^{\circ} \mathrm{C}$.

\section{Technical characteristics of OB-876Ts stand}

Rotor diameter, mm . . . . . . . . . . . . . . 220

Number of rotor revolutions, rpms . . . . . . . . . . 6000 Angle of attack of abrasive flow, deg . . . . . . . . . 5-70 Sample heating temperature, ${ }^{\circ} \mathrm{C} \ldots \ldots \ldots \ldots$ up to 450 Duration of sample heating up to $400{ }^{\circ} \mathrm{C}, \mathrm{h} \ldots \ldots \ldots \ldots . .5$

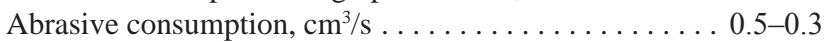
Power of rotor drive electric motor, $\mathrm{kW} \ldots \ldots \ldots \ldots \ldots . \ldots . \ldots$ Quantity of tested samples, pcs $\ldots \ldots \ldots \ldots \ldots \ldots \ldots$

Testing was conducted at temperatures of 25 and $450^{\circ} \mathrm{C}$. Quartz sand was used as abrasive.

Assessment of wear resistance was performed by the mass method. Difference in mass before and after testing was determined for each sample. In order to obtain more valid results, three samples of each type of metal were

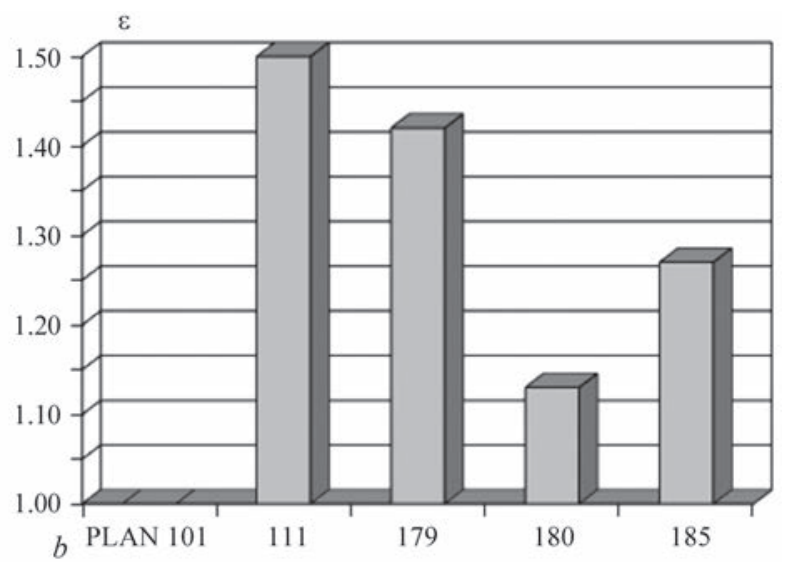

Figure 3. Relative wear resistance of the studied samples at room temperature (a) and at temperatures of $450-500{ }^{\circ} \mathrm{C}(b)$ 
Table 2. Relative wear resistance at room temperature

\begin{tabular}{|c|c|}
\hline Deposited metal type & Relative wear resistance $\varepsilon$ \\
\hline 300Kh22S3N2G2 & 1 \\
\hline 500KhX40N40S2GRTs & 1.43 \\
\hline 500Kh22B7M7V2F & 1.7 \\
\hline 450Kh30M & 1.2 \\
\hline 450Kh22B7 & 1.6 \\
\hline 250Kh10B8S2T & 1.35 \\
\hline
\end{tabular}

tested, which was followed by determination of average values. Assessment was based on relative wear resistance $\varepsilon$, which was calculated by the following formula:

$$
\varepsilon=\frac{\Delta m_{e}}{\Delta m_{n}},
$$

where $\Delta m_{e}$ is the standard mass loss; $\Delta m_{n}$ is the loss of tested sample weight.

$300 \mathrm{Kh} 22 \mathrm{~S} 3 \mathrm{~N} 2 \mathrm{G} 2$ alloy (sormite-1) was used as standard.

Results of studying the samples are shown in Tables 2, 3, as well as in Figure 3.

Thus, comparing the data, obtained under different temperature conditions, it was determined that wear resistance of the alloys drops with temperature rise, that correlates with the hot hardness data. It should be also noted that steel-based alloys, have a higher tendency to lowering of their wear resistance properties at temperature rise, than does nickel-chromium-carbide alloy. The most probable explanation for it, in our opinion, is the fact that testing was conducted under standard atmospheric conditions. Here, degradation of performance occurs not only due to hardness lowering, but also due to oxidation processes, which run on the deposited layer surface.

\section{Conclusions}

1. For alloys of $300 \mathrm{Kh} 25 \mathrm{~S} 3 \mathrm{~N} 2 \mathrm{G} 2$ type with relatively low alloying by carbide-forming elements, deposited metal hardness drops abruptly with temperature rise. Increase of chromium content to $30 \%$ and of carbon to $5 \%$ allows stabilizing rather high hardness up to temperatures of $350-400{ }^{\circ} \mathrm{C}$, as a result of formation of higher chromium carbides of $\mathrm{Cr}_{3} \mathrm{C}_{2}$.

2. Nickel-chromium carbide alloy $500 \mathrm{Kh} 40 \mathrm{~N} 40 \mathrm{~S}$ 2GRTs preserves a high hardness right up to the temperature of $650{ }^{\circ} \mathrm{C}$, due to a combination of a high concentration of higher chromium carbides with nickel-based matrix.

3. At complex doping of alloys by chromium, niobium, molybdenum, tungsten and vanadium, alloys of 500Kh22B7M7V2F type preserve a high hardness up to the temperature of $650{ }^{\circ} \mathrm{C}$.
Table 3. Relative wear resistance at temperatures of $450-500{ }^{\circ} \mathrm{C}$

\begin{tabular}{|c|c|}
\hline Deposited metal type & Relative wear resistance \\
\hline 300Kh22S3N2G2 & 37,735 \\
\hline 500Kh40N40S2GRTs & 1.5 \\
\hline 500Kh22B7M7V2F & 1.42 \\
\hline 450Kh30M & 1.13 \\
\hline 450Kh22B7 & 1.27 \\
\hline 250Kh10B8S2T & 1.1 \\
\hline
\end{tabular}

4. For $500 \mathrm{Kh} 22 \mathrm{~B} 7$ and $500 \mathrm{Kh} 22 \mathrm{~B} 7 \mathrm{M} 7 \mathrm{~V} 2 \mathrm{~F}$ alloys, an important role is played by niobium, which is a sort of modifier, delaying the growth of primary chromium carbide $(\mathrm{CrFe})_{7} \mathrm{C}_{3}$ and forming hard cubic niobium carbide of $\mathrm{NbC}$ type.

5. Wear resistance of deposited alloys drops with temperature rise, in keeping with the drop of deposited metal hardness.

6. Drop of wear resistance of iron-based alloys with temperature rise runs somewhat more intensively, than that of nickel-chromium-carbide alloy that is obviously associated with oxidizing processes on the strengthened layer surface.

1. (1978) Welding in machine-building: Refer. book, 4 Vol. Ed. by A.I. Akulov. Moscow, Mashinostroenie, Vol. 2 [in Russian].

2. Zhudra, A.P., Voronchuk, A.P. (2012) Cladding flux-cored strips (Review). The Paton Welding J., 1, 34-38.

3. Ryabtsev, I.A., Senchenkov, I.K., Turyk, E.V. (2015) Surfacing, materials, technologies, mathematical modeling. Wydawnictwo politechniki slaskiej, Gliwice, 362-365, 398-406 [in Polish].

4. Aleksyuk, M.M., Borisenko, V.A., Krashchenko, V.P. (1980) Mechanical tests at high temperatures. Kiev, Naukova Dumka [in Russian].

5. Borisenko, V.O., Oksametnaya, O.B. (1994) DSTU 2434-94: Calculations and strength tests. Method of determination of high-temperature hardness by indentation of pyramidal and bicylindrical indentor. Kiev, Gosstandart Ukrainy [in Russian].

6. Borisenko, V.A. (1975) General regularities in change of mechanical properties of refractory materials depending on temperature. Information 1. Problemy Prochnosti, 8, 58-63 [in Russian].

7. Rumshinsky, L.Z. (1971) Mathematical processing of results of experiment. Moscow, Nauka [in Russian].

8. Khansen, M., Anderko, K. (1962) Structures of binary alloys. Vol. 1, 2. Moscow, Metallurgizdat [in Russian].

9. Ivanko, A.A. (1968) Hardness. Kiev, Naukova Dumka [in Russian].

10. Gallo, C., Hubert, M. (1980) Soudage et Techniques Connexes, 34(11, 12), 371-386.

11. Schramm, H. (1984) Chrom-Niob-legierte Hartlegierungen fuer das Auftragschweissen. Ind.-Anz., 86, 75 [in German].

12. Zhudra, A.P. (2014) Investigation of wear resistance of composite alloys under the conditions of gas-abrasive wear at elevated temperatures. The Paton Welding J., 11, 28-31. 


\title{
APPLICATION OF CHIPS OF STEEL 5KhNM IN ELECTROSLAG SURFACING OF DIES IN CURRENT-CONDUCTING MOLD
}

\author{
Yu.M. KUSKOV, O.G. KUZMENKO and I.P. LENTYUGOV \\ E.O. Paton Electric Welding Institute of the NAS of Ukraine \\ 11 Kazimir Malevich Str., 03150, Kyiv, Ukraine. E-mail: office@paton.kiev.ua
}

\begin{abstract}
Different methods for melting chips during electroslag process are considered. For electroslag surfacing of dies, chips of a tool steel were used as a discrete surfacing material in combination with a special device for melting of filler and formation of deposited layer, which is the current-conducting mold. The results of surfacing the press dies with chips of steel $5 \mathrm{KhNM}$ are presented. The prospects of the proposed technology for renovation of dies from the point of view of producing high-quality die with a relatively low power consumption during surfacing are shown. 9 Ref., 5 Figures.
\end{abstract}

Keywords : chips of a tool steel, electroslag surfacing, dies, current-conducting mold

Extensive development of die stamping and pressing as economy methods of production of parts and necessity of hot deforming of increased strength materials required development of steels of different composition and differentiation of the areas of their application (groups) [1]. These are steels of increased toughness, namely semi-heat-resistant $(5 \mathrm{KhNM}, 5 \mathrm{KhNV}$, $5 \mathrm{Kh} 2 \mathrm{NMF}$, 4KhMFS etc.), moderate heat resistance (4Kh3MVF, 4Kh3VMS etc.), increased heat resistance (4Kh5MFS, 4Kh4VMFS, 5Kh3V3MFS, 4Kh$2 \mathrm{~V} 5 \mathrm{MF}, 3 \mathrm{Kh} 2 \mathrm{~V} 8 \mathrm{~F}$, etc.), high heat resistance (2Kh6V8M2K7, 2Kh5V5M2K5, 2Kh12V8K10, etc.).

Today steel $5 \mathrm{KhNM}$ is most widely used (mainly for forging dies) from all the variety of steels. Simplicity of its composition and relatively low price assisted this. Moreover, it started to be used as universal material for different groups of tools.

In this case it is possible to see the analogy with high-speed steels. Among the large range of these steels R6M5 steel got the widest distribution. Such «narrowing» of number of used grades of tool steels, on the one hand, reduces resistance of tool of separate designation groups and, on the other hand, simplifies collection of chips appearing at this treatment.

According to data of work [2] in 2017 in Ukraine $60107.9 \mathrm{t}$ of chips of steels of different designation and composition were formed at lathe turning and other types of machining. If to assume that at least $10 \%$ of this amount of formed chips is the tool steel chips, than it is sufficiently large stock for the case of appearance of possibility for usageing such wastes as surfacing material. Particularly, it is necessary to note in comparison with production of surfacing materials by Ukrainian enterprises in 2016. For example, there were manufactured around 2 thou $t$ of alloyed welding wire and around 0.5 thou t of flux-cored [3] one.

(c) Yu.M. KUSKOV, O.G. KUZMENKO and I.P. LENTYUGOV, 2019
The most widespread method of recycling of chips is its partial remelting in arc, induction and other types of furnaces in form of additional filler in metal melting. The rest of chips are stored in dumps deteriorating ecological situation at enterprises producing them as well as in whole in corresponding regions. At that it is necessary to take into account that at long-term storage they significantly oxidize; during transporting part of chips is lost and there is mixing of different their types; during remelting in metallurgical units content of alloying elements significantly drops.

Taking into account such evaluation of situation with chips processing existing today, it should be recognized that the most reasonable method of chips conversion is their transformation into liquid metal with the help of electroslag process. At that, they, on the one side, are purified passing in melting through refining slag and, on the other side, when providing their regulated addition into a slag pool it is possible to reach high quality of metal being crystallized. This in particular takes place using the chips in form of discrete filler in electroslag surfacing (ESS).

Of course, not all available chips of tool steel can be used in the initial state as surfacing material in ESS. Curling chips are not good for surfacing as well as chips containing cooling mixture $(\mathrm{CM})$. In this case, such chips should be subjected to additional technological operations for making them in correspondence with necessary technical conditions (crushing, cleaning with chemical agents, heat treatment) [4].

Three schemes of performance of electroslag process in water-cooled mold using filler material in form of chips have found practical application.

First of them assumes application of nonconsumable electrodes, usually graphitized, in ESS of dies. They are used in heating of surface being deposited, billet or worn die $[5,6]$. After melting of base metal 


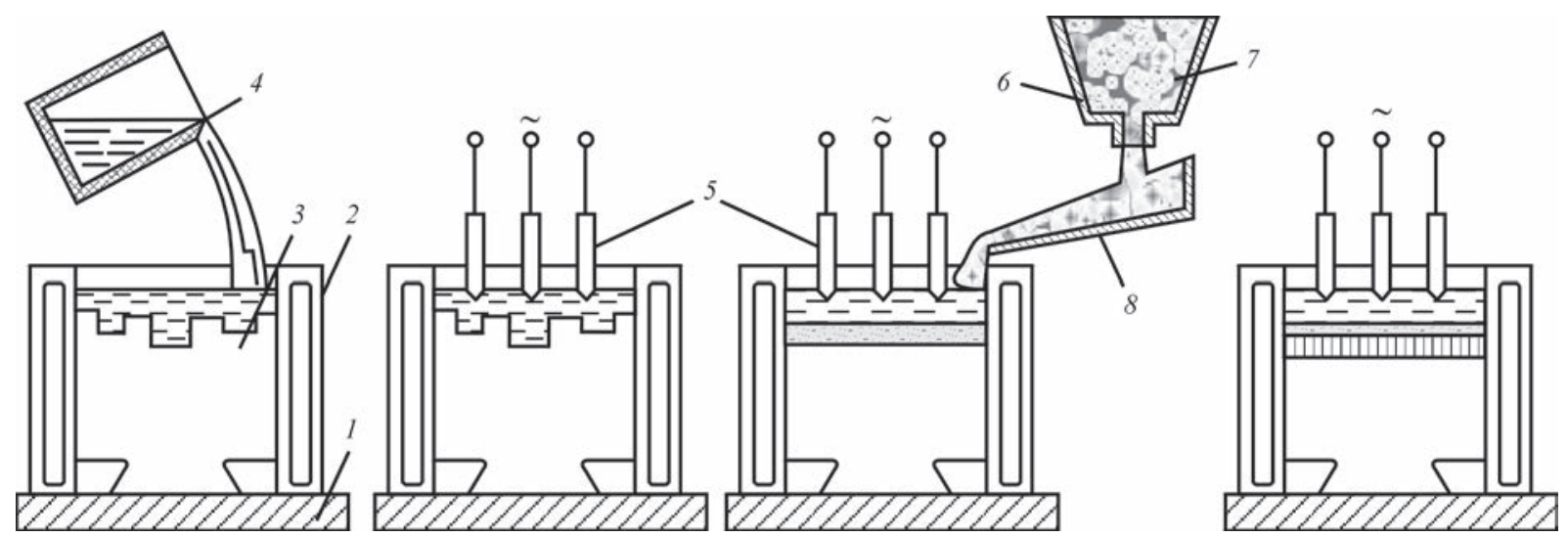

Figure 1. Scheme of electroslag surfacing of worn dies using chips of die steel as filler: 1 — bottom plate; 2 — fixed mold; 3 — worn die; 4 — ladle with liquid slag; 5 — nonconsumable electrodes; 6 - tank for filler material; 7 - filler material; 8 — channel

surface the slag pool is filled with chips of die steel, which in melting form deposited layer (Figure 1).

The next was determined under commercial conditions at supply of chips of 5KhNM steel, application of flux AN-15M and three-phase scheme of current connection to slag pool. Surfacing of press dies of $400 \times 260 \mathrm{~mm}$ size shall be performed at specific power of heating $2.2-2.5 \cdot 10^{4} \mathrm{~kW} / \mathrm{m}^{3}$. At that mass velocity of supply of chip particles should make $0.3-0.7 \mathrm{~kg} / \mathrm{h}$ per $1 \mathrm{~kW}$ of input power [5]. In work [6] surfacing of press dies with oxidized chips of steel $4 \mathrm{Kh} 5 \mathrm{MF} 1 \mathrm{~S}$ under AN-292 flux in $150 \mathrm{~mm}$ diameter mold and single-phase scheme of current supply was carried out at specific power $12.6-14.1 \cdot 10^{4} \mathrm{~kW} / \mathrm{m}^{3}$.

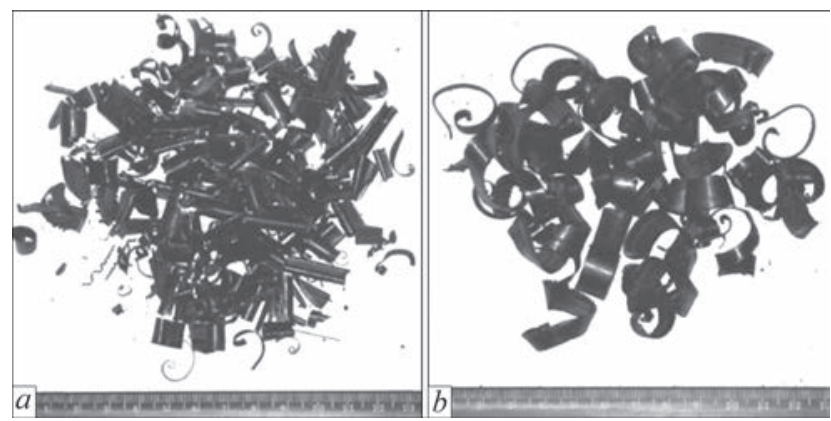

Figure 2. $5 \mathrm{KhNM}$ steel chips from continuous milling $(a)$ and planing (b) machines

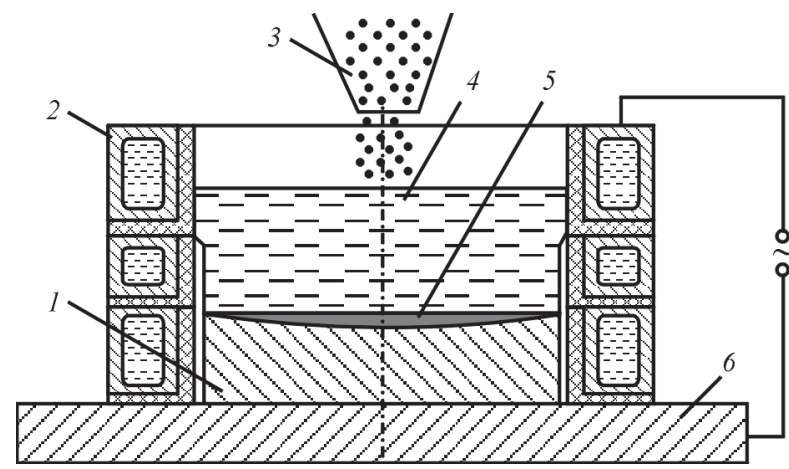

Figure 3. Scheme of surfacing of dies in CCM using discrete filler in form of chips: 1 - die being deposited; 2 - current-conducting mold; 3 - filler (chips); 4 - slag pool; 5 - metal pool (metal being deposited); 6 - bottom plate
The second scheme is also realized with the help of nonconsumable hollow electrode both graphitized and metallic water-cooled, but not solid one. The chips being remelted are supplied through inner cavity of it. The chips coming into underelectrode heat center of the slag pool promote decrease of slag temperature in whole volume of the pool, namely in the center due to effect of coming cold chips and on the edges due to cooling effect of mold walls. Therefore, using such scheme of surfacing it is difficult to provide good fusion of base and deposited metal, in particular, on the part edges. Obviously this is the reason of the fact that the scheme is usually proposed in form of a method for production of ingots from different composition steels, when formation of outer surface is not related with quality of joining $[7,8]$ of metals.

This paper outlines the results of surfacing of dies made on the third technological scheme of electroslag process using nonconsumable electrode and sectional type mold, named by designers as a current-conducting mold (CCM) [9]. Its peculiarity is supply of electric energy to a slag pool not on its center, but on periphery (through walls of current-conducting section). Therefore, the main heating-through of the pool takes place near the mold walls that affects a shape of metallic pool and, respectively, nature of base metal penetration.

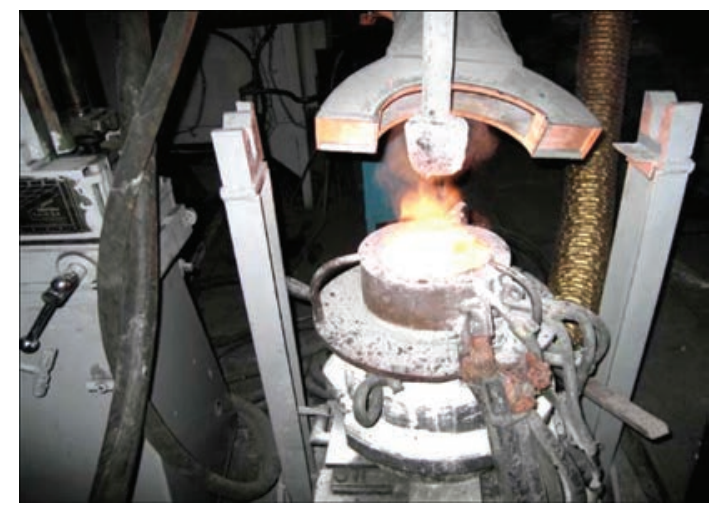

Figure 4. Stage of start of CCM work at removed from slag pool water-cooled electrode with graphite tip 

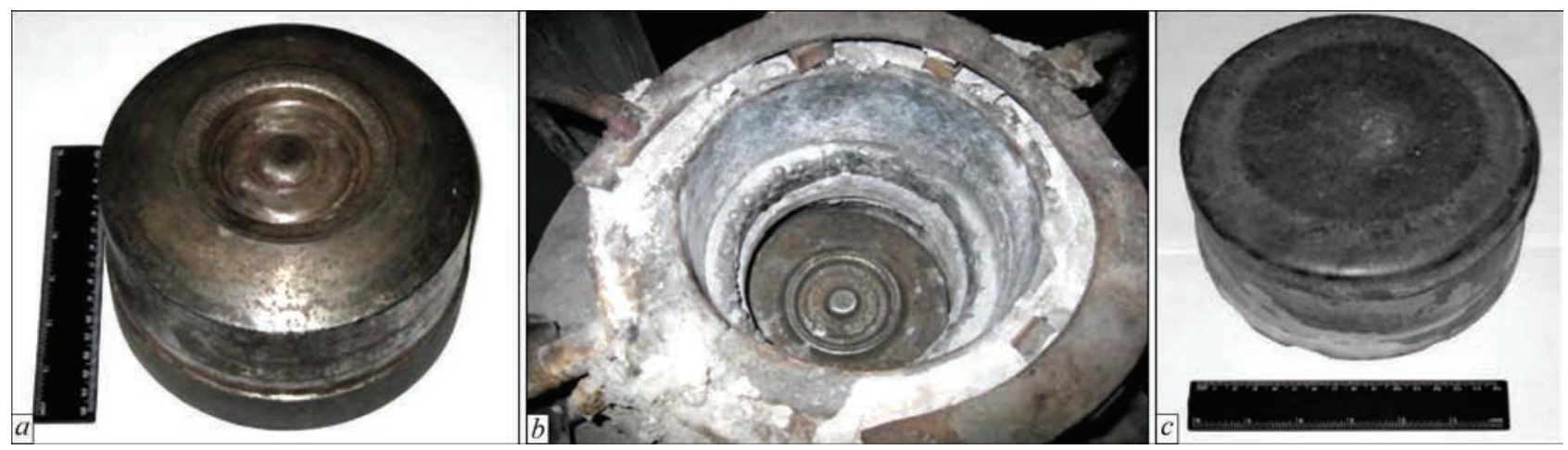

Figure 5. Press die of $170 \mathrm{~mm}$ diameter and $80 \mathrm{~mm}$ height of steel $5 \mathrm{KhNM}$ : $a$ - before surfacing; $b$ - in mold before surfacing; $c$ - after surfacing

There is one more feature of mold design. During electroslag process it promotes rotation of a slag pool in a horizontal plane, providing uniform distribution of chips over the pool surface and acceleration of their melting. Press tools of $170 \mathrm{~mm}$ diameter and $80 \mathrm{~mm}$ height made of steel $5 \mathrm{KhNM}$ were chosen for surfacing. The die bed contours before surfacing were not machined due to this the height difference of working surfaces in the center of dies reached up to $16 \mathrm{~mm}$ and on the edges up to $14 \mathrm{~mm}$.

$5 \mathrm{KhNM}$ chips from continuous milling and planning machines (Figure 2) were used as filler material.

Regardless the fact that the chips have no obvious traces of $\mathrm{CM}$, they still were backed in electric furnace at $400{ }^{\circ} \mathrm{C}$ temperature, $2 \mathrm{~h}$.

Surfacing was carried out in CCM of $180 \mathrm{~mm}$ diameter at its stationary position (Figure 3 ).

The chips were supplied in the mold working zone using vibrobatcher of PWI design. Flux AN-15M was used as a working flux. Start of the process was with «solid start» using water-cooled electrode having graphite tip. Transfer from arc to electroslag process took place in electric mode providing minimum penetration of die surface.

After generating a necessary slag pool volume in the mold using water-cooled electrode the process was performed only due to work of current-conducting section of CCM. At that, the electrode was removed from the slag pool (Figure 4).

After reaching the optimum mode of surfacing the filler (chips) was supplied on the slag pool surface by vibrobatcher. Surfacing process was stable. Thickness of deposited layer made approximately $25-30 \mathrm{~mm}$. Deposition rate made approximately $0.4 \mathrm{~kg} / \mathrm{min}$. Figure 5 shows the dies before surfacing, position of die in working space of CCM and appearance of deposited die.

Specific heat power, introduced into the slag pool, made approximately $2 \mathrm{~kW} / \mathrm{m}^{3}$, i.e. 6-7 times less than in surfacing of press tools at single-phase scheme of current supply to the slag pool (first technological scheme) in work [6].

For performance of commercial tests at PJSC «Tokmak Forging and Stamping Plant» two sets of M-112 press dies were repaired by ESS in CCM with chips of steel $5 \mathrm{KhNM}$ and billets of $170 \mathrm{~mm}$ diameter and $100 \mathrm{~mm}$ height were obtained. It should be noted that after surfacing the tool was machined without difficulties, no defects were found in the deposited layer. Deposited tool was tested in forge-and-press shop of PJSC «TFSP». The tests showed that in comparison with the serial forged dies the resistance of deposited ones increased 1.5 times.

Thus, resource-saving technology of surfacing of small size die tooling with $5 \mathrm{KhNM}$ chips using current-conducting mold allows obtaining quality deposited die tool at relatively low consumption of electric energy.

1. Geller, Yu.A. (1983) Tool steels. Moscow, Metallurgiya [in Russian].

2. http://www.ukrstat.gov.ua/operativ/menu_u/ns.htm:State statistics service of Ukraine. Economic statistics. Economic activity. Environment [in Ukrainian].

3. Mazur, A.A., Lipodaev, V.N., Pustovojt, S.V., Petruk, V.S. (2017) State-of-the-art of welding equipment and consumables market in Ukraine. The Paton Welding J., 11, 31.

4. Kuskov, Yu.M. (2014) Discrete filler materials for surfacing in current-conducting mould. Ibid., 6-7, 97-102.

5. Kuzmenko, O.G. (2002) Restoration of tool for hot die forging by electroslag surfacing with noncompact materials: Syn. of Thesis for Cand. of Techn. Sci. Degree. Kiev, PWI [in Russian].

6. Davydov, A.K., Goncharov, A.E., Soloviov G.I., Marfitsin, V.V. (1997) Electroslag surfacing with graphite electrode. Svarochn. Proizvodstvo, 6, 47-48 [in Russian].

7. Baktagirov, F.K. (2003) Application of nonconsumable electrode electroslag process for melting, refining and treatment of metals. Report 2. Advances in Electrometallurgy, 1, 4-8.

8. Kochkin, S.V. (2015) Development of technology of metal chips processing by electroslag remelting method. Sovremennye Nauchnye Issledovaniya i Innovatsii, 6, 41 [in Russian].

9. Kyskov, Yu.M. (2003) A new approach to electroslag welding. Welding J., 4, 42-45. 


\title{
EFFECT OF CHEMICAL COMPOSITION AND STRUCTURE OF DEPOSITED METAL ON DEFORMATION OF THIN STEEL PLATES
}

\author{
A.A. BABINETS
}

E.O. Paton Electric Welding Institute of the NAS of Ukraine

11 Kazimir Malevich Str., 03150, Kyiv, Ukraine. E-mail: office@paton.kiev.ua

\begin{abstract}
The paper gives a comparative experimental evaluation of effect of different factors on residual deformation in arc surfacing of thin steel plates. Effect of composition, structural state and method of part fixation in surfacing with Sv-08A, PP-Np-25Kh5FMS and Sv-Kh19N18G6M3V2 wires on plates of St.3 steel of 3x150x240 mm size were evaluated at different conditions of their fixation. It was experimentally found that differences in physical properties and structural state of base and deposited metal have the highest effect on the level of residual deformations. The results obtained in this work can be used in development of technology of wear-resistant surfacing of thin sheet structures. 9 Ref., 2 Tables, 4 Figures.
\end{abstract}

Keywords: arc surfacing, thin plate, residual deformations, structural changes, coefficient of thermal expansion, method of fixation, wear-resistant layer

It is known that in surfacing of thin-sheet structures the residual stresses and deformations are observed, the cause of which are the non-uniform heating of metal in the surfacing zone, casting shrinkage of the deposited metal, difference in coefficient of temperature expansion (CTE) of deposited and base metals, structural transformations in the deposited metal during the cooling process, and also method of part fixation [1-3].

Depending on the type and level of residual deformations after surfacing, the service characteristics of manufactured parts can be greatly deteriorated [1-3]. It refers to the greatest degree to thin plates or sheets with large areas of deposited surfaces. Therefore, the problem of evaluation of effect of different factors on residual surfacing deformations is the most urgent one for the surfacing (welding) production.

The aim of the present work is the comparative experimental investigations of effect of chemical composition, structure of deposited metal, as well as method of fixation of the part surfaced on the level of residual deformations during surfacing of thin steel plates.

It is known that with the growth in temperature in the surfacing zone the tensile strength, elasticity and heat conductivity of steel are decreased, and thermal expansion and specific heat capacity are increased. Such change in physical-mechanical properties of metal has an effect on heat emission and homogeneity of heat distribution in the part. The higher the heating temperature, the higher is CTE, the lower is heat conductivity of steel and, thus, the level of stresses and deformations in the workpiece is higher $[1,2]$.

(C) A.A. BABINETS, 2019
If the CTE of base and deposited metal differ greatly between themselves, this can cause the additional negative effect on the level of residual stresses and deformations.

Phase transformations during cooling of deposited metal also lead to the formation of stresses and deformations, which are accompanied by change in its volume [1-3]. In low-carbon steels it causes the change in about $1 \%$ of volume, however, in steels, containing more than $0.35 \%$ of carbon and most alloyed steels, tended to hardening, the large volume changes are observed due to martensite transformation.

The method of part fixation has also a definite effect on level of the residual deformations. In a general case, at rigid fixation of the deposited part up to the moment of its full cooling to a room temperature the stresses in the deposited metal will be observed, which will lead to the part deformation during clamps unfastening [1-3]. By using fixture with heat-removing surfaces, for example, copper backings, it is possible to provide some decrease in the level of residual deformations. Efficiency of heat removal in use of such backings depends on their sizes, difference in temperature of backing and part being deposited, thermal resistance in the zone of backing and part contact $[4,5]$.

Materials and procedures of investigation. In the present work for comparative experimental evaluation of effect of physical-mechanical properties of surfacing materials, their structure class, as well as the method of part fixation on the level of residual deformations in surfacing of thin plates of a rather large area the following materials and fixture were used. 
Table 1. Chemical composition of base and deposited metals [6, 7]

\begin{tabular}{|l|c|c|c|c|c|c|c|c|}
\hline \multirow{2}{*}{ Grade of steel or wire } & \multicolumn{7}{|c|}{ Weight share of elements, \% } \\
\cline { 2 - 10 } & $\mathrm{C}$ & $\mathrm{Si}$ & $\mathrm{Mn}$ & $\mathrm{Cr}$ & $\mathrm{Ni}$ & $\mathrm{V}$ & $\mathrm{Mo}$ & $\mathrm{W}$ \\
\hline St.3 & $0.14-0.22$ & $\leq 0.05$ & $0.3-0.6$ & $\leq 0.3$ & $\leq 0.3$ & - & - & - \\
\hline Sv-08A (08rimmed) & $0.05-0.12$ & $\leq 0.03$ & $0.25-0.45$ & $\leq 0.1$ & $\leq 0.3$ & - & - & - \\
\hline PP-Np-25Kh5FMS & $0.2-0.3$ & $0.8-1.3$ & $0.5-1.0$ & $4.6-5.8$ & - & $0.2-0.6$ & $0.9-1.5$ & - \\
\hline 4Kh5FMS* & $0.3-0.4$ & $0.9-1.2$ & $0.2-0.5$ & $4.5 \ldots-.5$ & - & $0.3-0.5$ & $1.2-1.5$ & - \\
\hline Sv-Kh19N18G6M3V2 & $0.1-0.2$ & $0.3-0.6$ & $4.0-0$ & $17.0-19.0$ & $16.0-18.0$ & - & $2.4-3.3$ & $1.8-2.5$ \\
\hline 20Kh23N18* & $\leq 0.2$ & $\leq 0.1$ & $\leq 2.0$ & $22.0-5.0$ & $17.0-20.0$ & - & - & - \\
\hline $\begin{array}{l}\text { Note. There is no data in literature on CTE for used materials: Sv-08A, PP-Np-25Kh5FMS and Sv-Kh19N18G6M3V2. Therefore, data are } \\
\text { given for the materials, most close to them by structural class and chemical composition of steels. }\end{array}$
\end{tabular}

Table 2. Coefficient of thermal expansion of base and deposited metals in the range of $20-900^{\circ} \mathrm{C}$ [6]

\begin{tabular}{|l|c|c|c|c|c|c|c|c|c|}
\hline \multirow{3}{*}{ Grade of steel } & \multicolumn{8}{|c|}{ Coefficient of thermal expansion $\alpha, 10^{-6} 1 /{ }^{\circ} \mathrm{C}$} \\
\cline { 2 - 13 } & $20-100$ & $20-200$ & $20-300$ & $20-400$ & $20-500$ & $20-600$ & $20-700$ & $20-800$ & $20-900$ \\
\hline 08rimmed & 12.5 & 13.4 & 14.0 & 14.5 & 14.9 & 15.1 & 15.3 & 14.7 & 14.7 \\
\hline 4Kh5FMS & 12.6 & 13.1 & 13.7 & 14.0 & 14.3 & 14.6 & 14.7 & 14.6 & 14.1 \\
\hline 20Kh23N19* & 14.9 & 15.7 & 16.6 & 17.1 & 17.5 & 17.8 & 18.2 & - & - \\
\hline
\end{tabular}

*There is no data in literature on CTE for used materials: Sv-08A, PP-Np-25Kh5FMS and Sv-Kh19N18G6M3V2. Therefore, data are given for the materials, most close to them by structural class and chemical composition of steels.

The surfacing was performed on $240 \times 150 \mathrm{~mm}$ plate of steel St. 3 of $3 \mathrm{~mm}$ thickness using three wires: low-carbon solid wire $\mathrm{Sv}-08 \mathrm{~A}$ of $1.2 \mathrm{~mm}$ diameter, providing the ferrite-pearlite deposited metal, close to base metal by chemical composition and properties; medium-alloyed flux-cored wire PP-Np-25Kh5FMS of $1.4 \mathrm{~mm}$ diameter, providing martensite-bainite deposited metal with a small amount of residual austenite; and high-alloyed solid wire Sv-Kh19N18G6M3V2 of $1.2 \mathrm{~mm}$ diameter, providing deposited metal with austenite structure. Chemical composition and properties of materials are given in Tables 1 and 2 [6, 7].

The selection of namely these surfacing materials is explained by difference in their physical-mechanical properties and structural state as compared with the base metal and, respectively, their assumed different effect on the level of residual deformations of plates being surfaced.

Thus, in surfacing with wire Sv-08A the level of deformation of plates of steel St.3 will depend only on the effect of a local heating, as there is almost no difference in CTE and structural state. For the wire PP-Np-25Kh5FMS it will depend on the effect of a local heating and martensite transformation, which is accompanied by increase in volume of deposited metal, as the difference in CTE in this case is minimum. In surfacing with wire Sv-Kh19N18G6M3V2 it will depend on the effect of a local heating and large difference in CTE of base and deposited metal.

The sizes of surfacing zone were $200 \times 100 \mathrm{~mm}$. Surfacing with all the wires was performed by single beads with overlapping of neighboring beads by 40
$50 \%$, at similar mode: $150-160$ A current; $22-23 \mathrm{~V}$ voltage; $30 \mathrm{~m} / \mathrm{h}$ surfacing speed. This mode of surfacing was realized in one or two layers for each type of wire.

Surfacing modes were selected coming from recommendations, available in technical literature about the feasibility of producing the quality deposited (welded) thin-sheet joints, which have no burn-outs, pores and other defects, as well as from positive results of own preliminary experiments $[8,9]$.

Plates for surfacing were fixed on a welding table with a copper surface and clamped to it by means of two metallic straps, located along the long sides of plates. One of the straps clamped the plate edge to the table, preventing completely its movement (rigid fixation), and another one prevented the plate edge from deforming in vertical direction, but gave the possibility to its displacement in horizontal plane (movable fixation) (Figure 1). The selection of this scheme of fixation was made on the base of positive results, obtained in preliminary experiments on surfacing of thin sheets [9].

Also, for evaluation of degree of effect of thermal contact between the part surfaced and welding table on residual surfacing deformations, the surfacing of plates was performed with similar fixation, but in gravity conditions. For this, the narrow steel straps were arranged under plate clamping edges so, that the surfacing could be realized with a gap of $10 \mathrm{~mm}$ from the welding table surface.

Surfacing of each plate started from the side of a rigid fixation and continued to the another edge without 


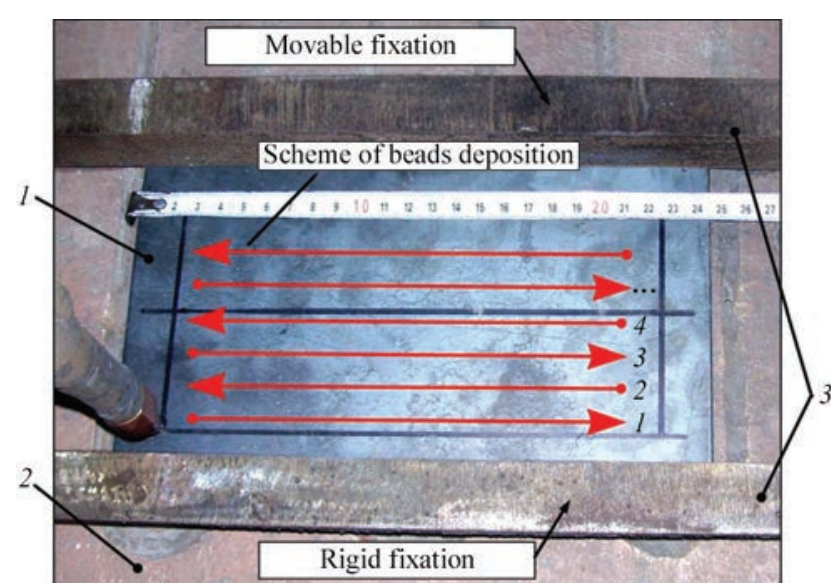

Figure 1. Appearance of plate being surfaced (1), fixed on welding table (2) by clamping straps (3) with indication of scheme of beads deposition

interruptions for cooling in accordance with a scheme shown in Figure 1. After surfacing of a layer the clamping straps were not removed up to a complete plate cooling, and then the visual inspection was made.

The measurement of deformations was carried out with a help of a rigid rule, mounted on the rear side of deposited plate, and an indicator head, moved along the rule, with a record of separate points by the scheme shown in Figure 2. As a large number of experiments was planned, then to facilitate the subsequent analysis the complete profilograms were taken only in a perpendicular direction to the deposited welds in plate centre, and value of maximum deformation in free edges of plates was also recorded as additional parameters.

Discussion of obtained results. It was found that during surfacing of plates in one and two layers, fully pressed to the welding table surface, the deposited metal has no defects of such types as burn-outs, pores, cracks, etc. Due to surfacing, all the plates had deformation in the form of upward deflection, howev-

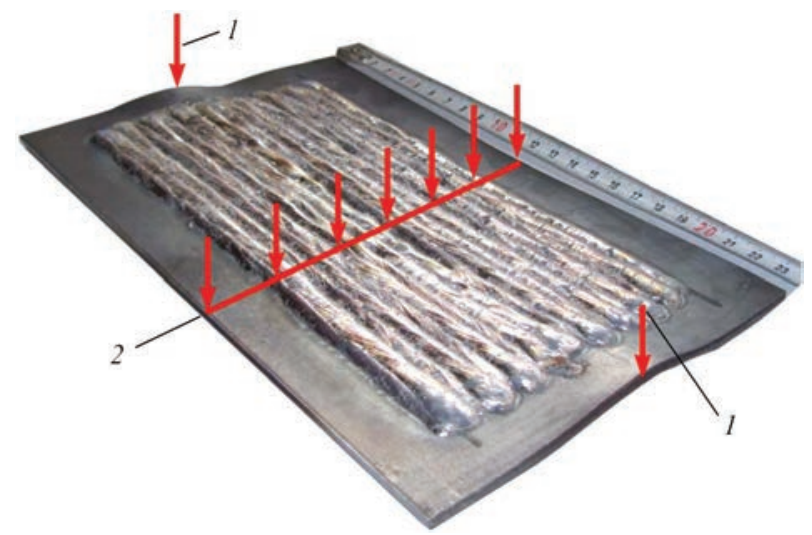

Figure 2. Scheme of measuring the value of plates deformation after surfacing: measurement of maximum value of deformation at free edges of plates; 2 - measurement of value of deformation in transverse direction in plate centre at different distance $l$ from its edge er, the value of these deformations in each case was different.

For the given type of fixation the largest deformations were recorded for plates, deposited by the austenite wire Sv-Kh19N18G6M3V2, maximum values of deformations for plates, deposited in two layers, were $2.7 \mathrm{~mm}$ in plate centre and $6.7 \mathrm{~mm}$ at their free edges. The intermediate value of deformation was in plates deposited by wire PP-Np-25Kh5FMS: their maximum deformation was 2.4 and $6.5 \mathrm{~mm}$, respectively. And the lowest value of deformations was noted in plates, deposited by wire Sv-08A: $0.8 \mathrm{~mm}$ in plate centre and $4.5 \mathrm{~mm}$ at the free edges.

Such difference in residual deformations of plates during surfacing with wires, different in chemical composition and structural class, is explained by the appearance of residual stresses, caused by a large difference between the values of CTE of base and deposited metals in case of surfacing with wire Sv-Kh19N18G6M3V2, as well as by martensite transformations with increase in volume in case of surfacing with wire PP-Np-25Kh5FMS.

In case of fixation of plates in gravity conditions with $10 \mathrm{~mm}$ gap to the welding table surface, it was managed to produce the deposited layer without burnouts only at increase in surfacing speed from 30 up to $40 \mathrm{~m} / \mathrm{h}$. The rest surfacing modes remained unchanged. It was also noted in this case that the largest deformations are typical for plates, deposited by an austenite wire Sv-Kh19N18G6M3V2, however, the
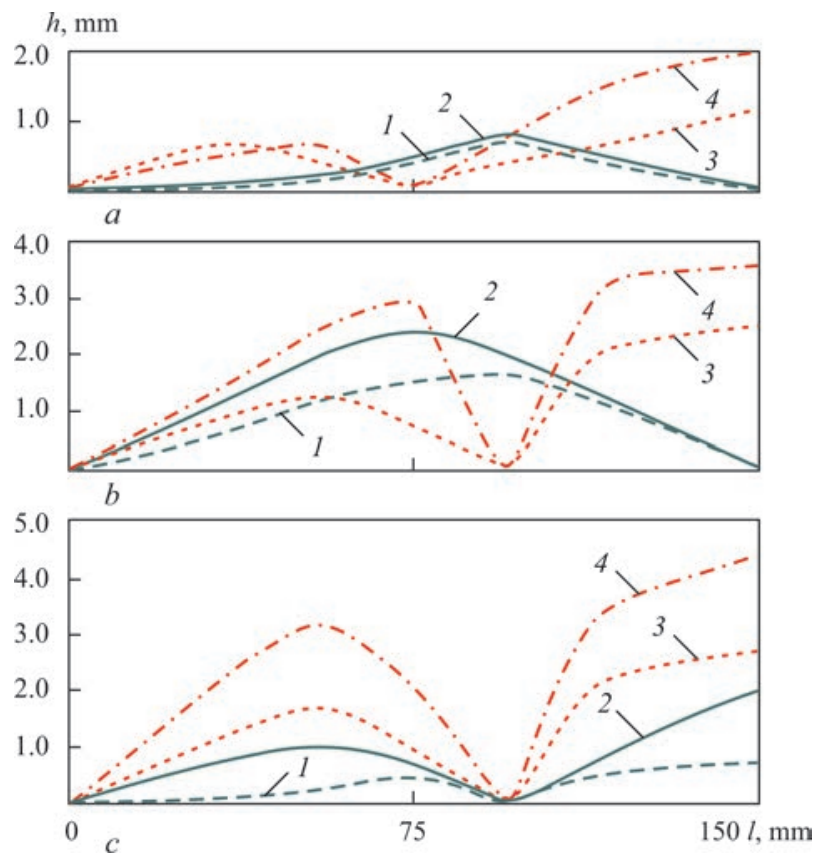

Figure 3. Value of deformation in centre of plates, fixed without a gap and with a gap, and deposited in one and two layers with the wires: Sv-08A (a), PP-Np-25Kh5FMS (b) and Sv-Kh19N18G6M3V2 (c): 1 - surfacing without a gap, $1^{\text {st }}$ layer; 2 - surfacing without a gap, $2^{\text {nd }}$ layer; 3 - surfacing with a gap, $1^{\text {st }}$ layer; $4-$ surfacing with a gap, $2^{\text {nd }}$ layer 
value and nature of deformation of plates, deposited in gravity conditions, differed from deformation of plates, deposited without a gap.

In spite of the fact that in surfacing with a gap the maximum deformation of plates at the free edges was somewhat lower, than without it: $5.8 \mathrm{~mm}$ for plates, deposited by wire Sv-Kh19N18G6M3V2; $5.5 \mathrm{~mm}$ during surfacing with wire PP-Np-25Kh5FMS and $3.6 \mathrm{~mm}$ in case of surfacing with wire $\mathrm{Sv}-08 \mathrm{~A}$, the value of deformation in plate centre was much higher than that in surfacing without a gap (Figure 3).

It should also be noted that as a result of deterioration of heat emission conditions of semi-products being deposited, and also rigidity of their fixation, the plates, deposited with a gap, obtained an unfavorable transverse profile from the point of view of subsequent possible straightening (Figure 4).

Thus, it was found experimentally that the difference in physical-mechanical properties and structural state of base and deposited metal, as well as the method of fixation of plates on the welding table have the greatest effect on residual deformations during electric arc surfacing of plates.

The application of electrode materials with CTE, close to that of base metal, but in which the significant structural transformations take place during cooling the deposited metal, is comparable by the level of effect on residual deformations with surfacing of materials without such transformations, but with a large difference in CTE of base and deposited metals.

It is planned in next works to give the more detailed description of established regularities with carrying out of comparative investigations of stressed and structural states of deposited plates.

\section{Conclusions}

1. In arc surfacing of thin steel plates the following main factors have an effect on the level of their deformation:

- difference in CTE of base and deposited metals;

- structural transformations, preceding in deposited metal during cooling;

- method of plate fixation on welding table.

2. Among the above-mentioned factors the chemical composition and structure of metal being deposit-

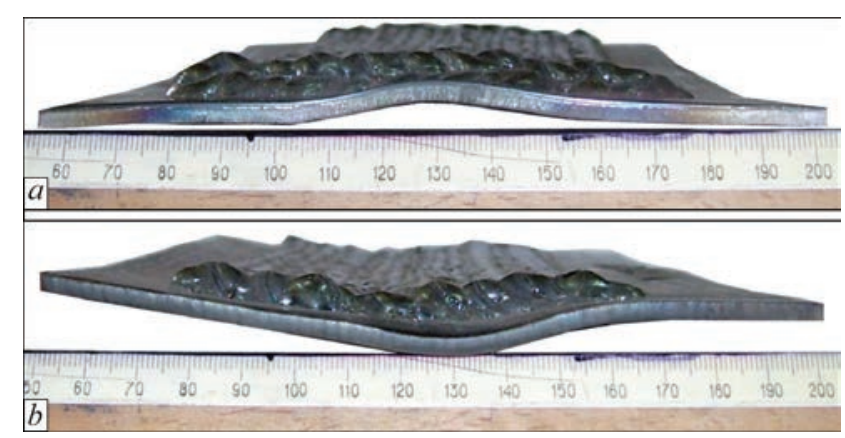

Figure 4. Appearance of deformed transverse edge of plate after surfacing of two layers with wire PP-Np-25Kh5FMS at fixation without a gap ( $a$ ) and with a gap $(b)$

ed have the greatest effect on value of residual deformations, which is pronounced in differences in CTE and structural transformations during cooling of base and deposited metals.

3. Application of clamping devices with heat removing surfaces in surfacing of thin plates can provide the decrease in residual deformations at keeping a good thermal contact between plate being deposited and heat removing surface.

1. Vinokurov, V.A., Grigoryants, A.G. (1984) Theory of welding strains and stresses. Moscow, Mashinostroenie [in Russian].

2. Kasatkin, B.S., Prokhorenko, V.M., Chertov, I.M. (1987) Welding stresses and strains. Kiev: Vyshcha Shkola [in Russian].

3. Makarov, E.L. (1991) Welding and welded materials. In: 3 Vol. Vol. 1: Weldability of materials. Moscow, Metallurgiya [in Russian].

4. Lobanov, L.M., Pavlovsky, V.I., Loginov, V.P., Pashchin, N.A. (1990) Regulation of thermodeformational cycles in welding of sheet structures using heat absorbers. Avtomatich. Svarka, 9, 39-46 [in Russian].

5. Gedrovich, A.I., Zhidkov, A.B. (2000) Application of heat sinks for reduction of welding strains and stresses (Review). The Paton Welding J., 2, 41-44.

6. Zubchenko, A.S., Koloskov, M.M., Kashirsky, Yu.V. (2003) Steel and alloy grades. 2nd Ed., Moscow, Mashinostroenie [in Russian].

7. Ryabtsev, I.A., Senchenkov, I.K. (2013) Theory and practice of welding works. Kiev, Ekotekhnologiya [in Russian].

8. Panteleenko, F.I., Lyalyakin, V.P., Ivanov, V.P. (2003) Restoration of machine parts: Refer. book. Ed. by V.P. Ivanov. Moscow, Mashinostroenie [in Russian].

9. Babinets, A.A., Ryabtsev, I.A. (2017) Flux-cored wire for wear-resistant surfacing of thin-sheet structures. The Paton Welding J., 1, 54-57. 


\title{
PECULIARITIES OF WELDING PROCESS USING METAL CORED WIRE OF TMV5-MK GRADE
}

\author{
A.A. GOLYAKEVICH ${ }^{1}$, L.N. ORLOV ${ }^{1}$ and S.Yu. MAKSIMOV ${ }^{2}$ \\ ${ }^{1}$ LLC TM.VELTEK \\ 15 Kazimir Malevich Str., 03150, Kyiv, Ukraine. E-maul: office@veldec.ua \\ ${ }^{2}$ E.O. Paton Electric Welding Institute of the NAS of Ukraine \\ 11 Kazimir Malevich Str., 03150, Kyiv, Ukraine. E-mail: office@paton.kiev.ua
}

\begin{abstract}
Currently, in the world market of welding consumables a steady tendency in growing the consumption of flax-cored wires is preserved. One of the rapidly developing technologies for manufacture of metal structures is arc welding in shielding gases using the metal cored wire. As to the technology of application the metal cored wires, do not differ from solid wires, and as to the number of technological characteristics they even surpass them. LLC TM.Veltek has developed and mastered the production of high-efficient metal cored wire TMV5-MK for welding in a mixture of $82 \% \mathrm{Ar}+18 \% \mathrm{CO}_{2}$. It was found that the metal cored wire provides a high stability of arc burning in a wide range of welding conditions. Using the solid wire $\mathrm{Sv}-08 \mathrm{G} 2 \mathrm{~S}$ in welding at the same modes in the optimum range, the value of stability of arc burning is 3 times lower as compared with the metal cored wire TMV5-MK. It is shown that the stability of welding process is significantly influenced by electrodynamic properties of the power source and this factor should be taken into account during evaluation of welding and technological properties of welding wires and working out of recommendations for their application. 8 Ref., 1 Table, 4 Figures.
\end{abstract}

Keywords : metal cored wire, solid wire, power source, stability of arc burning, short circuits

At the present time, in the EU countries, in particular Poland, Czech Republic, Slovakia and Germany, a significant increase is observed in production of different metal structures and, respectively, increase in volume of the welding works. At the world market of welding consumables a stable tendency is preserved in the growth of consumption of metal cored wires in various branches of industry $[1,2]$. During recent years one of the rapidly developing technologies in manufacture of metal structures is the arc welding using metal cored wire in $\mathrm{CO}_{2}$ or mixtures of argon with $\mathrm{CO}_{2}[3,4]$. Metal cored wires of the present assortment do not differ by the technology of application from the solid wires, and by a number of technological characteristics they are even superior [5-7]. First of all, it concerns the stability of arc burning process, transfer of molten electrode metal, characteristics of base metal penetration and formation of weld metal due to the used core composition. Except metal powders, the latter includes, a small amount of mineral components, stabilizing the arc burning and improving the metallurgical characteristics of wire melting and weld metal formation.

In welding with metal cored wire the almost the same technique is used as in welding with a metal cored wire, moreover, it is more convenient and simpler in operation, forms a smooth weld and provides minimum spattering of electrode metal and formation of only traces of slag on the weld surface.
As compared with a solid wire, the metal cored wire provides the higher quality of welds and comparable welding efficiency (92-98 \% deposition rate) and at the same time helps to decrease its cost. In addition, in the EU countries the welders are not demanded to pass the additional attestation for fulfillment of MAG process, therefore, they are admitted for work with a metal cored wire at once (standard ISO 9606, part1).

Taking into account the world tendencies of development of mechanized welding and the absence of national analogs, LCC TM.Veltek has developed and mastered the production of high-efficient metal cored wire of TMV5-MK grade for welding in mixture M21 $\left(82 \% \mathrm{Ar}+18 \% \mathrm{CO}_{2}\right)$.

The aim of the carried out investigations was to study the peculiar features of the process of welding with metal cored wire as compared with welding using a solid wire. Electric parameters of welding process were monitored by using the information-measuring system (IMS) on the base of personal computer and module of analog input E-440 [8]. Using IMS the continuous analysis and record of values of registered parameters at frequency of $10 \mathrm{kHz}$ during the whole welding cycle were made.

To evaluate the peculiarities of welding process, the following electric and time parameters were measured: $U_{\mathrm{a}}$ and $I_{\mathrm{w}}$ - arc voltage and welding current; $U_{\text {abb }}$ and $I_{\text {ab }}$ - voltage and current of are burning; $U_{\text {sh-c }}^{\text {a.b }}$ and $I_{\text {sh-c }}$ - short-circuit-voltage and current; 
Electric and time parameters of welding process with metal cored wire TMV5-MK

\begin{tabular}{|c|c|c|c|c|c|c|c|c|c|}
\hline No. & $U_{\text {mean }}, \mathrm{V}$ & $I_{\text {mean }}, \mathrm{A}$ & $K_{V}^{U}, \%$ & $K_{V}^{I}, \%$ & $N_{\text {sh-c }}$ & $\tau_{\text {sh-c } \text { mean }}, \mathrm{ms}$ & $N_{\text {sh-cresl }}$ & $\tau_{\text {sh-creal }}$, ms & $F_{\text {sh-c }}, \mathrm{Hz}$ \\
\hline 1 & 27 & 198 & 4.1 & 7.9 & - & - & - & - & - \\
\hline 2 & 24 & 187 & 4.9 & 11.0 & - & - & - & - & - \\
\hline 3 & 21 & 181 & 8.1 & 14.7 & 55 & 0.0009 & 16 & 0.0021 & 2.8 \\
\hline 4 & 22.5 & 124 & 4.7 & 16.1 & 11 & 0.0006 & - & - & 0.55 \\
\hline 5 & 19.9 & 118 & 9.0 & 25.7 & 134 & 0.0013 & 63 & 0.0024 & 6.1 \\
\hline 6 & 24.2 & 287 & 7.3 & 7.8 & - & - & - & - & - \\
\hline 7 & 27.9 & 302 & 3.7 & 3.6 & - & - & - & - & - \\
\hline 8 & 30.7 & 304 & 3.1 & 3.6 & - & - & - & - & - \\
\hline
\end{tabular}

Notes. $U_{\mathrm{m}}, I_{\mathrm{m}}-$ mean values of arc voltage and welding current; $K_{V}^{U}, K_{V}^{I}-$ coefficients of variation by voltage and current; $N_{\text {sh-s, }}, F_{\text {sh-c }}-$ number and frequency of short circuits; $\tau_{\text {sh-c } \operatorname{mean}}$ - mean value of duration of short circuits; $N_{\text {sh-c }}$ and $\tau_{\text {sh-creal }}$ - number and duration of real short circuits.

$T_{\text {sh-c }}$ - interval between short-circuiting of electrode gap with molten metal drop. Nature of metal transfer was evaluated by the duration of short circuits $\tau_{\text {sh-c }}$, their number $N_{\text {sh-c }}$, and frequency $f_{\text {sh-c }}$. Analysis of peculiarities of arc burning was made from histograms of arc voltage and welding current by using the method of stage-by-stage processing of multimodal distributions. In this case the number of events (measurements), mean value of parameter, dispersion and coefficient of variation $K_{V}$ were determined for each separate region of the histogram [8].
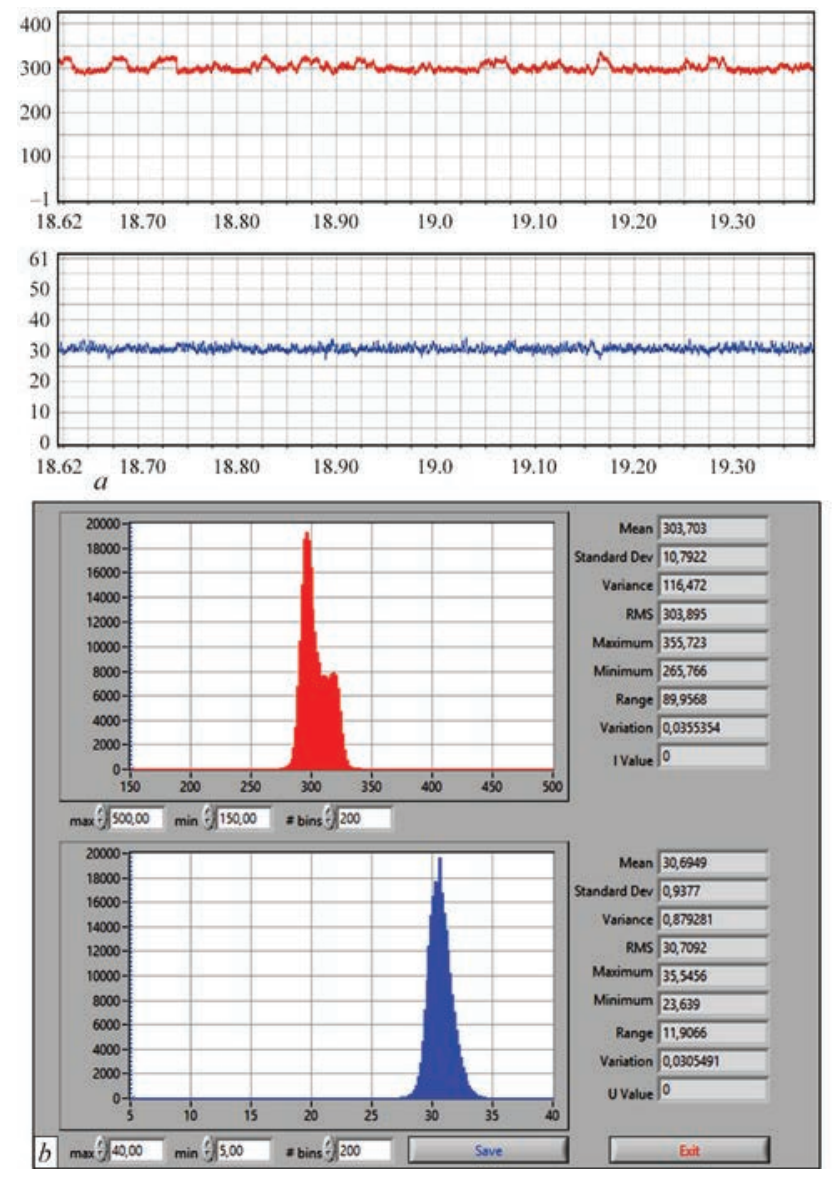

Figure 1. Oscillogram $(a)$ of welding process with metal cored wire TMV5-MK and histograms of current and voltage $(b)$
The obtained information allows providing the quantitative evaluation of metal cored wire melting kinetics and transfer of molten metal into welding pool, stability of welding arc burning process.

Welding with metal cored wire TMV5-MK of $1.2 \mathrm{~mm}$ diameter was performed in the automatic mode. The mode parameters were changed in the following range: $I_{\mathrm{w}}=120-300 \mathrm{~A}, U_{\mathrm{a}}=21-31 \mathrm{~V}, v_{\mathrm{w}}=$ $=14 \mathrm{~m} / \mathrm{h}$. The obtained data are given in Table.

As is seen from the given data in welding at a short $\operatorname{arc}\left(U_{\mathrm{a}} \leq 23 \mathrm{~V}\right)$ the process is accompanied by shorttime short circuits. With increase in voltage they are
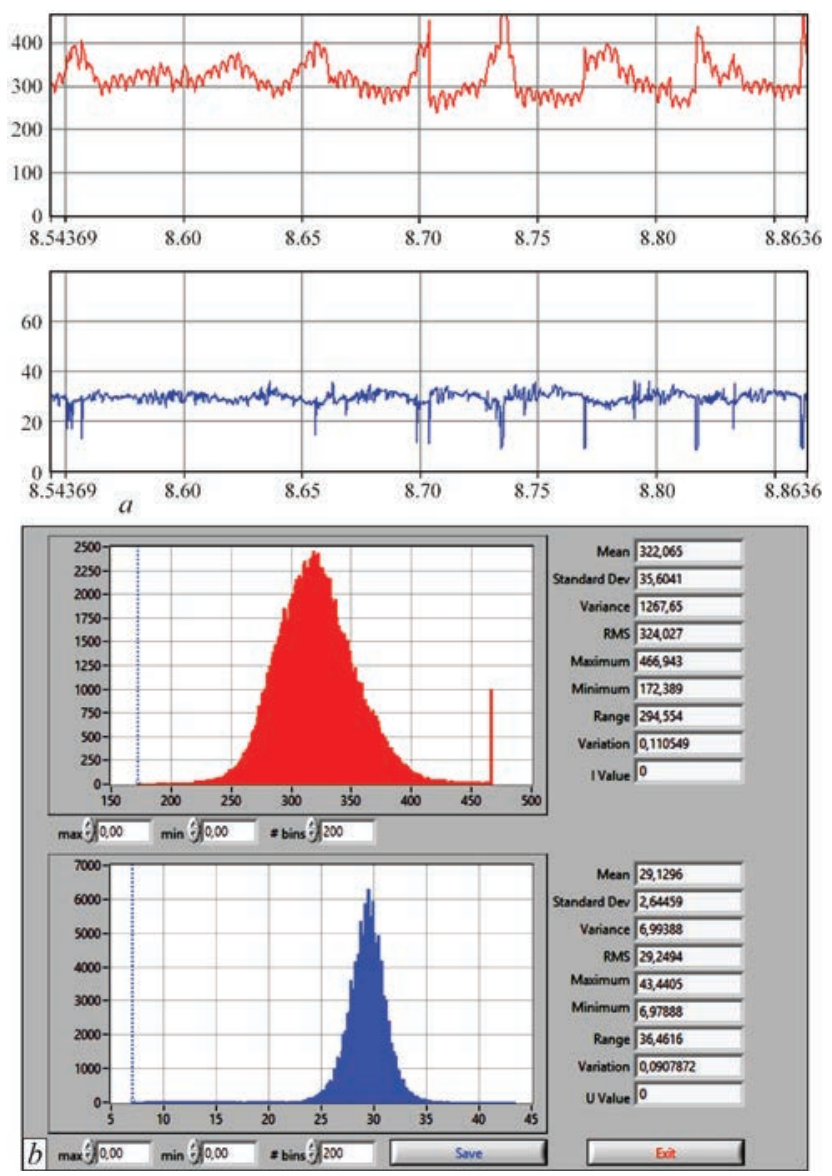

Figure 2. Oscillogram $(a)$ of welding process with solid wire Sv-08G2S and histograms of current and voltage (b) 

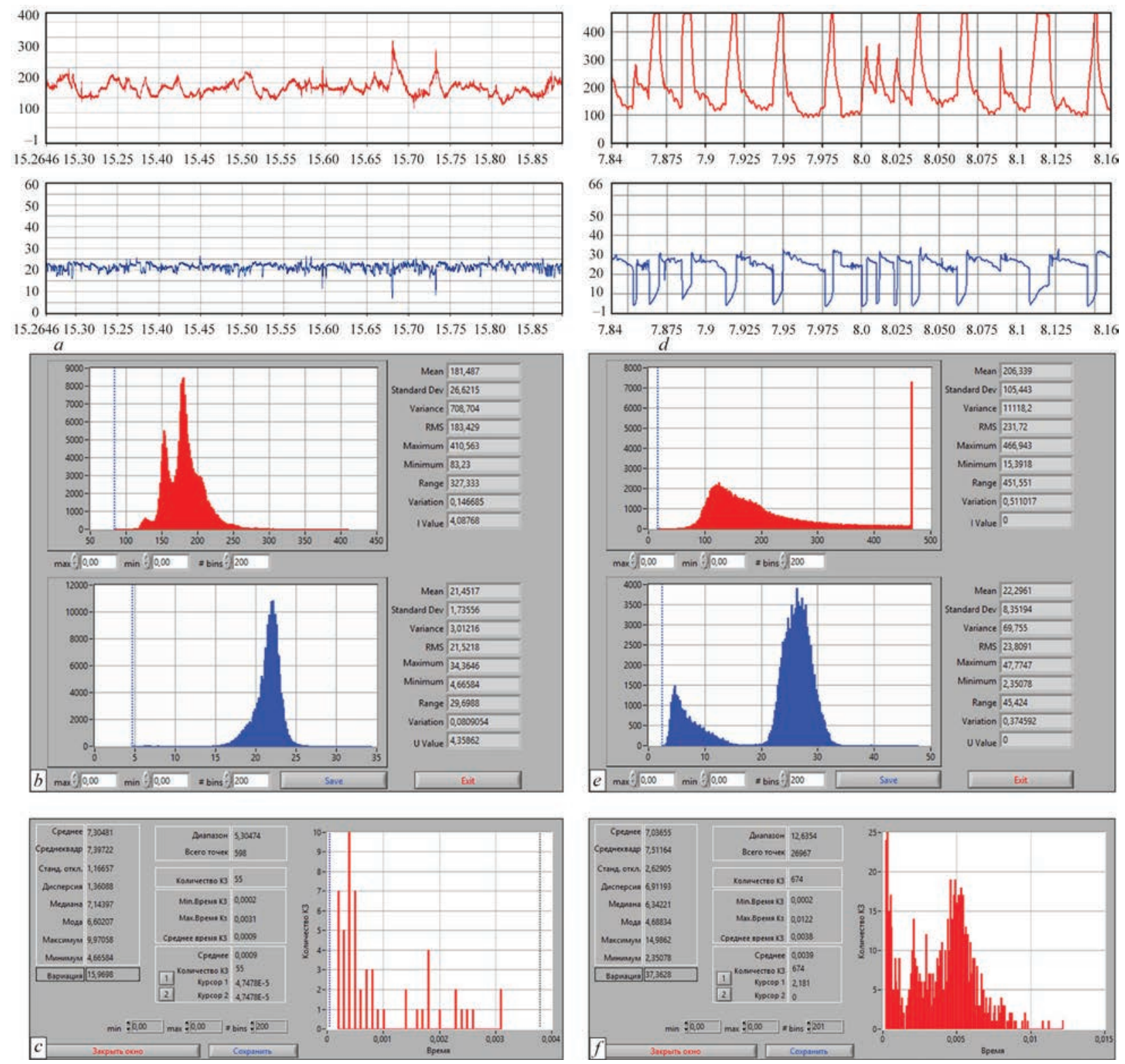

Figure 3. Oscillograms $(a, d)$, histograms of current and voltage $(b, e)$ of short circuits $(c, f)$ in welding at lower mode with wires TMV5-MK and Sv-08G2S, respectively

disappeared and maximum stability of the welding process is attained at maximum modes: $I_{\mathrm{w}}=300 \mathrm{~A}$, $U_{\mathrm{a}}=31 \mathrm{~V}$. This is proved by minimum value of coefficient of variation by voltage $(3.1 \%)$. The process oscillogram and histograms of current and voltage are given in Figure 1. The ordinate axis of histograms represents the number of repetitions of instant value of parameter being investigated.

For comparison, Figure 2 gives the similar information, obtained in welding with solid wire Sv-08G2S.

It is seen from the given Figures that in the latter case the welding is less stable with periodic fluctuations of current and voltage at the moment of drops transfer, coefficient of variation by voltage is almost 3 times higher (9.1\%). At the lower modes of welding the advantage of the metal cored wire becomes more noticeable (Figure 3), In spite of appearance of short- time short circuits with a mean duration of $2.1 \mathrm{~ms}$ the coefficient of variation by voltage is preserved at a low level $(8.1 \%)$. Welding with wire Sv-08G2S is accompanied by periodic short circuits with a mean duration of $4.7 \mathrm{~ms}$, coefficient of variation by voltage was increased by more than 4 times $(37.5 \%)$. It should be noted that the histograms of short circuits have the two-modal nature: left mode represents random short circuits, while the right one represents the real short circuits.

During investigations the significant effect of welding power source type on welding process stability was noted, which is connected with its external characteristic and electrodynamic values. Figure 4 presents the dynamic volt-ampere characteristics of welding process at applying the thyristor power source VDU-503 and inverter power source LET- 

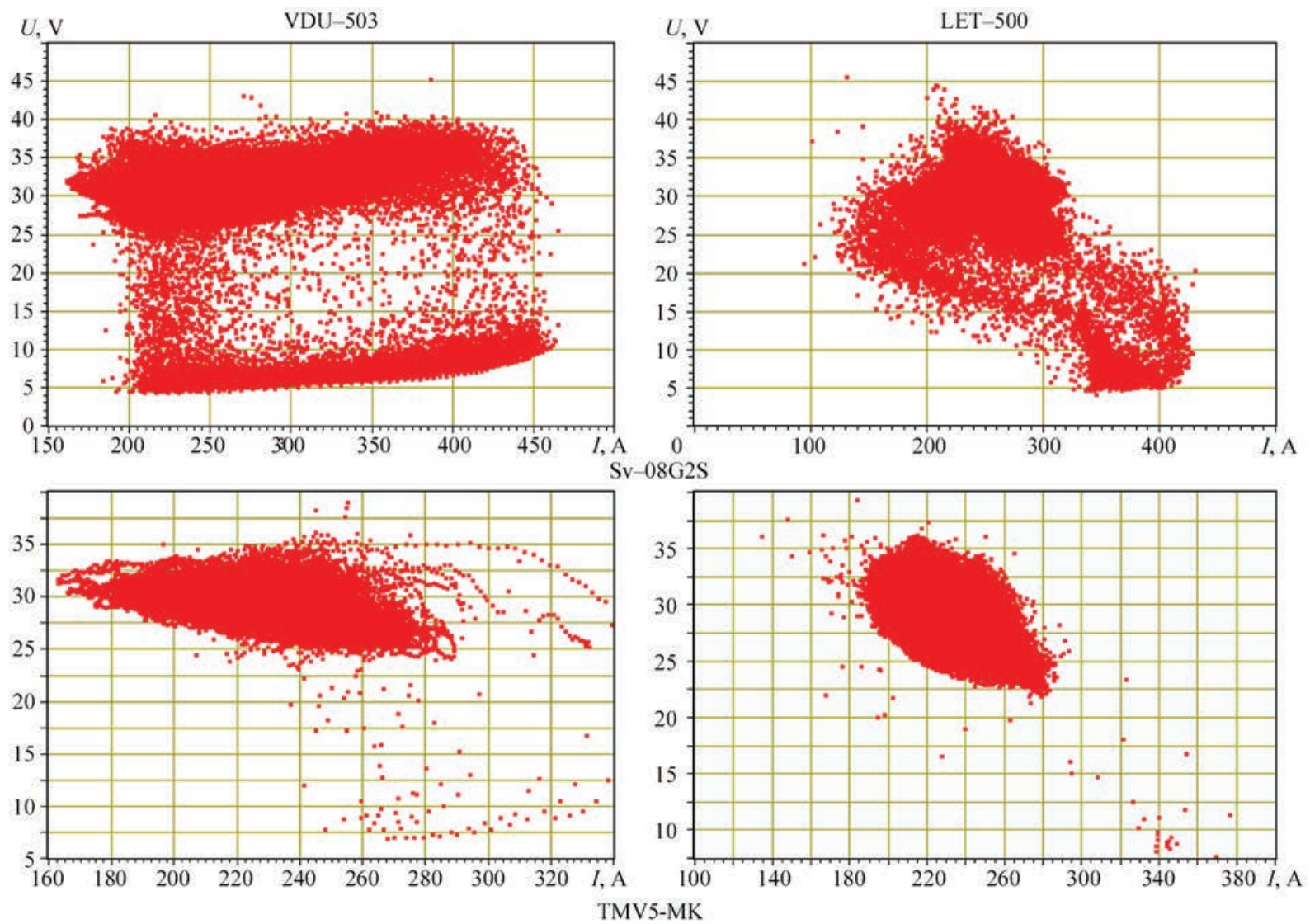

Figure 4. Dynamic volt-ampere characteristics of the welding process

500 . The inverter power source LET-500 provided the more stable process, which is characterized by more localized zone of events of recorded electric parameters of welding arc burning.

\section{Conclusions}

1. The process of welding with metal cored wire is characterized by a high stability of arc burning within the wide range of welding modes with higher technological characteristics of its application as compared with solid wire Sv-08G2S.

2. In welding at similar modes within the optimum range the value of stability of arc burning in use of solid wire $\mathrm{Sv}-08 \mathrm{G} 2 \mathrm{~S}$ is 3 times lower.

3. Welding at lower modes of welding leads to the appearance of short circuits, however, for the metal cored wire the coefficient of variation by voltage is preserved at the level of $8.1 \%$, while for the solid wire it increased by more than 4 times up to $37.5 \%$, that exceeds greatly the allowable value $20 \%$.

4. Electrodynamic properties of power source show the significant effect on the stability of welding process and this factor should be taken in consideration when evaluating the welding-technological properties of welding wires.
1. Mazur, A.A., Makovetskaya, O.K., Pustovojt, S.V., Brovchenko, N.S. (2015) Metal cored wires at the world and regional markets of welding consumables (Review). The Paton Welding J., 5-6, 63-69.

2. Shlepakov, V.N., Gavrilyuk, U.A., Kotelchuk, A.S. (2010) State-of-the-art of development and application of flux-cored wires for welding of carbon and low-alloyed steels. Ibid., 3, 38-42.

3. Rosert, R., Karasyov, M.V. (2012) Metal cored wires: tendencies, development and their application in industry. In: Proc. of St.-Petersburg Int. Conf. on Welding Consumables -2012 to 100th Anniversary of TsNIIM (Russian, St.-Petersburg, 16-18 October, 2012), 220-230.

4. Karasyov, M.V., Rabotinsky, D.N., Alimov, A.N. et al. (2008) Welding of butt joints of bridge structures and pipelines using metal cored wire and equipment for metal transfer control. The Paton Welding J., 10, 42-45.

5. Metal cored wire OUTERSHIELD ${ }^{\circledR}$. https:www.lincolnelectric.com/ruru/support/process-and-theory/Pages/metal coredwires.aspx.

6. Advantages and disadvantages of metal cored wires. http:// www.esabna.com./us/en/education/blog/advantages-anddisadvantages-of-metal cored-wires.cfm

7. Gas-arc welding of metal structures by metal cored wire withmetal core. http://www.spetselectrode.ru/download/2017-Gazoelectricheskaya-svarka-metallokonstrukciyporoshkovoy-provolokoy-s-metallicheskim-serdechnikom/1.htm

8. Pirumov, A.E., Skachkov, I.O., Suprun, S.A., Maksimov, Yu.S. (2007) Specialized information-measuring system for monitoring the process of arc welding. The Paton Welding J., 8, 34-36.

Received 17.04.2019 


\title{
INVESTIGATION OF CONDITIONS OF DEEP PENETRATION IN MANUFACTURE OF SAMPLES OF HEAT-RESISTANT ALLOY Inconel 718 BY THE METHOD OF SELECTIVE LASER MELTING
}

\author{
S.V. ADZHAMSKY ${ }^{1,2}$ and A.A. KONONENKO ${ }^{2,3}$ \\ ${ }^{1} \mathrm{O}$. Gonchar Dnipro National University \\ 72 Gagarin Ave., 49000, Dnipro, Ukraine E-mail: pk_dnu@i.ua \\ ${ }^{2}$ LLC «Additive Laser Technology of Ukraine» \\ 144 Rybinskaya Str., 49000, Dnipro, Ukraine. E-mail: info@alt-print.com \\ ${ }^{3}$ Z.I. Nekrasov Iron \& Steel Institute of the NAS of Ukraine \\ 1 Academician Starodubov Square, 49000, Dnipro, Ukraine.E-mail: office.isi@nas.gov.ua
}

\begin{abstract}
The relationship was established between the parameters of selective laser melting process (laser power and distance between tracks) and microstructure of samples of alloy Inconel 718 at the condition of applying a small diameter beam $(0.05 \mathrm{~mm})$. Using the method of selective laser melting, the samples of alloy Inconel 718 were manufactured in the installation ALT Alfa-150 of the LLC «Additive Laser Technology of Ukraine» production. For the first series of samples the alternating laser power was preset in the range of $150-250 \mathrm{~W}$, and for the second series the distance was changed between tracks in the interval of $0.09-0.13 \mathrm{~mm}$. Examination of microstructure was made in optical microscope AXIOVERT 200M MAT. The problems of effect of parameters of selective laser melting process (laser power, distance between tracks) on structure of Inconel 718 material were considered. From the results of work the relationships between the parameters of selective laser melting process and depth and width of the melt pool were determined. The conditions of a deep penetration with a formation of large pores were determined. 20 Ref., 1 Table, 6 Figures.
\end{abstract}

Keywords : additive technologies, selective laser melting, powder materials, heat-resistant nickel alloys, Inconel 718 , melt pool, conditions of deep penetration

The technologies of 3D printing of products of metallic powders appeared in the middle of the 1980s [1] and differed from the traditional methods by that the manufacture of products occurs by a successive layer-by-layer growing of powder material under the action of a high-energy source [2]. The wide spreading during recent years was found by the technology
Selective Laser Melting (SLM), i.e. selective laser melting due to the feasibility of manufacture of intricate-profiled products according to the computer model of almost any metallic powders (zinc, bronze, steel, titanium and titanium alloys, aluminium and aluminium alloys, precious metals, etc.).

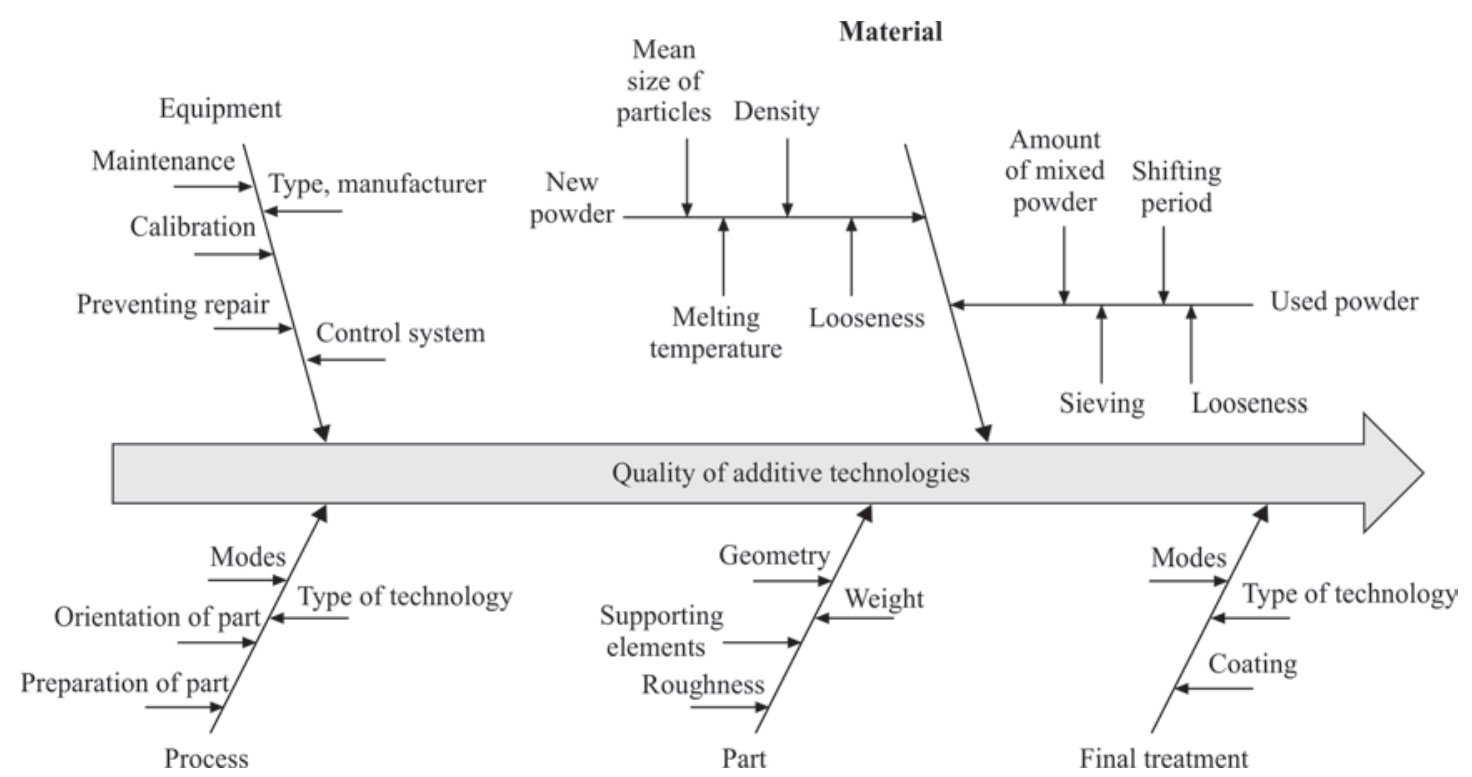

Figure 1. Factors, influencing the quality of metal products in selective laser melting [5[ 
This technology is capable to replace the classic industrial processes, allows manufacturing products, superior by the physical-mechanical properties to metal products manufactured by standard technologies. Using the selective laser melting it is possible to produce the unique intricate-profiled products without application of mechanical treatment and expensive rigging. Nowadays, the SLM technology found the application in defense industry, medicine, aircraft industry and rocketry. However, the manufacture of any products by this technology is rather expensive due to a high complication of the process.

In production of aircraft and rocket-space hardware a special place is occupied by complicated technological processes, used in manufacture of rocket engines and highly-loaded units of pneumo-hydraulic system of the rocket carrier, made of heat-resistant alloys. Technology of the selective laser melting allows several times reducing the time and number of technological operations, and the quantity of required main equipment, calculated in tens, decreasing to several ones [3].

At the present time, the urgent task is the design and improvement of equipment for realization of the selective laser melting process and development of the process rational modes, depending on the tasks: material, geometry, properties.

Aim of investigations is to establish the relation between the parameters of the selective laser melting (change in laser power and distance between tracks at constant speed laser movement at the condition of using the relatively small beam diameter: $0.05 \mathrm{~mm}$ ) and microstructure of samples manufactured of alloy Inconel 718 at the deep penetration modes.

Problem statement. Except the technological properties of powder materials, used in SLM technology, a large number of parameters of the laser melting process itself has an effect on the quality of final products (Figure 1). They include the laser power, distribution of energy in laser spot, rate and trajectory of laser beam scanning, distance between scanning tracks, thickness of powder material layer, preheating of platform, type of shielding gas [4].

A large number of works were devoted to investigation of effect of technological characteristics of

Printing parameters, porosity and parameters of melt pools of test samples

\begin{tabular}{|c|c|c|c|c|c|}
\hline $\begin{array}{c}\text { Number of } \\
\text { sample }\end{array}$ & $\begin{array}{c}\text { Laser } \\
\text { power, W }\end{array}$ & $\begin{array}{c}\text { Laser } \\
\text { movement } \\
\text { speed, } \\
\mathrm{mm} / \mathrm{s}\end{array}$ & $\begin{array}{c}\text { Porosity, } \\
\%\end{array}$ & $\begin{array}{c}\text { Width of } \\
\text { basin, } \\
\mu \mathrm{m}\end{array}$ & $\begin{array}{c}\text { Depth of } \\
\text { basin, } \\
\mu \mathrm{m}\end{array}$ \\
\hline 1 & 150 & 800 & 0.5 & 58.1 & 193.5 \\
\hline 2 & 175 & 800 & 0.3 & 70.6 & 225.8 \\
\hline 3 & 200 & 800 & 0.7 & 83.9 & 258.1 \\
\hline 4 & 225 & 800 & 2.1 & 90.3 & 322.6 \\
\hline 5 & 250 & 800 & 3.2 & 96.7 & 351.8 \\
\hline
\end{tabular}

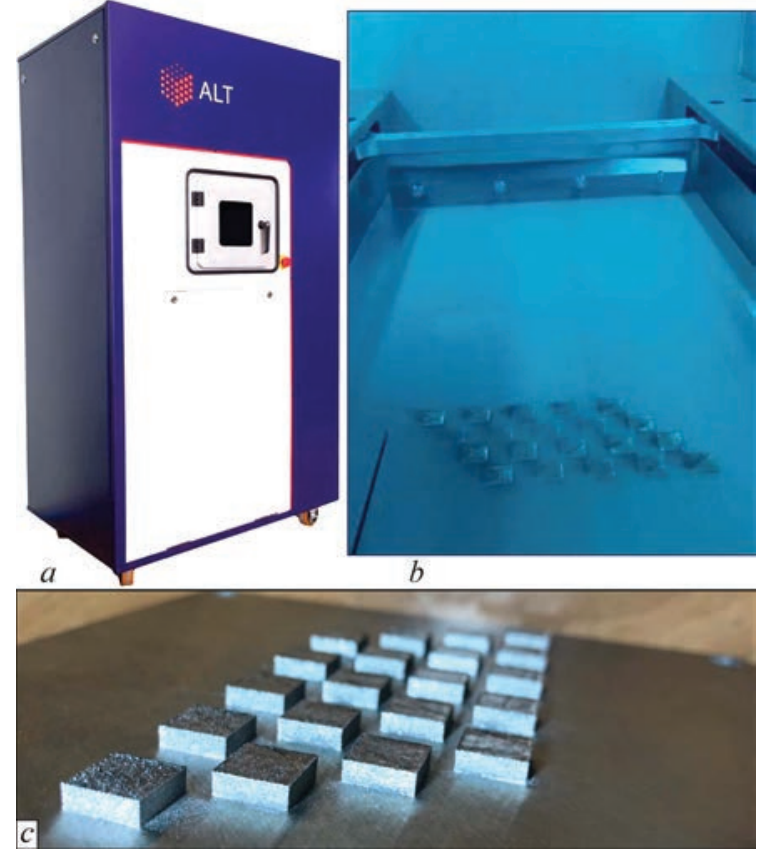

Figure 2. General view of installation ALT Alfa-150 LLC «Additive Laser Technology of Ukraine» $(a)$, working zone $(b)$ and general view of samples on the building-up platform $(c)$

powders [5-11] and manufacturing conditions [1214) on properties of products.

It follows from the results of analysis of the mentioned investigations that the main factors, influencing the formation of fused layer in realization of SLM technology, is the power of laser radiation, rate of scanning and trajectory of beam movement (law of filling the part inner area).

Description of experiment conditions and discussion of results. Samples of $10 \mathrm{x} 10 \mathrm{~mm}$ size were manufactured at $50 \mu \mathrm{m}$ thickness of powder mixture layer, 60 layers were printed. Samples were fused in argon. As a substrate, the plates of stainless steel were used. Substrate with powder was heated up to $80^{\circ} \mathrm{C}$. Argon was supplied to the chamber during the whole process of melting, amount of oxygen in chamber did not exceed $0.09 \%$. Figure 2 presents the general view of installation, working zone, where building-up of object takes place, and general view of ready samples on platform. Strategy of scanning by a laser beam in

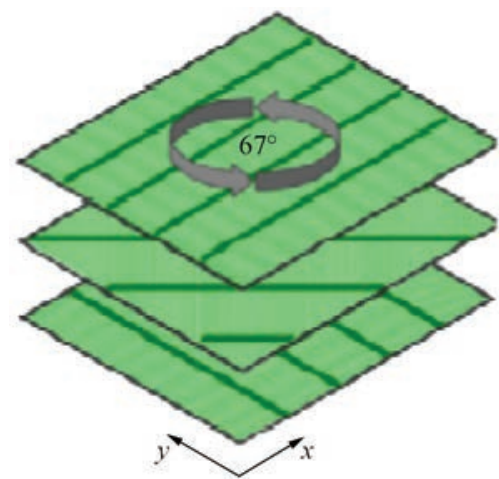

Figure 3. Scheme of layers rotation relative to the previous one 


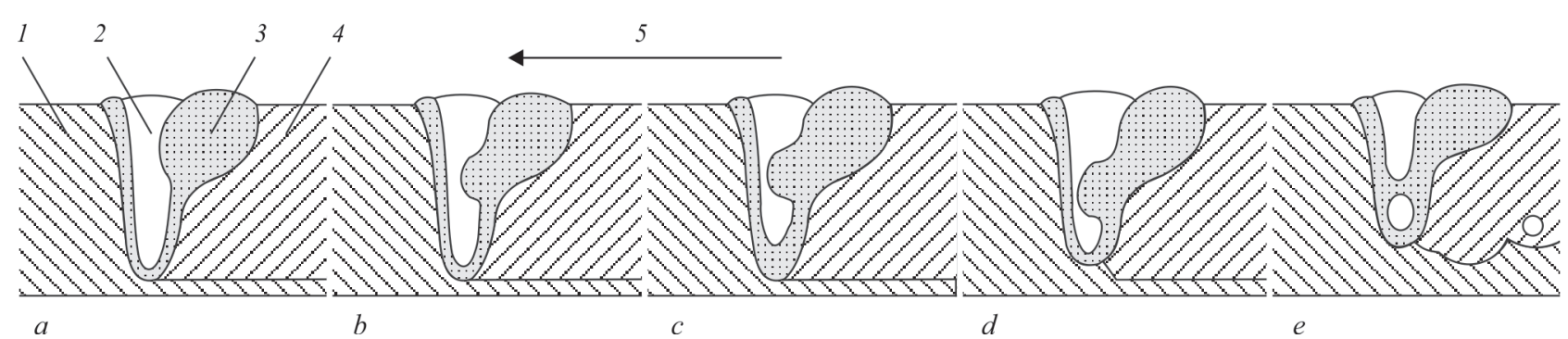

Figure 4. Scheme of porosity formation inside melt pool of track, made with parameters of deep penetration [18] (a-e — correspond to test samples Nos 1-5): 1 - substrate; 2 - crater; 3 - melt; 4 - fused track; 5 — direction of laser movement

filling the part inner area is line by line with a zigzag. The building-up was made from the platform. Experiment was performed in installation ALT Alfa-150 of LLC «Additive Laser Technology of Ukraine» manufacture. The examination of microstructure was made in optical microscope AXIOVERT 200M MAT.
To study the effect of laser power on the geometry of molten pool, five samples of alloy Inconel 718 were manufactured, keeping the scanning rate of $800 \mathrm{~mm} / \mathrm{s}$, interval between the tracks was $0.1 \mathrm{~mm}$ and alternating laser power was preset, respectively, 150, 175, 200, 225 and $250 \mathrm{~W}$. Angle of rotation of layers relative to

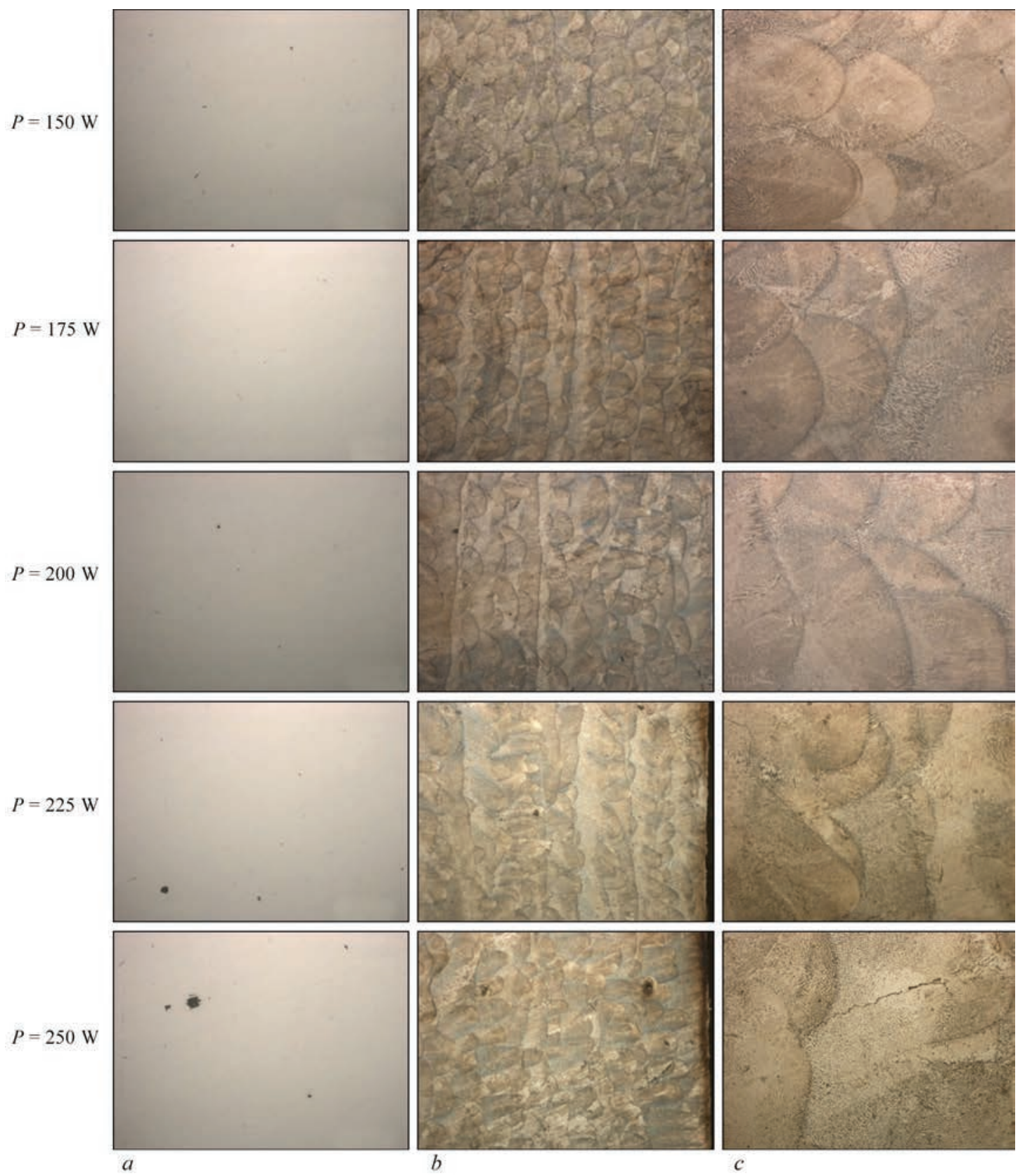

Figure 5. Porosity $(a-\times 100)$ and microstructure $(b-\times 100, c-\times 500)$ of test samples Nos $1-5$ at different laser powers 
the previous one was $67^{\circ}$ (Figure 3). Figure 4 shows the microstructure of test samples Nos 1-5.

Definite sizes of molten pools in the upper part of each sample were measured and mean value of width $w$ and depth $h$ of one pool of melt for each laser power were determined. Results of measurements are shown in Table.

It is seen that values $w, h$ and laser power $P$ are correlated that corresponds to the results obtained for other alloys [15]. It is seen that values $w$ and $h$ were increased with increase in the laser power, but the intensity of change was successively decreased. Probably, it is connected with the fact that the increased laser energy cannot be completely absorbed by powder and molten matrix due to a limited convection of melt and heat transfer. Therefore, the depth and width of a basin show the relation with laser power $P$, but they are not directly proportional $[16,17]$.

Thickness of coating layer, used in this experiment, was $50 \mu \mathrm{m}$. When the laser power was 150 $\mathrm{W}$, the depth of molten pool was $193.5 \mu \mathrm{m}$, that is larger than thickness of three layers, and when the laser power reached $250 \mathrm{~W}$ the basin depth of melt was $354.8 \mu \mathrm{m}$, exceeding the layer thickness by seven times. As a result of experiment it was found that at laser power of more than $175 \mathrm{~W}$, speed of laser movement of $800 \mathrm{~mm} / \mathrm{s}$, layer thickness of $50 \mu \mathrm{m}$ and $0.05 \mathrm{~mm}$ beam diameter the conditions of deep penetration are created. At the further increase of this parameter the pool depth is increased, the crater collapse is occurred, which leads to the formation of large pores, which is a non-repairable rejection for the printed part. Such section of the track is called «key hole». Externally the track, made in this region, looks stable and almost has no external defects. However, in the track section depth the large pores are formed, dissipating along the whole track, caused by incomplete filling of crater volume with melt and developing of shrinkage processes in it. Scheme of porosity formation inside the melt pool is shown in Figure 4.

In addition, the area of regions with a rough microstructure is increased and microcracks are observed, forming as a result of microstresses, occurring in solidification and cooling of melt due to a significant overheating.

It was determined in work [19] that at certain values of scanning interval, the reducing of porosity is observed at other equal parameters. Therefore, it is necessary for each alloy to find this optimum and this is one of possible ways to improve the structure.

Interval between the tracks is the distance between two neighboring trajectories of laser scanning (Figure 5). This distance has a direct effect on the quality of formation of each layer [20] and on the process efficiency. In addition, adjustment on inter-track interval also has an effect on the part appearance quality.

If the scanning step is too small in spite of increase in continuity of material between neighboring tracks, and pores formation will be less, the secondary remelting increase the tendency to formation of coarsegrain structure. If the scanning step is too large, the overlapping between two tracks will be insufficient.
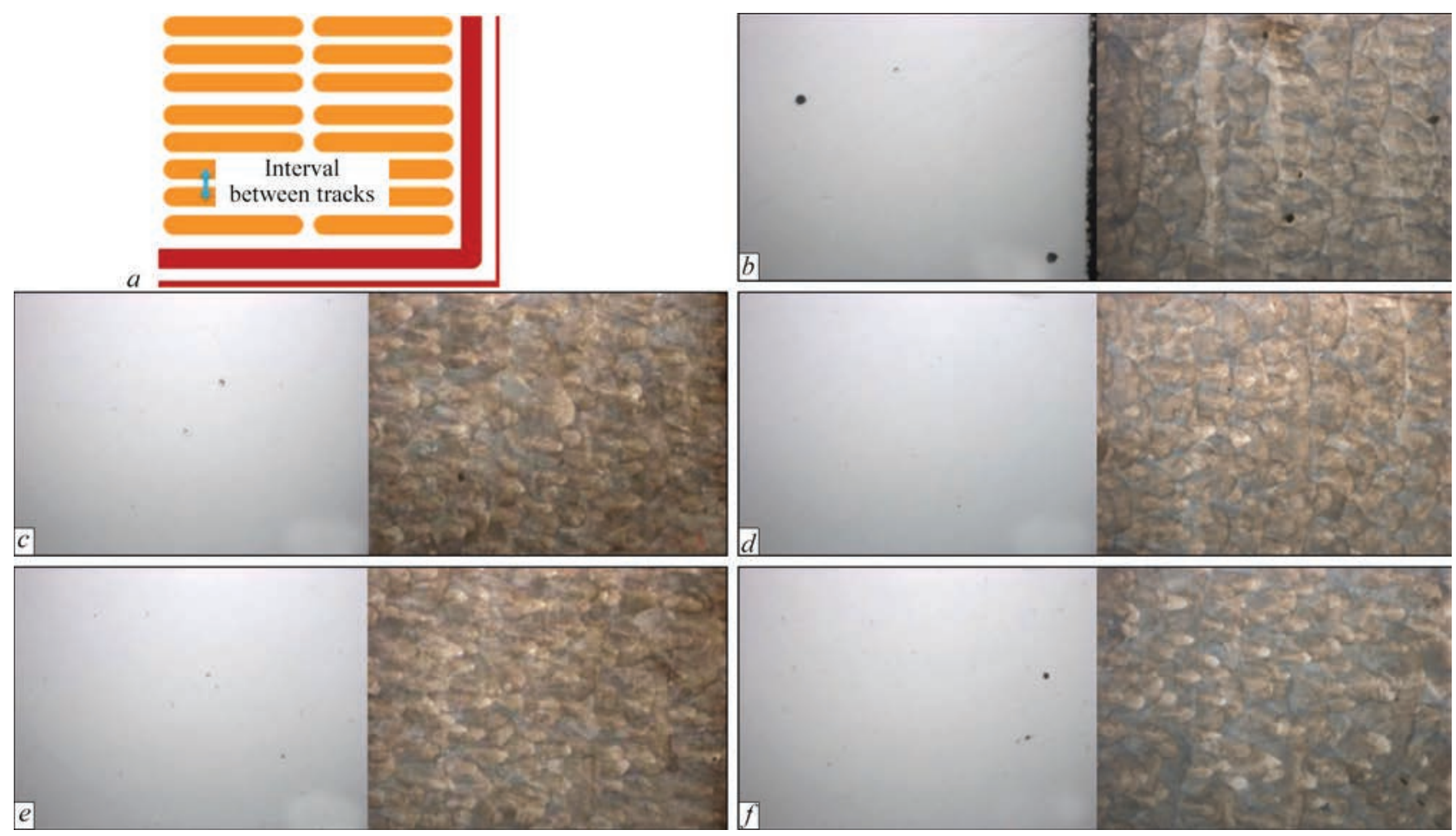

Figure 6. Scheme of determination of interval between tracks $(a-\times 100)$, microstructure $(\times 100)$ of samples Nos $6-10$ at different distances between tracks: $b-0.09 ; c-0.10 ; d-0.11 ; e-0.12 ; f-0.13 \mathrm{~mm}$ 
There will be no relation between the neighboring tracks. This generates a large number of pores, thus decreasing the density. But the rise in intertrack interval increases the area of remelting, thus increasing the coefficient of laser utilization and rate of production.

To study the effect of distance between tracks on morphology of metal structure of heat-resistant alloy Inconel 718, the samples were manufactured with change in the mentioned parameter from 0.09 up to $0.13 \mathrm{~mm}$. Figure 6 shows the microstructure at different modes of scanning. It was found within the scope of this experiment that at the distance between tracks of 0.09 and $0.1 \mathrm{~mm}$ the local overheating is occurred, due to which the porosity is increased, regions with a coarse-grain microstructure are formed. With increase in this parameter up to $0.11 \mathrm{~mm}$ the number of pores was decreased. However, with increase in interval between tracks up to $0.13 \mathrm{~mm}$ the gaps between melting pools were formed, repeated recrystallization, favorably influencing the final microstructure, was not occurred. It was established as a result of experiment that optimum values of interval between the tracks at the condition of a thin beam of laser (of $0.05 \mathrm{~mm}$ order) are $0.11-0.12 \mathrm{~mm}$.

The further investigations will be directed for establishing the optimum modes in changing the scanning rate and better combination of speed and power of laser with account for radiation density to attain the high quality of metal and efficiency of installation.

\section{Conclusions}

It is shown as a result of investigations that morphology of molten pool is connected with laser power and distance between the scanning lines. Determined are the values of scanning parameters for alloy Inconel 718 from the point of view of decrease in porosity and creation of the dispersed microstructure: distance between tracks is $0.1 \mathrm{~mm}$, laser power is $175 \mathrm{~W}$ at laser movement speed of $800 \mathrm{~mm} / \mathrm{s}, 50 \mu \mathrm{m}$ layer thickness, $0.05 \mathrm{~mm}$ beam diameter. It was established that at laser power of more than $175 \mathrm{~W}$ the conditions of deep penetration with formation of large pores are created.

1. Zlenko, M.A., Nagajtsev, M.V., Dovbysh, V.M. (2015) Additive technologies in mechanical engineering. Moscow, NAMI [in Russian].

2. Campanelli, S.L., Contuzzi, N., Angelastro, A., Ludovico, A.D. (2010) Capabilities and Performances of the Selective Laser Melting 279. Process: New Trends in Technologies: Devices, Computer, Communication and Industrial Systems, 233-252.

3. Huzel, D.K., Huang, D.H. (1967) Design of Liquid Propellant Rocket Engines. Huston, National Aerospace and Space Administration.

4. Babakova, E.V., Khimich, M.A., Saprykin, A.A., Ibragimov, E.A. (2016) Application of selective laser melting for produc- ing of low modulus alloy of Ti-Nb system. Vestnik PNIPU, 18(1), 117-131 [in Russian].

5. Kempen, K., Thijs, L., Van Humbeeck, J., Kruth, J.-P. (2012) Mechanical properties of AlSi10Mg produced by SLM. Physics Procedia, 39, 439-446.

6. Olakanmi, E.O. (2013). Selective laser sintering/melting (SLS/SLM) of pure Al, Al-Mg, and Al-Si powders: Effect of processing conditions and powder properties. J. Mater. Process. Technol., 213, 1387-1405.

7. (1983) GOST 25849-83: Metallic powders. Method for determination of particle shape. Moscow, Standarty [in Russian].

8. Louvis, E., Fox, P., Sutcliffe, Ch.J. (2011) Selective laser melting of aluminium components. J. Mater. Process. Technol., 211, 275-284.

9. Olakanmi, E.O., Dalgarno, K.W., Cochrane, R.F. (2012). Laser sintering of blended AlSi powders. Rapid Prototyping J., 18(2), 109-119.

10. Aboulkhair, N.T., Everitt, N.M., Ashcroft I., Tuck Ch. (2014) Reducing porosity in AlSil0Mg parts processed by selective laser melting. Additive Manufacturing J., 1-4, 77-86.

11. Yadroitsev, I., Krakhmalev, P., Yadroitsava, I. et al. (2013) Energy input effect on morphology and microstructure of selective laser melting single track from metallic powder. J. Mater. Process. Technol., 213, 606-613.

12. Maamoun, A.H., Xue, Yi F., Elbestawi M.A., Veldhuis S.C. (2018) Effect of selective laser melting process parameters on the quality of Al alloy parts: Powder characterization, density, surface roughness, and dimensional accuracy. Materials, 11, 2343, doi:10.3390/ma11122343.

13. Calignano, F., Manfredi, D., Ambrosio, E.P. et al. (2013) Influence of process parameters on surface roughness of aluminum parts produced by DMLS. Int. J. Adv. Manuf. Technol., 67, 2743-2751.

14. Koutiri, I., Pessard, E., Peyre, P. et al. (2018) Influence of SLM process parameters on the surface finish, porosity rate and fatigue behavior of as-built Inconel 625 parts. J. Mater. Process. Techn., 255, 536-546.

15. Tucho, W.M., Lysne, V.H., Austbø, H. et al. (2018) Investigation of effects of process parameters on microstructure and hardness of SLM manufactured SS316L. J. Alloys Compd., 740, 910-925.

16. Kurzynowski, T., Gruber, K., Stopyra, W. et al. (2018) Correlation between process parameters, microstructure and properties of $316 \mathrm{~L}$ stainless steel processed by selective laser melting. Mater. Sci. Eng. A, 718, 64-73.

17. Liverani, E., Toschi, S., Ceschini, L., Fortunato, A. (2017) Effect of selective laser melting (SLM) process parameters on microstructure and mechanical properties of 316L austenitic stainless steel. J. Mater. Process. Technol., 249, 255-263.

18. Amara, E.H., Fabbro, R. (2008) Modelling of gas jet effect on the melt pool movements during deep penetration laser welding. J. of Physics D: Applied Physics, 41, 10. doi:10.1088/0022-3727/41/5/055503.

19. Sukhov, D.I., Mazalov, P.B., Nerush, S.V., Khodyrev, N.A. (2017) Effect of parameters of selective laser melting on pore formation in synthesized material of corrosion-resistant steel. Trudy VIAM, 8, 34-44 [in Russian].

20. Gu, D.D., Shi, Q.M., Lin, K.J., Xia, L.X. (2018) Microstructure and performance evolution and underlying thermal mechanisms of Ni-based parts fabricated by selective laser melting. Addit. Manuf., 22, 265-278. 


\title{
NITROGEN ALLOYING OF WELD METAL IN ARC WELDING OF CORROSION-RESISTANT STEELS (Review)
}

\author{
V.N. LIPODAEV \\ E.O. Paton Electric Welding Institute of the NAS of Ukraine \\ 11 Kazimir Malevich Str., 03150, Kyiv, Ukraine. E-mail: office@paton.kiev.ua
}

\begin{abstract}
The paper shows the favourable effect of nitrogen alloying of high-alloyed corrosion-resistant steels and weld metal on stabilization of the structure, prevention of grain boundary segregation in the HAZ and weld metal, and ensuring high corrosion resistance and technological strength of welded joints. 15 Ref., 2 Tables, 10 Figures.
\end{abstract}

Ke y w o r d s : arc welding, corrosion-resistant steels, nitrogen alloying, structure, corrosion resistance, technological strength, coated electrodes

Today corrosion-resistant austenite and two-phase (duplex) nitrogen alloyed steels make a considerable portion among structural steels used in operation in contact with high and even highly corrosive media [1-3]. They are used in production of technological equipment for manufacture of sulfate and phosphorous fertilizers, carbamide, in pulp-and-paper industry, oil-and-gas and pharmaceutical industry. Such steels demonstrate high resistance to effect of sulfuric, ortophosphoric, acetic, formic acids and sea water.

Alloying of noted steels with nitrogen allows [4, 5]:

- reduce without damage to life time, reliability and life duration of the material, content in it of nickel at conservation of set austenite or austenite-ferrite structure;

- increase without variation of phase composition the content in steels of elements-ferritizers (Mo, V, W) having positive effect on life duration, mechanical and corrosion characteristics of products;

- strengthen $\alpha$ - and $\gamma$-solid solutions at virtually invariable levels of their ductility and toughness and, thus, rising allowable stresses in the structures;

- provide increased resistance of equipment to intercrystalline corrosion (Figure 1) and stress corrosion, and at simultaneous nitrogen and molybdenum alloying - increased resistance to general, pitting and crevice corrosion;

- eliminate alloying of steels with titanium or niobium and, thus, preventing the possibility of appearance of «knife-like» corrosion in welded joints (Figure 2);

- improve the characteristics of technological ductility as a result of expansion of interval of existence of austenite in high-temperature field;

- provide an economical effect due to implementation of new, more sparsely-alloyed steels, having increased mechanical characteristics, reliability and life duration of operation of equipment made of them.

The publications do not describe in a lot of details the effect of nitrogen in high-alloy steels on their weldability. Nevertheless, work [7] outlines the relevance of elimination of titanium or niobium from
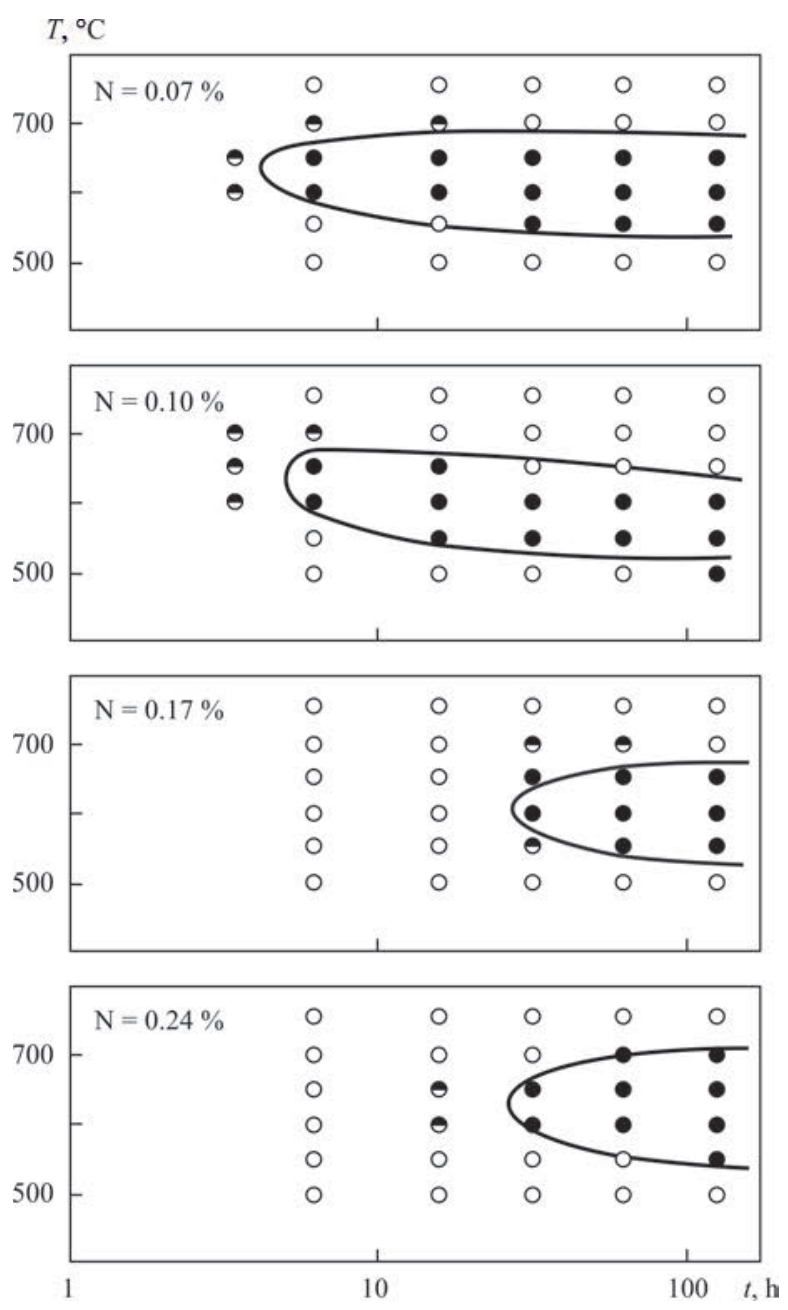

Figure 1. Temperature fields of susceptibility of 03Kh19N10AG3 steel to ICC (method DU GOST 6032-84 [6] 


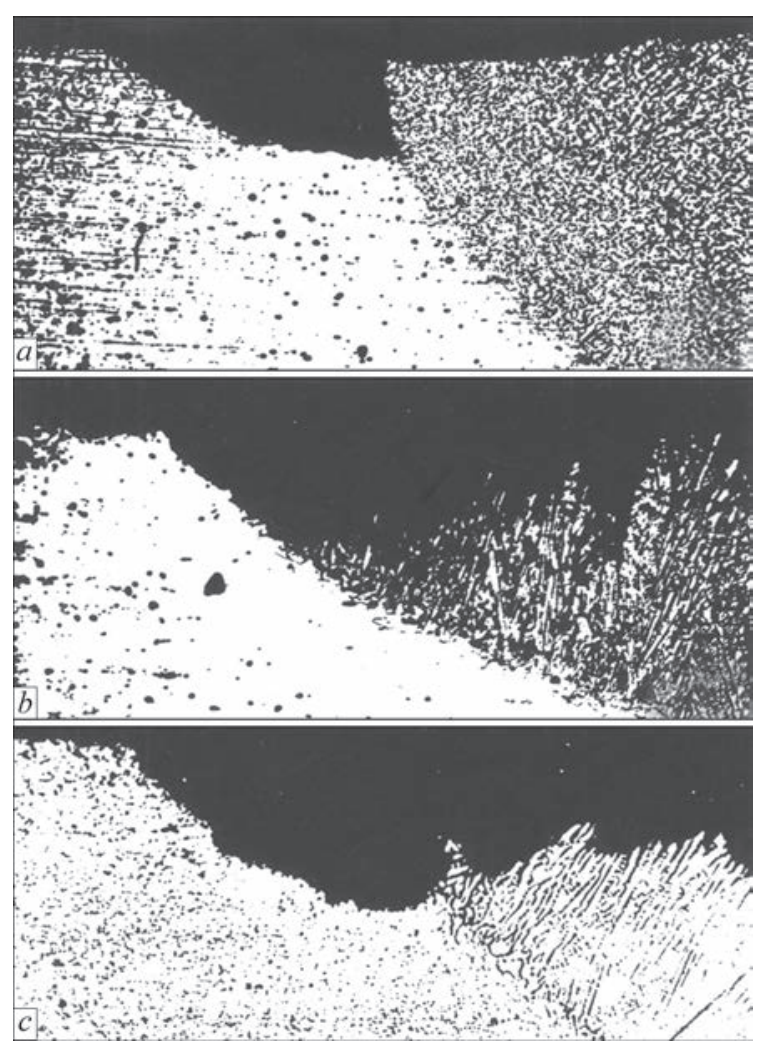

Figure 2. Knife corrosion of welded joints in production of nitrophoska: $a$ - welded joint of steel 10Kh17N13M3T (EA-400/ (10u electrodes) $(\times 100)$; $b-$ welded joint of 06KhN28MDT alloy (KhL-1 electrodes) $(\times 200) ; c-$ welded joint of $03 \mathrm{Kh} 21 \mathrm{~N}$ 21M4GB steel (OZL-17U electrodes) $(\times 100)$

composition of steel $03 \mathrm{Kh} 12 \mathrm{~N} 21 \mathrm{M} 4 \mathrm{~GB}$ and alloys 03KhN28MDT and 06KhN28MDT titanium or niobium, limitation in their content of sulfur and phosphor and their additional alloying with nitrogen in the limits of equilibrium solubility ( $0.15-0.25 \%)$. It is shown that in this case the materials are not susceptible to knife-like corrosion (Figure 3), demonstrate increased ICC corrosion resistance (Figure 4) as well as have resistance to near-weld crack formation (Figures 5, 6). This effect is achieved due to effect of nitrogen on suppression of segregation processes in high-temperature segment of near-weld metal zone [8].

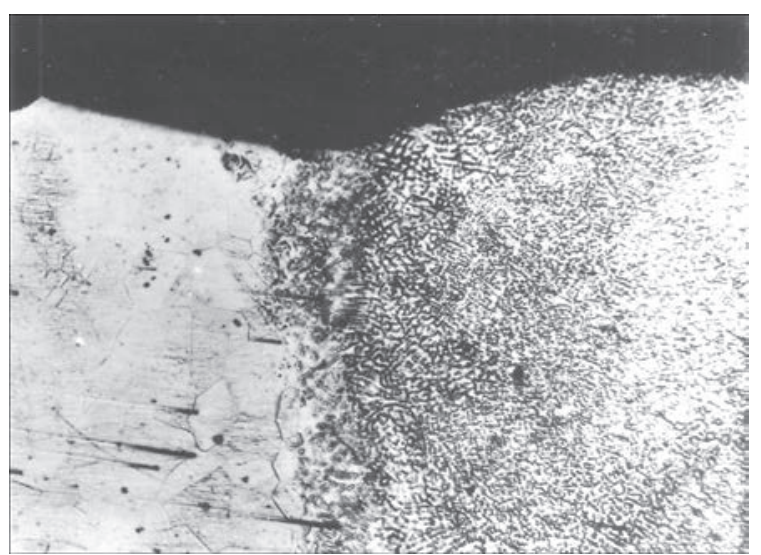

Figure 3. Microstructure $(\times 200)$ of fusion zone of welded joint of steel $02 \mathrm{Kh} 22 \mathrm{~N} 20 \mathrm{M} 4 \mathrm{AG}$ after corrosion tests on susceptibility to knife corrosion
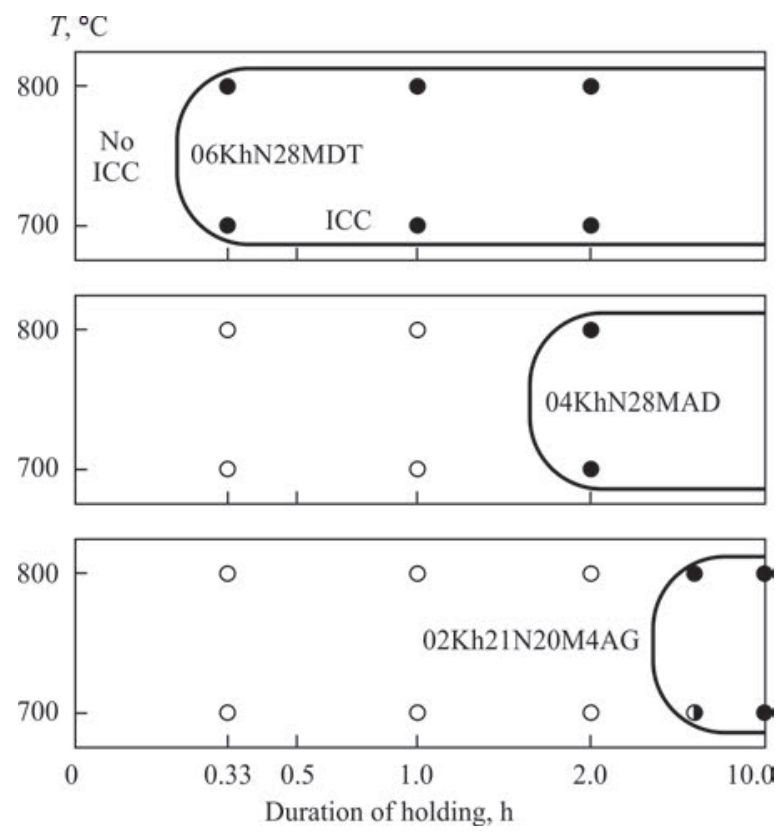

Figure 4. Resistance of materials to ICC

Today, nitrogen alloying is used for steels designed for manufacture of welding equipment and apparatuses, in the amounts, as a rule, corresponding to its normal solubility under atmospheric pressure, and other alloying elements in the amounts, providing after

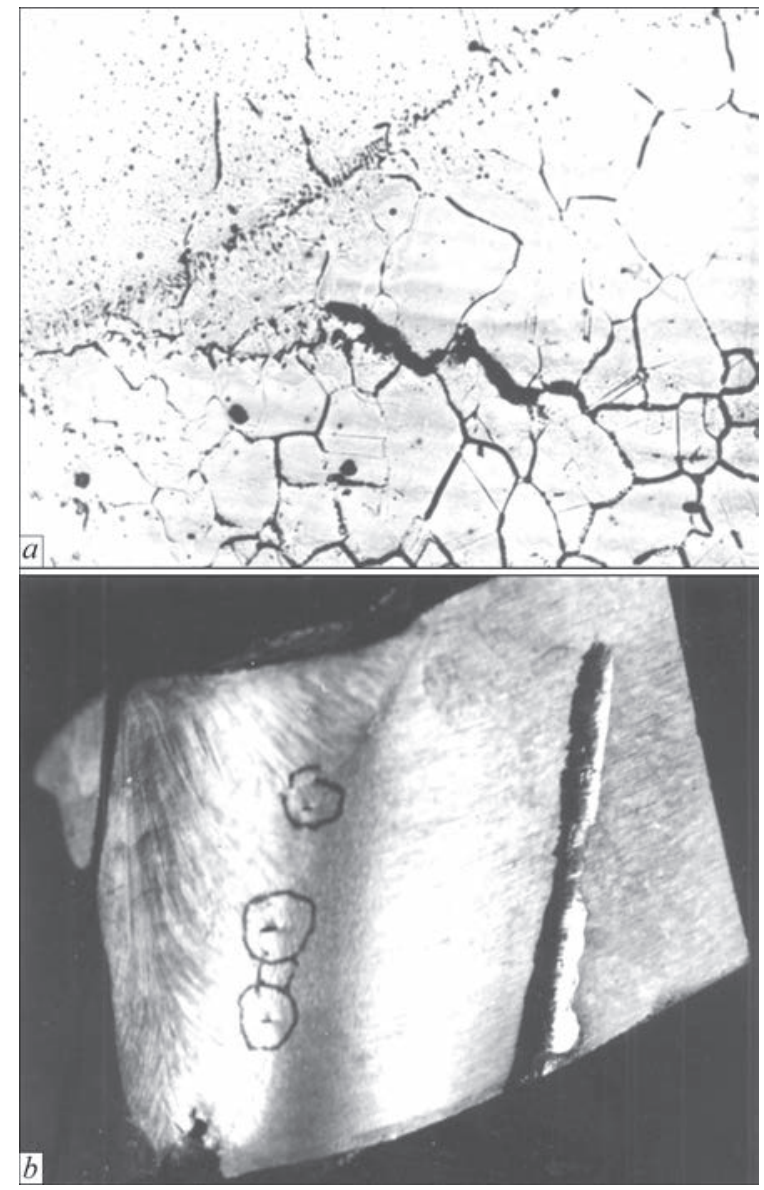

Figure 5. Hot cracks in near-weld zone of welded joints: $a-$ steel 03Kh21N21M4GB (ANV-17 grade electrodes) $(\times 250)$; $b-$ alloy 06KhN28MDT (ANV-28 grade electrodes) $(\times 1.5)$ 
quenching conservation of nitrogen in solid solution for obtaining the maximum corrosion resistance.

Below, Table 1 provides the typical compositions of modern high-alloy nitrogen-containing steels, found wide application in different branches of industry, mainly, abroad.

It can be interesting to analyze the efficiency of application of nitrogen as an alloying element in the metal of corrosion-resistant welds. Paper [9] showed that in order to reach corrosion resistance equivalent to base metal of $03 \mathrm{Kh} 17 \mathrm{~N} 14 \mathrm{AM} 5$ type it is reasonable also to alloy it with nitrogen in $0.14-0.20 \%$ amount. At that, weld metal containing $0.06 \%$ of carbon and alloyed with nitrogen, without $\mathrm{Ti}$ and $\mathrm{Nb}$ stabilizing, is not susceptible to ICC.

The investigations, carried at the E.O. Paton Electric Welding Institute, revealed that alloying of austenite weld metal with nitrogen promotes increase of its resistance to hot cracking. The effect is strengthened at simultaneous alloying of welds with nitrogen together with manganese. These peculiarities were used in development of welding wire $01 \mathrm{Kh} 19 \mathrm{~N}$ 18G10AM4 and electrodes of ANV-17 grade [10].

It was also determined that nitrogen alloying of weld metal of $03 \mathrm{Kh} 18 \mathrm{~N} 18 \mathrm{G} 5 \mathrm{AM} 4$ type in welded joint of steel $03 \mathrm{Kh} 16 \mathrm{~N} 15 \mathrm{M} 3$ even under conditions of testing in $65 \%$ boiling $\mathrm{HNO}_{3}$ does not reveal tendency to ICC (Figure 7).

One more positive feature of nitrogen in weld metal alloying was determined in evaluation of behavior of welded joints of steels $03 \mathrm{Kh} 16 \mathrm{~N} 15 \mathrm{M} 3$, $03 \mathrm{Kh} 17 \mathrm{~N} 14 \mathrm{M} 3$, used in carbamide production. Tests of joints with purely austenite weld metal structure (electrodes ANV-17) and austenite-ferrite (electrodes NZh-13, 09Kh19N10G2M2B alloying type), showed that in the second case there is development of structure-selective corrosion on ferrite phase (Figure 8). It was determined that this phenomenon is caused by redistribution of alloying elements between austenite

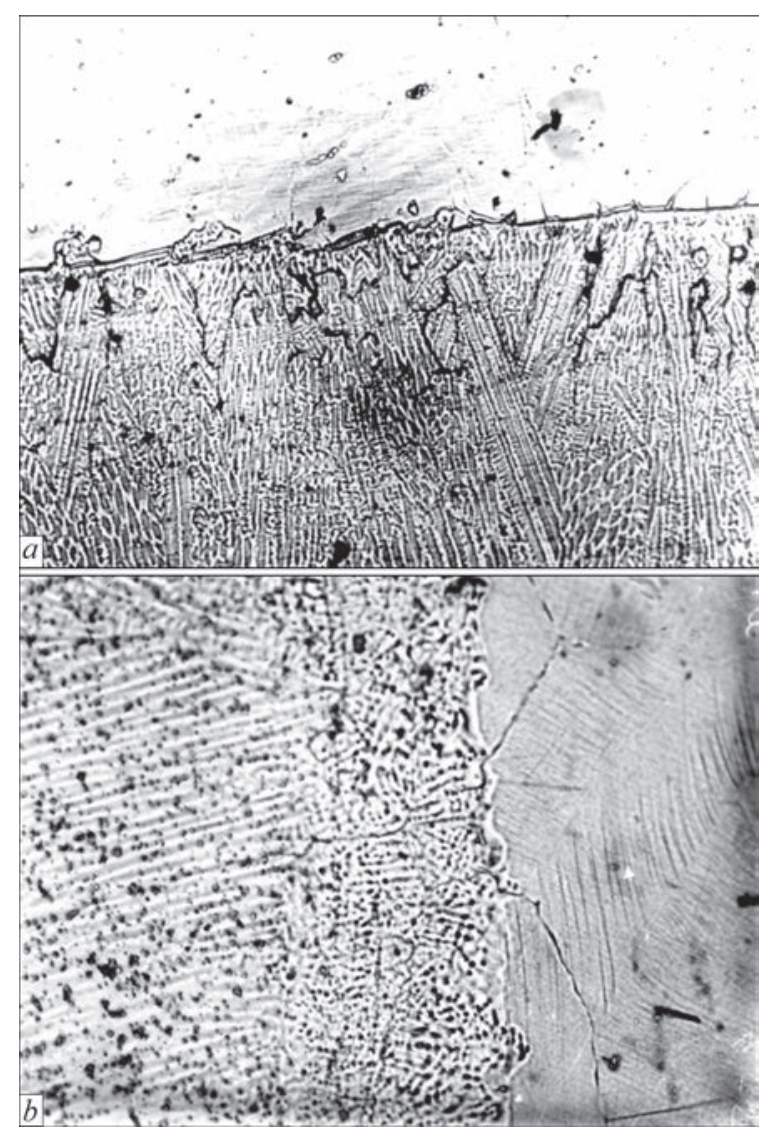

Figure 6. Microstructure of fusion zone: $a-$ steel $02 \mathrm{Kh} 22 \mathrm{~N}$ 20M4AG4 (×100); $b$ - alloy 04KhN28MAD $(\times 400)$

and ferrite phases, resulting in appearance of a galvanic microcouple (ferrite is the anode).

High-alloy weld metal, having molybdenum in its content, can show a tendency to embrittlement due to precipitation in it of $\sigma$-phase. This phase precipitates at metal staying in $600-900{ }^{\circ} \mathrm{C}$ temperature range. Its appearance was determined, for example, in performance of multipass welding of steel 10Kh1713M3T of $45 \mathrm{~mm}$ thickness with NZh-13 grade electrodes (content of ferrite phase in the deposited metal 2-8\%). Purely austenite welds with nitrogen, made of

Table 1. High-alloy corrosion-resistant nitrogen-containing steels

\begin{tabular}{|c|c|c|c|c|}
\hline \multicolumn{2}{|c|}{ Steel grade on standards } & \multirow{2}{*}{ Alloying type } & \multirow{2}{*}{$\begin{array}{l}\text { Average content of } \\
\text { nitrogen, wt. } \%\end{array}$} & \multirow{2}{*}{ Field of application } \\
\hline EN & ASTM/AISI & & & \\
\hline \multicolumn{4}{|c|}{ Austenitic } & \multirow{12}{*}{$\begin{array}{l}\text { Oxidizing media, production of carbamide, sea tankers, } \\
\text { pulp and paper industry, chemical and oil and chemical } \\
\text { branches, production of fertilizers }\end{array}$} \\
\hline 1.4311 & 303LN & 0318AN10 & 0.13 & \\
\hline 1.4439 & 317LN & 03Kh17N13AM5 & 0.12 & \\
\hline 1.4539 & N08904 & 04Kh25N20AM5 & 0.25 & \\
\hline 2293NL & 2209 & 02Kh23N9M3AG & 0.16 & \\
\hline $25104 \mathrm{~L}$ & 2594 & 02Kh25N10AM4 & 0.25 & \\
\hline \multicolumn{4}{|c|}{ Duplex } & \\
\hline 1.4482 & S32001 & 02Kh20N2G5AD & 0.15 & \\
\hline 1.4655 & & 02Kh23N5G2AD & 0.10 & \\
\hline 1.4462 & S32205 & 02Kh22N6M3AG & 0.18 & \\
\hline 1.4507 & S32550 & 02Kh26N6M3AG & 0.17 & \\
\hline 1.4501 & S32760 & 02Kh25N7M4GAD & 0.27 & \\
\hline
\end{tabular}




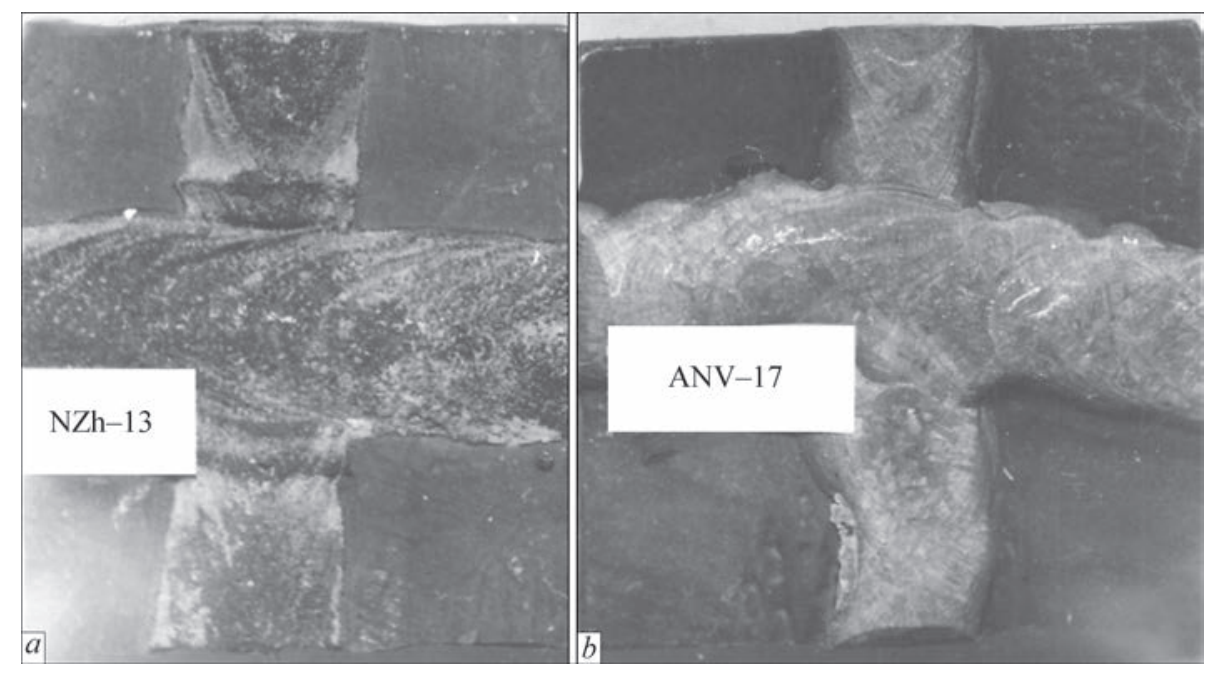

Figure 7. Samples with cross welds on steel 06Kh17N16M3T: $a-$ NZh-13 electrodes (5.7 \% of ferrite); $b-$ ANV-17 electrodes (purely austenitic) after boiling in $65 \% \mathrm{HNO}_{3} 200 \mathrm{~h}$

this steel with ANV-17 electrodes, do not demonstrate such susceptibility [11].

In general, with increase of content of element-ferritizers (chromium, molybdenum) in a composition of high-alloy austenite steels and homogeneous to them weld metal for the purpose of improvement of corrosion resistance in highly corrosive medium there is a rise of susceptibility to appearance of intermetallic phases. It can result in loss of their corrosion resistance (Figure 9). And in this case the weld metal alloying with nitrogen promotes prevention of appearance of excessive phases and conservation of high corrosion resistance.

Application of nitrogen as an alloying element in welding consumables has found application in modern developments of such well-known companies as
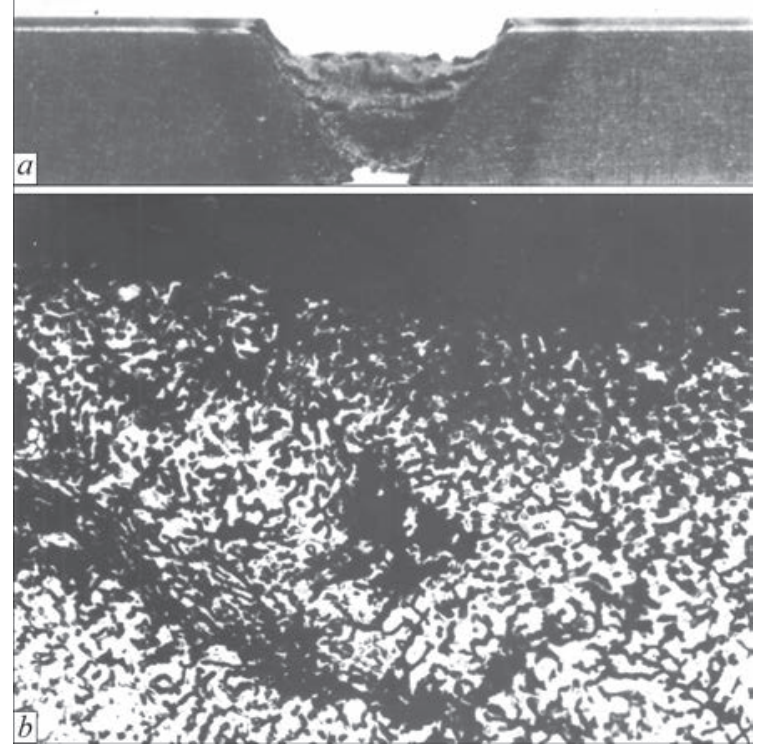

Figure 8. Corrosion resistance of welded joint of steels in carbamide production [11]: $a$ - appearance of welded joint of steel $08 \mathrm{Kh} 17 \mathrm{~N} 16 \mathrm{M} 3 \mathrm{~T}$, made by NZh-13 electrodes ( $\alpha$-phase 75 vol.\%) after testing in synthesis column during $6337 \mathrm{~h} ; b$ microstructure $(\times 200)$ of sample surface section
ESAB, Kobelco, Sandvik, voistalpine Bohler Welding and others.

Let's consider such alloying realized by the example of a range of coated electrodes of ESAB Concern [12].

OK 64.30 grade electrodes (04Kh19N13M4AG alloying type, nitrogen content in the deposited metal 0.08 wt.\%). The electrodes are used for welding of standard austenite steels of 17-13-3 type, but due to increased content of chromium and molybdenum in the deposited metal it is possible to achieve increase of total corrosion resistance and resistance to pitting corrosion in joint weld metal. Nitrogen can help to provide improvement of ICC resistance as well as

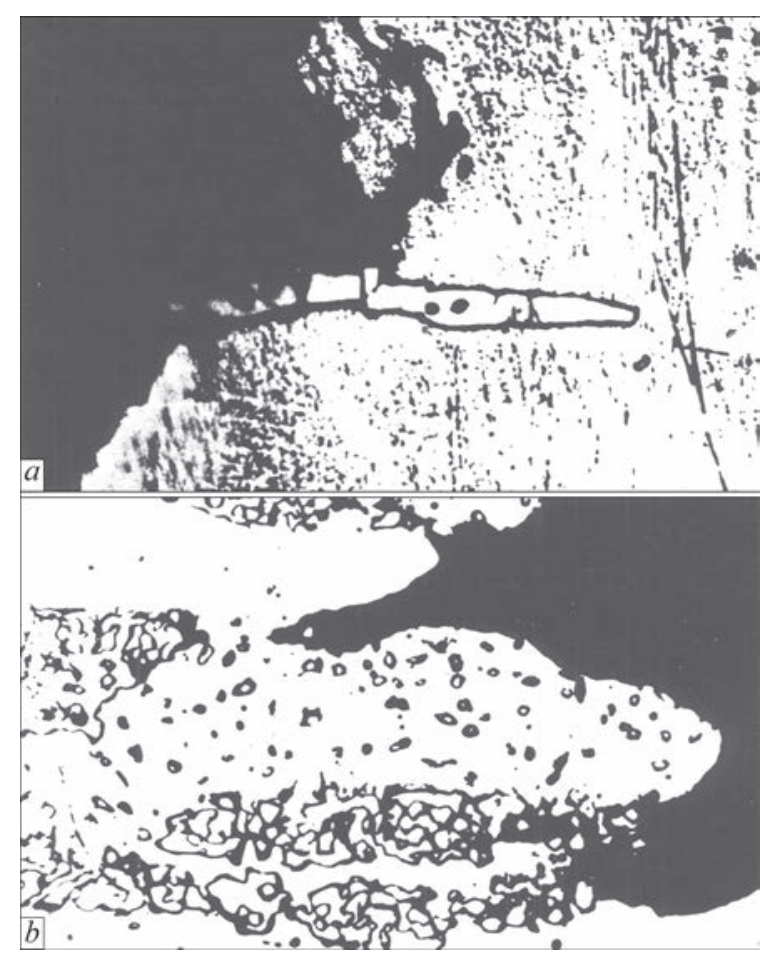

Figure 9. Nature of corrosion of mixing machine blade of steel 05Kh25N25M2T: $a$ - after testing at Shchekinsky PJSC «Azot» $(\times 200) ; b$ - after testing in $40 \% \mathrm{HNO}_{3}+2 \% \mathrm{HF}(\times 1000)$ 
limitation of amount (3-6\%) of ferrite phase in the deposited metal.

OK 310Mo-L grade electrodes (alloying type 04Kh24N22M3AG4, nitrogen content 0.14 wt.\%). They are used for welding of steels of carbamide class: 03Kh17N14M3T, 06Kh16N15M3T，02Kh25N22AM2 and similar to them. The deposited metal is completely austenite and has exclusively high corrosion resistance in highly corrosive media, for example, in contact with carbamide.

OK 69.33 grade electrodes (03Kh20N25M5AD2 alloying type, nitrogen content 0.08 wt.\%). Deposited purely austenite metal is resistant to effect of sulfuric, orthophosphoric, acetic, formic acids and sea water. It is resistant to ICC, pitting and crevice corrosion cracking.

Three grades of coated electrodes are recommended for welding of austenite-ferrite (duplex) steels:

- OK 57.56 electrodes (04Kh23N7AG alloying type, nitrogen content 0.15 wt.\%) are used for welding of «budget-friendly» (lower alloying) steels of 08Kh22N6T type and similar to them;

- OK 67.50 electrodes (04Kh22N9M2AG alloying type, nitrogen content $0.16 \mathrm{wt} . \%$ ) are used for welding of standard duplex steels of $21 \% \mathrm{Cr}-5 \%$ $\mathrm{Ni}-3 \% \mathrm{Mo}-\mathrm{N}$ type or similar to them;

- OK 68.54 electrodes (04Kh25N9M4AG alloying type, nitrogen content $0.16 \mathrm{wt} . \%$ ) are used for welding of super duplex steels of $25 \% \mathrm{Cr}-7 \%$ $\mathrm{Ni}-4 \% \mathrm{Mo}-\mathrm{N}$ type and similar to them.

Nitrogen alloying provides limitation of content of ferrite phase in weld metal in 25-35\% amount.

Similar materials for welding of nitrogen-containing steels are proposed on the market by voistalpine Bohler Welding Company: FOX CH22/9 (03Kh23N9AM2 alloying type, nitrogen content 0.17 wt.\%), FOX ASNS (04Kh19N17M4AG3 type, nitrogen content 0.15 wt.\%), FOX CN20/25M-A (04Kh20N25M6G4AD2 alloying type, nitrogen content 0.14 wt.\%).
Sumy-Electrode LLC, a leading in Ukraine manufacturer of special electrodes for welding of high-alloy, high-strength steels and dissimilar joints also produces a series of coated electrodes providing nitrogen-containing deposited metal. Among them are the electrodes EA-395/9, NIAT-5, TsT-10 (11Kh15N25M6AG2 alloying type, nitrogen content 0.10-0.12 wt.\%), EA-112/15, EA-951/15 (09Kh15N25M6AG2F alloying type, nitrogen content 0.08 0.10 wt.\%), ANV-17 (02Kh19N18G5AGM3 alloying type, nitrogen content $0.2 \mathrm{wt} . \%$ ).

It should be noted that high-alloy nitrogen-containing materials, for example, EA-395/9, NIAT-5 and other, are used in welding of critical structures of alloyed high-strength steels with limited weldability - welding of steels of austenite class of $08 \mathrm{Kh} 18 \mathrm{~N} 10 \mathrm{~T}, 10 \mathrm{Kh} 17 \mathrm{~N}-$ 13M2T type and similar to them with steels of pearlite class, performance of transition layer in multipass welds in products of double-layer clad steels. Besides, they are used for preliminary surfacing of edges of products from pearlite class steels in their welding with steels of austenite class. Work [13] demonstrates the cases of appearance of porosity in weld metal in welding with austenite electrodes with core of Sv-10Kh16N25M6AF wire in overhead position. The recommendations were made on limitation of nitrogen content in weld metal by $0.09 \%$ value (instead $0.1-0.2 \%$ ).

At once elimination of pores of nitrogen origin can be reached by increase of oxygen concentration in the melt of weld pool [14] by means of addition, for example, oxides of iron or chromium in the electrode coating.

Method of nitrogen addition as alloying element into a weld metal. Alloying via welding wire is mostly used . In a series of cases such alloying is possible using nitrogen-containing metallic powders or ferroalloys in the electrode coatings or flux-cored wire cores. Content of nitrogen in them can reach 25-35 wt.\% (Table 2).

Table 2. Composition of nitrated ferroalloys and metallic powders produced by Meldis-Ferro LLC

\begin{tabular}{|c|c|c|c|c|c|c|}
\hline \multirow{3}{*}{ Material } & \multirow{3}{*}{$\begin{array}{l}\text { Main element, } \\
\text { wt. } \%\end{array}$} & \multicolumn{5}{|c|}{ Content of elements, wt. $\%$} \\
\hline & & \multicolumn{5}{|c|}{ Not more } \\
\hline & & $\mathrm{N}$ & $\mathrm{C}$ & $\mathrm{Si}$ & $\mathrm{Al}$ & $\mathrm{S}$ \\
\hline Nitrated ferrochrome FeCr55N10 & Cr 55-60 & $8-10$ & 0.06 & 1.5 & 5.0 & 0.02 \\
\hline Nitrated metallic chrome Cr77N20 & $\mathrm{Cr} 75-79$ & $18-22$ & 0.03 & 0.4 & 0.7 & 0.02 \\
\hline Nitrated ferroniobium & $\mathrm{Nb} 45-50$ & $10-14$ & 0.20 & 15.0 & 5.0 & 0.05 \\
\hline Nitrated ferrovanadium FeV45N10 & $\mathrm{V} 40-50$ & $7-11$ & 0.75 & 5.0 & 2.5 & 0.05 \\
\hline Nitrated ferrovanadium FeV37N10 & V 36-45 & $7-15$ & 0.75 & $5 \ldots 15$ & 2.5 & 0.05 \\
\hline Nitrated metallic manganese Mn85N10 & Mn 83-87 & $8-11$ & 0.20 & 1.8 & - & 0.05 \\
\hline Nitrated ferromanganese FeMn8N7 & Mn 75-78 & $7-8$ & 2.0 & 3.0 & - & 0.03 \\
\hline Nitrated ferromanganese FeMn8N10 & Mn 70-75 & $9-14$ & 1.5 & 1.0 & - & 0.03 \\
\hline Nitrated ferrosilicon FeSi55N25 & Si $50-58$ & $20-28$ & 0.15 & - & 1.5 & 0.02 \\
\hline Silicon nitride & Si 63-68 & $25-35$ & 0.1 & - & 0.4 & 0.02 \\
\hline Nitrated Ferrosilicomanganese FeSiMnN12 & Mn 50-62 & $10-15$ & 2.5 & $12-17$ & - & 0.03 \\
\hline Nitrated silicocalcium & Ca 24 & $15-20$ & 0.5 & 40.0 & 2.0 & - \\
\hline
\end{tabular}




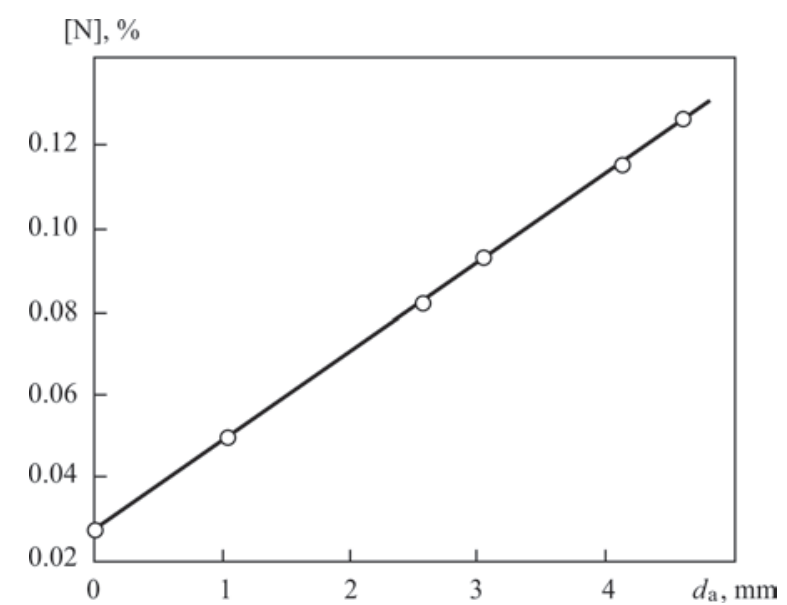

Figure 10. Effect of diameter of torch nozzle on content of nitrogen in austenite deposited metal of 08Kh17N9G3 type

In MIG and MAG processes weld metal alloying with nitrogen can be provided in the same way using a special injector torch (Figure 10).

In the conclusion it should be noted that provided short review indicates favorable effect of nitrogen in content of high-alloy corrosion-resistant weld metals in order to increase their resistance to local types of corrosion, strength characteristics without decrease of ductility and toughness, technological strength, stabilization of structural state.

1. Shnajdel, M.O. (2005) New nitrogen-containing austenitic stainless steels with high strength and plasticity. MiTOM, 11, 9-14 [in Russian].

2. Berezovskaya, V.V., Kostina, M.V., Blinov, E.V. et al. (2008) Corrosion properties of austenitic $\mathrm{Cr}-\mathrm{Mn}-\mathrm{Ni}-\mathrm{N}$ alloys with different content of manganese. Metally, 1, 36-41 [in Rusian].

3. Han Dong, Jie Su, Speidel, V.O. (2006) In: Proc. of $9^{\text {th }}$ Int. Conf. on High Nitrogen Steels. HNS (Beijing, China). Beijing, Metallurgical Industry Press.
4. Blinov, E.V. (2018) Development of alloying systems of high-nitrogen austenitic steels for heavy loaded products of cryogenic engineering: Syn. of Thesis for Dr. of Techn. Sci. Degree [in Russian].

5. Kamachi Mudali, U., Ningshen, S., Tyagi, A.K., Dayal, R.K. (1988) Influence of metallurgical and chemical variables on the pitting corrosion behavior of nitrogen-bearing austenitic stainless steel. In: Abstr. of Pap. of 5th Int. Conf. on High Nitrogen Steels. Espoo-Stockholm.

6. Shapiro, M.B., Beryshtejn, M.L., Barsukova, I.M. (1984) Influence of nitrogen on resistance of steel of 03Kh19AG3N10 type to intercrystalline corrosion. MiTOM, 1, 45-47 [in Russian].

7. Lipodaev, V.N., Yushchenko, K.A., Novikova, D.P. et. al. (1986) Improvement of weldability and corrosion resistance of welded joints from stable austenitic steels and alloys. Avtomatich. Svarka, 8, 4-7 [in Russian].

8. Ogawa, T., Tsenetomi, E. (1982) Hot cracking susceptibility of austenitic stainless steels. Weld. J., 3, 82-83.

9. Gottschalck, H. (1976) Schweissen neuer Korrosion bestaendiger Stahl. Die Schweisstechnik in Diente der Energieversorgung und des Chemianlagenbaus, 6, 91-99 [in German].

10. Kakhovsky, N.I., Fartushny, V.G., Yushchenko, K.A. (1975) Electric arc welding of steels: Reference Book. Kiev, Naukova Dumka [in Russian].

11. Sidorkina, Yu.S., Mankevich, T.V., Zinchenko, N.G. et al. (1986) Alloying of weld metal for increase of its corrosion resistance. Khimicheskoe i Neftyanoe Mashinostroenie, 4, 26-28 [in Russian].

12. (2017) ESAB welding consumables: Product catalog.

13. Elagin, V.P., Snisar, V.V., Lipodaev, V.N., Artyushenko, B.N. (1995) Injector torch for consumable electrode shielded-gas arc welding. Avtomatich. Svarka, 5, 60-61 [in Russian].

14. Grishchenko, L.V., Kiselev, Ya.N., Petrykin, V.I. (1978) Decrease of susceptibility to pore formation in weld metal during welding with austenitic electrodes based on chromenickel. Voprosy Sudostroeniya. Seriya Svarka, 26, 20-24 [in Russian].

15. Pisarev, V.A., Zhiznyakov, S.N. (2016) Oxygen influence on the process of nitrogen-induced pore formation in consumable electrode arc welding. The Paton Welding J., 7, 47-50.

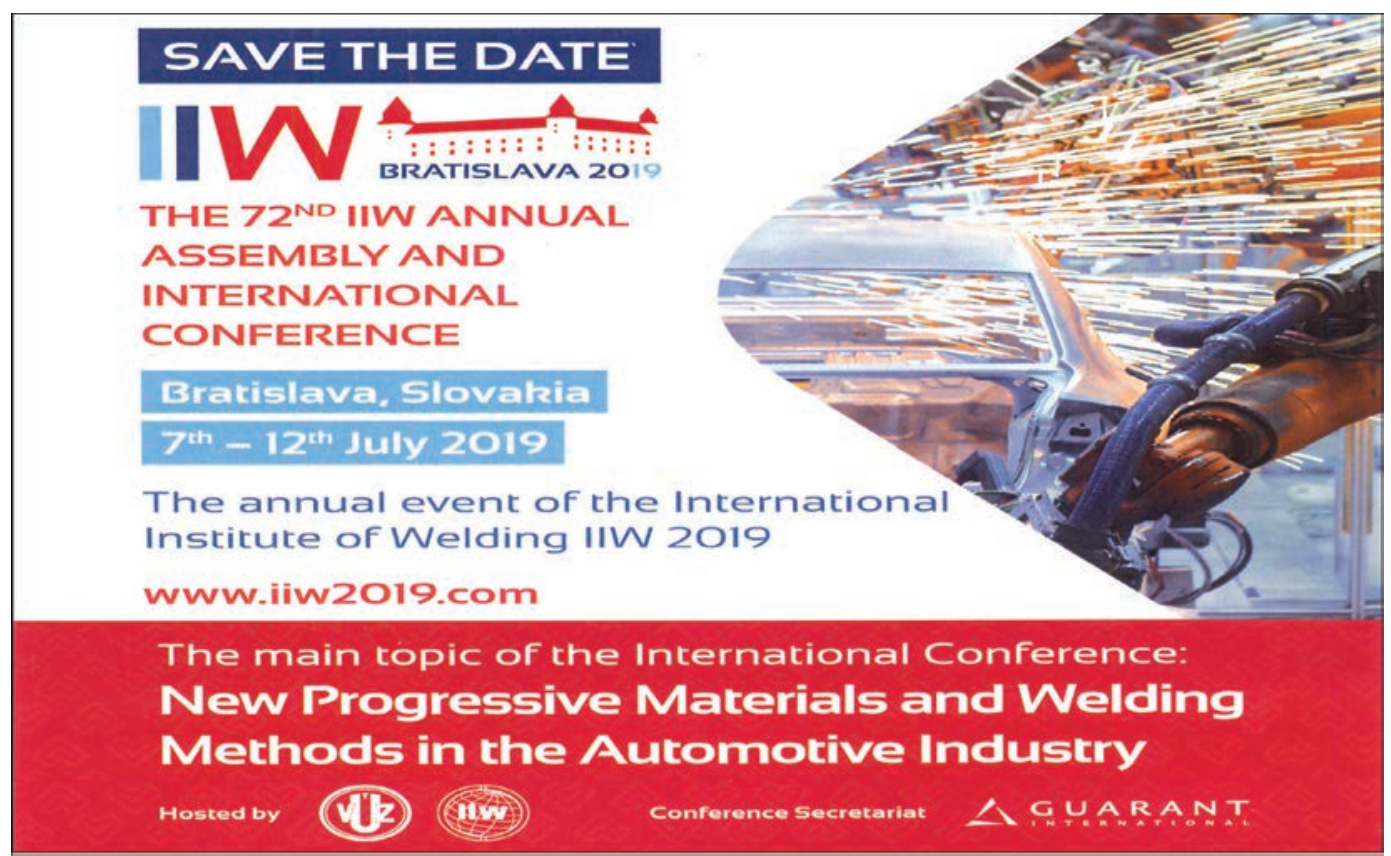




\title{
SCANDIUM EFFECT ON THE PROPERTIES AND STRUCTURE OF ALLOYS OF Al-Zn-Mg-Cu SYSTEM AND THEIR WELDED JOINTS
}

\author{
V.E. FEDORCHUK ${ }^{1}$, A.G. POKLYATSKY ${ }^{2}$, Yu.V. FALCHENKO ${ }^{1}$ and G.P. KISLAYA ${ }^{2}$ \\ ${ }^{1}$ E.O. Paton Electric Welding Institute of the NAS of Ukraine \\ 11 Kazimir Malevich Str., 03150, Kyiv, Ukraine. E-mail: office@paton.kiev.ua \\ ${ }^{2}$ NTUU «Igor Sikorsky KPI» \\ 37 Pobedy Ave., 03056, Kyiv, Ukraine
}

\begin{abstract}
The effect of scandium additives on structure and mechanical properties of cast metal, sheet semi-finished products and butt joints made by nonconsumable electrode argon-arc welding of aluminum alloys of $\mathrm{Al}-\mathrm{Zn}-\mathrm{Mg}-\mathrm{Cu}$ alloying system was studied. It is shown that scandium-containing alloys, both in the cast metal, and in their sheet semi-finished products, all the structural components have smaller dimensions, than in the alloys without scandium, that ensures the ultimate strength of the sheets on the level of 640-700 MPa, depending on content of main alloying elements in them. It is established that in nonconsumable argon-arc welding of $3 \mathrm{~mm}$ sheets from scandium-containing alloys the total length of the softening zone is reduced by $20 \%$ at simultaneous increase of weld metal hardness that provides higher mechanical properties of such joints. Complex addition of scandium to base material and filler wire simultaneously that ensures its content in the weld metal on the level of $0.30-0.35 \%$ allows significantly increasing the resistance of welded joints of $\mathrm{Al}-\mathrm{Zn}-\mathrm{Mg}-\mathrm{Cu}$ system to hot solidification cracking. 16 Ref., 3 Tables, 4 Figures.
\end{abstract}

Keywords : aluminum alloys, Al-Zn-Mg-Cu alloying system, scandium, microstructure, mechanical properties, hot cracks

In the recent years there is an intensive investigation of efficiency of scandium application in form of modifier with aluminum alloys of different alloying systems. The main factor explaining the unique effect of scandium on their structure and properties is a dimension-structural affinity of crystalline lattices of aluminum (4.405 $\AA$ ) and intermetallic phase $\mathrm{Al}_{3} \mathrm{Sc}$ $(4.407 \AA)$ due to what the particles of the latter act as effective nucleuses of crystallization centers in the ingots and welds [1-3]. It results in refinement of structure of metal being crystallized that has positive effect on its physical-mechanical properties [4]. Thus, in wrought aluminum alloys based on $\mathrm{Al}-\mathrm{Mg}$ alloying system without heat treatment the scandium additives provide higher indices of ultimate and yield strength of sheet semi-finished products as well as their welded joints and also rises their resistance to formation of solidification cracks in fusion welding [5-7].

It is positive effect of scandium addition into heat hardenable aluminum alloys of $\mathrm{Al}-\mathrm{Mg}-\mathrm{Li}$ alloying system. At that in addition to increase of ultimate strength of their welded joints there are prerequisites for additional strengthening of weld metal due to their heat treatment thanks to precipitation of secondary dispersed aluminum-scandium phases and strengthening particles of the main alloying elements [8-10]. Additives of scandium in aluminum alloys, containing copper as alloying element can reveal in different way. Thus, for 1201 and 1460 alloys the ul- timate strength of arc welds is higher using welding wire of Sv1201 type, containing $0.5 \%$ of Sc [11]. At the same time in welding of copper-containing aluminum alloys copper with scandium can form a compound (W-phase) [12]. In the case of their interaction the scandium additives will not participate in alloy strengthening and provide refinement of its structure. And increase of volume fraction of the excess phases will lead to decrease of strength, ductility and fracture toughness of weld metal. A proof of this can be the results obtained in testing D16 ( $\mathrm{Al}-\mathrm{Cu}-\mathrm{Mg})$ alloy additionally containing $0.4 \%$ of Sc [13]. As for highstrength complexly-doped aluminum alloys of Al$\mathrm{Zn}-\mathrm{Mg}-\mathrm{Cu}$ alloying system then the results obtained at investigation of some alloys indicate that scandium additives can also have positive effect on their physical-mechanical characteristics $[14,15]$.

Aim of the investigation lied in investigation of effect of Sc additives on structure and mechanical properties of cast metal, sheet semi-finished products and butt joints made by nonconsumable electrode argon-arc welding of aluminum alloys of $\mathrm{Al}-\mathrm{Zn}-\mathrm{Mg}-$ $\mathrm{Cu}$ alloying system as well as their resistance to formation of solidification cracks.

Investigation procedure. Four pilot alloys of $\mathrm{Al}-$ $\mathrm{Zn}-\mathrm{Mg}-\mathrm{Cu}$ alloying system with different content of $\mathrm{Zn}, \mathrm{Mg}$ and Sc (Table 1) were produced for investigations. A combined method of pressure treatment was used for manufacture of $3 \mathrm{~mm}$ thick sheets of $150 \mathrm{~mm}$ 
Table 1. Composition of ingots and sheets produced from pilot alloys of $\mathrm{Al}-\mathrm{Zn}-\mathrm{Mg}-\mathrm{Cu}$ alloying system

\begin{tabular}{|c|c|c|c|c|c|}
\hline \multirow{2}{*}{ Number of alloy } & \multicolumn{5}{|c|}{ Content of elements, wt.\% } \\
\cline { 2 - 6 } & Zn & $\mathrm{Mg}$ & $\mathrm{Cu}$ & $\mathrm{Zr}$ & $\mathrm{Sc}$ \\
\hline 1 & $8.0-8.2$ & $1.8-2.1$ & $2.2-2.3$ & $0.10-0.13$ & - \\
\hline 2 & $8.0-8.2$ & $1.8-2.1$ & $2.2-2.3$ & $0.10-0.13$ & $0.08-0.14$ \\
\hline 3 & $8.3-8.7$ & $2.5-2.8$ & $2.2-2.4$ & $0.15-0.20$ & - \\
\hline 4 & $8.3-8.7$ & $2.5-2.8$ & $2.2-2.4$ & $0.15-0.20$ & $0.28-0.32$ \\
\hline
\end{tabular}

diameter ingot. The extruded billets of $10 \times 100 \mathrm{~mm}$ section were obtained by a hot-pressing method. They were further subjected to hot and cold rolling up to $3 \mathrm{~mm}$ thickness. Since rolling of sheets can result in different level of their cold working, then structural peculiarities and mechanical properties of obtained alloys were investigated on the samples cut of the cast billets in cold state (natural aging for 30 days), after annealing $\left(310{ }^{\circ} \mathrm{C}\right.$ during $1 \mathrm{~h}$ ) and after quenching (at $465{ }^{\circ} \mathrm{C}$ ) with next artificial aging (at $120^{\circ} \mathrm{C}$ for $16 \mathrm{~h}$ ) as well as on the samples cut of ready sheets of $3 \mathrm{~mm}$ thickness.

Automated nonconsumable electrode argon-arc welding (NEAAW) of obtained sheets was carried out by alternating current with rectangular wave form MW-450 power supply (Fronius, Austria) using welding torch ACTV-2M. Welding rate made $14 \mathrm{~m} / \mathrm{h}$, welding current value was $300 \mathrm{~A}$, rate of feed of filler wire of $1.6 \mathrm{~mm}$ diameter $-96 \mathrm{~m} / \mathrm{h}$. Alloys without scandium were welded by serial welding wire SvAMg63 (Al-6.3 Mg-0.5 Mn-0,2Zr) and pilot welding wire SvAMg63Sc of the same composition, but additionally containing $0.5 \%$ of Sc, and welding of scandium-containing alloys was performed only with pilot wire SvAMg63Sc. Before welding sheet billets were chemically etched by generally accepted technology and then mechanical dressing was used for edges and surfaces of edges to around $0.1 \mathrm{~mm}$ depth in order to eliminate defect formation in form of pores and macroinclusions of oxide film. To evaluate the tendency of welded joints to formation of hot solidification cracks a standard procedure with Houldcroft samples in two variants was used, namely welding without filler wire and welding with filler wire. Nonconsumable electrode argon-arc welding of such samples was also carried out on the equipment mentioned above at $12 \mathrm{~m} / \mathrm{h}$ rate. A value of welding current made $235 \mathrm{~A}$, rate of feed of $1.6 \mathrm{~mm}$ filler wire was $92 \mathrm{~m} / \mathrm{h}$.

Hardness of metal was measured on transverse macrosections of obtained welded joints. A level of metal softening in welding zone was evaluated on Rockwell device at $P=600 \mathrm{~N}$ loading. The ultimate strength of welded joints $\sigma_{t}^{\mathrm{w} . \mathrm{j}}$. was determined at static tension on universal servohydraulic complex MTS 318.25 of standard samples with weld reinforcement and removed weld penetration and weld metal ultimate strength $\sigma_{t}^{\mathrm{w} . \mathrm{m}}$ on the same samples, but without weld reinforcement. Other mechanical properties of the base metal and welded joints were also performed in accordance with the standard [16]. Evaluation of structural peculiarities of investigated semi-finished products and their welded joints was carried out using optical electron microscope MIM-8.

Investigation results and their discussion. As a result of carried investigations it was determined that addition of $\mathrm{Sc}$ in aluminum alloys of $\mathrm{Al}-\mathrm{Zn}-\mathrm{Mg}-\mathrm{Cu}$ alloying system has positive effect on structure and mechanical properties of semi-finished products and welded joints. Thus, analysis of microstructure of cast metal showed that noticeable (3-5 times) decrease of grain size (Figure 1) is observed in scandium-containing alloys. In initial state after natural aging, caused by sequence of technological operations of manufacture of pilot alloy ingots and preparation of investigated samples, in weld metal without scandium there is formation of typical cast structure with crystalline particle size in 120-240 $\mu \mathrm{m}$ limits. Microstrucutre of the ingots in initial state is characterized by presence of $\alpha$-solid solution, $\eta\left(\mathrm{Mg}(\mathrm{CuZn})_{2}\right), \mathrm{T}(\mathrm{ZnMgAlCu})$ phases and eutectic precipitations on the boundaries of crystals containing $\mathrm{Zn}(24-26 \%), \mathrm{Mg}$ (7.7-8.6\%), $\mathrm{Cu}(13-15 \%)$ and traces of $\mathrm{Zr}(0.098 \%)$. Eutectic precipitations in the alloys with scandium also contain traces of scandium $(0.028 \%)$ as well as intermetallics $\mathrm{Al}_{3}(\mathrm{Sc}, \mathrm{Zr})$ of 3-7 $\mu \mathrm{m}$ size (Figure 1, $\left.a, b\right)$. At that in scandium-containing alloys there is formation of finer $(30-50 \mu \mathrm{m})$ crystalline particles due to presence of primary phase particles $\mathrm{Al}_{3}(\mathrm{Sc}, \mathrm{Zr})$ being effective nucleuses of metal crystallization centers.

In process of manufacture in order to get optimum mechanical properties of the cast billets they are subjected to technological operations of heat treatment, which provide performance of high-temperature heating for annealing or quenching with further aging. Performance of such thermal operations for aluminum alloys does not result in significant change of their microstructure, except for appearance of disperse precipitations of secondary phase (Figure 1, $c-f$ ).

Such structural peculiarities of alloys with scandium and without it, affect mechanical properties of obtained cast billets. It is clearly demonstrated by the results of testing of the samples of metal of pilot alloys 1 and 2 (Table 2). After natural aging the cast metal of alloy 2 containing scandium has higher indices of ultimate strength, conventional yield strength and relative elongation than cast metal of alloy 1 without scandium. Annealing of the samples of cast metal of these alloys results in decrease 


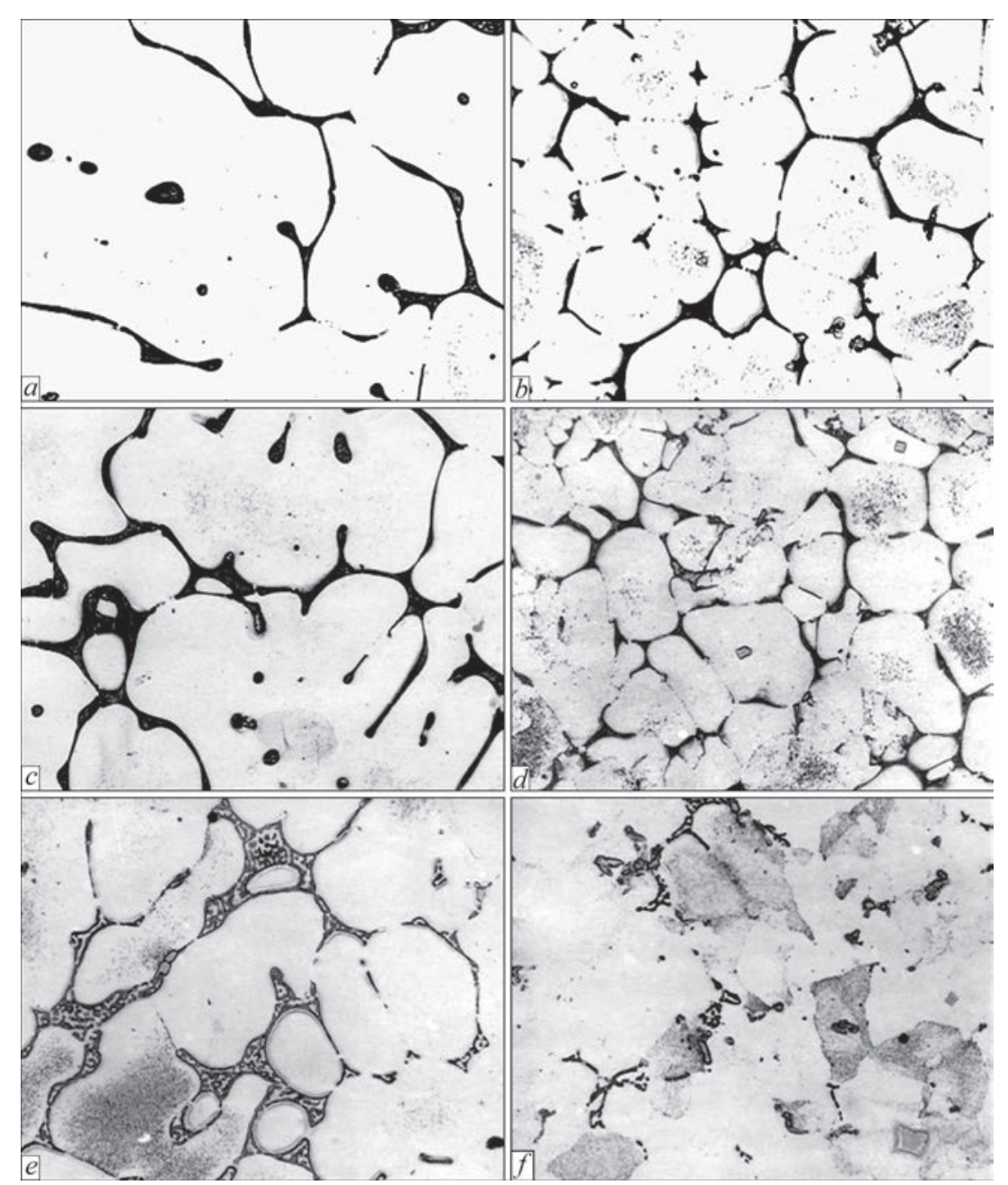

Figure 1. Microstructure $(\times 500)$ of cast metal of aluminum alloys $1(a, c, e)$ and $2(b, d, f)$ in initial condition after natural aging during 30 days $(a, b)$, after annealing at $310^{\circ} \mathrm{C}$ for $1 \mathrm{~h}(c, d)$ and after quenching at $465^{\circ} \mathrm{C}$ and further artificial aging at $120^{\circ} \mathrm{C}$ for $16 \mathrm{~h}(e, f)$

of their ultimate strength. But if at that in alloy 1 without scandium the ultimate yield limit of cast metal reduces by $50 \mathrm{MPa}$ and relative elongation rises from 2.3 to $3.3 \%$ then presence of scandium in alloy 2 results in rise of conventional yield strength of cast metal by $25 \mathrm{MPa}$ and decrease of relative elongation from 3.7 to $2.3 \%$. It is related with precipitation of secondary intermetallics based on scandium aluminide, which inhibit dislocation displacement. Quenched and artificially aged samples of cast metal have the maximum ultimate strength.

Investigations of cast billets show that their microstructure was formed as a result of two processes, namely gradual transformation of initial cast structure and formation of new elements of deformation origin - roll texture (Figure 2). Microstructure of such $3 \mathrm{~mm}$ thick sheets is characterized by presence of elongated in rolling direction grains of solid solution of main alloying elements in aluminum, elongated and chipped eutectic precipitations as well as large number of small secondary intermetallics uniformly distributed on sheet section and oriented along billet deformation direction. At that virtually all constituents of microstrucutre of sheet billets of alloys with scandium have smaller size than one in which scandium is absent. This ensures their higher mechanical properties. Thus, sheets of alloy 1 have ultimate

Table 2. Mechanical properties of metal of ingots of pilot alloys in initial state and after heat treatment

\begin{tabular}{|c|c|c|c|c|}
\hline \multirow{2}{*}{ Number of alloy } & \multirow{2}{*}{ State } & \multicolumn{3}{|c|}{ Mechanical properties } \\
\hline & & $\sigma_{\mathrm{t}}, \mathrm{MPa}$ & $\sigma_{y}, \mathrm{MPa}$ & $\delta, \%$ \\
\hline \multirow{3}{*}{1} & Natural aging: 30 days & 326 & 219 & 2.3 \\
\hline & Annealing: $310^{\circ} \mathrm{C}, 1 \mathrm{~h}$ & 210 & 169 & 3.3 \\
\hline & Quenching: $465^{\circ} \mathrm{C}+$ artificial aging: $120^{\circ} \mathrm{C}, 16 \mathrm{~h}$ & 455 & - & - \\
\hline \multirow{3}{*}{2} & Natural aging: 30 days & 339 & 225 & 3.7 \\
\hline & Annealing: $310^{\circ} \mathrm{C}, 1 \mathrm{~h}$ & 251 & 250 & 2.3 \\
\hline & Quenching: $465^{\circ} \mathrm{C}+$ artificial aging: $120^{\circ} \mathrm{C}, 16 \mathrm{~h}$ & 525 & - & - \\
\hline
\end{tabular}



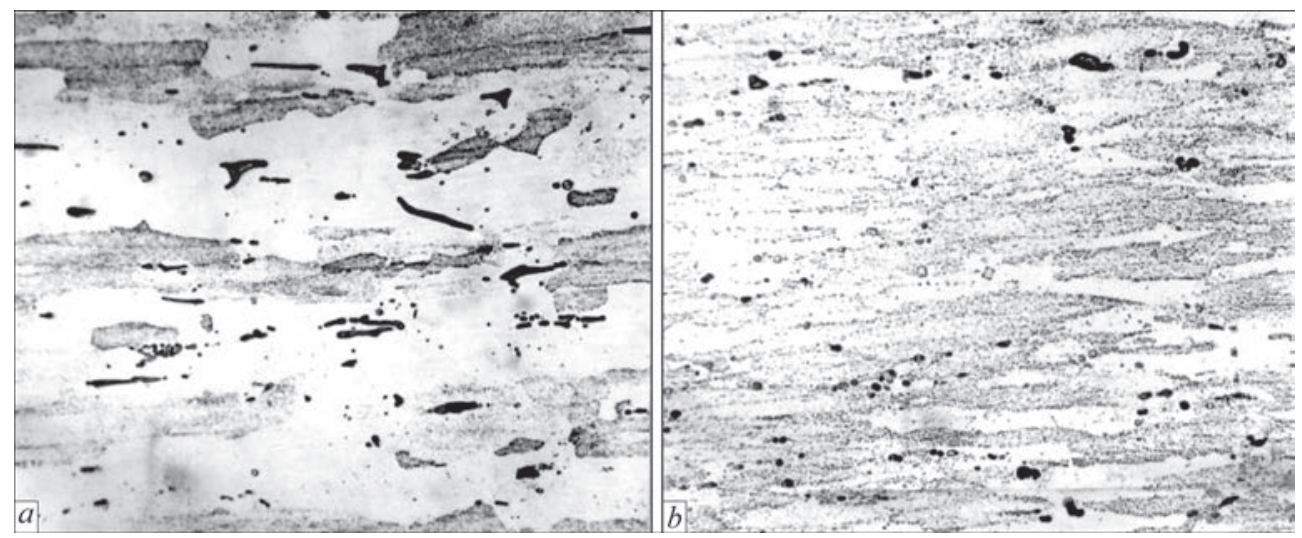

Figure 2. Microstructure $(\times 500)$ of $3 \mathrm{~mm}$ thick sheets of pilot alloys $3(a)$ and $4(b)$ after quenching and artificial aging

strength at $600 \mathrm{MPa}$ level and sheets from alloy 3 at $640 \mathrm{MPa}$ level, whereas in corresponding to them scandium-containing alloys 2 and 4 this index makes 630 and $700 \mathrm{MPa}$. At that conventional yield strength of sheet from alloy 4 makes $645 \mathrm{MPa}$, of alloy 2 $580 \mathrm{MPa}$, of alloy $3-573 \mathrm{MPa}$ and of alloy $1-$ $560 \mathrm{MPa}$. However, relative elongation in sheets with scandium-containing alloys 2 and 4 is on the level of 6.3 and $5.0 \%$, respectively, that almost 2 times lower than in sheets without scandium (10.0\%).

Positive effect of scandium in alloys, caused by grain refinement, has an impact on sheet welded joints. Thus, total extension of softening zone in nonconsumable electrode argon-arc welding of $3 \mathrm{~mm}$ thick sheets of alloy 4 with scandium makes around $35 \mathrm{~mm}$, and of alloy 3 without scandium it is around $46 \mathrm{~mm}$ (Figure 3). At that minimum hardness of weld metal in the first case is on HRB 99 level and in the second only HRB 94. Base metal hardness in its fusion zone with weld metal for alloy without scandium makes HRB 100-102 and for alloy with scandium it is HRB 105-107. In the annealing zone there are also different levels of decrease of metal hardness, namely HRB 95 in alloy without scandium and HRB 101 in alloy with scandium. Such differences in nature of distribution of metal hardness in welded joints with scandium and without it are caused by their structural peculiarities (Figure 4). In weld metal

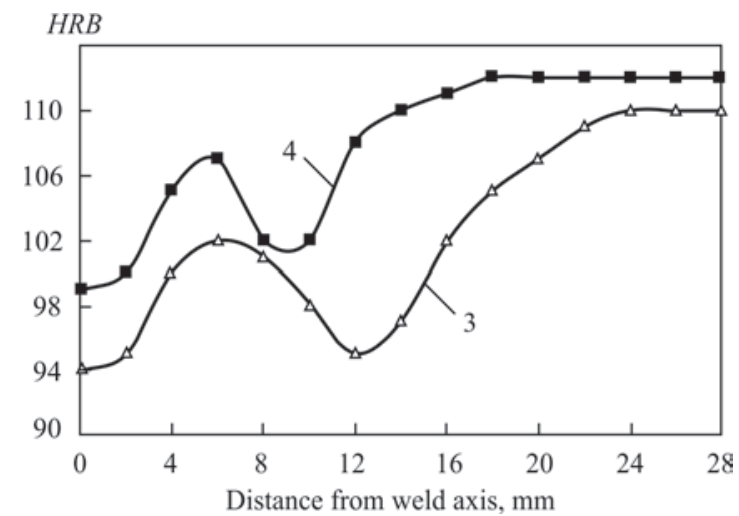

Figure 3. Distribution of hardness in welded joints produced by nonconsumable electrode argon-arc welding of $3 \mathrm{~mm}$ thick sheets from pilot alloys 3 and 4 using welding filler wires SvAMg63 and SvAMg63Sc, respectively obtained in welding of scandium-containing alloy, there is formation of fine equiaxial crystalline particles with the finest interlayers of eutectic precipitations on the grain boundaries. Whereas in welding of alloy without scandium formation of coarser dendrites takes place and large accumulation of secondary phases in intergranular space is observed. It indicates smaller volume fraction of grain boundaries. However, more noticeable is the difference in sizes of structural constituents in a heat-affected zone adjacent to weld. In alloy 3 without scandium recrystallization of grains results in formation of coarse dendrite metal structure with precipitations on their boundaries of thickened eutectic interlayers. And presence of scandium in alloy 4 allows virtually preventing recrystallization of grains in the heat-affected zone and get fine crystalline metal structure.

Higher levels of metal hardness in typical zones of welded joints of alloys with scandium, caused by formation of fine crystalline metal structure in a zone of formation of permanent joints, can indicate increase of their strength characteristics. The results of mechanical tests of the samples, given in Table 3, prove the efficiency of scandium application in the investigated alloys for rising ultimate strength of their welded joints. Thus, if this index for welded joints of pilot alloys 1 and 3 without scandium is on the level of 309 and $343 \mathrm{MPa}$, respectively, then for alloys 2 and 4 it is on the level of 329 and $441 \mathrm{MPa}$ using in the latter case filler wire SvAMg63Sc. At that higher value of ultimate strength of weld metal and bending angle $\alpha$ of welded joints can be observed. However, scandium has more substantial effect on increase of ultimate strength of welded joints and weld metal after heat treatment of the samples including quenching at $465{ }^{\circ} \mathrm{C}$ and further artificial aging at $120^{\circ} \mathrm{C}$ aging during $16 \mathrm{~h}$. Such thermal effect as a result of heating of metal to quenching temperature leads to decay of solid solution of scandium into aluminum and precipitation of secondary intermetallics $\mathrm{Al}_{3} \mathrm{Sc}$ having strengthening effect on weld metal. The artificial aging of the sample promotes decay of solid solution of main alloying elements. As a consequence the ultimate strength of welded joints in alloys 2 and 4 with scandi- 


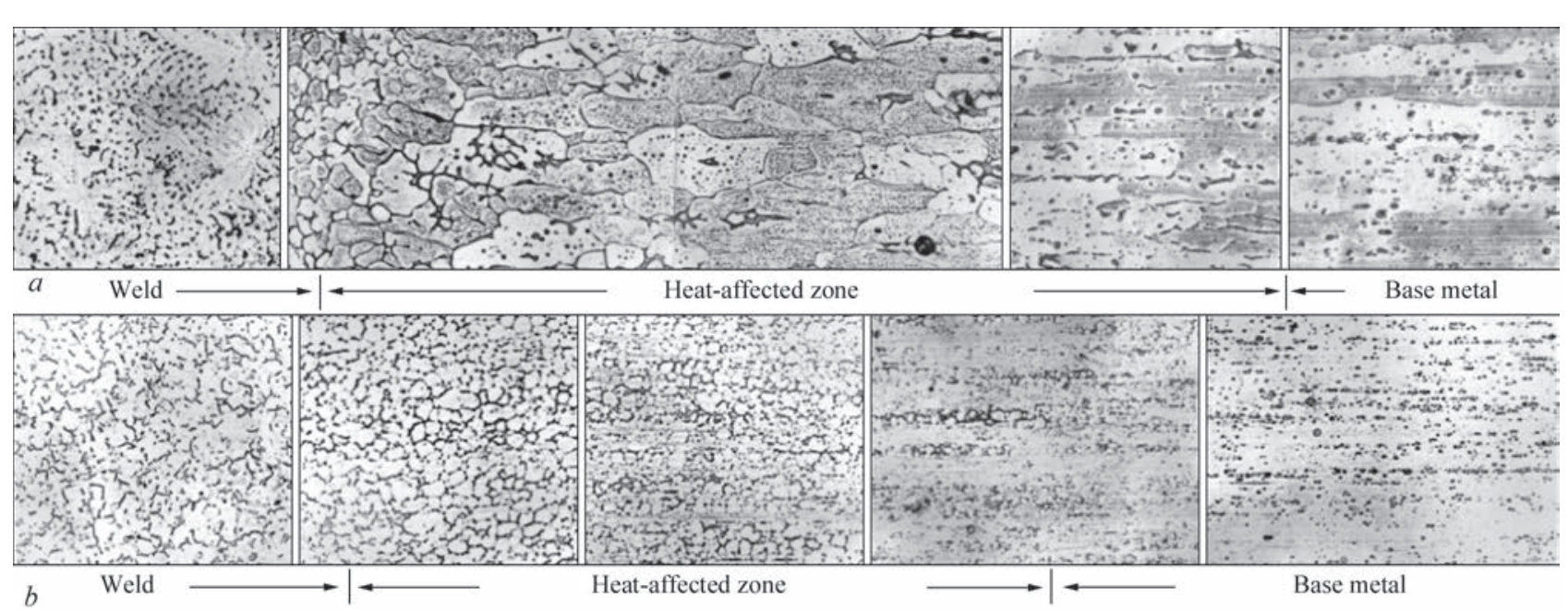

Figure 4. Microstructure $(\times 256)$ of welded joints produced by nonconsumable electrode argon-arc welding of $3 \mathrm{~mm}$ thick sheets from pilot alloys 3 (a) and 4 (b) using filler wires SvAMg63 and SvAMg63Sc, respectively

um rises to 572 and $660 \mathrm{MPa}$, respectively, that exceeds this index for alloys 1 and 3 without scandium by 68 and $52 \mathrm{MPa}$. At that for ultimate strength of weld metal this difference makes 66 and $45 \mathrm{MPa}$, respectively.

Peculiarities of primary crystallization of weld metal and formation of structural and chemical inhomogeneities in a zone of permanent joint formation in many aspects is determined by resistance of high multicomponent aluminum alloys to formation of hot solidification cracks in welding. They are formed and propagate at the final stage of weld crystallization and have intergranular nature. Therefore, obtaining the fine-crystalline structure of welds with large volume fraction of discrete grain boundaries is one of the effective methods for increase of welded joint resistance to formation of such defects. The results of carried investigations determined that in nonconsumable electrode argon-arc welding of Houldcroft samples without filler wire, propagation of hot solidification cracks takes place in the weld center. Presence of continuous extended eutectic interlayers along the grain boundaries promotes formation of long cracks virtually independently from structure type. Therefore, the indices of hot brittleness $A$ reflecting crack length to

Table 3. Mechanical properties of welded joints of sheets of pilot alloys of alloying system

\begin{tabular}{|c|c|c|c|c|c|}
\hline \multirow{2}{*}{$\begin{array}{l}\text { Number of } \\
\text { alloy }\end{array}$} & \multirow{2}{*}{$\Sigma(\mathrm{Zn}+\mathrm{Mg}+\mathrm{Cu}), \%$} & \multirow{2}{*}{ Filler wire } & \multicolumn{3}{|c|}{ Mechanical properties after welding } \\
\hline & & & $\sigma_{t}^{\text {w.j }}, \mathrm{MPa}$ & w.m, MPa & $\alpha, \operatorname{deg}$ \\
\hline \multirow{2}{*}{1} & \multirow{3}{*}{12.3} & SvAMg63 & $\frac{314-305}{309}$ & $\frac{336-329}{330}$ & $\frac{22-21}{21}$ \\
\hline & & SvAMg63Sc & $\frac{321-315}{319}$ & $\frac{344-339}{341}$ & $\frac{25-23}{24}$ \\
\hline 2 & & SvAMg63Sc & $\frac{333-326}{329}$ & $\frac{351-348}{347}$ & $\frac{25-23}{24}$ \\
\hline \multirow{2}{*}{3} & \multirow{3}{*}{13.4} & SvAMg63 & $\frac{349-340}{343}$ & $\frac{408-399}{403}$ & $\frac{22-21}{21}$ \\
\hline & & СвАМг63Sc & $\frac{361-355}{357}$ & $\frac{418-404}{411}$ & $\frac{23-22}{22}$ \\
\hline 4 & & SvAMg63Sc & $\frac{445-439}{441}$ & $\frac{419-405}{412}$ & $\frac{23-22}{22}$ \\
\hline \multicolumn{6}{|c|}{ Mechanical properties after heat treatment ${ }^{*}$} \\
\hline 1 & \multirow{2}{*}{12.3} & SvAMg63 & $\frac{512-500}{504}$ & $\frac{540-529}{536}$ & - \\
\hline 2 & & SvAMg63Sc & $\frac{579-568}{572}$ & $\frac{608-600}{602}$ & - \\
\hline 3 & \multirow{2}{*}{13.4} & SvAMg63 & $\frac{616-605}{608}$ & $\frac{638-629}{633}$ & - \\
\hline 4 & & SvAMg63Sc & $\frac{665-655}{660}$ & $\frac{685-672}{678}$ & - \\
\hline
\end{tabular}


total length of Houldcroft sample in percent relationship as a result of welding of 6-8 such samples for alloys 1 and 3 without scandium are on the level of 59.0 and $53.7 \%$ and for scandium-containing alloys 2 and 4 it is on the level of 50.0 and $45.7 \%$.

In welding of Houldcroft samples using filler wires cracking of metal does not take place in the weld center, since hot cracks are formed in a zone of its fusion with base metal, where in process of crystallization of molten metal takes place accumulation of fusible eutectic phases in form of intergranular interlayers. Therefore, application of scandium-containing filler wire in welding of alloys without scandium can not have considerable effect on extension of such defects. And only at simultaneous addition of scandium into the base material and filler wire, keeping its level in the weld on the level of $0.30-0.35 \%$, it is possible to rise significantly the resistance of welded joints of alloys of $\mathrm{Al}-\mathrm{Zn}-\mathrm{Mg}-\mathrm{Cu}$ alloying system to formation of hot solidification cracks. Thus, in welding of Houldcroft samples of alloy 2 containing $0.08-0.14 \% \mathrm{Sc}$, with filler wire SvAMg63Sc, which includes in its composition $0.5 \%$ of Sc, the index of hot brittleness $A$ reduced to $42.4 \%$ and in welding of such samples of alloy 4 , containing $0.28-0.32 \%$ of Sc, with the same filler wire it is up to $39.8 \%$.

\section{Conclusions}

1. Addition of $0.08-0.32 \%$ of Sc in aluminum alloys of $\mathrm{Al}-\mathrm{Zn}-\mathrm{Mg}-\mathrm{Cu}$ alloying system due to formation of primary phase particles $\mathrm{Al}_{3}(\mathrm{Sc}, \mathrm{Zr})$, being effective nucleuses of metal crystallization centers, provides formation in the ingots of fine $(30-50 \mu \mathrm{m})$ grains that are 3-5 times less in comparison with typical structural parameters of alloys without scandium.

2. Metal structure refinement reached due to scandium additives is conserved after thermodeformation treatment of ingots and provides higher (by 15-20\%) mechanical properties of obtained semi-finished products in comparison with their scandium-free analogues.

3. Nonconsumable electrode argon-arc welding of $3 \mathrm{~mm}$ thick sheet of scandium-containing alloys leads to decrease of total extension of softening zone and reduction of level of softening of metal in the weld on the boundary of its fusion with base material and in zone of annealing, due to what ultimate strength of weld metal and welded joint in whole rises.

4. Simultaneously, scandium addition into the base material and filler wire in order to provide its content in the weld on the level of $0.30-0.35 \%$ allows reducing indices of hot brittleness of the joint by $11-26 \%$ depending on total content of main alloying elements in the alloy.
1. Bondarev, B.I., Elagin, V.I. (1992) New aluminium alloys, doped with scandium. Tekhnologiya Lyogkikh Splavov, 5, 22-28 [in Russian].

2. Davydov, V.G., Elagin, V.I., Zakharov, V.V., Rostova, T.D. (1996) On alloying of aluminium alloys with scandium and zirconium additives. Metallovedenie i Termich. Obrab. Metallov, 8, 25-30 [in Russian].

3. Ishchenko, A.Ya. (2003) Aluminium high-strength alloys for welded structures. Progresyvni Materialy i Tekhnologii. Kiev, Akademperiodika, Vol. 1, 50-82 [in Russian].

4. Milman, Yu.V. (2003) Effect of scandium on structure, mechanical properties and corrosion resistance of aluminium alloys. Progresyvni Materialy i Tekhnologii. Kiev, Akademperiodika, Vol. 1, 335-360 [in Russian].

5. Elagin, V.I., Shvechkov, E.I., Filatov, Yu.L., Zakharov, V.V. (2005) Corrosion resistance of sheets of Al-Mg-Sc alloys. Tekhnologiya Lyogkikh Splavov, 1-4, 40-44 [in Russian].

6. Ishchenko, A.Ya., Lozovskaya, A.V., Poklyatsky, A.G. et al. (1999) Structure and properties of joints produced in welding of AMg6 alloy using the filler wires with scandium. Avtomatich. Svarka, 4, 19-25 [in Russian].

7. Ryazantsev, V.I., Filatov, Yu.A. (2003) Technological aspects of arc welding of aluminium alloys with scandium. Aviats. Promyshlennost, 1, 13-17 [in Russian].

8. Turkina, N.I., Semenova, B.V. (1992) Structure and properties of Al-Mg--Li system alloys doped with scandium. Tekhnologiya Lyogkikh Splavov, 1, 57-59 [in Russian].

9. Ishchenko, A.Ya., Lozovskaya, A.V., Poklyatsky, A.G. et al. (2002) Increase in strength of welds in arc welding of alloy 1420 using the Sc-containing fillers. The Paton Welding J., 1, 10-14.

10. Bratukhin, A.G., Tretyak, N.G., Sklabinskaya, I.E. (1993) Structure and mechanical properties of welded joints of aluminium-lithium alloys in welding by experimental additives with scandium. Avtomatich. Svarka, 12, 11-15 [in Russian].

11. Poklyatsky, A.G., Lozovskaya, A.V., Grinyuk, A.A. et al. (2006) Improvement of weld strength in arc welding of Al$\mathrm{Cu}$ alloys with application of Sc-containing fillers. The Paton Welding J., 2, 26-29.

12. Zakharov, V.V., Rostova, T.D. (1995) Alloying with scandium of Cu-containing alloys. Metallovedenie i Termich. Obrab. Metallov, 2, 23-27 [in Russian].

13. Elagin, V.I., Zakharov, V.V., Rostova, T.D., Filatov, Yu.A. (1989) Some materials science principles of alloying, technology of manufacturing and heat treatment of Sc-containing aluminium alloys. Tekhnologiya Lyogkikh Splavov, 9, 27-34 [in Russian].

14. Fedorchuk, V.E. (2015) Special features of the formation of the microstructure and chemical heterogeneity in welded joints in alloys of the $\mathrm{Al}-\mathrm{Zn}-\mathrm{Mg}-\mathrm{Cu}$ system alloyed with scandium. Welding International, 29(8), 619-623. doi:10.10 80/09507116.2014.960695.

15. Fridlyander, I.N., Senatorova, O.G., Novikov, I.N. et al. (1993) Superplasticity of high-strength Sc-doped alloys of $\mathrm{Al}-\mathrm{Zn}-\mathrm{Mg}-\mathrm{Cu}$ system. Tekhnologiya Lyogkikh Splavov, 7-8, 43-47 [in Russian].

16. (1967) GOST 6996-66: Welded joints. Methods of mechanical tests. Moscow, Standarty [in Russian]. 


\section{Electrode manufacturing at PPWE of the E.O. Paton Electric Welding Institute}

Pilot Plant of Welding Equipment (PPWE) manufactures a wide range of professional welding equipment, and now The Plant is its leading manufacturer in the territory of Ukraine and CIS countries.

In order to widen the range of manufactured products and strengthen its market positions, PPWE management took the decision to master production of coated welding electrodes. After a long preparation process, at the beginning of April, 2016, electrode manufacturing was started under PATON ${ }^{\mathrm{TM}}$ trade mark. Modern technologies and strict incoming inspection of raw material quality are used in the new production section, and a professional expert team is continuously following development of welding consumables manufacturing with the purpose of timely introduction of innovations.

Pilot Plant of Welding Equipment produces electrodes by the classic formulations of demanded electrode grades: ANO-21, ANO-36, ANO-4, UONI 13/45, UONI 13/55, MR-3, special electrodes for surfacing T-590, cast iron welding TsCh-4, high-alloyed steel welding OZL-8 and TsL-11; as well as electrodes of ELITE series by improved formulation: Elite ANO-36, Elite ANO-21, 7018 Elite.

Thus, the range of PATON ${ }^{\mathrm{TM}}$ coated electrodes now looks as follows:

Elite series

- UNIVERSAL (RUTILE, WITH IRON POWDER);

- 7018 (BASIC, WITH IRON POWDER);

- Elite ANO-36 (RUTILE-CELLULOSE WITH 8 \% CELLULOSE CONTENT);

- Elite ANO-21 (RUTILE-CELLULOSE WITH 6 \% CELLULOSE CONTENT);

- Elite MD6013 (RUTILE).

\section{Classic series}

- ANO-36 (RUTILE-CELLULOSE WITH 8 \% CELLULOSE CONTENT);

- ANO-21 (RUTILE-CELLULOSE WITH 6 \% CELLULOSE CONTENT);

- ANO-4 (RUTILE);

- MR-3 (RUTILE);

- UONI-13/55 (BASIC).

\section{SPETSELEKTRODY series}

- T-590 for surfacing;

- OZL-8; TsL-11 for welding stainless steels;

- TsCh-4 for welding cast iron.

The most well-known and accepted group of electrodes of E46 type includes electrodes of ANO-4, MR-3, ANO-21, ANO-36 grades and other welding electrodes.

Over the recent years rutile-cellulose electrodes of ANO-21 and ANO-36 grades, made by PWI formulation, became the most widely accepted. By their purpose and applications, they are designed for manual arc welding at direct or alternating current of conventional and critical structures from low-carbon steels, supplied to DSTU 2651/GOST380 (St0, St1, St2, St3 of all groups A, B, C and all degrees of deoxidation - «KP»(rimmed), «PS»(semi-killed), «SP»(killed)) and to GOST 1050 (05kp(rimmed), 08kp(rimmed), 08, 10kp(rimmed), 10ps(semi-killed), 10, 15kp(rimmed), 15sp(semi-killed), 15, 20kp(rimmed), 20sp(semi-killed), 20), in all positions (except for vertical downward for $5.0 \mathrm{~mm}$ electrodes).

Formulations and manufacturing technology of these electrode grades, corresponding to the requirements of GOST $9466-75$ by their composition and mechanical properties, are very broad, that sometimes allows the manufacturer maneuvering under the conditions of tough competition, without going beyond the GOST requirements. Therefore, the main quality indices of welding electrodes from different manufacturers, and even from one manufacturer taken separately, can be somewhat different by their welding-technological characteristics. The change of welding characteristics of the electrodes is also influenced by the ability of each 


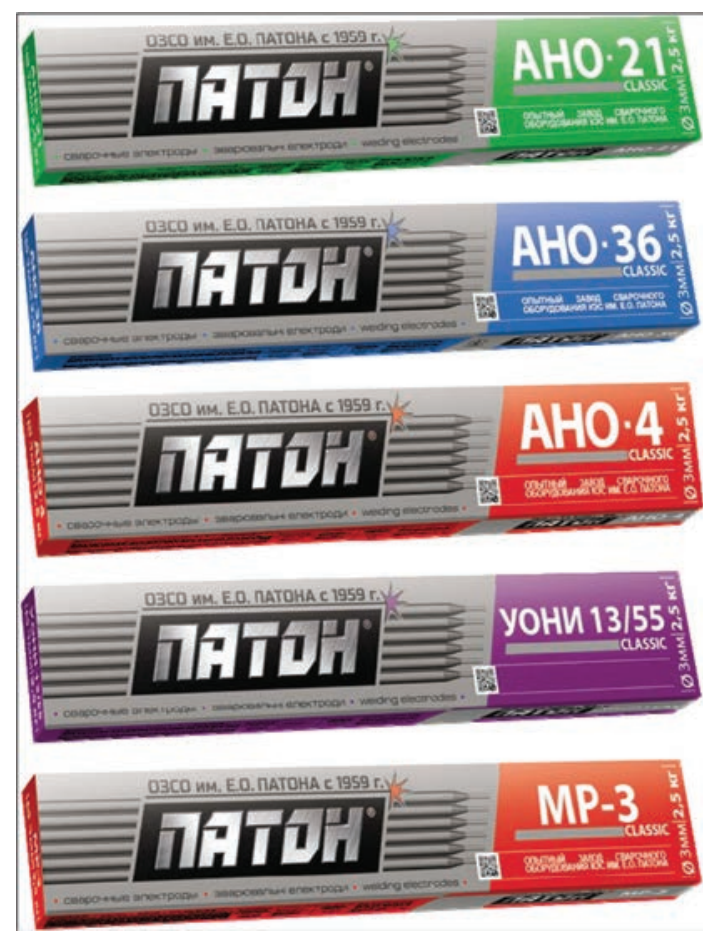

manufacturer to develop their own specification, which later on allows using new components and technological operations in electrode manufacture.

PWI PPWE took a number of measures to improve the quality of manufactured products. They include: modification of the formulations applied in manufacture of the main electrode grades, for improvement of welding-technological and consumer characteristics, introduction of advanced innovation developments (application of a complex ferroalloy modifier from one of the world's best manufacturers); supply diversification and geographic expansion of the known and new raw materials, also from foreign countries (cellulose - Switzerland, potassium-sodium lump — Germany, mica — India, etc.); toughening both incoming and outgoing inspection of the quality of raw materials and products; redesigning and improving the quality of packing materials with application of three layer packing, that guarantees preservation of welding-technological properties of the electrodes all the way from the Plant to end user.

Application of new kinds of raw materials allowed considerable improvement of welding-technological characteristics of the electrodes that expanded their application both in the industrial sector and for household purposes. When upgrading the formulations, a lot of attention was given to their ecological safety, sanitary-hygienic characteristics and safety for welder's health.

In 2017, within the strategy of development of this area, the technology park for electrode manufacture was complemented by a modern automatic line of the capacity of $12 \mathrm{t}$ per shift. In the same year $2017 \mathrm{CE}$ certificate was obtained, which confirmed the product compliance with EC norms, and deliveries to the markets of the European countries were started. Today PATON ${ }^{\mathrm{TM}}$ electrodes are supplied to the markets of more than 25 countries all over the world - from Latin America to South Korea.
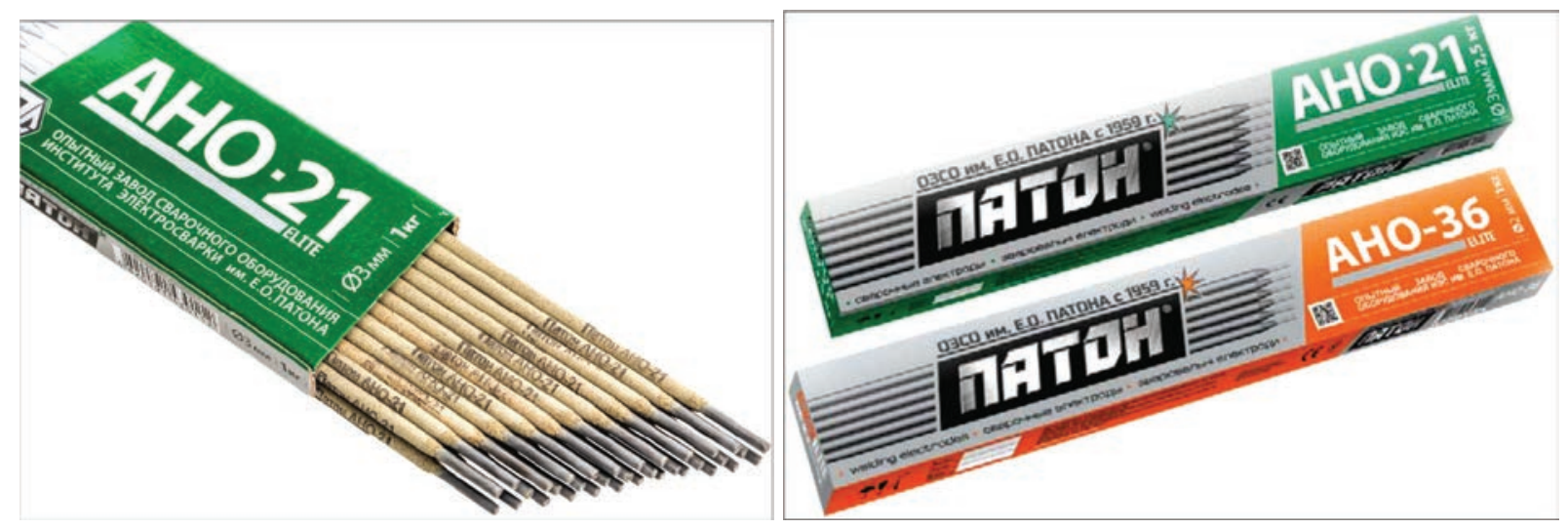

Despite the short term presence in the welding electrode market PATON ${ }^{\mathrm{TM}}$ welding electrodes managed to prove themselves and become an indispensable assistant in welding operations in different areas: construction, machine- and ship-building, agriculture, fabrication of different metal structures, etc. And electrodes of Elite series, manufactured by the improved formulation, became widely accepted for welding operations by ordinary users to solve household tasks, due to their insensitivity to the quality of the surfaces being welded, easy initial and secondary ignition, as well as stable arcing.

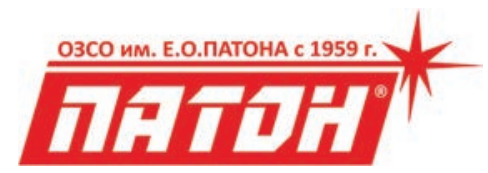

66 Novopyrohivska Str., 03045, Kyiv, Ukraine

+38 (044) 259-40-00

E-mail: office@paton.kiev.ua 


\section{Calendar of June}

JUNE 1, 1925 At the beginning of June, the company «Chrysler», an American automotive company, was founded. From the very beginning of its foundation the company used welding in cars manufacturing. Since 1930, «Chrysler» begins to use new welded structures for cars which were assembled from steel beams welded-on to body panels. A high reliability of cars brought fame to «Chrysler» and its models of the 1930 s became the most sold ones.

JUNE 2, 1844 At the outskirts of Paris, Edmond Marie-Mong tested the first in the world aeronautical metal structure. The copper sphere was manufactured of welded copper sheets of $0.1 \mathrm{~mm}$ thickness. However, the primitive technology of forge welding caused serious damage to the project. On thin copper sheets the holes, deformations and cuts spontaneously appeared, resulting in leakage of hydrogen. Gas escaped through tiny holes with a hiss and, therefore, the launching failed. However, despite the failure, the metal structure of Edmond Marie-Mong inspired many engineers and enthusiasts. Inventors of metal vehicles patented in eager rivalry their projects in Europe and America.

JUNE 3, 1951 In early June, at the E.O. Paton Electric Welding Institute of the Academy of Sciences of the UkrSSR

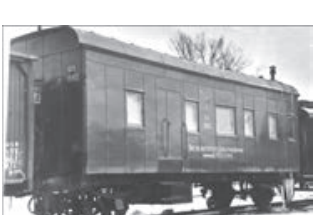
a special wagon-laboratory was created, equipped with models of the latest automatic welding equipment and demonstration devices, which, as a mobile laboratory, was sent to the enterprises of the Urals to promote automatic welding technologies and to render assistance in their implementation.

JUNE 4, 1958 In summer of 1958, the first Soviet (third in the world) nuclear-powered submarine was put into service. Back in the early 1930s in the USSR and in the United States the creation of radically new submarines with nuclear-powered plants was started. In the list of necessary qualities of the new submarine, the depth of immersion of $300 \mathrm{~m}$ was mentioned. The immersion to such a depth exceeded by several times all the previously achieved records. After a series of experiments, the required properties and the required quality of welded joints were obtained.

June 5, 1934 The solemn commemorations of crew of the icebreaker «Chelyuskin» were held. During an unsuccessful voyage and a following days-long drift, the crew noticed one important technical detail. When the ship hull was squeezed by ice, the rivets could not withstand the pressure and flew out from the ship board like bullets. After the wreck of «Chelyuskin», crushed by ice, the designers began to refuse from rivets in favor of welding. As experience showed, the ship hull became lighter and the labor intensity during building decreased by one third. Welding began also to be widely used in ship repair.

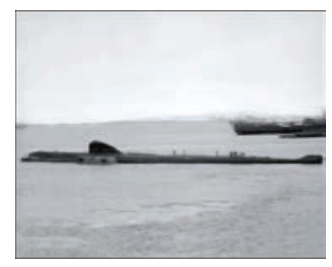

JUNE 6, 1927 The scientist and engineer V.P. Vologdin (1883-1950) in his short handwritten note «The use of electric

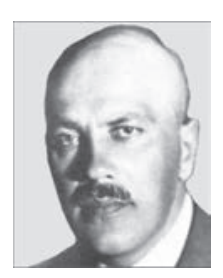
arc welding during construction of bridges and large iron structures» proposed the idea of construction of an all-welded bridge. In 1928, he designed and constructed an all-welded bridge at the Shkot peninsula in Vladivostok. Four welders welded a bridge with a span of $25 \mathrm{~m}$ just only for 20 days, saving $25 \%$ of metal as compared to the riveted structure. In 1929-1931 he constructed two more all-welded bridges, including a heavy-type bridge with a span of $36.6 \mathrm{~m}$ and total weight of 300 tons.

JUNE 7, 1977 At the beginning of June 1977, the company «Kemppi» manufactured the first in the world inverter-type power source «Hilarc-250», assembled on the base of the so-called quick-response thyristors. «Quick-response thyristors» allowed converting a direct current into alternating one at the frequency of $2-3 \mathrm{kHz}$. Thus, the first inverter power sources for welding appeared. Unlike conventional rectifiers, where the transformer operates at an industrial frequency of $50 \mathrm{~Hz}$, in inverter rectifiers it began to operate at a frequency of $2 \mathrm{kHz}$ or higher. The increase in the operation frequency of a welding transformer can significantly reduce its weight and dimensions.

JUNE 8, 1946 The idea of applying the high-frequency currents for welding of metals was for the first time proposed in 1946 by Soviet specialists headed by A.V. Ulitovsky. In the 1950s in the Soviet Union and abroad, intensive investigations began on the development of technology and equipment for high-frequency welding of pipes, and a little later, also for cable sheaths and profiles.

\footnotetext{
*The material was prepared by the Steel Work Company (Krivoy Rog, Ukraine) with the participation of the editorial board of the Journal. The Calendar is published every month, starting from the issue of «The Paton Welding Journal» No.1, 2019.
} 
JUNE 9, 1959 The first nuclear-powered strategic submarine of the US Navy of the type «George Washington» with ballistic missiles on the board was launched. In the submarine hull behind the deckhouse a 40-meter missile compartment was «inserted», in which 16 missile launchers were located. To create a missile compartment, the submarine structure was divided in half, and then a compartment for ballistic missiles was «inserted» into it. After assembly of the missile section, all parts of the submarine were welded together. The general layout of the submarines of type «George Washington» with vertical launching tube, located behind the deckhouse, was very successful and became a classic scheme for underwater strategic missile-carriers.

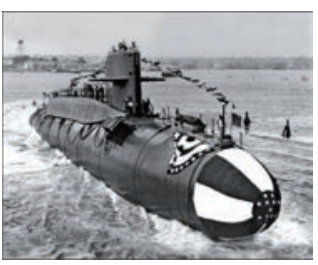

JUNE 10, 1931 Date of birth of E.M. Esibyan (1931-2015). His research activities are related to the development of

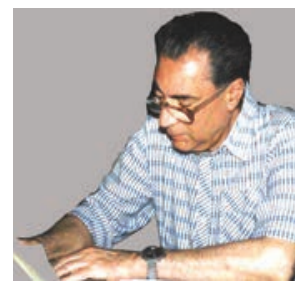
transistor-type power sources for a low-ampere arc supply in argon and putting devices AP-4 into serial production at the Simferopol Electric Machine-Building Plant. Also, E.M. Esibyan was involved in the development of the first in the world practice power sources and plasmatrons for air-plasma cutting of metals, the organization of large-scale production of installations «AVPR» and «Kiev-4» and their implementation at the machine-building plants in Ukraine.

JUNE 11, 1997 An official presentation of the first eight multifunctional fighters Su-30K was held at the Indian Air Force's airbase in Lohegaon near the city of Pune (Maharashtra). They were manufactured under the contract in India and, before that, successfully completed a number of test flights. To create this type of aircraft, a special installation KL-132 (developed by the E.O. Paton Electric Welding Institute) was used for electron beam welding of the jet engine AL-31F components at the plant of the «HAL» company (Koraput, India).

JUNE 12, 1944 The fascist Germany began bombing of London and other British cities with V-1 flying bombs "V-1». Their mass production during the World War II became possible due to the application of welding, with the help of which the spherical cylinders for compressed air, required for engine operation, were manufactured. The fairing and body lining were made of aluminum alloys. The structures of fuselage, wings, stabilizer and other assemblies were manufactured of low-carbon steel using spot welding, mainly with hand tongs.
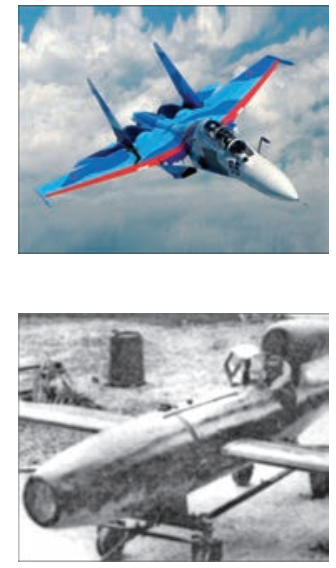

JUNE 13, 1901 In the middle of 1901, the first acetylene-oxygen welding torch was designed by French engineers Edmond Fouche and Charles Picard. Its design has not fundamentally changed until nowadays. The development of acetylene generators led to an increase in their reliability, and in 1960, the industrial application of this type of welding in the construction of gas pipelines, technological equipment and other structures began.

JUNE 14, 1952 The construction of USS Nautilus (SSN-571), the first in the world nuclear-powered submarine, began. It was adopted by the US Navy on September 30, 1954. On August 3, 1958 «Nautilus» reached the North Pole and became the first ship in the history of mankind, which passed this point of the Earth on its own power. In the United States, to manufacture the first nuclear-powered submarine «Nautilus» the company «General Dynamics» used different joining technologies, mainly submerged arc welding and oxyacetylene welding.

JUNE 15, 1911 After repair, the armored cruiser «Men» was repeatedly put into service. The ship conducted combat training and made voyages along the east coast of the United States. During its repair, the autogenous welding was used as one of the first precedents in the US military shipbuilding. As for the very first cases, they occurred in 1906-1908 in Genoa and Marseilles. There, the autogenous welding was used to repair boilers and other equipment of ships. During that period, about 80 vessels passed a similar repair procedure.
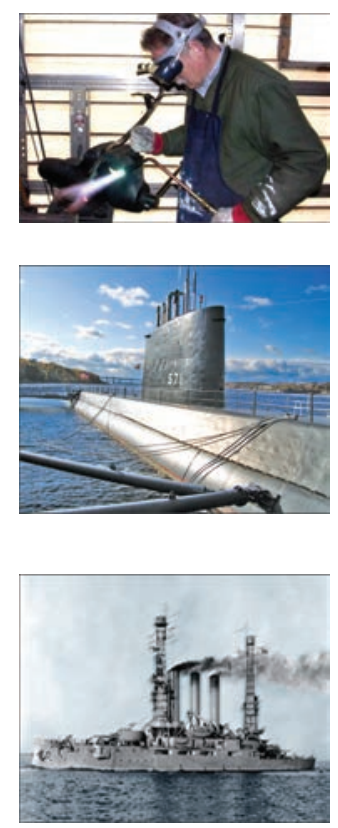

JUNE 16, 1965 From the Baikonur Cosmodrome the first launch of the «Proton-K» rocket-carrier was successfully realized. The «Proton-K» rocket-carrier belongs to the heavy class and became the main means for the cargo delivery to the orbit. In the engine design the welding was widely used. In particular, in the main lines of the rocket there are 11connectors in total. The oxidizer tank of the load-carrying structure is welded and made of aluminum alloy. It consists of a smooth cylindrical shell of a sectional type, reinforced with frame rings and two spherical bottoms. The shell of the oxidizer tank is smooth and welded from three sections.

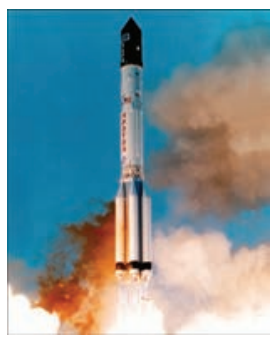




\section{JUNE 17, 1911}

A unique solution for development of welding electrodes was found by $A$. Stromenger. As a chemist and organizer of the analytical laboratory in London, he was well aware of the properties of different materials and suggested the company «Tudor» to apply a coating of blue asbestos containing compounds of iron and sodium impregnated with silicate. This cord was wound on a metal rod. Also, over this coating a thin aluminum wire was wound. Such a structure of the electrode coating provided protection of the weld pool and metal of electrode drops from atmospheric air due to the formation of slag. Already in the middle of 1911, under the name «Quasi-arc», these electrodes began to be used in the repair of trams and ships.

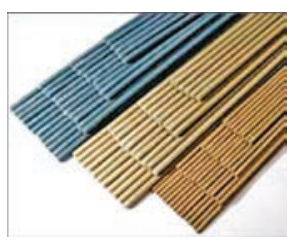

JUNE 18, 1970

Since 1969, the Publishing House «Naukova Dumka» began to publish a series of one-volume editions of selected works of famous Ukrainian scientists. The works of V.I. Vernadsky, D.K. Zabolotny,

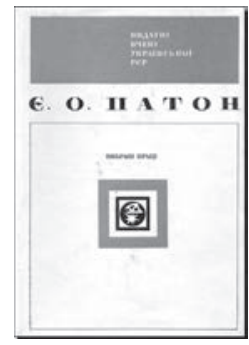
A.A. Bogomolets were published. In the summer of 1970, a collection of selected works of E.O. Paton (more than 400 articles) was published on such topics as: span structures of bridges, welded structures, welding technology and shapes of welded structures.

JUNE 19, 1941 Date of birth of AG. Grigoryants, Doctor of Technical Sciences, Professor, Head of the Bauman Moscow State Technical University, a specialist in the field of laser engineering and technology. His activities are focused on strength, welding deformations and stresses. Also the publications of Grigoryants on the application of laser radiation energy in medicine are known.

JUNE 20, 1939 The first ever flight of German jet aircraft «Heinkel He 176» was performed. This is the first aircraft in the world, driven by a fluid-fuelled jet engine. In the design of the aircraft the welding was widely used. In the course of the works, it turned out that in welding of wing structures the serious technological problems appear. Then, a different wing was designed and manufactured, made by the usual scheme with two longerons, and welding at the critical place was decided to be removed. The wing consoles with an area of only $5.4 \mathrm{~m}^{2}$ and a span of $5 \mathrm{~m}$ had a very high load, being almost $300 \mathrm{~kg} / \mathrm{m}^{2}$ at $1620 \mathrm{~kg}$ take-off weight.

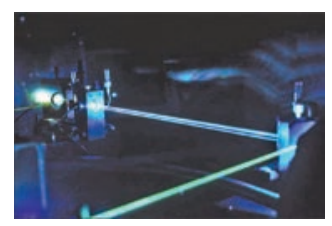

JUNE 21, 1956 In the USSR, the R-5M missile was added to the armament. That was a Soviet single-stage liquid-propellant ground-based medium-range ballistic missile with a nuclear warhead. The tanks of the rocket represented thin-walled load-bearing structures joined by welding, for manufacture of which an aluminum alloy was used. A special attention was paid to the quality of the tank welds: manual (acetylene-oxygen) welding was replaced by argon-arc welding, while the longitudinal welds of the shells and welding of the bottoms were done by automatic machines, and welding-on of connecting pipes and flanges was done manually, but also by argon-arc welding. This improved the quality of welded joints and their anti-corrosion properties.

JUNE 22, 1957 In the USSR, the R-12 missile was launched. That was a Soviet liquid-propellant single-stage ground-based ballistic missile with a flight range of up to $2,000 \mathrm{~km}$. The oxidizer tank of the rocket, made of AMg-6 alloy, had a complex structure and consisted of two compartments: the upper and the lower ones, separated by a common hemispherical bottom. The cylindrical frame rings of the compartments are smooth, welded and consist of rings formed by welding of rolled sheets with thickenings in the places of welding. The rocket parts were joined using automatic welding in argon. Namely, the missiles R-12 became the cause of the Caribbean crisis, when in the frames of the «Anadyr» operation they were deployed in Cuba.

JUNE 23, 2009 The type-45 destroyer «Daring», a modern destroyer with a guided missile weapon was transferred to the British Navy. This type of ships was produced since 2003 for the British Navy. Due to the automation of welding process from «Gullco International (UK) Limited» it became possible for a short time to provide joining of parts of two-phase steel in the structures of the «Type-45» ships. Also, welded tractors were applied, which significantly reduced the time and costs of welding. This had a positive effect on the quality of welds and the time of their completion. In that project, automation of welding process from «Gullco» brought more than $50 \%$ savings in time and costs.

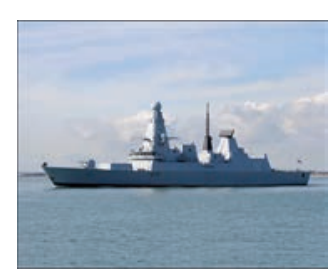


JUNE 24, 1924 The English experimental all-welded self-propelled barge «Fullagar» with a length of $46 \mathrm{~m}$ and a displacement of 398 tons slammed into the rocks, but, despite deformation of the bottom, it remained afloat. The vessel was designed by J.S. Goodwin. He took into account all the features of welding, including welding stresses, which were reduced due to holes in gussets and floors. The hull of the vessel was assembled according to the old method: by bolts, which were removed after welding, and the holes were rewelded. The commission came to the conclusion that a riveted vessel with such damages would have sunk, and the mark «experimental» was removed. Namely this event was widely publicized and made welding to be a popular technology in shipbuilding.

JUNE 25, 1919 The first flight of the aircraft «Junkers F-13» took place. That was the first in the world all-metal transport aircraft, designed in Germany at the end of the World War I. Among the several options, a scheme of a monoplane with a low wing was adopted for the further development. This scheme has become a classic one for the most subsequent airliners. The design of «Junkers F-13» was based on welded duralumin pipes, covered with corrugated duralumin lining. This created a very strong structure. The plane was easy in maintenance and could be equipped with wheels, skis or floats for landing on the water. The airliner was on service in all the continents and in all the climatic zones.

JUNE 26, 1824 Date of birth of William Thomson, Lord Kelvin (1824-1907), a British physicist and mechanic. He is

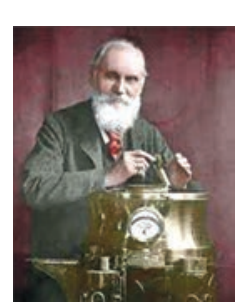
known for his works in the field of thermodynamics, mechanics and electrodynamics. He proposed an absolute temperature scale (1848), gave one of the formulations of the second law of thermodynamics (1851), and introduced the concept of energy dissipation. Later, these laws formed the basis for many designs of equipment, including welding one. In 1856, William Thomson, during his investigations, fused the bundles of wires in a box with coal, passing electric current through the wires. Thus, for the first time, he performed a butt welding.

JUNE 27, 1940 The battleship of the American armed forces «lowa» started its building. In total, it was planned to build six ships of this type. In 1939, the US government issued an order for the construction of «lowa» and «New Jersey». It should be noted that the construction of battleships was conducted at an unprecedented pace. Electric welding was used, which was not typical for that time. Using automatic welding machines during construction, the workers were able to accelerate and simplify the process of building ships. The first pair of ships of this series was put into service in 1943. Among those ships the place of a flagship was taken by the battleship «lowa». It was distin-

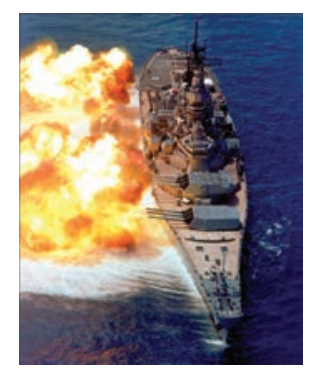
guished by a larger conning-tower.

JUNE 28, 1935 One of the patents for welding of «Pullman-Standard Car Manufacturing» (USA) was registered. Back in 1929, the company received quite satisfied results in arc welding of thin armor plates, and in 1931 an all-welded armored vehicle was designed and manufactured there. In February of 1933, the first armored train left the workshop of the same company.

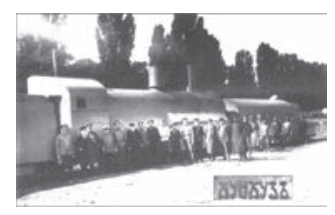

JUNE 29, 1796 Date of birth of P.P. Anosov (1796-1851), a Russian mining engineer, metallurgical scientist, a major organizer of the mining industry. P.P. Anosov, who worked at the Zlatoust Metallurgical Plant for more than 30 years, is the author of different grades of steels, including damask steel, for the production of unsurpassed cold arms. He developed a hammer for peening of ball iron. According to the results of his investigations, different methods were proposed to improve the quality of metal and to produce bimetal by a forge welding.
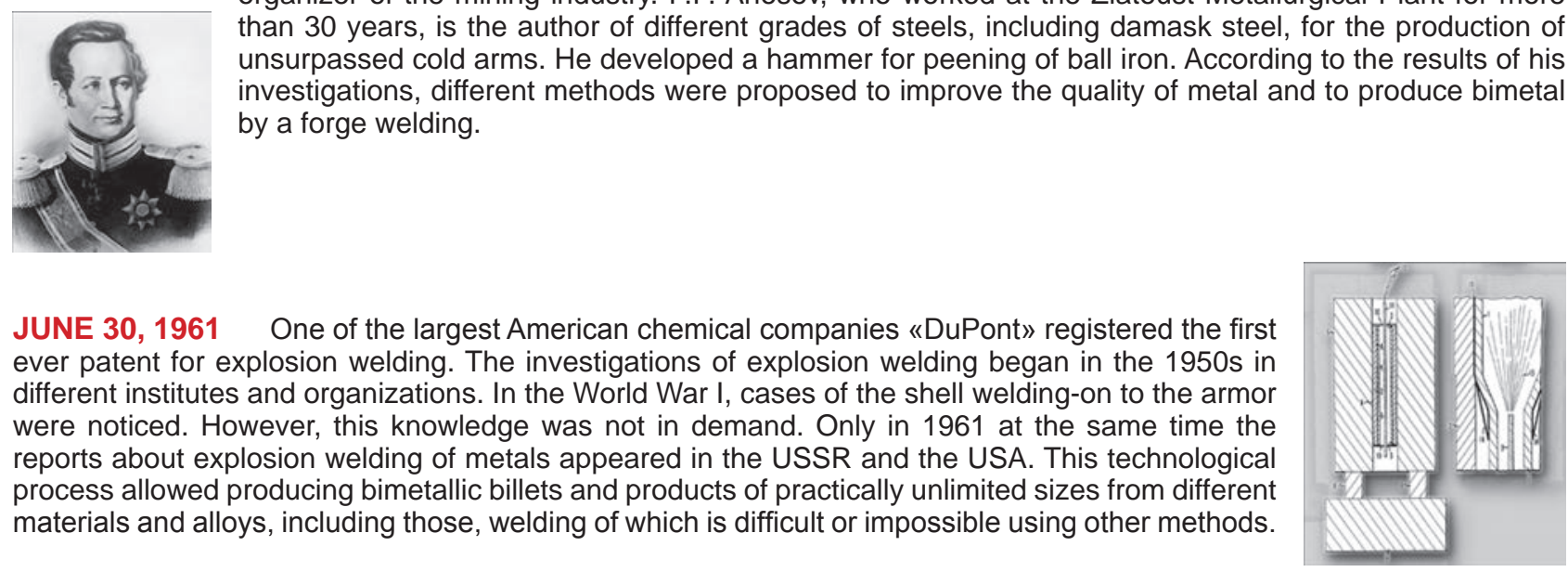

JUNE 30, 1961 One of the largest American chemical companies «DuPont» registered the first ever patent for explosion welding. The investigations of explosion welding began in the 1950s in different institutes and organizations. In the World War I, cases of the shell welding-on to the armor were noticed. However, this knowledge was not in demand. Only in 1961 at the same time the reports about explosion welding of metals appeared in the USSR and the USA. This technological process allowed producing bimetallic billets and products of practically unlimited sizes from different materials and alloys, including those, welding of which is difficult or impossible using other methods. 